\title{
Neue Enzyminhibitoren und Rezeptoragonisten durch Variation funktionaler Schleifen von Mikroproteinen
}

\author{
Dissertation \\ zur Erlangung des Doktorgrades \\ der Mathematisch-Naturwissenschaftlichen Fakultäten \\ der Georg-August-Universität zu Göttingen \\ vorgelegt von \\ Hans-Ulrich Schmoldt \\ aus Stade
}

Göttingen 2005 
D7

Referent:

PD Dr. Harald Kolmar

Korreferent:

PD Dr. Andreas Schwienhorst

Tag der mündlichen Prüfung: 28.04.2005 


\section{Inhaltsverzeichnis}

1. Einleitung und Zielsetzung ___ 1

1.1. Cystin-Knoten Mikroproteine als Grundgerüst für das rationale Design ___ 2

1.2. Humane Mastzell-Tryptasen __ 6

1.2.1. Die immunologische Bedeutung der Mastzellen ___ 6

1.2.2. Tryptasen und ihre (patho-)physiologische Bedeutung __ 7

1.2.3. Tryptase Inhibitoren __ 9

1.3. Thrombopoietin (TPO)

1.4. Zielsetzung _ _ 13

2. Materialien 14

2.1. Bakterien- und Hefestämme

2.2. Plasmide _ 14

2.3. DNA-Längenstandards und Protein-Molekulargewichtsmarker $\_15$

2.3.1. DNA-Längenstandards _ 15

2.3.2. Molekulargewichtsmarker für Proteine___ 15

2.4. Oligodesoxyribonukleotide __ 15

2.5. Enzyme und Proteine

2.6. Chemikalien

2.7. Sonstige Materialien und Geräte

2.8. Nährmedien zur Anzucht von Escherichia coli und Pichia pastoris ___ 24

2.9. Lösungen und Puffer

3. Methoden 28

3.1. Mikrobiologische Arbeitsmethoden

3.1.1. Stammhaltung und Kultivierung von Escherichia coli-Zellen ___ 28

3.1.2. Stammhaltung und Kultivierung von Pichia pastoris-Zellen __ 28

3.1.3. Bestimmung der Zelldichte ___ 28

3.1.4. Transformation von Escherichia coli durch Elektroporation ___ 28

3.1.5. Transformation von Pichia pastoris durch Elektroporation __ 29

3.1.6. Suche nach Pichia pastoris multi copy Transformanten ___ 30

3.1.7. Expression von Barnase'-Fusionsproteinen in Escherichia coli__ 30

3.1.7.1. Expression im Schüttelkolben __ 30

3.1.7.2. Expression im Fermenter __ 30 
3.1.8. Expression von Barnase'-Fusionsproteinen in Pichia pastoris

3.2. Molekularbiologische Arbeitsmethoden

3.2.1. Vorbereitung von Geräten und Lösungen 31

3.2.2. Fällung von DNA aus wässrigen Lösungen ___ 32

3.2.2.1. Fällung von DNA mit Ethanol___ 32

3.2.2.2. Fällung von DNA mit Isopropanol___ 32

3.2.3. Extraktion von DNA in wässrigen Lösungen mit organischen Lösungsmitteln__ 32

3.2.3.1. Präparation einer Phenollösung [Grinsted und Bennett, 1988] ___ 32

3.2.3.2. Extraktion von DNA mit Phenol, Phenol/Chloroform oder Chloroform__ 33

3.2.4. Agarosegelelektrophorese ___ 33

3.2.5. Bestimmung der DNA-Konzentration in wässrigen Lösungen___ 34

3.2.6. Isolierung von Plasmid-DNA aus E. coli _ 34

3.2.7. Reinigung von DNA aus Agarosegelen __ 34

3.3. Enzymatische Manipulation von DNA

3.3.1. Spaltung von DNA mit Restriktionsendonukleasen ___ 34

3.3.2. Ligation von DNA-Fragmenten __ 35

3.3.3. Polymerasekettenreaktion (PCR) [Mullis und Faloona, 1987] [Saiki et al., 1988] 35

3.3.4. Auffüllen von überhängenden Enden mit T4-DNA-Polymerase ___ 37

3.4. Biochemische Methoden __ 38

3.4.1. SDS-Polyacrylamid-Gelelektropohorese (SDS-PAGE) ___ 38

3.4.2. Gewichts- und Konzentrationsbestimmung von Proteinen___ 39

3.4.3. Dauerhafte Lagerung von Proteinen

3.4.4. Dialyse__ 40

3.4.5. Konzentrierung von Kulturüberständen und Proteinlösungen ___ 40

3.4.5.1. TCA-Fällung __ 40

3.4.5.2. Säure-Fällung mit konzentrierter $\mathrm{HCl} \_40$

3.4.5.3. Konzentration von Proteinlösungen mit Vivaspin-Konzentratoren ___ 40

3.4.6. Reinigung von Barnase'-Fusionsproteinen___ 41

3.4.6.1. Destabilisierung der E. coli Membran mit Essigsäure [Hartley, 1988] ___ 41

3.4.6.2. Kombinierte Kationenaustausch-/Reversed-phase-Chromatographie an der

Vision Biocad $^{\circledR}$ workstation __ 41

3.4.6.3. Kationenaustauschchromatographie an der Vision Biocad ${ }^{\circledR}$ workstation __ 42

3.4.6.4. Präparative Reversed-phase-Chromatographie an der Vision Biocad ${ }^{\circledR}$ workstation 
3.4.6.5. Reversed-phase HPLC 43

3.4.7. Gelfiltration 43

3.4.8. Rückfaltung von reduzierten Mikroproteinen 44

3.4.9. Spaltung von Barnase'-Fusionsproteinen 44

3.4.9.1. Chemische Spaltung mit Bromcyan 44

3.4.9.2. Proteolytische Spaltung mit Thrombin 45

3.4.9.3. Proteolytische Spaltung mit Faktor XA 45

3.4.10. Bestimmung der Inhibitionskonstante $\mathrm{K}_{\mathrm{i}}$ gegenüber Trypsin 46

3.4.11. Bestimmung der Inhibitionskonstante $\mathrm{K}_{\mathrm{i}}$ gegenüber Porcine Pankreas Elastase (PPE) 46

3.5. Chemische Modifikation von Mikroproteinen 47

3.5.1. Dimerisierung von Mikroproteinen mit Disuccinimidylsuberat (DSS) 47

3.5.2. Umsetzung von Homoserinlakton mit Hydrazin-Monohydrat 47

3.5.3. Selektive Oxidation von N-terminalen Serinen mit Natrium-Periodat 48

4. Ergebnisse und Diskussion 50

4.1. Entwicklung eines rekombinanten Expressionssystems für die Produktion von Mikroproteinen 50

4.1.1. Wahl des Trägerproteins 51

4.1.2. Escherichia coli Barnase'-Fusionsprotein-System 52

4.1.2.1. Klonierung der Expressionsvektoren ___ 52

4.1.2.2. Produktion und Reinigung der Barnase'-Fusionsproteine ___ 55

4.1.2.3. Bestimmung der inhibitorischen Aktivität gegenüber Trypsin ___ 57

4.1.2.4. Abspaltung des Trägerproteins und Isolierung der Mikroproteine ___ 58

4.1.3. Pichia Pastoris Barnase'-Fusionsprotein-System__ 60

4.1.3.1. Klonierung von Barnase'-EETI-II M7I __ 61

4.1.3.2. Transformation von Pichia pastoris und Durchmusterung nach MehrfachInsertionen __ 62

4.1.3.3. Expressionsanalyse___ 63

4.1.3.4. Expression im größeren Maßstab ___ 65

4.1.4. Barnase'-Fusionierung von Mikroproteinen als Werkzeug für die

Röntgenstrukturanalyse___ 65

4.1.4.1. Klonierung, Expression und Reinigung von Barnase'-McoEeTI ___ 66

4.1.4.2. Kristallisation und Röntgenstrukturanalyse von Barnase'-McoEeTI ___ 68

4.1.5. Diskussion und Ausblick__ 70 
4.2. Design von Protease Inhibitoren 74

4.2.1. Transformation eines Trypsin in einen Elastase Inhibitor 74

4.2.1.1. Klonierung von pBar100-XA-McEeTI _ 76

4.2.1.2. Produktion und Reinigung von Barnase'-McEeTI___ 77

4.2.1.3. Untersuchung der inhibitorischen Aktivität von McEeTI __ 78

4.2.2. Inhibitoren der humanen $\beta$-Tryptase ___ 79

4.2.2.1. Chemische Synthese und Rückfaltung von McoTI Varianten___ 81

4.2.2.2. Klonierung, Expression und Reinigung von McoEeTI Varianten ___ 84

4.2.2.4. Inhibition der humanen $\beta$-III Tryptase

4.2.2.5. Analyse der Selektivität ___ 91

4.2.2.5. Bivalente Inhibitoren ___ 93

4.2.2.5.1. Klonierung, Expression und Reinigung von EETI-II TR-1 ___ 94

4.2.2.5.2. Dimerisierung von EETI-II TR-1 __ 97

4.2.2.5.3. Inhibition der humanen $\beta$-III Tryptase mit dem dimerisierten EETI-II TR-

1 Protein 997

4.2.3. Diskussion und Ausblick___ 98

4.3. Generierung Thrombopoietin mimetischer Mikroproteine $\_101$

4.3.1. Klonierung, Produktion und Reinigung der Varianten ___ 103

4.3.2. Inhibition der Aktivierung des TPO Rezeptors___ 107

4.3.3. Dimerisierung der Variante E21 _ 109

4.3.4. Aktivierung des TPO Rezeptors ___ 111

4.3.5. Stimulation der Proliferation von Knochenmarkszellen ___ 113

4.3.6. Diskussion und Ausblick__ 114

4.4. Zyklisierung von Cystin-Knoten Mikroproteinen __ 118

4.4.1. Klonierung von pBar100-cyclo-McoEeTI _ 122

4.4.2. Rekombinante Produktion und Reinigung von cyclo-McoEeTI___ 123

4.4.3. Hydrazinolyse und Ringschluß durch Natrium-Periodat Oxidation ___ 124

4.4.4. Charakterisierung des putativen Hydrazons __ 127

4.4.5. Diskussion und Ausblick___ 128

5. Zusammenfassung _ 131

6. Literaturverzeichnis

7. Anhang 
7.3. Danksagungen 


\section{Einleitung und Zielsetzung}

Proteine sind die wichtigsten molekularen Funktionsträger in der belebten Natur. Innerhalb und außerhalb der Zelle nehmen sie unterschiedlichste Aufgaben war, nachdem sich ihre aus Aminosäuren zusammengesetzte lineare Peptidkette in einem bis heute kaum verstandenem Faltungsprozeß zu einer definierten dreidimensionalen Struktur angeordnet hat. In den letzten Jahrzehnten wurden die molekularbiologischen Grundlagen gelegt, Proteine gezielt zu verändern, um sie für die Modulation biomolekularer Wechselwirkungen im Zuge medizinischer oder rein wissenschaftlicher Anwendungen zu funktionalisieren. Ansätze zur gezielten Modifikation von Proteinen werden unter dem Begriff rationales Protein Design zusammengefaßt und stehen evolutiven Verfahren [Becker et al., 2004, Brakmann und Schwienhorst, 2004, Olsen et al., 2000], bei denen zufallsmäßige Modifikationen innerhalb eines Proteins eingeführt werden, und dem de novo Protein Design [Beasley und Hecht, 1997, Hill et al., 2000] gegenüber.

Als Alternative zu häufig verwendeten natürlichen oder rekombinanten Antikörpern oder Antikörperfragmenten für das gezielte Protein Design haben sich sogenannte scaffolds (Grundgerüste) etabliert [Skerra, 2000]. Als scaffolds werden konformationell stabile Proteine bezeichnet, die als Grundgerüst für die Integration bzw. Transplantation bestimmter meist bindender bzw. inhibierender Funktionen verwendet werden. Die scaffolds unterscheiden sich im Wesentlichen in der Art der austauschbaren oder variierbaren Bereiche. So können entweder einzelne Schleifen oder größere nicht-kontinuierliche Bereiche in Sekundärstrukturelementen und komplexeren Anordnungen von Schleifen verändert werden [Nygren und Skerra, 2004]. Die Wahl eines scaffolds für einen gegebenen Zweck hängt somit insbesondere von der Art des Zielproteins und von den für die gegebene Applikation zusätzlich relevanten Eigenschaften des scaffolds ab.

In dieser Arbeit soll an zwei Beispielen die Eignung von Cystin-Knoten Mikroproteinen (Abschnitt 1.1.) als scaffold für den rationalen Ansatz zur Funktionalisierung von Proteinen aufgezeigt werden. Cystin-Knoten Mikroproteine weisen in vielfacher Hinsicht positive Eigenschaften insbesondere hinsichtlich einer Verwendung als Leitstruktur für medizinische Applikationen auf (Abschnitt 1.1.). Zum einen sollen in dieser Arbeit auf Grundlage von Vertretern dieser Protein Familie Inhibitoren der vermutlich in inflammatorische und asthmatische Prozesse involvierten humanen Mastzell-Tryptase (Abschnitt 1.2.) entwickelt werden. Zum anderen sollen durch Transplantation funktioneller Peptide in das CystinKnoten Grundgerüst nicht nur bindende sondern agonistisch wirkende Mimetika des Zytokins 
Thrombopoietin (Abschnitt 1.3.), dem primären Regulator der Bildung von Thrombozyten, generiert werden.

\title{
1.1. Cystin-Knoten Mikroproteine als Grundgerüst für das rationale Design
}

Der Cystin-Knoten ist ein faszinierendes Strukturmotiv, daß durch die charakteristische Verknüpfung von sechs Cystein-Resten gebildet wird. Dabei wird ein Ring bestehend aus zwei Disulfidbrücken und deren verbindendem Rückgrat mit einer dritten Disulfidbrücke „durchzogen“ (Abbildung 1.1.).

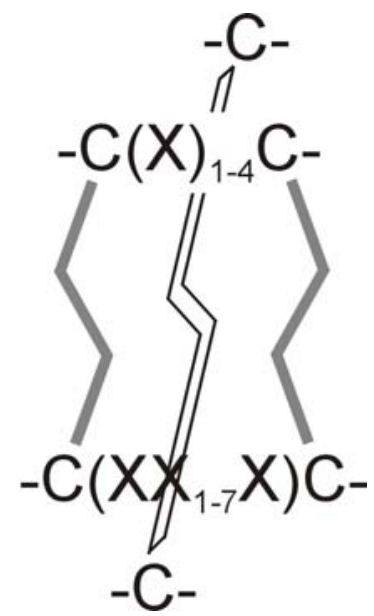

\begin{abstract}
Abbildung 1.1.: Schematische Darstellung des Cystin-Knoten Motivs, bei dem eine Disulfidbrücke durch einen Ring bestehend aus zwei weiteren Disulfidbrücken und deren verbindendem Rückgrat (angegeben durch die variablen Aminosäuren X) gefädelt ist. Die angegebenen Abstände basieren auf den Sequenzen von bekannten Cystin-Knoten Proteinen (Abbildung modifiziert nach [Craik et al., 2001]).
\end{abstract}

Die Superfamilie der Cystin-Knoten Proteine kann man topologisch in drei verschiedene Gruppen einteilen (Abbildung 1.2.), obwohl die Verknüpfung der sechs Cysteinreste immer in der gleichen Sequenzreihenfolge, nämlich Cys (I-IV), Cys (II-V) und Cys (III-VI), anzutreffen ist. Zum einen gibt es die Gruppe der Wachstumsfaktor Cystin-Knoten Proteine [McDonald und Hendrickson, 1993, Murray-Rust et al., 1993], zu der z.B. NGF [Holland et al., 1994, McDonald und Blundell, 1991], TGF- $\beta 2$ [Schlunegger und Grutter, 1992] oder PDGF-BB [Oefner et al., 1992] gehören. Bei den Wachstumsfaktor Cystin-Knoten Proteinen ist der Cystin-Knoten, bei dem die Disulfidbrücke zwischen Cystein I und IV die „durchgezogene“ ist, assoziiert mit mehreren $\beta$-Strängen. Auf der anderen Seite gibt es die später entdeckten Cystin-Knoten Proteine mit dem sogenannten ICK (inhibitor cystine knot) [Pallaghy et al., 1994] und dem CCK (cyclic cystine knot) [Craik et al., 1999] Faltungsmotiv. ICK Proteine wurden ursprünglich auch als knottins bezeichnet [Gelly et al., 2004, Le Nguyen et al., 1990]. Beide Gruppen zeichnen sich topologisch durch ein dreisträngiges antiparalleles $\beta$-Faltblatt und einen Cystin-Knoten aus, bei dem die Cys (III-VI) 
Disulfidbrücke diejenige ist, die den aus den anderen beiden Disulfidbrücken und deren verbindendem Rückgrat gebildeten Ring durchdringt (Abbildung 1.2.).

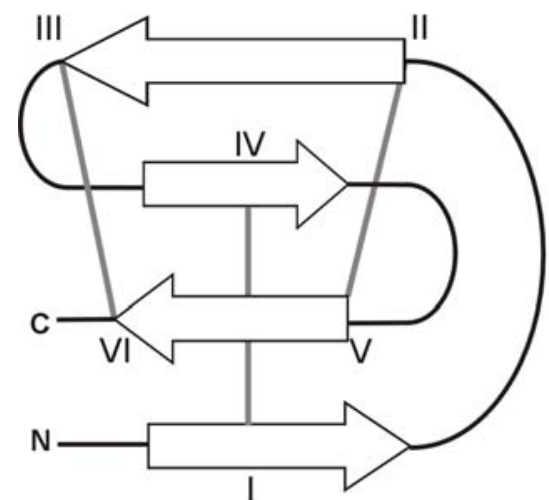

Wachstumsfaktor

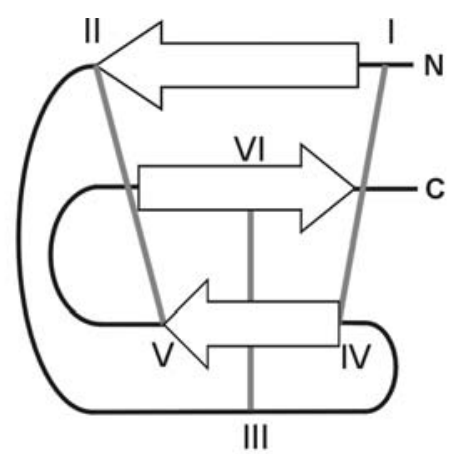

ICK

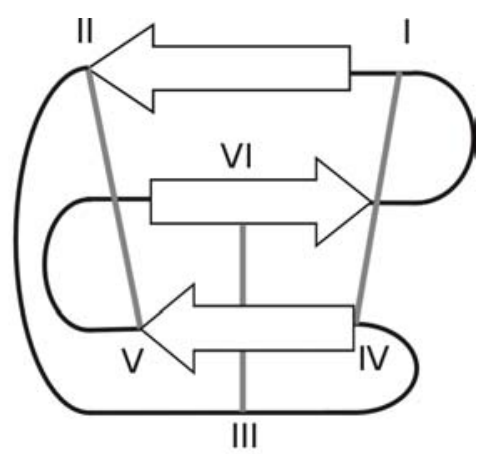

CCK

Abbildung 1.2.: Schematische Darstellung der Topologie der drei verschiedenen Gruppen von Cystin-Knoten Proteinen Wachstumsfaktor Cystin-Knoten Proteine, Inhibitor Cystin-Knoten (ICK) Proteine und zyklische Cystin-Knoten (CCK) Proteine. Die Cystein Reste sind startend vom N-Terminus mit I-VI gekennzeichnet. $\beta$ Faltblatt Stränge sind als Pfeile dargestellt.

Der Haupt-Unterschied zwischen der ICK und der CCK Gruppe besteht in dem bei den CCK Proteinen zyklischen Grundgerüst, bei dem N- und C-Terminus über eine flexible Schleife durch eine zusätzliche Peptidbindung verknüpft ist. Aufgrund ihrer sehr ähnlichen Topologie und einer geringen Größe von nur etwa 26-48 Aminosäuren werden jedoch hier beide Gruppen als Cystin-Knoten Mikroproteine zusammengefaßt.

Cystin-Knoten Mikroproteine sind trotz ihrer geringen Größe in der Lage, geordnete dreidimensionale Strukturen mit hoher Stabilität einzunehmen. Diese Stabilität wird hauptsächlich dem Cystin-Knoten und bei den Mitgliedern der CCK Familie zusätzlich dem zyklischen Rückgrat zugeschrieben [Colgrave und Craik, 2004]. Ein Beispiel hierfür ist das erste bekannte Mitglied der CCK Familie, Kalata B1 [Saether et al., 1995], das von Naturvölkern aus den Blättern der afrikanischen Pflanze Oldenlandia affinis DC durch Kochen extrahiert und aufgrund Uterus-kontrahierender Wirkung zur Geburtshilfe eingesetzt wird [Gran, 1973]. Kalata B1 ist nur ein Vertreter von inzwischen über 40 zyklischen Mikroproteinen pflanzlichen Ursprungs. Diese als Zyklotide [Craik et al., 1999, Craik et al., 2004, Craik et al., 2002, Rosengren et al., 2003] bezeichneten Vertreter wurden hauptsächlich aus den Pflanzen-Familien der Rubiaceae und Violaceae isoliert und weisen verschiedenste biologische Aktivitäten auf wie z.B. anti-HIV Aktivität [Gustafson et al., 2004], hämolytische Aktivität [Daly et al., 1999, Tam et al., 1999] oder Trypsin-inhibitorische Aktivität [Hernandez et al., 2000]. Eine der größten Gruppen innerhalb der Cystin-Knoten Mikroproteine stellen Proteinase Inhibitoren dar [Chiche et al., 2004, Wieczorek et al., 1985], die in der Regel bei der Durchmusterung von Pflanzen-Extrakten identifiziert werden konnten 
[Favel et al., 1989, Hamato et al., 1995, Hernandez et al. , 2000, Miura und Funatsu, 1995, Otlewski et al., 1984, Polanowski et al., 1980]. Beispiele sind die Trypsin Inhibitoren EETI-II aus der Spritzgurke Ecbalium elaterium [Heitz et al., 1989, Le-Nguyen et al., 1989] und MCoTI-II aus Momordica cochinchinensis [Felizmenio-Quimio et al., 2001, Heitz et al., 2001, Hernandez et al., 2000] sowie der Elastase Inhibitor MCEI-III aus Momordica charantia [Hamato et al., 1995].

Tierische Cystin-Knoten Mikroproteine wie die Conotoxine aus marinen Kegelschnecken [Terlau und Olivera, 2004] oder das Gift der Trichternetzspinne Atrax robustus [Temple et al., 1999] wirken oftmals neurotoxisch, indem sie bestimmte Ionenkanäle blockieren und damit z.T. letale Folgen beim Menschen auslösen können. Einige Vertreter der Conotoxine finden jedoch aufgrund dieser blockierenden Eigenschaften als Medikament in der Schmerztherapie Anwendung bzw. befinden sich in klinischen Studien (Zikonotide, Elan Pharmaceuticals; AM-336, AMRAD Corp.; CGX-1160, Cognetix Inc.). Vor kurzem wurde das ICK Faltungsmotiv zum ersten Mal in humanen Proteinen identifiziert. Bisher stellen die aktiven Domänen des Agouti Related Proteins (AGRP) [Bolin et al., 1999, Jackson et al., 2002, McNulty et al., 2001] und des Agouti Signaling Proteins (ASIP) [McNulty et al., 2005] jedoch die einzigen Beispiele dieser Proteinfamilie in Säugern dar.

Aufgrund ihrer außergewöhnlichen Stabilität und der besonderen geordneten dreidimensionalen Struktur scheinen Cystin-Knoten Mikroproteine prädestiniert für eine Anwendung als molekulares Grundgerüst (scaffold) für die Generierung neufunktionalisierter Moleküle [Craik et al., 2001, Craik et al., 2002]. In bisherigen Arbeiten mit dem Trypsin Inhibitor EETI-II konnte bereits gezeigt werden, daß die Inhibitor Schleife ohne Verlust der strukturellen Integrität gegen neue Sequenzen ausgetauscht werden kann, um die Funktion der eingeführten Sequenzen zu übertragen [Christmann et al., 1999, Hilpert et al., 2003, Wentzel et al., 2001]. Zudem konnte durch Elongation von EETI-II mit den vier Aminosäuren vom CTerminus (PYVG) des Kartoffel Carboxypeptidaseinhibitors CPI ein potenter bivalenter Inhibitor gegen Trypsin und Carboxypeptidase A generiert werden [Le-Nguyen et al., 1989]. Die Inhibitionskonstante gegenüber Trypsin war zwar mit $1,8 \times 10^{-9} \mathrm{M}$ schlechter als im Wildtyp EETI-II $\left(10^{-12} \mathrm{M}\right)$, die Inhibition von Carboxypeptidase A lag jedoch mit $3 \times 10^{-9} \mathrm{M}$ im Bereich von CPI. EETI-II und CPI sind kaum sequenzhomolog, jedoch eindeutig strukturhomolog. Die NMR-Struktur des chimären Proteins aus EETI-II und CPI zeigte das EETI-II Protein in seiner nativen Form mit einer C-terminalen Extension [Chiche et al., 1993]. 
In dieser Arbeit wurden drei verschiedene Cystin-Knoten Mikroproteine bzw. davon abgeleitete Varianten als Grundgerüst für das rationale Protein Design verwendet. Die dreidimensionalen Strukturen der Wildtyp Formen sind in Abbildung 1.3. schematisch dargestellt.

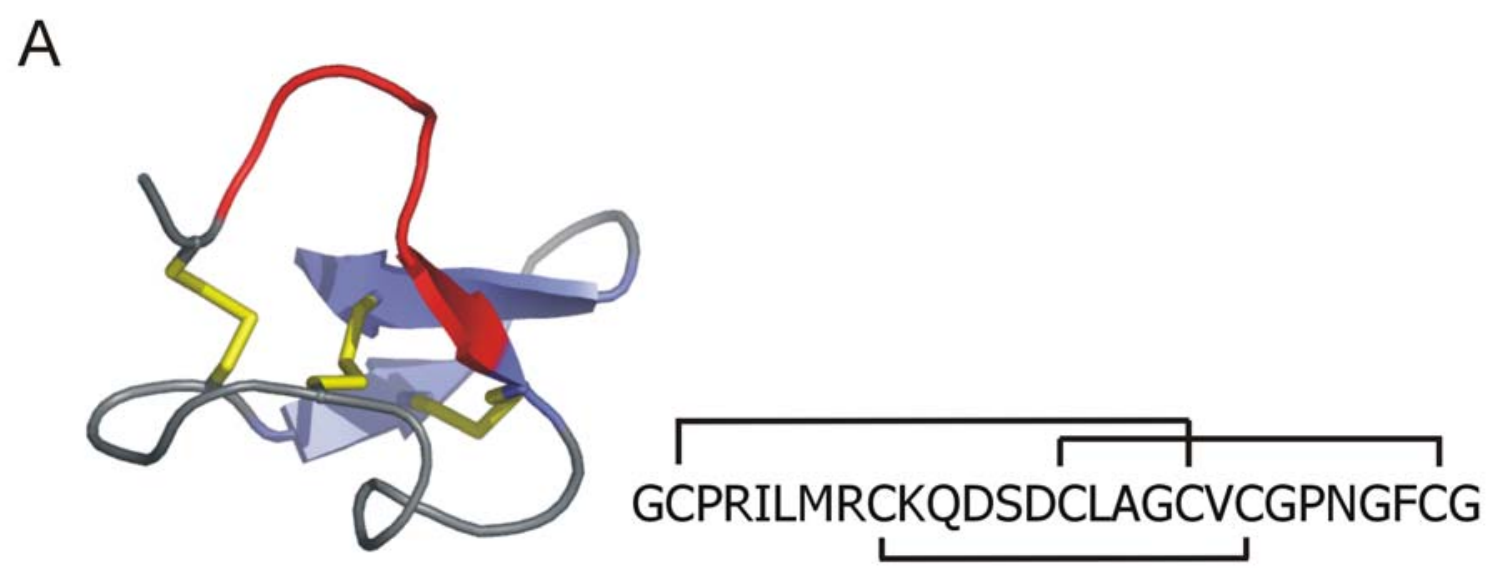

B

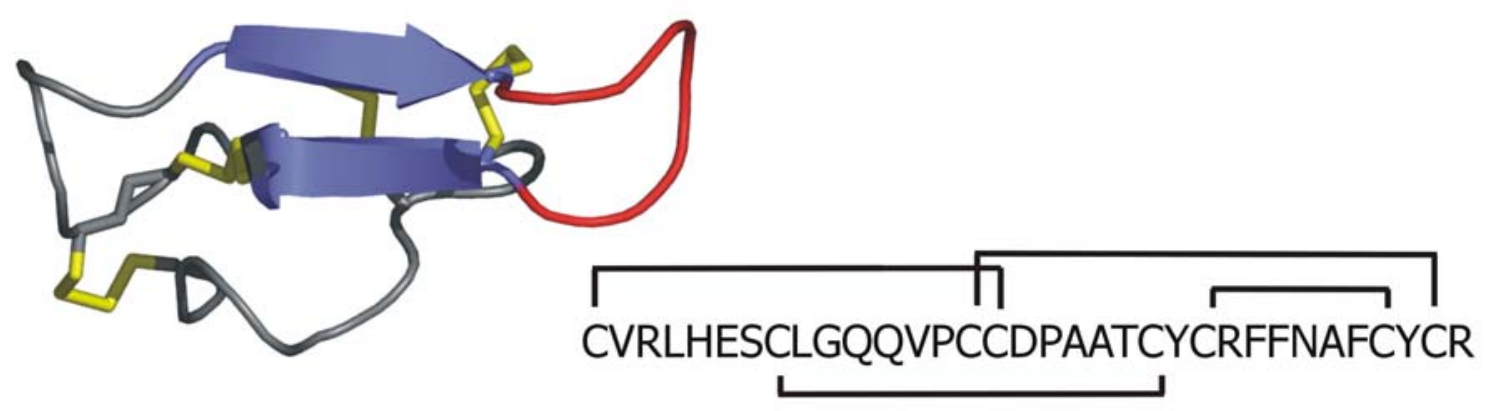

C

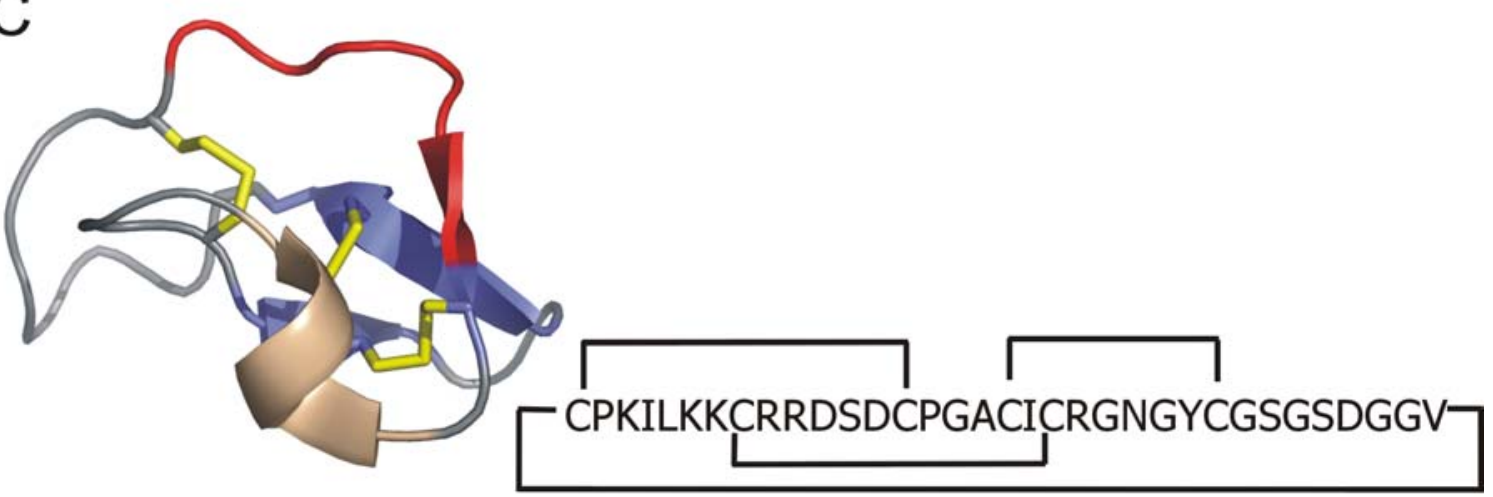

Abbildung 1.3.: Schematische Darstellung der dreidimensionalen Strukturen der in dieser Arbeit (modifiziert) als Grundgerüst für das rationale Design von Tryptase Inhibitoren und Thrombopoietin Mimetika verwendeten Cystin-Knoten Mikroproteine. Die Aminosäuresequenz und die Disulfid Verknüpfungen sind neben der jeweiligen Struktur angegeben. (A) Trypsin Inhibitor EETI-II aus Ecbalium elaterium [Heitz et al., 1989]. (B)

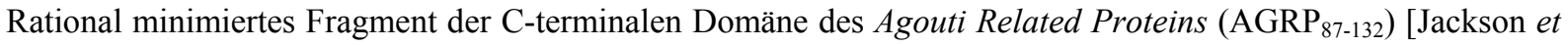
al., 2002]. (C) Trypsin Inhibitor MCoTI-II aus Momordica cochinchinensis [Felizmenio-Quimio et al., 2001]. Disulfidbrücken sind in gelb, $\beta$-Stränge in blau und $\alpha$-Helices in beige dargestellt. Die Inhibitorschleife von MCoTI-II und EETI-II bzw. die für die Bindung des Melanocortin-Rezeptors verantwortliche Schleife in AGRP $_{87-132}$ ist jeweils in rot hervorgehoben. 
Bei den dargestellten Proteinen handelt es sich um EETI-II [Heitz et al., 1989], AGRP $87-132$ [Jackson et al., 2002] und MCoTI-II [Felizmenio-Quimio et al., 2001]. Alle drei Strukturen weisen die für die Proteinfamilie typische Cystin-Knoten Konformation und ein antiparalleles $\beta$-Faltblatt auf. EETI-II (Abbildung 1.3. A) und MCoTI-II (Abbildung 1.3. C) sind pflanzliche Trypsin Inhibitoren. Die für die Inhibition verantwortliche Schleife ist in rot hervorgehoben. Der für die Trypsin Spezifität entscheidende positiv geladene sogenannte P1 Rest [Bode und Huber, 1992, Czapinska und Otlewski, 1999] ist in EETI-II das erste Arginin, bei MCoTI-II das erste Lysin in der Primärsequenz zwischen den Cysteinen I und II. Das dritte Grundgerüst, $\mathrm{AGRP}_{87-132}$ (Abbildung 1.3. B), ist ein rational minimiertes Fragment der Cterminalen Domäne des Agouti Related Proteins (AGRP) [Jackson et al., 2002], das die volle Aktivität von AGRP besitzt. AGRP ist ein endogener Antagonist der Melanocortin Rezeptoren MCR3 und MCR4 im Hypothalamus mit orexigenen (Appetit-steigernden) Eigenschaften [McNulty et al., 2001]. Die für die Bindung des Rezeptors verantwortliche Schleife ist in rot hervorgehoben.

\subsection{Humane Mastzell-Tryptasen}

\subsubsection{Die immunologische Bedeutung der Mastzellen}

Mastzellen (Abbildung 1.4. A) sind spezielle, den Stammzellen des Knochenmarks entstammende Leukozyten, die ubiquitär im menschlichen Körper vorkommen, jedoch gehäuft an Grenzepithelien in der Haut, dem Respirationssystem und dem Darmtrakt zu finden sind. Hier nehmen sie ihre Funktionen im erworbenem Immunsystem als primäre Effektorzellen der IgE-vermittelten allergischen Sofortreaktion wahr. Zudem sind sie jedoch auch im Zuge der angeborenen und erworbenem Immunabwehr von Parasiten und der Bekämpfung bakterieller Infektionen von Bedeutung [Henz et al., 2001, Marshall und Jawdat, 2004]. Andererseits tragen Mastzellen vermutlich zur Pathogenese verschiedener entzündlicher Erkrankungen wie Asthma, Psoriaris oder Autoimmunerkrankungen wie rheumatoider Arthritis oder Multipler Sklerose [Benoist und Mathis, 2002] bei, wo es zu einer Zunahme der Zahl und einer vermehrten Aktivierung der Mastzellen kommt [Temann et al., 1998].

Mastzellen sind sehr stark granuliert (Abbildung 1.4. B) [Dvorak, 2002]. Die Granula sind Speicher für verschiedene Mediatoren wie Histamin, Heparin und verschiedene Proteasen wie z.B. Chymase und Tryptase [Payne und Kam, 2004]. Die Freisetzung der Mediatoren durch Degranulisation kann sowohl durch IgE-abhängige und -unabhängige Immunmechanismen 
als auch durch verschiedene andere Faktoren erfolgen. Neben diesen gespeicherten werden verschiedene andere inflammatorisch wirksame Mediatoren erst nach IgE-vermittelter Aktivierung der Mastzelle gebildet. Hierzu gehören z.B. Prostaglandine, Zytokine, TNF- $\alpha$ oder IL (Interleukin)-4, -5 und -6.

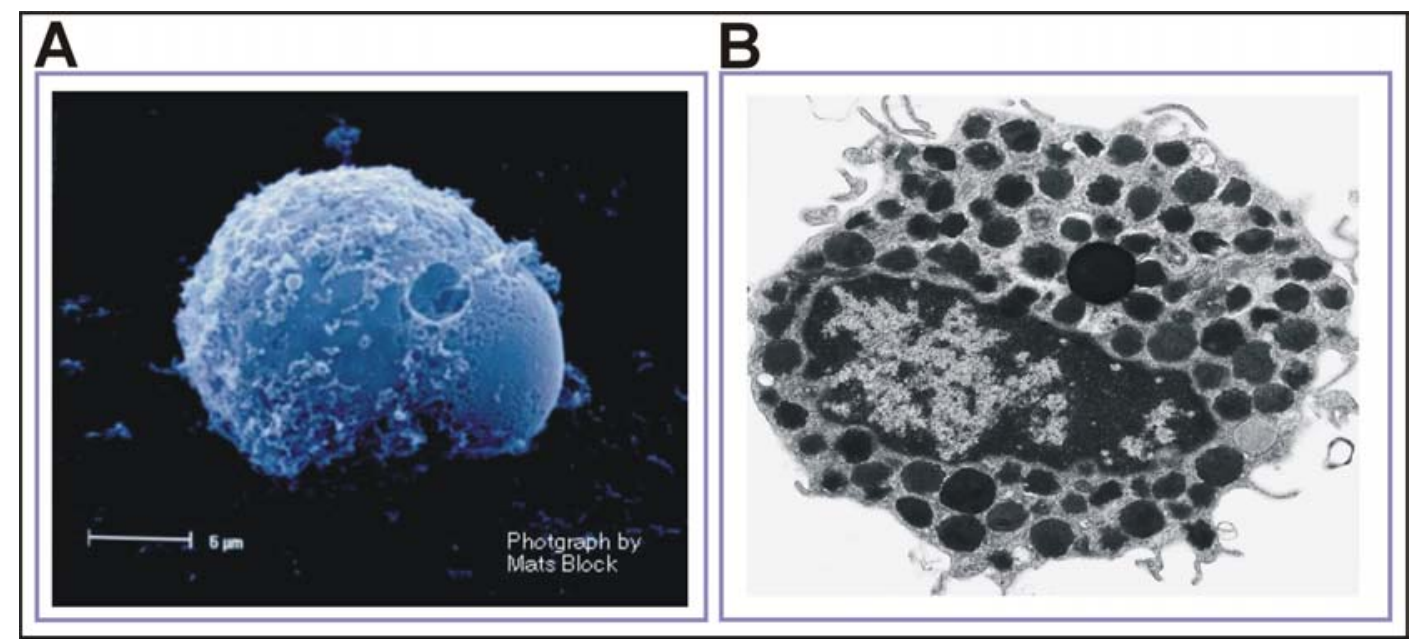

Abbildung 1.4.: (A) Elektronenmikroskopische Aufnahme einer IgE-aktivierten Mastzelle (Quelle: http://www.genpat.uu.se/Forskargrupper/macebi/macebi.html). (B) Elektronenmikroskopische Aufnahme eines Querschnitts durch eine granulierte humane Mastzelle (aus [Dvorak, 2002]).

Immunohistochemisch werden zwei verschiedene Subtypen von humanen Mastzellen in Haut, Lunge und Dünndarm nach ihrer Protease-Ausstattung unterschieden [Irani et al., 1986]. Während der sogenannte $\mathrm{M}_{\mathrm{TC}}$-Subtyp sowohl Tryptase als auch Chymase besitzt und gehäuft in der Haut und der Submukosa des Dünndarms vorkommt, enthält der zweite, der sogenannte $\mathrm{M}_{\mathrm{T}}$-Subyp nur Tryptase und findet sich gehäuft in Lunge und Dünndarmmukosa.

\subsubsection{Tryptasen und ihre (patho-)physiologische Bedeutung}

Die Familie der Tryptasen ist mit 10-35 $\mu \mathrm{g} / 10^{6}$ Zellen mengenmäßig das vorherrschende Protein in humanen Mastzellen [Schwartz et al., 1987]. Die Familie wird selektiv in Mastzellen und in geringerem Maße in Basophilen exprimiert [Xia et al., 1995] und wird daher als Marker für die Aktivierung und Lokalisation von Mastzellen benutzt [LudolphHauser et al., 1999]. Sie umfaßt eine Gruppe von sequenzhomologen Trypsin-ähnlichen Serinproteasen, deren entsprechenden Gene auf dem kurzen Arm von Chromosom 16 lokalisiert sind [Schwartz, 2001]. Man unterscheidet zwei Tryptase Typen, $\alpha$-Tryptase und $\beta$ Tryptase, die $90 \%$ Sequenzidentität zueinander aufweisen. $\beta$-Tryptasen sind in $\beta$-I, $\beta$-II und $\beta$-III Tryptase und die $\alpha$-Tryptasen in $\alpha$-I und $\alpha$-II Tryptase unterteilt [Peng et al., 2003, Soto et al., 2002]. Während die $\alpha$-Formen konstitutiv von der Mastzelle als inaktives Proenzym sekretiert werden, sind die $\beta$-Formen in aktivierter Form in den Granula der Mastzellen gespeichert [Sakai et al., 1996]. Nach Aktivierung der Zelle werden $\beta$-Tryptasen gebunden an 
Heparin zusammen mit anderen Mediatoren im Zuge diverser allergischer und inflammatorischer Prozesse wie Asthma, Rhinitis, Psoriaris oder Multipler Sklerose sekretiert. Mehrere Studien im Tiermodell und im Menschen haben insbesondere Evidenzen für eine direkte Beteiligung von Tryptasen in der Pathogenese von Asthma geliefert [Caughey, 1997, Johnson et al., 1997, Rice et al., 1998].

Mehrere interessante Eigenschaften unterscheiden Tryptasen von anderen Trypsin-ähnlichen Serinproteasen. Besonders auffällig ist, daß Tryptasen in ihrer aktiven Form als nichtkovalent verknüpftes Tetramer vorliegen [Pereira et al., 1998] [Sommerhoff et al., 1999] (Abbildung 1.5.).
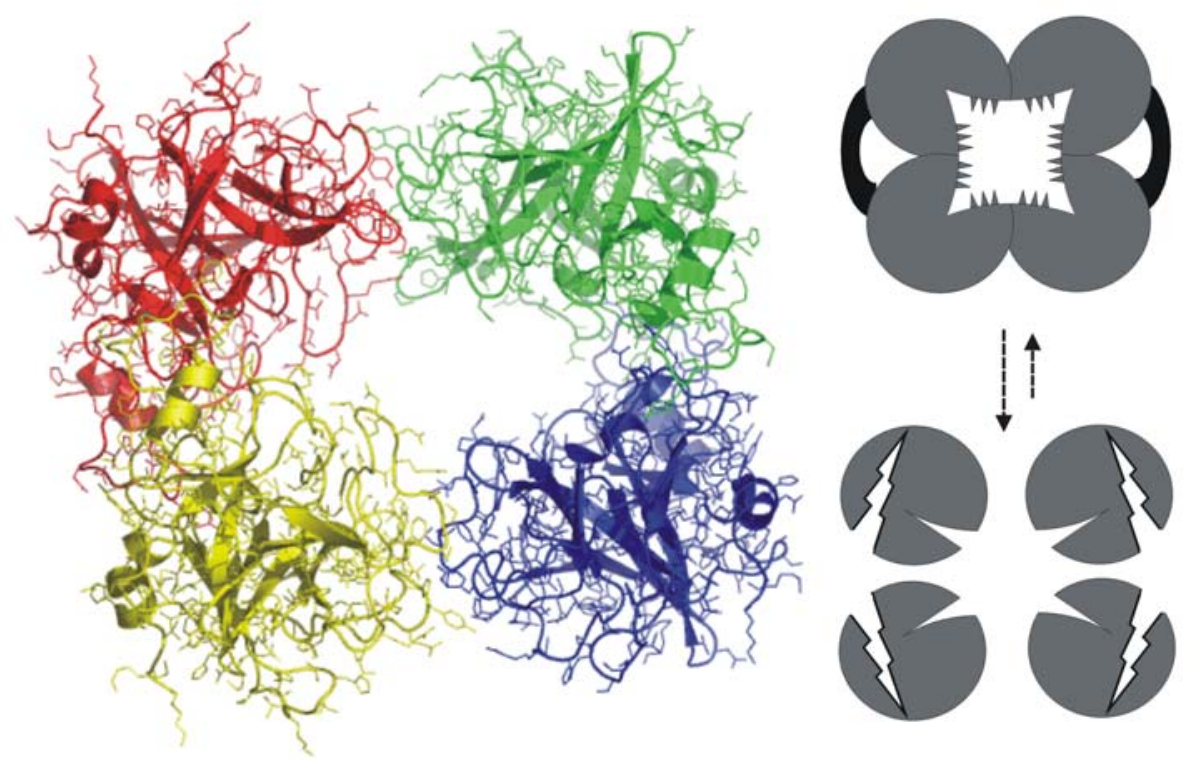

Aktives $\beta$-Tetramer
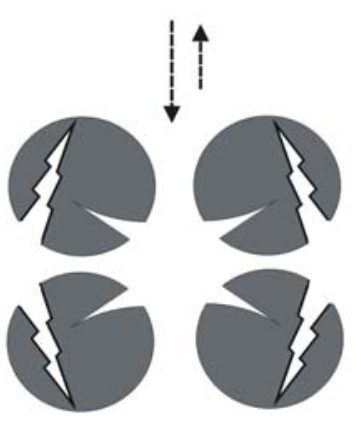

Inaktive $\beta$-Monomere

Abbildung 1.5.: Schematische Darstellung der tetrameren Struktur der humanen $\beta$-II Tryptase aus der Lunge [Pereira et al., 1998]. Die Abbildung wurde mit dem Programm Pymol (www.pymol.org) erstellt. Die Tryptase ist nur in ihrer durch Heparin stabilisierten tetrameren Struktur enzymatisch aktiv.

Das Tetramer wird durch negativ geladene Aminoglykane wie z.B. Heparin oder in vitro durch eine hohe Ionenkonzentration stabilisiert. Nach nur unter bestimmten Bedingungen reversibler Dissoziation in die Monomere geht die enzymatische Aktivität verloren. Die an den Ecken des Tetramers positionierten Tryptase Monomere schließen eine etwa 50 x $30 \AA ̊$ große Pore ein, wobei die aktiven Zentren der Monomere in diese Pore gerichtet sind [Pereira et al., 1998]. Die unmittelbare Umgebung des aktiven Zentrums der Tryptase ist der von Trypsin sehr ähnlich, d.h. wie bei Trypsin ist die Bindungstasche für die Bindung von geladenen Lysin bzw. Arginin Seitenketten ausgerichtet. Untersuchungen zur biologischen Funktion der Tryptase konzentrierten sich zunächst auf die Fähigkeit, extrazelluläre Substrate wie z.B. Fibronektin [Lohi et al., 1992] oder Kininogene [Walls et al., 1992] zu spalten. Des weiteren kann Tryptase den G-Protein-gekoppelten Rezeptor PAR2 („Protease-aktivierbaren Rezeptor"), der auf sensorischen Nervenzellen vorkommt, durch Spaltung aktivieren [Molino 
et al., 1997]. Nach Aktivierung schütten die Nervenzellen die Entzündungs-induzierenden Neuropeptide Substanz P und CGRP (calcitonin gene-related peptide) aus [Steinhoff et al., 2000]. Tryptase kann somit auf diesem Weg als Auslöser neurogener Entzündungsreaktionen wirken. Tryptase stimuliert zudem das Wachstum von Epithelzellen, Fibroblasten und der glatten Muskulatur in den Atemwegen [Brown et al., 2002, Cairns und Walls, 1996, Ruoss et al., 1991] und trägt dadurch vermutlich zum remodeling Prozeß im asthmatischen Krankheitsprozess bei.

\subsubsection{Tryptase Inhibitoren}

Angesichts der evidenten Bedeutung humaner Mastzell-Tryptasen im Zuge inflammatorischer und allergischer Prozesse wird Tryptase als therapeutisches Zielprotein bei der Behandlung von Asthma und inflammatorischer Störungen angesehen [Cairns, 2005, Gangloff, 2000, Levi-Schaffer und Piliponsky, 2003]. Aufgrund der speziellen tetrameren Architektur der Tryptase konzentrierten sich bisherige Inhibitor Entwicklungen zum einen auf Heparin Antagonisten [Elrod et al., 1997, Hallgren et al., 2001] und zum anderen auf peptidische und nicht-peptidische Inhibitoren, die klein genug sind, in das Tetramer einzudringen [Burgess et al., 1999, Caughey et al., 1993, Costanzo et al., 2003, Zhao et al., 2004]. Der bisher einzige bekannte ,proteinerge“ Tryptase Inhibitor ist der leech-derived-tryptase-inhibitor (LDTI) aus Hirudo medicinales [Mühlhahn et al., 1994], der Tryptase zwar mit hoher Affinität bindet, aber aufgrund seiner Größe von 46 Aminosäuren nur zwei der vier Monomere des Tryptase Tetramers inhibiert [Pohlig et al., 1996, Sommerhoff et al., 1994]. Seit Klärung der Tryptasestruktur (siehe oben), die eine symmetrische Anordnung der Monomere zeigt, besteht die Möglichkeit, bivalente Inhibitoren herzustellen [Rice et al., 2000, Schaschke et al., 2002, Schaschke et al., 2001, Selwood et al., 2003], die aufgrund der bivalenten Bindung höhere Bindungskonstanten und Selektivitäten aufweisen sollten.

Trotz der Vielzahl von Entwicklungsprojekten [Newhouse, 2002] befindet sich zur Zeit kein Tryptase Inhibitor für therapeutische Anwendungen auf dem Markt. Die bisher synthetisierten Inhibitoren sind oftmals für Applikationen in vivo nicht geeignet, da sie toxisch, instabil oder $\mathrm{zu}$ unspezifisch sind. Trotz dessen konnten einige dieser Inhibitoren Wirksamkeit im Tiermodell in Bezug auf Tryptase vermittelte inflammatorische Prozesse zeigen [Clark et al., 1995, Krishna et al., 2001, Oh et al., 2002, Rice et al., 2000, Tremaine et al., 2002], was die Eignung von Tryptase als therapeutisches Zielprotein validiert.

Cystin-Knoten Mikroproteine sollten daher, da sie zum einen deutlich kleiner sind als LDTI und damit in das Tryptase Tetramer passen sollten und da sie zum anderen die für eine in vivo 
Anwendung gewünschten Eigenschaften wie Stabilität, Spezifität und evtl. auch orale Verfügbarkeit aufweisen, als Leitstruktur für das rationale Design von Tryptase Inhibitoren geeignet sein.

\subsection{Thrombopoietin (TPO)}

Der Begriff Thrombopoietin wurde zum ersten Mal im Jahre 1958 als Bezeichnung für die humorale Substanz verwendet, die nach induzierter Thrombozytopenie (Mangel an Thrombozyten) für die Bildung von neuen Blutplättchen sorgte [Kelemen et al., 1958]. Obwohl es in den 80er Jahren verschiedene Anläufe gab, das Protein zu reinigen und zu klonieren, dauerte es bis in das Jahr 1992, als die Identifizierung des humanen Homologs des v-mpl Onkogens veröffentlicht wurde, das verschiedene Eigenschaften eines putativen TPO Rezeptors aufwies [Vigon et al., 1992], neue Ansätze zur Klonierung und Reinigung von TPO zu stimulieren. Diese Versuche mündeten in der nahezu gleichzeitigen Identifizierung des Liganden von fünf verschiedenen Arbeitsgruppen [Bartley et al., 1994, de Sauvage et al., 1994, Kuter und Rosenberg, 1994, Lok und Foster, 1994, Sohma et al., 1994], die dem Zytokin zunächst verschiedene Namen gaben: Mpl Ligand (ML oder Mpl-L), Thrombopoietin (TPO), Megapoietin und megacaryocyte growth and development factor (MGDF).

Humanes TPO wird hauptsächlich in der Leber, aber auch in Niere und verschiedenen anderen Geweben exprimiert. Es ist nach Abspaltung eines 21 Aminosäuren langen Signalpeptids ein 332 Aminosäuren großes Protein. Von der Gensequenz ergibt sich eine molekulare Masse von etwa $35 \mathrm{kDa}$, aber die Angaben gehen von 18-70 kDa in Serum bzw. in Kulturmedium rekombinanter Zellen, je nach Glykosylierungsgrad und proteolytischer Prozessierung [Kaushansky, 1995, Lok und Foster, 1994]. Das Molekül kann strukturell und funktionell in zwei Domänen geteilt werden. Die C-terminale Domäne zeigt keine Sequenzhomologie $\mathrm{zu}$ anderen bekannten Proteinen, und weist eine große Divergenz zwischen den einzelnen Spezies auf [Wendling, 1999]. Sie beinhaltet mehrere Glykosilierungsstellen. Die 153 Aminosäuren große N-terminale Domäne hingegen ist zwischen den verschiedenen Spezies stark konserviert und weist $23 \%$ Sequenzidentität und 50 \% Sequenzähnlichkeit zu Erythropoietin (EPO) einschließlich vier konservierter Cystein Reste auf. Kürzlich wurde die dreidimensionale Struktur dieser für die Rezeptorbindung verantwortlichen Domäne im Komplex mit einem neutralisierenden Antikörperfragment aufgeklärt [Feese et al., 2004] (Abbildung 1.6.). Die Rezeptor-Binde Domäne ist ein VierHelix-Bündel mit einem seitlichen antiparallelen doppelsträngigem $\beta$-Faltblatt. Der CTerminus von Helix A und der N-Terminus von Helix C ist durch eine Disulfidbrücke 
miteinander verknüpft. Eine weitere Disulfidbrücke verbindet die N- und C-terminale Region des Vier-Helix-Bündels und ist essentiell für die biologische Funktion. Es konnte gezeigt werden, daß die Bindedomäne zwei Binderegionen aufweist, die unterschiedliche Bindungskonstanten zum Rezeptor aufweisen, d.h. die Aktivierung des TPO-Rezeptors erfolgt in einer 1:2 Stöchometrie.

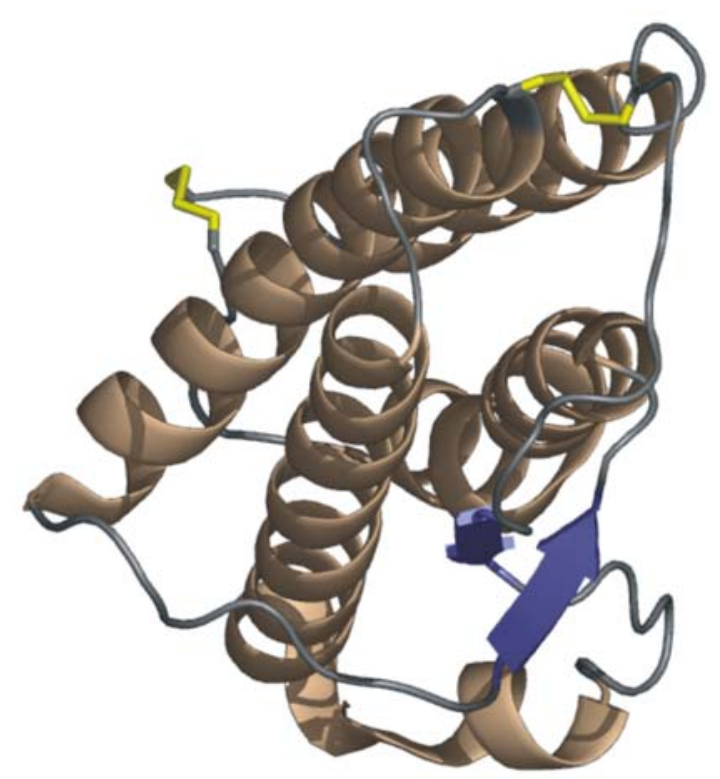

Abbildung 1.6.: Schematische Darstellung der dreidimensionalen Struktur der N-terminalen Region von Aminosäure 1-163 des humanen Zytokins Thrombopoietin [Feese et al., 2004] (Die Abbildung wurde mit dem Programm Pymol erstellt). $\alpha$-Helices sind in beige, $\beta$-Faltblatt Strukturen in blau dargestellt. Die Disulfidbrückenbindungen zwischen Cys 29 und Cys 85 und zwischen Cys 7 und Cys 151 sind in gelb hervorgehoben.

Obwohl TPO hauptsächlich in der Leber produziert wird, nimmt das Zytokin seine Hauptfunktion im Knochenmark wahr, wo es neben anderen Faktoren wie z.B. IL-6 und -11 die Differenzierung von Stammzellen zu Megakaryozyten-Vorläufern und Wachstum und Differenzierung von Megakaryozyten stimuliert [Kaushansky et al., 1995, Wendling, 1999] (Abbildung 1.7. A). TPO nimmt damit eine Schlüsselrolle bei der Bildung von Megakaryozyten und Blutplättchen ein, obwohl in TPO knock-out Mäusen gezeigt werden konnte, daß zumindest die Rolle bei der Stimulation der Differenzierung von Megakaryozyten in vivo von anderen Faktoren übernommen werden kann [Bunting et al., 1997].

Nach Bindung von TPO an den TPO-Rezeptor, der in der Zelloberfläche von Knochenmarkszellen, Megakaryozyten und Thrombozyten verankert ist, erfolgt dessen Aktivierung durch die Dimerisierung zweier Rezeptormoleküle [Dower et al., 1998, Geddis et al., 2002]. Für die Signalweiterleitung wird unter anderem, wie bei anderen Mitgliedern der 
Zytokin Rezeptor Superfamilie, der JAK/STAT (JAKs: Janus kinases; STATs: signal transducer and activator of transcription) Signaltransduktionsweg (Abbildung 1.7. B) verwendet [Drachman et al., 1999, Schulze et al., 2000]. Hierbei werden assoziierte JAKs nach Dimerisierung des Rezeptors aktiviert und vermitteln die Phosphorylierung bestimmter Tyrosin Reste des Rezeptors. Dadurch werden spezielle STATs rekrutiert, die dann ebenfalls phosphoryliert und damit aktiviert werden. Aktivierte STATs werden vom Rezeptor freigesetzt, dimerisieren und binden nach Transport in den Kern an Operatorregionen der $\gamma$ activated site (GAS) Familie von Enhancern, wodurch letztendlich die Expression bestimmter Gene stimuliert wird.

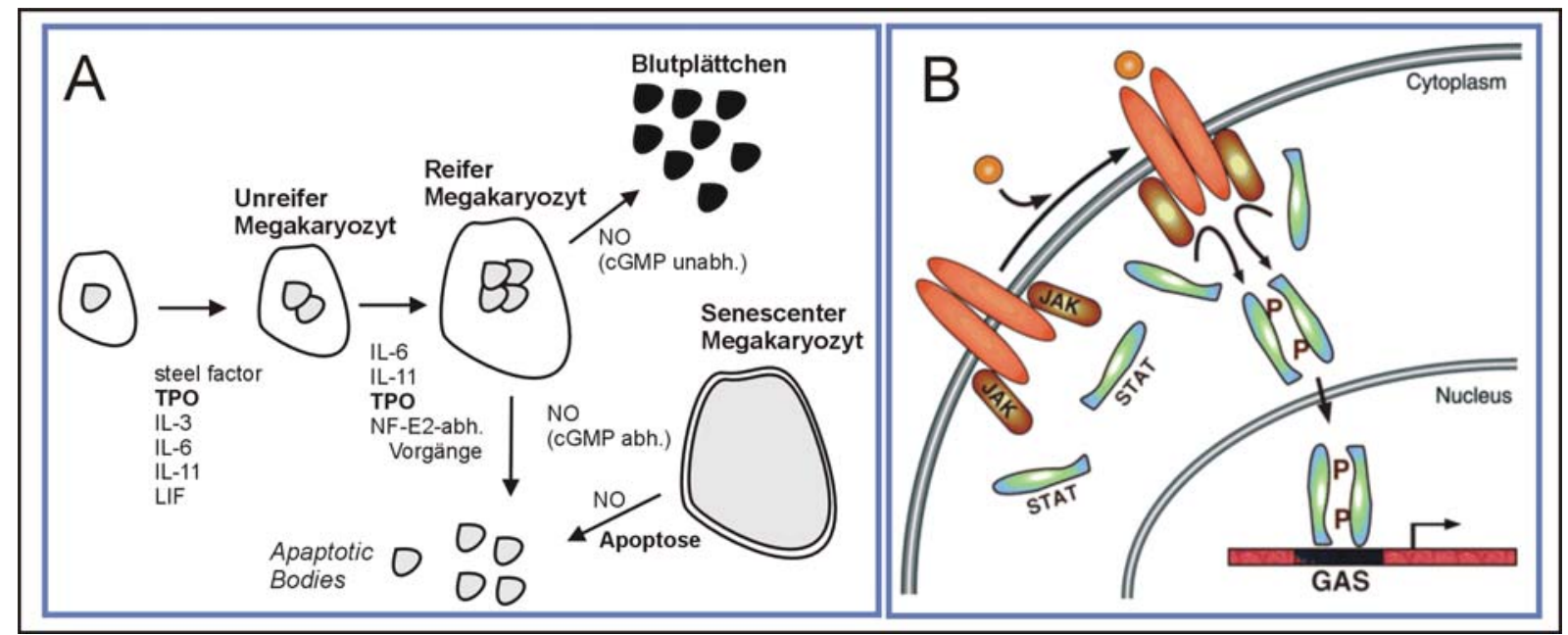

Abbildung 1.7.: (A) Überblick über die Bildung, Reifung und Apoptose von Megakaryozyten und die Bildung von Thrombozyten (modifiziert nach [Battinelli et al., 2001]). LIF: lymphocyte inhibitory factor; NF-E2: Essentieller Transkriptionsfaktor, der in der Megakaryozyten-Reifungs Phase aktiviert wird (NF-E2 ist ein heterodimeres Protein aus der Leuzin Zipper Familie). (B) Überblick über den JAK-STAT Signaltransduktionsweg (aus [Schindler, 2002]). Durch die Bindung des Liganden an den Rezeptor werden assoziierte JAKs aktiviert und vermitteln die Phosphorylierung bestimmter Tyrosin Reste des Rezeptors. Dadurch werden spezielle STATs rekrutiert, die dann ebenfalls phosphoryliert und damit aktiviert werden. Aktivierte STATs werden vom Rezeptor freigesetzt, dimerisieren und binden nach Transport in den Kern an Operatorregionen der $\gamma$-activated site (GAS) Familie von Enhancern.

Thrombozytopenie, ein Mangel an Blutplättchen, kann sowohl iatrogen verursacht sein z.B. durch myelosuppressive Chemotherapien, Radiotherapien oder allergische Reaktionen auf die Gabe des blutgerinnungshemmenden Medikaments Heparin und des Antibiotikums Chloramphenicol als auch durch Infektionen sowie seltene Erbkrankheiten wie das TARSyndrom (Thrombocytopenia with Absent Radius) ausgelöst werden. Erste klinische Studien untersuchten die Wirksamkeit der Gabe von rekombinantem TPO für die Rückbildung der Thrombozyten bei Krebspatienten [Jones et al., 1998] bzw. bei Stammzelltransplantationen [Nash et al., 2000]. Weitere Studien wurden mit an Polyethylenglykol (PEG) gekoppeltem megakaryocyte differentiation factor (peg-MGDF, ein an PEG gekoppeltes N-terminales TPO Fragment) [Fanucchi et al., 1997] durchgeführt. Bei den Studien traten jedoch Probleme bzgl. 
der Antigenizität der rekombinanten Proteine auf [Basser et al., 2002, Battinelli et al., 2001]. Diese Befunde führten zur vermehrten Entwicklung von TPO-Mimetika mit potentiell besseren Eigenschaften als das rekombinant hergestellte Zytokin. So wurden inzwischen potentielle Wirkstoffe mit TPO mimetischer Funktion auf Basis von niedermolekularen Substanzen [Erickson-Miller et al., 2005, Inagaki et al., 2004], Antikörpern [Orita et al., 2005] und Peptiden [Cwirla et al., 1997] generiert.

Die von Cwirla et al. [Cwirla et al., 1997] mittels Phage display selektierten peptidischen TPO Mimetika sollen im Rahmen dieser Arbeit in das Grundgerüst von Cystin-Knoten Mikroproteinen transplantiert werden, um TPO mimetische Mikroproteine zu generieren.

\subsection{Zielsetzung}

Das hier vorgestellte Promotionsvorhaben soll die Eignung von Cystin-Knoten Mikroproteinen als strukturelles Grundgerüst (scaffold) für das rationale Protein Design zur Funktionalisierung dieser Proteine im Wesentlichen an zwei Beispielen aufzeigen:

Zum einen sollen auf Basis von Mikroproteinen Inhibitoren der humanen Mastzell-Tryptase entwickelt werden (Kapitel 4.2.). Die Familie der humanen Mastzell-Tryptasen umfaßt eine Gruppe sequenzhomologer Trypsin-ähnlicher Serinproteasen, die eine wichtige Rolle als Mediatoren im Zuge verschiedener inflammatorischer und allergischer Prozesse spielen.

Zum anderen sollen durch Transplantation funktioneller Peptide in das Cystin-Knoten Grundgerüst Mikroproteine generiert werden, die in der Lage sind, die Funktion des Zytokins Thrombopoietin zu imitieren (Kapitel 4.3.), das eine zentrale Rolle in der Bildung und Differenzierung von Megakaryozyten spielt.

Als Basis für die Entwicklung rational designter Cystin-Knoten Mikropoteine ist jedoch zunächst die Etablierung eines robusten Produktions- und Reinigungssystems erforderlich. Daher soll ein kosteneffizientes und auch für die Produktion größerer Mengen geeignetes rekombinantes Expressionssystem aufgebaut werden, das die Herstellung von Mikroprotein Varianten in korrekt gefalteter Cystin-Knoten Konformation ermöglicht (Kapitel 4.1.).

Schließlich soll ein methodischer Zugang für die Zyklisierung von Cystin-Knoten Mikroproteinen geschaffen werden, womit für mögliche zukünftige therapeutische Applikationen die Stabilität hergestellter Mikroproteine durch Generierung eines zyklischen Rückgrats weiter erhöht werden könnte (Kapitel 4.4.). 


\section{Materialien}

\subsection{Bakterien- und Hefestämme}

Escherichia coli

BMH71-18 (Quelle: B. Müller-Hill)

[F' lac $\mathrm{I}^{\mathrm{q}}$ lacZ $\Delta \mathrm{M} 15$, pro $A^{+} B^{+} ; \Delta($ lac-proAB)supE, thi]

BL21 (DE3) (Novagen)

$\left[\mathrm{F}^{-}\right.$ompT hsd $\mathrm{SB}\left(\mathrm{rB}^{-} \mathrm{mB}^{-}\right)$gal dcm (DE3)]

Pichia pastoris

GS115 (Invitrogen)

[his4] (Phänotyp: His' ${ }^{-} \mathrm{Mut}^{+}$)

\subsection{Plasmide}

Die folgenden Konstrukte pMT416 [Hartley, 1988] (Abbildung 2.1.) und pASKInt101 (Abbildung 2.2.), ein Derivat des Plasmids pASKInt100 [Wentzel et al., 2001], lagen am Beginn dieser Arbeit vor und wurden als Ausgangsplasmide für die Erstellung eines Expressionsvektors zur Produktion von Mikroproteinen verwendet. Alle weiteren, aus diesen hervorgegangenen Vektoren, werden im Abschnitt Ergebnisse und Diskussion dargestellt und erläutert. Die Plasmidkarten und Sequenzen der in dieser Arbeit verwendeten kommerziell erhältlichen Vektoren pPIC9K (Invitrogen), pREP4 (Qiagen), pET22b(+) (Novagen), pCR $^{\circledR}$ 4-TOPO ${ }^{\circledR}$ (Invitrogen), pMAL-p2 (NEB) und pTWIN2 (NEB) können auf der Homepage der jeweiligen Firma heruntergeladen werden.

\section{Abbildung 2.1.:}

Genetische Karte des Vektors pMT416 [Hartley, 1988]. Die Pfeilrichtungen geben die funktionellen Orientierungen der genetischen Elemente an.

Barnase: Kodierende Sequenz für die extrazelluläre RNase Barnase aus Bacillus amyloliquefaciens; barstar: Gen für den natürlichen Barnase Inhibitor Barstar aus Bacillus amyloliquefaciens; tac: Promotor/Operator Region des synthetischen tac-Promotors; AmpR: Ampicillin-Resistenz Gen; phoA s: Alkalische Phosphatase Periplasma Signalsequenz; ori c: Replikationsursprung.

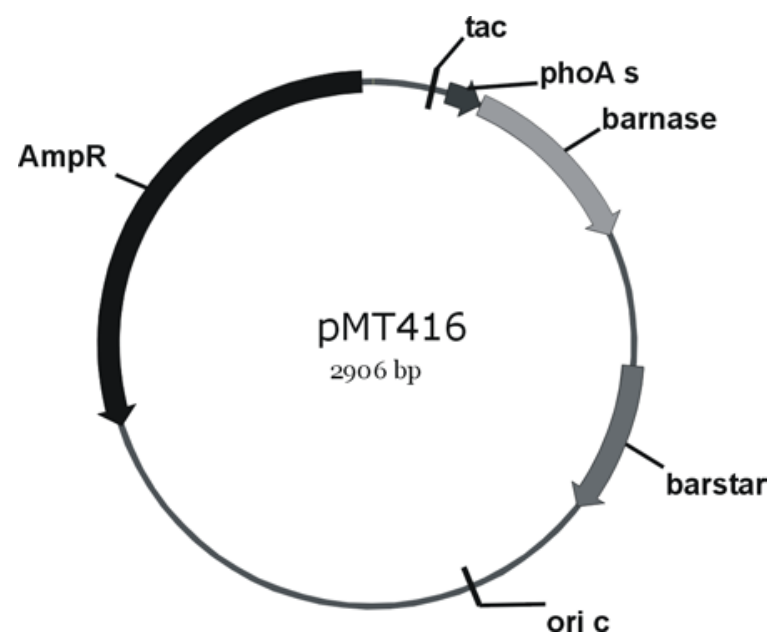


Abbildung 2.2.:

Genetische Karte des Vektors pASKInt101, einem Derivat des Zelloberflächenpräsentationsvektors pASKInt100 [Wentzel et al., 2001]. Die Pfeilrichtungen geben die funktionellen Orientierungen der genetischen Elemente an. Tet P/O: Promotor/Operator Region; colE1 ori: Replikationsursprung; cat: ChloramphenicolAcetyl-Transferase Gen; Tet R: kodierende Region für den Tetracyclin Repressor; fl-ori: Replikationsursprung des Phagen f1; etag: kodierender Bereich für das Epitop, das durch Anti-E Antikörper erkannt wird; intimin: auf die Codone 1 bis 659 verkürztes Struturgen für das intimin EaeA aus enterohämorrhagischen $E$. coli O157:H7.

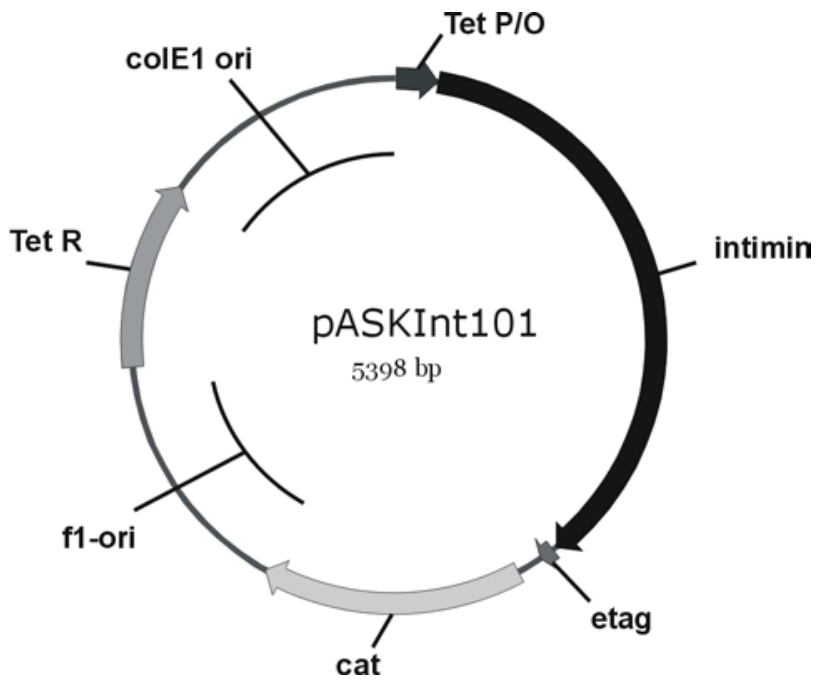

\subsection{DNA-Längenstandards und Protein-Molekulargewichtsmarker}

\subsubsection{DNA-Längenstandards}

Lösungen von DNA-Längenstandards (MBI-Fermentas) wurden mit TE-Puffer und Sucrosefarbmarker auf eine DNA-Konzentration von $0,1 \mu \mathrm{g} / \mu \mathrm{l}$ eingestellt und bei $4{ }^{\circ} \mathrm{C}$ gelagert.

\section{$\lambda$-DNA, Eco 47I geschnitten}

Fragmentlängen in bp:

$8126,6555,6442,3676,2605,2555,2134,2005,1951,1612,1420,1284,985,974,894,597$, 590, 513, 511, 433, 345, 398, 310, 308, 272, 242, 215, 151, 88, 72, 67, 45, 42, 32, 28, 23.

\subsubsection{Molekulargewichtsmarker für Proteine}

Protein Ladder (MBI Fermentas) zur Molekulargewichtsbestimmung von Proteinen mittels Polyacrylamidgelelektrophorese. Beinhaltet sieben Banden der relativen Molekulargewichte $14400,18400,25000,35000,45000,66200,116000$.

\subsection{Oligodesoxyribonukleotide}

3` AOX: 5' GCAAATGGCATTCTGACATCC 3'

5 AOX: 5' GACTGGTTCCAATTGACAAGC 3'

AGTP11-SOE1lo: 5' GGAGATCCATTCACGCAGGGTCGGACCGTCAGCGCAACCAC CGCAGGTAGCCGCGGGGTCG 3' 
AGTP11-SOE2up: 5' CCCTGCGTGAATGGATCTCCTTCTGCGGTGGTTGCAAAGGA TCCTAAATACCTGTG 3'

AGTP12-SOE1lo: 5' GAAGGAGATCCATTCACGCAGGGTCGGACCGTCAGCGCAGT AGCAGGTAGCCGCGG 3'

AGTP12-SOE2up: 5' CCTGCGTGAATGGATCTCCTTCTGCTACTGCAAAGGATCCTA AATACCTGTGAC 3'

AGTP21-SOElo1: 5' GCCAGCCACTGACGCAGGGTCGGACCTTCGATGCAGGTAGC CGCGGGGTC 3'

AGTP22-SOEup2:

5' GACCCTGCGTCAGTGGCTGGCTGCTCGTGCTTGCAAAGGATCCTAAATACCTG TGACGGA 3'

AGTP31-SOE1-lo:

5' CTGACGCAGGGTCGGACCTTCGATAGCCAGAGCGGTACCACCGCAGGTAGCC GCGGGGTCG 3'

AGTP31-SOE2-up:

5' GAAGGTCCGACCCTGCGTCAGTGGCTGGCTGCTCGTGCTTGCAAAGGATCCTA AATACCTGTGAC 3

AGTP41-SOE1-lo: 5' CCACTGACGCAGGGTCGGACCTTCGATAGCCAGGCAGGTAC CACCGCAGGTAGCCGCGGGGTC 3'

AGTP41-SOE2-up: 5' GGTCCGACCCTGCGTCAGTGGCTGTGCGCTCGTGCTTGCAA AGGATCCTAAATACCTGTGAC 3'

AGTP51-SOE1lo: 5' GCAGCCAGCCACTGACGCAGGGTCGGACCTTCGATGCAGTA GCAGGTAGCCGC 3'

AGTP51-SOE2up: 5' CCTGCGTCAGTGGCTGGCTGCTTGCTACTGCAAAGGATCCT AAATACCTGTGAC 3'

Alpha-Faktor: 5' TACTATTGCCAGCATTGCTGC 3'

Askspeup: 5' CCGTGATGGTAACTTCACTAG 3'

AvrIIBarnase-up: 5' GCGCCCTAGGGCACAGGTTATCAACACGTTTGAC 3'

Barlo4: 5' CTGTCCCGGGCGAATTCGGTCTGATTTTTGTAAAGGTCTGATAGGCG TCCG TTGTTTTG 3'

Barmitte lo: 5' GTTCGTCCGCTTTTGCCCGGAAGTTTGCCTTCCCTGTTTGAG 3'

Barmitte up: 5' CTTCCGGGCAAAAGCGGACGAAC 3'

BarnaseEco-lo new: 5' GCGCGCGAATTCGGTCTGATTTTTG 3' 
BarnaseUp-MscI/NcoI: $\quad$ 5' CCGGCGATGGCCATGGATGCACAGGTTATCAACACG TTTG 3'

Barsoelo: 5' CGATGGTTACATGGAAGAGCTTCTGATTTTTGTAAAGGTCTG 3'

Bsp120I-McoTI-SMGDGG-lo: 5' GCGCGGGCCCTTAACCACCGTCGCCCATAGAA CCGCAGTAACCGTTACCACGG 3'

BspHI-McoTI-MSDGG-up： 5' CGACCGGTCATGAGTGACGGTGGTGTTTGCCCGA AAAT 3'

Cat-Hind-Mitte-lo: 5' CCACAAGCTTGAAAACGTTTCAG 3'

Cole1swaxbalo: 5' GCGCTCTAGATTTAAATTGTCGGGTCATGTGAGCAAA AGGCC 3'

Cotilink: 5' CGTCGACATTTTTTCAGGATTTTCGGGCAAACACCACCGTCGGATCCG GAACCGCAG 3'

Cotilo: 5' GCATGCGCTCTTCTGCAAGCACCCGGGCAGTCGGAGTCACGTCGACATT TTTTCAGG 3'

Cotiup2: 5' GCATGCGCTCTTCTAACTGCATATGCGGGCCCAACGGTTACTGCGGTT CCGGATCC 3

ETI-NotI-lo: 5' GCTACGCGGCCGCTATTTAGGATCCGCAGAAACCG 3'

ETI-TNNK-SOE-up: 5' CTCCGACTGCCTGGCTGGCTGCGTTTGCACCAACAATAAA TTCTGC 3'

ETI-TR-SOE-lo: 5' AGCCAGCCAGGCAGTCGGAGTCACGGGTGCAAC 3'

ETTP11-SOE110: 5' GATCCATTCACGCAGGGTCGGACCGTCAGCGCAACCACCGCA CCCCATGGAAGAGCT 3'

ETTP11-SOE2up: 5' CGACCCTGCGTGAATGGATCTCCTTCTGCGGTGGTTGCAAAC AGGACTCCGACT 3'

ETTP21-SOE1lo: 5' CAGCCAGCCACTGACGCAGGGTCGGACCTTCGATGCACCCCA TGGAAGAGCTTC 3'

ETTP21-SOE2up: 5' CCTGCGTCAGTGGCTGGCTGCTCGTGCTTGCAAACAGGACTC CGACTG 3'

ETTP51-SOE110: 5' CCAGCCACTGACGCAGGGTCGGACCTTCGATGCACCCCATGG AAGAGC 3'

MCEIupNco: 5' CTCTTCCATGGGGATCGAGGGAAGGGAAGAACGTATCTGCCCGC TGATCTGGATGG 3'

MCETIup1: 5' ATCTGCCCGCTGATCTGGATGGAATGCAAACGTGACTCCGACTGC C TGGCT 3 
McoTi- TNNKSOE2up: 5' TCCGACTGCCTGGCTGGCTGCGTTTGCACCAACAATAA ATTCTGCG GATCCTAAATAC 3'

MCoTI-ARDeinzel-SOE-lo: 5' AACGCAGCCAGCCAGGCAGTCGGAGTCACGAGCAC ATTTTTTCAGGATTTTCGGGCAAACCCCCATGGA 3'

MCoTI-KKV3R-up: 5' AGCTCTTCCATGGGGAAAAAAGTTGGGGTTTGCCCGCGAA TCCTG 3'

McoTI-KnachR-SOE1lo: 5' ACGCAGCCAGCCAGGCAGTCGGAGTCACGTCGACAAC GTCGCAGGATTCGCGGGCAAACCCCCATGGA 3'

MCoTI-MSDGGhinten-SOE-lo： 5' CTTAACCACCGTCGGACATGGACCCGCAGAAA CCGTTG 3'

MCoTI-MSDGGhinten-SOE-up: 5' CCATGTCCGACGGTGGTTAAGGGCCCAACGTT CTG 3'

McoTI-PRNRQK-SOE1lo: 5' ACGCAGCCAGCCAGGCAGTCGGAGTCACGTCGACAT TTCTGTCGGTTTCGGGGGCAAACCCCCATGGA 3'

McoTI-PRNRQR-SOE2lo: 5' ACGCAGCCAGCCAGGCAGTCGGAGTCACGTCGACAT CGCTGTCGGTTTCGGGGGCAAACCCCCATGGA 3'

MCoTI-RAD-SOE-lo: 5' AACGCAGCCAGCCAGGCAGTCGGAGTCAGCACGACATTT TTTCAGGATTTTCGGGCAAACCCCCATGGA 3'

McoTI-Wt-SOE1lo: 5' ACGCAGCCAGCCAGGCAGTCGGA 3'

McoTi-WTSOE2up: 5' TCCGACTGCCTGGCTGGCTGCGTTTGCGGGCCCAACGGT 3'

Nco-XA-etiup: 5' GACTCCGGCCATGGGGATCGAGGGAAGGGGGTGCCCGCGCATT CTGATGCGCTGCAAACAGGACTC 3'

NcoMCoTI-ARD-up: 5' AGCTCTTCCATGGGGGTTTGCCCGAAAATCCTGAAAGCCT GTGCTCGTGACTCCGACTGCCTGGC 3'

NcoMCoTI-KKV-up: 5' AGCTCTTCCATGGGGAAAAAAGTTGGGGTTTGCCCGAAA ATCCTGAAA 3'

NcoMCoTI-LKA-up: 5' AGCTCTTCCATGGGGGTTTGCCCGAAAATCCTGAAAGCCT GTCGACGTGACTCCGACTGC 3'

NcoThromMCoTi-up: 5' AGCTCTTCCATGGGGCTGGTTCCGCGTGGGTCCGTTTGCC CGAAAATCCTGAAAAAATG 3'

T7 Prom: 5' TAATACGACTCACTATAGgG 3'

T7-Spe-Nhe-up: 5' GCGCACTAGTGCTAGCGATCTCGATCCCGCGAA 3'

Tacpromup: 5' TTTCAATGAATTCGAGCTCG 3'

Tetpromsoeup: 5' GCTCTTCCATGTAACCATCGAATGGCCAGATGATTAATTCC 3' 
Tetpromsoexbalo: 5' GCGCTCTAGATTTTTGTCGAACTA 3'

TetR-Bsp120-up: 5' GATCAGGGCCCTGATAGGGAGTGGTAAAATAAC 3'

TetR-Spe-lo: 5' GCGCACTAGTTTAAGACCCACTTTCACATTTAAG 3'

TP1-Screen: 5' TGACGGTCCGACCCTGCGTG 3'

TP1lin-SOE1lo: 5' CCATTCACGCAGGGTCGGACCGTCAGCGCAACCACCCATGGAA GAGCTTCTGATTT 3'

TP1lin-SOE2up: 5' CGGTCCGACCCTGCGTGAATGGATCTCCTTCTGCGGTGGTTAA ATACCTGTGACGGAAGATC 3'

TP2-5-Screen-up: 5' ATCGAAGGTCCGACCCTGCG 3'

TP2lin-SOElo1: 5' GCCAGCCACTGACGCAGGGTCGGACCTTCGATCATGGAAGAG CTTCTGATTT 3'

Tp2lin-SOEup2: 5' CCTGCGTCAGTGGCTGGCTGCTCGTGCTTAAATACCTGTGACG GAAGATC 3'

\subsection{Enzyme und Proteine}

\section{Fluka, Neu-Ulm}

Trypsin aus Rinder Pankreas.

\section{MBI Fermentas, Vilnius, Litauen}

DNA-Längenstandard, Restriktionsendonukleasen, Protein Molekulargewichtsmarker, T4DNA-Ligase, T4 DNA Polymerase.

New England Biolabs, Bad Schwalbach

Restriktionsendonukleasen, Taq DNA Polymerase.

Serva, Heidelberg

Porcine Pankreas Elastase (PPE).

Sigma, Deisenhofen

Factor X Activated (F2027), Thrombin from human plasma (T-7009).

\subsection{Chemikalien}

\section{Applichem, Darmstadt}

Isopropyl- $\beta$-D-thiogalactopyranosid (IPTG), Acetonitril.

\section{Baker, Deventer, Holland}

$\mathrm{N}^{\prime}, \mathrm{N}^{\prime}$-Dimethylformamid (DMF).

Biozym, Hess. Oldendorf

Biozym DNA Agarose. 


\section{Boehringer Mannheim, Mannheim}

Ampicillin (Natriumsalz), 2'-Desoxyribonukleosid-5'-triphosphate (dATP, dCTP, dGTP, dTTP).

\section{Calbiochem, Schwalbach}

G418 (Geniticin).

\section{Difco, Dreieich}

Bacto-Agar.

\section{Fluka, Neu-Ulm}

Dimethylsulfoxid (DMSO), Bromphenolblau, Glyzerin, $\beta$-Mercaptoethanol, Saccharose, Coomassie Brillant Blue, Natriumchlorid, D(+)-Glukose Monohydrat, Bromcyan, Hydroxylamin-Hydrochlorid, Trifluoressigsäure (TFA), Hydrazin-Monohydrat.

\section{Gibco BRL, Eggenstein}

Hefe Extrakt.

\section{ICN Biochemicals, Aurora, USA}

Borsäure, Ethylendiamintetraessigsäure Dinatriumsalz (EDTA), Tris(hydroxy-methyl)aminomethan (Tris).

\section{Life Technologies Inc., Gaithersburg, USA}

UltraPure Agarose (Electrophoresis Grade).

\section{Merck, Darmstadt}

Alle nicht explizit aufgeführten Chemikalien, die zur Anwendung kamen.

\section{MJ Research, Watertown, USA}

Chill out $14^{\circledR}$ (Flüssigwachs).

\section{Oxoid, Wesel}

Agar Bacteriological, Trypton, Hefe-Extrakt.

\section{Pierce, Rockford, IL, USA}

Disuccinimidylsuberat (DSS).

\section{Riedel-De Haen, Seelze}

Ammoniumacetat, Chloroform, Ethanol, Formamid, Methanol, Natriumchlorid, Salzsäure, Ammoniumsulfat, Aceton.

\section{Roth, Karlsruhe}

Essigsäure, Trichloressigsäure (TCA), ROTI ${ }^{\circledR}$-QUANT Bradford Kit. 


\section{Serva, Heidelberg}

Dithiotreitol (DTT), Ethylendiamintetraessigsäure Dinatriumsalz (EDTA), D(+)-Glukose Monohydrat, Natriumdodecylsulfat (SDS), N,N,N',N'-Tetramethyl- ethylendiamin (TEMED), Ammoniumpersulfat (APS).

\section{Sigma, Deisenhofen}

Borsäure, Ethidiumbromid, Tris(hydroxymethyl)-aminomethan (Tris), Chloramphenicol, Kanamycin, Na-Periodat, Boc-Leu-Gly-Arg-pNA, Triethylamin, Suc-(Ala) 3 $_{3}$-pNA.

\subsection{Sonstige Materialien und Geräte}

American National Can., Chicago, USA

Parafilm $^{\circledR}$ "M" Laboratory Film.

\section{Applied Biosystems}

Biocad VISIONTM Workstation.

Bender \& Hobein, Zürich, Schweiz

Vortex ${ }^{\circledR}$ Genie 2.

\section{BioRad, München}

Gene Pulser ${ }^{\circledR}$ und Pulse Controller, Elektroporationsküvetten.

\section{Biozym, Hessisch Oldendorf}

PCR-Tube ultradünn, 0,2 $\mathrm{ml}$.

\section{Braun Biotech}

Biostat M 11 Fermenter.

\section{CEAG Schirp Reinraumtechnik}

Envirco Sterilbank.

\section{Eppendorf-Netheler-Hinz, Hamburg}

Reaktionsgefäße 2,0 ml Safe-Lock, Reaktionsgefäße 1,5 ml (blau, grün, gelb, rot), Multipipette, Combitips für die Multipipette 0,5 ml, 1,25 ml, 2,5 ml, 12,5 ml, BioPhotometer.

\section{Genomed, Bad Oeyenhausen}

JetStar Plasmid Midiprep Kit 2.0.

\section{Gilson, USA}

Mikroliter-Pipetten, $1000 \mu 1,200 \mu 1$ und $20 \mu 1$.

\section{A. Greiner \& Söhne, Nürtingen}

Petrischalen, Röhrchen $12 \mathrm{ml}$.

\section{Heinemann, Schwäbisch Gmünd}

Ultraschallgerät Branson Sonifier W-250, SLM Aminco French Press. 


\section{Helma, Müllheim/Baden}

Quarzküvetten (0,5 $\mathrm{ml}$ und $2 \mathrm{ml}, 1 \mathrm{~cm}$ Schichtdicke).

Herolab, Wiesloch

UVT2035 302 nm UV-Leuchttisch.

\section{Hettich Zentrifugen, Tuttlingen}

Kühlzentrifuge Mikro Rapid/K, Kühlzentrifuge Rotanta/RPC, Kühlzentrifuge Roto Silenta/RP, Kühlzentrifuge Rotixa/RP, Mikroliter-Tischzentrifuge.

\section{Ingold, Steinbach/Ts}

pH-Elektrode U402-M5.

\section{IKA-Labortechnik, Staufen}

Beheizbarer Magnetrührer IKAMAG RCT.

InforMax Inc, Bethesda, USA

VectorNTI5 Bioinformatik-Software, Demoversion.

\section{Invitek, Berlin}

Invisorb Spin Plasmid Mini Kit, Invisorb Spin DNA Extraction Kit.

Invitrogen, Karlsruhe

TOPO TA Cloning ${ }^{\circledR}$ Kit.

\section{Kimberley-Clark, USA}

Kimwipes ${ }^{\circledR}$ Papiertücher, fusselfrei.

\section{Knick, Berlin}

pH-Meter 761 Calimatic.

\section{Kontron, Eching}

Centrikon ${ }^{\circledR}$ T-1055 Ultrazentrifuge + TST41-14 Schwenkbecherrotor, HPLC-Anlage.

\section{Köttermann Labortechnik, Uetze/Hänigsen}

Wasserbad, Schüttelwasserbad.

\section{Machery-Nagel, Düren}

Nucleotrap ${ }^{\circledR}$ und NucleotraP ${ }^{\circledR}$ CR Kit.

\section{Menzel-Gläser, Braunschweig}

Objektträger (76 x 26 mm), Deckgläser (18 x 18 mm).

\section{Millipore, Eschborn}

Filtereinheiten Millex FG13, Ultrafree-20 Nanopore-Wasser-Anlage.

\section{MJ Research, Watertown, USA}

DNA Thermal Mini-Cycler ${ }^{\circledR}$ PTC-150. 


\section{Nalgene, Hereford, England}

Cryoware Cryovial (2 ml-Röhrchen für Gefrierkulturen).

\section{Pharmacia /LKB, Freiburg}

Elektrophorese Stromversorger ECPS 3000/150, Ultrospec II Spektralphotometer (LKB Biochrom), LCC-500 PLUS FPLC Anlage.

\section{Promega, Mannheim}

Wizard $^{\circledR}$ SV Gel and PCR Clean-up System, Wizard ${ }^{\circledR}$ Plus SV MiniprepsDNA Purification System.

\section{Qiagen, Hilden}

QIAprep Spin Miniprep Kit, QIAGEN Plasmid Midi Kit, QIAquick Gel Extraction Kit.

\section{Sarsted, Nürnbrecht}

Reaktionsgefäße 1,5 ml, Röhrchen 5 ml, Röhrchen $50 \mathrm{ml}$.

\section{Sartorius, Göttingen}

Minisart NML Sterilfilter, Sartorius Universal U 4800P Feinwaage.

\section{Savant Instruments, Vaterstetten}

Speed Vac ${ }^{\circledR}$ Concentrator SVC $200 \mathrm{H}$.

\section{Schott, Mainz}

Glaswaren.

\section{Sorvall, Bad Nauheim}

Zentrifuge RC-5C, Rotortypen SS34 und GSA.

\section{Terumo, Leuven, Belgien}

Syringe Spritzen, $5 \mathrm{ml}, 10 \mathrm{ml}, 30 \mathrm{ml}$.

\section{Vivascience, Hannover}

Vivaspin Proteinkonzentratoren.

\section{Wissenschaftlich-Technische Werkstätten, Weilheim}

pH-Meter-522.

\section{Zeiss, Oberkochen}

Mikroskop Axioskop mit Durchlicht- und Auflichtfluoreszenz (Filtersätze: 487902 und 487909) und Kameraaufsatz, Okulare: Vergrößerung 10 x, Sehfeldzahl 20, Objektive: Plan Neofluar 63 x/1,25 Oil, 440480, Plan Neofluar 100 x/1,25 Oil, 440460, Acroplan 20 x, 440845, Immersionsöl.

\section{Ziegra, Stockport, England}

Eismaschine. 


\subsection{Nährmedien zur Anzucht von Escherichia coli und Pichia pastoris}

\section{dYT-Medium}

$10 \mathrm{~g}$ Hefe-Extrakt, $16 \mathrm{~g}$ Trypton, $5 \mathrm{~g} \mathrm{NaCl}, \mathrm{H}_{2} \mathrm{O}$ ad $1000 \mathrm{ml}$.

\section{TB Medium}

$12 \mathrm{~g}$ Trypton, $24 \mathrm{~g}$ Hefe-Extract, $4 \mathrm{ml}$ Glyzerin, $\mathrm{H}_{2} \mathrm{O}$ ad $900 \mathrm{ml}$. Komplettiert mit $100 \mathrm{ml}$ steriler Lösung aus $0,17 \mathrm{M} \mathrm{KH}_{2} \mathrm{PO}_{4}$ und 0,72 $\mathrm{M} \mathrm{K}_{2} \mathrm{HPO}_{4}$.

\section{M9-Minimalmedium}

$7 \mathrm{~g} \mathrm{Na}_{2} \mathrm{HPO}_{4}$ x $2 \mathrm{H}_{2} \mathrm{O}, 3 \mathrm{~g} \mathrm{K \textrm {KH } _ { 2 }} \mathrm{PO}_{4}, 1 \mathrm{~g} \mathrm{NH} \mathrm{NCl}_{4} \mathrm{H}_{2} \mathrm{O}$ ad $1000 \mathrm{ml}$. Komplettiert mit $25 \mathrm{ml}$

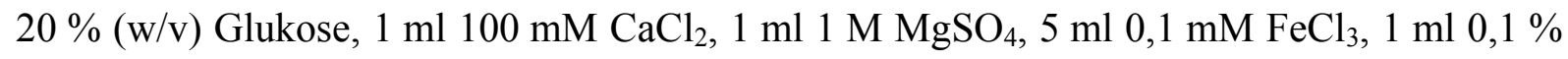
(w/v) Thiamin, jeweils aus sterilen Lösungen zugesetzt.

\section{YPD-Medium}

20 g Pepton, 10 g Hefe-Extrakt, $\mathrm{H}_{2} \mathrm{O}$ ad $900 \mathrm{ml}$. Komplettiert mit $100 \mathrm{ml}$ steriler 10xD Lösung (200 g D-Glukose auf $\left.11 \mathrm{H}_{2} \mathrm{O}\right)$.

\section{MD-Agarplatten}

15 g Agar Bacteriological, $\mathrm{H}_{2} \mathrm{O}$ ad $800 \mathrm{ml}$. Komplettiert durch Zugabe von $100 \mathrm{ml}$ steriler 10xD Lösung (200 g D-Glukose auf $11 \mathrm{H}_{2} \mathrm{O}$ ), $2 \mathrm{ml}$ steriler 500xB Lösung (20 mg D-Biotin auf $100 \mathrm{ml} \mathrm{H} \mathrm{H}_{2} \mathrm{O}$ ) und $100 \mathrm{ml}$ steriler 10xYNB Lösung (34 g YNB ohne $\mathrm{NH}_{4}{ }^{+} \mathrm{SO}_{4}$ ohne Aminosäuren mit $100 \mathrm{~g} \mathrm{NH}_{4}{ }^{+} \mathrm{SO}_{4}$ auf $11 \mathrm{H}_{2} \mathrm{O}$ ).

\section{BMGY-Medium}

20 g Pepton, 10 g Hefe-Extract, $10 \mathrm{ml}$ Glyzerin, $\mathrm{H}_{2} \mathrm{O}$ ad $700 \mathrm{ml}$. Komplettiert durch Zugabe von $100 \mathrm{ml}$ steriler 10xYNB Lösung (s.o.), $100 \mathrm{ml}$ sterilem Kalium-Phosphat Puffer, pH 6.0 und $2 \mathrm{ml}$ steriler 500xB Lösung (s.o.).

\section{BMMY-Medium}

20 g Pepton, 10 g Hefe-Extrakt, $\mathrm{H}_{2} \mathrm{O}$ ad $700 \mathrm{ml}$. Komplettiert durch Zugabe von $100 \mathrm{ml}$ steriler 10xYNB Lösung (s.o.), $100 \mathrm{ml}$ sterilem Kalium-Phosphat Puffer, pH 6.0, 2 ml steriler 500xB Lösung (s.o.) und $100 \mathrm{ml} 10 \%$ iges Methanol.

Die Nährmedien wurden zur Sterilisation $20 \min$ bei $120^{\circ} \mathrm{C}$ autoklaviert.

Für feste Medien wurden vor dem Autoklavieren 1,5\% (w/v) Agar Bacteriological (Oxoid) zugegeben. Zur Herstellung von YPD-G418 Platten wurde außerdem sterile G418 Stammlösung bis zu einer Endkonzentration von 0,25, 0,5 bzw. 0,6 mg/ml zugesetzt. 
Antibiotika wurden aus den entsprechenden 1000fach konzentrierten Stammlösungen bis zu einer Endkonzentration von $25 \mathrm{mg} / 1$ Chloramphenicol, $100 \mathrm{mg} / 1$ Ampicillin bzw. $75 \mathrm{mg} / \mathrm{l}$ (oder 37,5 mg/l) Kanamycin zugegeben.

\subsection{Lösungen und Puffer}

\section{Ampicillin-Stammlösung}

$100 \mathrm{mg} / \mathrm{ml} \mathrm{Ampicillin} \mathrm{(Na-Salz)} \mathrm{in} \mathrm{Wasser,} \mathrm{sterilfiltriert.}$

\section{APS-Stammlösung}

$10 \%$ APS in Wasser.

\section{Chloramphenicol-Stammlösung}

$25 \mathrm{mg} / \mathrm{ml}$ Chloramphenicol in $96 \%$ Ethanol.

\section{dNTP-Stammlösung}

je $100 \mathrm{mM}$ dNTP $(\mathrm{N}=\mathrm{A}, \mathrm{C}, \mathrm{G}, \mathrm{T})$, mit $1 \mathrm{M}$ Tris-Base auf $\mathrm{pH}$ 7,0 eingestellt.

\section{dNTP-Stammlösung für die PCR}

je $10 \mathrm{mM}$ dNTP $(\mathrm{N}=\mathrm{A}, \mathrm{C}, \mathrm{G}, \mathrm{T})$, aus dNTP-Stammlösungen mit Wasser verdünnt.

\section{E1 (Jetstar 2.0 Plasmid Kit (Genomed))}

$50 \mathrm{mM}$ Tris-HCl, $\mathrm{pH}$ 8,0, 10 mM EDTA, $100 \mu \mathrm{g} / \mathrm{ml}$ RNaseA.

\section{E2 (Jetstar 2.0 Plasmid Kit (Genomed))}

$200 \mathrm{mM} \mathrm{NaOH}, 1 \%(\mathrm{w} / \mathrm{v})$ SDS.

\section{E3 (Jetstar 2.0 Plasmid Kit (Genomed))}

3,2 M Kaliumacetat-Essigsäure, pH 5,5.

\section{E4 (Jetstar 2.0 Plasmid Kit (Genomed))}

$600 \mathrm{mM} \mathrm{NaCl}, 100$ mM Natriumacetat-Essigsäure, pH 5,0.

\section{E5 (Jetstar 2.0 Plasmid Kit (Genomed))}

$800 \mathrm{mM} \mathrm{NaCl}, 100$ mM Natriumacetat-Essigsäure, $\mathrm{pH}$ 5,0.

\section{E6 (Jetstar 2.0 Plasmid Kit (Genomed))}

1,25 M NaCl, 100 mM Tris-HCl, pH 8,5.

Ethidiumbromid-Stammlösung (10x)

$10 \mathrm{mg} / \mathrm{ml}$ Ethidiumbromid.

\section{Formamid-Farbmarker}

91,2 \% Formamid, 20 mM EDTA, pH 8,3, 0,15 mM Bromphenolblau.

\section{G418 Stammlösung}

$100 \mathrm{mg} / \mathrm{ml}$ in $\mathrm{H}_{2} \mathrm{O}$, sterilfiltriert. 


\section{Hoechst-Puffer (nicht reduzierend)}

8 M Harnstoff, $200 \mathrm{mM}$ Tris-Base, $2 \%$ (w/v) SDS, 0,15 mM Bromphenolblau.

\section{Hoechst-Puffer (reduzierend)}

8 M Harnstoff, $200 \mathrm{mM}$ Tris-Base, $2 \%$ (w/v) SDS, $200 \mathrm{mM}$ Dithiothreitol (DTT), 0,15 mM Bromphenolblau.

\section{IPTG-Stammlösung}

1 M IPTG in Wasser, sterilfiltriert.

\section{Kanamycin-Stammlösung}

$75 \mathrm{mg} / \mathrm{ml}$ Kanamycin in Wasser, sterilfiltriert.

\section{Laemmli-Puffer (Laufpuffer für die SDS-PAGE)}

$25 \mathrm{mM}$ Tris-HCl, $200 \mathrm{mM}$ Glycin, 0,1 \% (w/v) SDS.

Nucleotrap $^{\circledR}$ - und NucleotraP ${ }^{\circledR}$ CR-Puffer (Macherey \& Nagel)

Zusammensetzung der Puffer NT1, NT2, NT3, sowie der Nucleotrap ${ }^{\circledR}$ - und NucleotraP $^{\circledR}$ CRSuspension sind vom Hersteller nicht angegeben.

\section{PAG-Entfärbelösung}

$10 \%$ Essigsäure, $40 \%$ Ethanol, $50 \%$ Wasser.

\section{PAG-Färbelösung}

$1000 \mathrm{ml}$ Methanol, $15 \mathrm{~g}$ Coomassie Brillant Blue $\mathrm{R}^{\circledR}$.

\section{PBS-Puffer}

$140 \mathrm{mM} \mathrm{NaCl}, 10 \mathrm{mM} \mathrm{KCl}, 6,4 \mathrm{mM} \mathrm{Na}_{2} \mathrm{HPO}_{4}, 2 \mathrm{mM} \mathrm{KH} \mathrm{PO}_{4}$.

\section{Phenol/TE}

Phenol p.A. mit TE-Puffer gesättigt, 0,1\% (w/v) 8-Hydroxychinolin.

\section{Phenol/Chloroform}

1 Vol Phenol/TE, 1 Vol Chloroform.

\section{Reaktionspuffer für Restriktionsendonukleasen (MBI Fermentas 10x)}

Blau: $\quad 10 \mathrm{mM}$ Tris- $\mathrm{HCl}, \mathrm{pH} 7,5,10 \mathrm{mM} \mathrm{MgCl}_{2}$

Grün: $\quad 10 \mathrm{mM}$ Tris- $\mathrm{HCl}, \mathrm{pH} 7,5,10 \mathrm{mM} \mathrm{MgCl}_{2}, 50 \mathrm{mM} \mathrm{NaCl}$

Orange: $50 \mathrm{mM}$ Tris- $\mathrm{HCl}, \mathrm{pH} 7,5,10 \mathrm{mM} \mathrm{MgCl}_{2}, 100 \mathrm{mM} \mathrm{NaCl}$

Rot: $\quad 10 \mathrm{mM}$ Tris- $\mathrm{HCl}, \mathrm{pH} 8,5,10 \mathrm{mM} \mathrm{MgCl}_{2}, 100 \mathrm{mM} \mathrm{KCl}$

Gelb: $\quad 33 \mathrm{mM}$ Tris-Essigsäure, $\mathrm{pH}$ 7, 9, $10 \mathrm{mM}$ Magnesiumacetat, $66 \mathrm{mM}$ Kaliumacetat.

\section{Reaktionspuffer für Restriktionsendonukleasen (NEB 10x)}

NEB1: $\quad 10 \mathrm{mM}$ Bis-Tris Propan-HCl, pH 7,0, $10 \mathrm{mM} \mathrm{MgCl}_{2}, 1 \mathrm{mM}$ DTT

NEB2: $\quad 10 \mathrm{mM}$ Tris- $\mathrm{HCl}, \mathrm{pH} 7,9,10 \mathrm{mM} \mathrm{MgCl} 2,50 \mathrm{mM} \mathrm{NaCl} 1 \mathrm{mM}$ DTT 
NEB3: $\quad 50 \mathrm{mM}$ Tris-HCl, $\mathrm{pH}$ 7,9, $10 \mathrm{mM} \mathrm{MgCl} 2,100 \mathrm{mM} \mathrm{NaCl}, 1 \mathrm{mM}$ DTT

NEB4: $\quad 20 \mathrm{mM}$ Tris-Essigsäure, $\mathrm{pH}$ 7,9, $10 \mathrm{mM}$ Magnesiumacetat, $50 \mathrm{mM}$ Kaliumacetat, 1 mM DTT.

\section{RNaseA-Stammlösung}

$10 \mathrm{mg} / \mathrm{ml}$ RNaseA, $10 \mathrm{mM}$ Tris-HCl, $\mathrm{pH} 7,5,15 \mathrm{mM} \mathrm{NaCl}, 20 \mathrm{~min}$ auf $100{ }^{\circ} \mathrm{C}$ erhitzt, langsam auf RT abgekühlt und bei $4{ }^{\circ} \mathrm{C}$ gelagert.

\section{Rückfaltungspuffer}

200 mM Ammoniumcarbonat, $\mathrm{pH} 9,1$.

\section{Sammelgelpuffer für SDS-Polyacrylamidgele}

1,25 M Tris-HCl, pH 6,8.

\section{Sucrosefarbmarker}

$60 \%$ (w/v) Sucrose, 0,1\% (w/v) Bromphenolblau, 0,1\% (w/v) Xylencyanol FF in 1x TAE.

\section{T4-DNA-Ligase-Puffer (MBI, Fermentas 10x)}

$400 \mathrm{mM}$ Tris- $\mathrm{HCl}, \mathrm{pH} 7,8$ bei $25^{\circ} \mathrm{C}, 100 \mathrm{mM} \mathrm{MgCl} 2,100 \mathrm{mM}$ DTT, $5 \mathrm{mM}$ ATP.

\section{Taq-Polymerase-Puffer / Taq-Puffer (10x)}

$50 \mathrm{mM} \mathrm{KCl,} 100$ mM Tris-HCl, pH 9,0, 15 mM MgCl 2,1 \% (w/v) Triton X 100.

\section{TAE-Puffer}

$40 \mathrm{mM}$ Tris-Acetat, $5 \mathrm{mM}$ Natriumacetat, $1 \mathrm{mM}$ EDTA, pH 7,4.

\section{TBE-Puffer}

89 mM Tris-Base, 89 mM Borsäure, 2,5 mM EDTA.

\section{TE-Puffer}

10 mM Tris-HCl, 0,5 mM EDTA, pH 8,0, aus Stammlösungen zusammengestellt.

\section{Thrombin Spalt-Puffer}

$20 \mathrm{mM}$ Tris- $\mathrm{HCl} \mathrm{pH} 8,45,150 \mathrm{mM} \mathrm{NaCl}, 2,5 \mathrm{mM} \mathrm{CaCl}_{2}$.

\section{Trenngelpuffer für SDS-Polyacrylamidgele}

1,875 M Tris-HCl, $\mathrm{pH} 8,8$.

\section{Tris-Puffer}

Tris(hydroxymethyl)-aminomethan (z.B. Sigma 7-9) in Wasser auflösen und den pH-Wert mit Säure einstellen. Für Tris-HCl wird Salzsäure, für Tris-Acetat wird Essigsäure verwendet.

\section{Trypsin Puffer}

$50 \mathrm{mM}$ Tris- $\mathrm{HCl} \mathrm{pH} 7,8,150 \mathrm{mM} \mathrm{NaCl}, 5 \mathrm{mM} \mathrm{CaCl}_{2}$.

Alle Puffer und Lösungen wurden, soweit nicht anders angegeben, mit demineralisiertem Wasser (Millipore, Nanopore-Wasser-Anlage) angesetzt. 


\section{Methoden}

\subsection{Mikrobiologische Arbeitsmethoden}

\subsubsection{Stammhaltung und Kultivierung von Escherichia coli-Zellen}

Die verwendeten Bakterienstämme von Escherichia coli wurden zur längerfristigen Aufbewahrung als Glyzerinkulturen gelagert. Dazu wurden $2 \mathrm{ml}$ autoklaviertes Glyzerin mit $1 \mathrm{ml}$ einer Übernachtkultur des betreffenden Bakterienstammes vermischt und bei $-20{ }^{\circ} \mathrm{C}$ aufbewahrt. Bakterienstämme, die häufig verwendet wurden, wurden auf M9Minimalagarplatten oder entsprechenden Selektivplatten ausgestrichen, über Nacht bei $37^{\circ} \mathrm{C}$ angezogen und konnten so bei $4^{\circ} \mathrm{C}$ für einige Wochen aufbewahrt werden.

Die Anzucht der Stämme erfolgte in dYT-Medium bei $37^{\circ} \mathrm{C}$. Waren die Stämme antibiotikaresistent, so wurde dem Medium das entsprechende Antibiotikum zugesetzt. Kulturen von einem Volumen von $5 \mathrm{ml}$ oder weniger wurden in Reagenzröhrchen auf einem Roller inkubiert, größere Kulturen wurden im Kolben auf einem Schüttler bei $150 \mathrm{u} / \mathrm{min}$ geschüttelt. Kulturen mit einem Volumen von $1000 \mathrm{ml}$ wurden mit $150 \mathrm{u} / \mathrm{min}$ bei $37^{\circ} \mathrm{C} \mathrm{bzw}$. $30{ }^{\circ} \mathrm{C}$ inkubiert.

\subsubsection{Stammhaltung und Kultivierung von Pichia pastoris-Zellen}

Pichia pastoris wurde zur kurzfristigen Lagerung auf YPD-Agarplatten oder in YPD-Medium im Kühlschrank aufbewahrt. Für eine längerfristige Lagerung wurde $1 \mathrm{ml}$ einer Übernachtkultur mit $1 \mathrm{ml}$ autoklaviertem Glyzerin vermischt und bei $-70^{\circ} \mathrm{C}$ eingefroren. Die Anzucht von $P$. pastoris erfolgte bei $30^{\circ} \mathrm{C}$ in YPD-Medium in Reagenzröhrchen auf einem Roller bzw. im Kolben auf einem Schüttler bei $200 \mathrm{u} / \mathrm{min}$.

\subsubsection{Bestimmung der Zelldichte}

Die optische Dichte der bewachsenen Kultur wurde in einem Eppendorf Photometer (BioPhotometer) bei $600 \mathrm{~nm}$ gegen das unbeimpfte Medium bestimmt. Die Zellen wurden davor so verdünnt, dass die $\mathrm{OD}_{600}$ kleiner als 1 war. Die tatsächliche Zelldichte wurde dann aus dem gemessenen Wert errechnet.

\subsubsection{Transformation von Escherichia coli durch Elektroporation}

Zur Transformation von Escherichia coli wurde standardmäßig nach der Elektroporationsmethode [Dower et al., 1988] verfahren. Zur einfachen Plasmid-Vermehrung und zur Vermehrung von Ligationsprodukten wurden $50 \mathrm{ml}$ dYT mit dem entsprechenden 
Stamm von Escherichia coli von M9-Minimalplatte inokuliert und bis zu einer $\mathrm{OD}_{600}$ von ca. 0,5 herangezogen. Die Zellen wurden durch Zentrifugation $\left(4000 \mathrm{u} / \mathrm{min}, 10 \mathrm{~min}, 4{ }^{\circ} \mathrm{C}\right)$ geerntet, in $30 \mathrm{ml}$ eiskaltem, sterilem Wasser resuspendiert und erneut abzentrifugiert. Dieser Waschschritt wurde zweimalig wiederholt, wobei beim zweiten Mal in $20 \mathrm{ml}$, beim dritten Mal in $10 \mathrm{ml}$ eiskaltem, sterilem Wasser resuspendiert wurde. Nach dem letzten Zentrifugationsschritt wurde der Überstand abgegossen und das Zellpellet in dem im Gefäß verbleibenden Wasser resuspendiert. Während der gesamten Prozedur wurden die Zellen auf Eis gehalten. Zur Transformation wurden 50-150 $\mu$ Z Zellsuspension mit einer zur gewünschten Transformantenzahl führenden DNA-Menge versetzt und in eine gewaschene und vorgekühlte Elektroporationsküvette überführt. Die Elektroporation erfolgte nach 20 minütiger Inkubation des Zell/DNA-Gemisches auf Eis im Gene Pulser ${ }^{\circledR}$ (BioRad) bei folgenden Einstellungen: $200 \mathrm{~mA}$ Stromstärke, 2,5 kV Spannung, $6250 \mathrm{~V} / \mathrm{cm}$ Feldstärke, $5 \mathrm{~s}$ Impuls, 4,0-4,5 ms Zeitkonstante und Raumtemperatur. Unmittelbar nach dem Spannungspuls wurde $1 \mathrm{ml}$ steriles dYT-Medium in die Elektroporationsküvette pipettiert, der Inhalt in ein 1,5 ml Reaktionsgefäß überführt und die Zellsuspension für eine Stunde bei $37^{\circ} \mathrm{C}$ im Heizblock inkubiert. Anschließend wurde die Kultur auf Selektivplatten ausgestrichen bzw. $50 \mathrm{ml}$ selektives dYT-Medium mit der Kultur beimpft.

\subsubsection{Transformation von Pichia pastoris durch Elektroporation}

Zur Transformation von Pichia pastoris GS115 wurde die in Higgins und Cregg [Higgins und Cregg, 1998] beschriebene Methode zur Elektroporation in modifizierter Form durchgeführt. Dazu wurden $50 \mathrm{ml}$ YPD-Medium mit $500 \mu$ einer frischen Pichia pastoris Übernachtkultur beimpft und bei $30^{\circ} \mathrm{C}$ und $200 \mathrm{u} / \mathrm{min}$ im Schüttler bis zu einer $\mathrm{OD}_{600}$ von ca. 1,3-1,5 inkubiert. Die Zellsuspension wurde für $5 \mathrm{~min}$ bei $4{ }^{\circ} \mathrm{C}$ und $1500 \mathrm{~g}$ abzentrifugiert und die Zellen nacheinander mit $50 \mathrm{ml}$ eiskalten sterilem Wasser, mit $25 \mathrm{ml}$ Wasser und mit $5 \mathrm{ml} 1 \mathrm{M}$ Sorbitol gewaschen. Dabei wurden die Zellen soweit möglich auf Eis gehalten. Schließlich wurden die Zellen in $250 \mu 11 \mathrm{M}$ Sorbitol resuspendiert. Etwa $80 \mu 1$ der Suspension wurden dann mit 10-20 $\mu \mathrm{g}$ linearisierter pPIC9K (mit einkloniertem Barnase-MikroproteinFusionsgen) DNA gemischt und in einer vorgekühlten Elektroporationsküvette für $10 \mathrm{~min}$ inkubiert. Die Elektroporation erfolgte im Gene Pulser ${ }^{\circledR}$ (BioRad) bei folgenden Einstellungen: $200 \mathrm{~mA}$ Stromstärke, 1,5 kV Spannung, $6250 \mathrm{~V} / \mathrm{cm}$ Feldstärke, $5 \mathrm{~s}$ Impuls, 4,0 - 4,5 ms Zeitkonstante und Raumtemperatur. Unmittelbar nach dem Spannungspuls wurde $1 \mathrm{ml}$ steriles eiskaltes $1 \mathrm{M}$ Sorbitol in die Elektroporationsküvette pipettiert, der Inhalt in ein 1,5 ml Reaktionsgefäß überführt und jeweils $200 \mu$ l auf MD-Agarplatten zur Selektion über 
den his4 Marker des pPIC9K Vektors ausplattiert. Die Platten wurden dann bei $30{ }^{\circ} \mathrm{C}$ bis zum Erscheinen von Kolonien inkubiert (etwa 2 Tage).

\subsubsection{Suche nach Pichia pastoris multi copy Transformanten}

Bei der Transformation von Pichia pastoris mit rekombinanten, integrativen Vektoren kann es $\mathrm{zu}$ spontanen Mehrfachinsertionen kommen. Da eine höhere Gendosis des zu expremierenden Proteins in der Regel zu einer höheren Ausbeute führt [Scorer et al., 1994], ist es erstrebenswert, solche multi copy Transformanten $\mathrm{zu}$ isolieren. Der verwendete Expressionsvektor pPIC9K enthält das Tn903 kanr Gen, das Resistenz gegen G418 (Geniticin) vermittelt. Die Transformanten wurden daher auf YPD Platten mit 0,25, 0,5 bzw. $0,6 \mathrm{mg} / \mathrm{ml} \mathrm{G} 418$ gestempelt.

\subsubsection{Expression von Barnase'-Fusionsproteinen in Escherichia coli}

\subsubsection{Expression im Schüttelkolben}

Die Expression von Barnase'-Fusionsproteinen in Escherichia coli im Schüttelkolben wurde in dYT- bzw. TB-Medium mit den entsprechenden Antibiotika im analytischen Maßstab in $50 \mathrm{ml}$ Kolben sowie im präparativen Maßstab in 11 Kolben bei $30^{\circ} \mathrm{C}$ und $160 \mathrm{u} / \mathrm{min}$ durchgeführt. Dazu wurde der entsprechende E. coli Stamm am Tag zuvor mit dem Expressionsplasmid transformiert und ü.N. in $50 \mathrm{ml} \mathrm{dYT} \mathrm{mit} \mathrm{den} \mathrm{entsprechenden} \mathrm{Antibiotika}$ angezogen. Aus dieser Übernachtkultur wurde dann mit $1 / 20$ bis $1 / 10$ Volumen Zellkultur inokuliert und die Expression bei Erreichen einer $\mathrm{OD}_{600}$ von 0,7 durch Zugabe von 1/1000 Volumen $1 \mathrm{M}$ IPTG induziert. Nach weiteren $3 \mathrm{~h}$ bzw. ü.N. konnte dann die Expression analysiert bzw. das Fusionsprotein aus dem Kulturüberstand gereinigt werden (siehe Abschnitt 3.4.6.).

\subsubsection{Expression im Fermenter}

Die Fermentation von E. coli erfolgte im Biostat M Fermenter (Braun Biotech) in TBMedium bei $30^{\circ} \mathrm{C}$ bei kontinuierlicher Luftzufuhr ( 2 bar Druck) und unter ständigem Rühren mit $900 \mathrm{u} / \mathrm{min}$. Zudem bestand die Möglichkeit, eine Expression im 51 Fermenter (Bioengineering $^{\circledR}$ ) bei der Selecore $\mathrm{GmbH}$ durchführen zu lassen. Wie in 3.1.7.1. beschrieben, wurde das Expressionsplasmid am Tag zuvor in den entsprechenden E. coli Stamm durch Elektroporation eingebracht. Für die Fermentation wurde ausschließlich E. coli BMH 71-18 verwendet, der bereits vorher mit dem Plasmid pREP4 (Qiagen) transformiert wurde, dass durch konstitutive Expression des Lac-Repressors für eine Verminderung der toxischen 
Effekte von Barnase' in der ersten Wachstumspahse vor Induktion sorgen sollte. Der Fermenter wurde mit 1/10 Volumen der frischen Übernachtkultur angeimpft und die Expression bei Erreichen einer $\mathrm{OD}_{600}$ von 3-5 durch Zugabe von 1/1000 Volumen 1 M IPTG induziert. Durch die hohe Sauerstoffzufuhr konnte so ü.N. eine $\mathrm{OD}_{600}$ von bis zu 12-15 erreicht werden.

\subsubsection{Expression von Barnase'-Fusionsproteinen in Pichia pastoris}

Die in dieser Arbeit beschriebenen Expressionsversuche in P. pastoris erfolgten mit Stämmen, bei denen das heterologe Barnase'-Mikroprotein-Fusionsgen auf dem pPIC9K Vektor unter Kontrolle des methanolinduzierbaren Promotors der Alkoholoxidase 1 (AOX1) steht. Da der AOX1 Promoter durch Glukose reprimiert wird, wurden die Klone zunächst in Glukose-haltigem Medium (BMMG) bei $30{ }^{\circ} \mathrm{C}$ und $250 \mathrm{u} / \mathrm{min}$ in $50 \mathrm{ml}$ Falcon Röhrchen (mit Löchern im Deckel) für 2 Tage angezogen. Es wurden keine Vortests zur Bestimmung des Mut-Phänotyps gemacht, d.h. es wurde ein Mut ${ }^{\mathrm{S}}$-Phänotyp bei allen Klonen angenommen, bei dem ein Wachstum mit Methanol als C-Quelle nicht mehr möglich ist. Nachdem die Kulturen 2 Tage gewachsen waren, wurden die Zellen bei $1500 \mathrm{~g}$ abzentrifugiert, der Überstand wurde verworfen und das Pellet in $3 \mathrm{ml}$ BMMY (Methanol) Medium aufgenommen. Die Kulturen wurden anschließend für weitere 3 Tage bei $30^{\circ} \mathrm{C}$ und $250 \mathrm{u} / \mathrm{min}$ geschüttelt, wobei jeden Tag $15 \mu 1$ Methanol zugegeben wurden. Schließlich wurden $20 \mu 1$ Kulturüberstand direkt auf einem 15 \%igen SDS Polyacrylamidgel analysiert.

Expressionen im präparativen Maßstab unter kontrollierten Bedingungen wurden im FedBatch Verfahren in Kooperation mit der Selecore $\mathrm{GmbH}$ an der Gesellschaft für Biotechnologische Forschung (GBF) in Braunschweig durchgeführt.

\subsection{Molekularbiologische Arbeitsmethoden}

\subsubsection{Vorbereitung von Geräten und Lösungen}

Hitzestabile Geräte wurden durch Erhitzen für 20 min auf $181{ }^{\circ} \mathrm{C}$ sterilisiert. Hitzestabile Lösungen wurden für 20 min bei $121^{\circ} \mathrm{C}$ autoklaviert. In der Hitze nicht beständige Geräte wurden mit $70 \%(\mathrm{v} / \mathrm{v})$ Ethanol gereinigt und getrocknet. Hitzelabile Bestandteile von Lösungen wurden als konzentrierte Stammlösungen hergestellt und vor der Zugabe zu bereits sterilen Lösungen durch einen Membranfilter der Porengröße von 0,2 $\mu 1$ sterilfiltriert. 


\subsubsection{Fällung von DNA aus wässrigen Lösungen}

\subsubsection{Fällung von DNA mit Ethanol}

Die Ethanolfällung diente der Konzentration von DNA und der Entfernung von Proteinen, Salzen und freien Nukleotiden. Proteine und Salze wurden zwar nicht vollständig, für viele Zwecke jedoch in ausreichendem Maße entfernt. Dabei wurde die Konzentration monovalenter Kationen erhöht, was durch Erhöhung der Dielektrizitätskonstante die Abstoßung des negativ geladenen Phosphodiester-Rückgrats verminderte, wodurch bei Lösungsmittelentzug durch Zugabe von Ethanol die DNA-Fällung ermöglicht wurde.

Die DNA-haltige Lösung wurde mit 1/10 Vol 7 M Ammonimacetatlösung und 3 Vol 96 \% Ethanol p.A. je nach zu erwartender DNA-Menge 5 bis $45 \mathrm{~min}$ bei $-20^{\circ} \mathrm{C}$ gefällt und danach bei $13000 \mathrm{u} / \mathrm{min}$ in der Tischzentrifuge abzentrifugiert. Das Pellet wurde optional mit $70 \%$ (v/v) Ethanol gewaschen und 10 min bei gleichen Bedingungen zentrifugiert. Der Ethanol wurde dann so gut wie möglich abgetrennt. Dazu wurden die Gefäße nach Entfernen des Überstandes offen $10 \mathrm{~min}$ bei $37^{\circ} \mathrm{C}$ im Heizblock stehen gelassen. Anschließend wurde das DNA-Pellet je nach gewünschter Konzentration in einem entsprechenden Endvolumen Millipore-Wasser oder TE-Puffer aufgenommen.

\subsubsection{Fällung von DNA mit Isopropanol}

DNA kann auch mit Isopropanol anstelle von Ethanol gefällt werden. Bei der Verwendung von Isopropanol wird dabei die Präzipitation von Salzen vermindert. Diese Art der Fällung bietet sich besonders dann an, wenn Salze aus der zu fällenden Lösung entfernt werden sollen. Dazu wurde analog zur DNA-Fällung mit Ethanol verfahren. Im Unterschied dazu wurden jedoch nur 0,7 Vol bis 1 Vol Isopropanol eingesetzt. Wie auch nach der Ethanolfällung wurde anschließend mit $70 \%$ (v/v) Ethanol gewaschen.

\subsubsection{Extraktion von DNA in wässrigen Lösungen mit organischen}

\section{Lösungsmitteln}

\subsubsection{Präparation einer Phenollösung [Grinsted und Bennett, 1988]}

$500 \mathrm{~g}$ festes Phenol wurden in $130 \mathrm{ml}$ Wasser, 7,5 ml $2 \mathrm{~N} \mathrm{NaOH}$ und $6 \mathrm{ml} 1 \mathrm{M}$ Tris-HCl, pH 7,5 gelöst. Zum Schutz vor Oxidation wurde 8-Hydroxychinolin $(0,1 \%$ (w/v)) hinzugefügt und die Lösung lichtgeschützt in einer dunklen Flasche bei Raumtemperatur gelagert. 
Die so präparierte Phenollösung wird im Folgenden als Phenol, die Mischung aus je $50 \%$ (v/v) Phenollösung und Chloroform wird im Folgenden als Phenol/Chloroform bezeichnet.

\subsubsection{Extraktion von DNA mit Phenol, Phenol/Chloroform oder Chloroform}

Zur Entfernung von Proteinen, Ethidiumbromid oder Resten anderer hydrophober Kontaminationen diente die Extraktion von DNA mit Phenol, Phenol/Chloroform und Chloroform. Die Extraktion mit Chloroform diente auch der Entfernung von Phenol aus der wäßrigen Phase. Die DNA-Lösung wurden mit 1 Vol Phenol, Phenol/Chloroform oder Chloroform versetzt und gründlich gemischt. Um die zwei Phasen zu trennen, wurde der Ansatz zentrifugiert (Tischzentrifuge, $13000 \mathrm{u} / \mathrm{min}, 3 \mathrm{~min}, \mathrm{RT}$ ) und anschließend die wässrige Oberphase in ein neues Reaktionsgefäß überführt. In der Regel folgte auf eine Extraktion mit Phenol/Chloroform eine Ethanolfällung, wodurch evtl. vorhandene Chloroformreste entfernt werden können.

\subsubsection{Agarosegelelektrophorese}

Die Auftrennung von doppel- und einzelsträngiger DNA wurde in Agarosegelen unterschiedlicher Größe und Konzentration (1\%-2\% (w/v) Agarose in TBE-Puffer) durchgeführt. Lange Fragmente wurden in niederprozentigen, kurze Fragmente in höherprozentigen Gelen oder in HEC (Hydroxyethyl-Cellulose)-Gelen aufgetrennt, bei der eine benötigte Menge einer 2\%igen HEC-Stammlösung (2\% HEC in $10 \mathrm{mM}$ Tris/ $\mathrm{HCl} \mathrm{pH}$ 8,0, 1 mM EDTA pH 8,0) 1:1 mit einer 2\%igen Agarose-Lösung gemischt und aufgekocht wurde.

Die Agarose wurde im Puffer bis zur vollständigen Lösung in einem Mikrowellenofen aufgekocht. Nach Abkühlen der Lösung auf ca. $60^{\circ} \mathrm{C}$ wurde zum Anfärben von DNA in der Regel $0,5 \mu \mathrm{g} / \mathrm{ml}$ Ethidiumbromid zugesetzt. Das Gel wurde in eine Flachbett-Gelkammer $(100 \times 7 \times 0,5 \mathrm{~mm})$, direkt in einen abgegrenzten Bereich der Elektrophoresekammer gegossen und der Taschenkamm gesetzt. Nach dem Erstarren des Gels wurde der Taschenkamm entfernt und soviel TBE-Puffer hinzugefügt, bis das Gel komplett bedeckt war. Die Proben wurden mit mindestens 1/5 Vol Sucrosefarbmarker versetzt und in die Geltaschen gefüllt. Die Elektrophorese wurde bei einer konstanten Spannung zwischen $40 \mathrm{~V}$ und $130 \mathrm{~V}$ für 30 - 60 min durchgeführt ( 5 bis $10 \mathrm{~V} / \mathrm{cm}$ Feldstärke). Die aufgetrennten DNA-Fragmente wurden im UV-Durchlicht (302 nm) durch Fluoreszenz des eingelagerten Ethidiumbromids sichtbar gemacht und fotografiert. Zur Längen- und Konzentrationsbestimmung für die resultierenden DNA-Banden wurden DNA-Fragmentlängenstandards (DNA-Konzentration: $100 \mathrm{ng} / \mu \mathrm{l})$ verwendet. 


\subsubsection{Bestimmung der DNA-Konzentration in wässrigen Lösungen}

Die DNA-Konzentration wurde in einem Eppendorf-Photometer (BioPhotometer) ermittelt. Für doppelsträngige DNA wurde die Absorption bei einer Wellenlänge von $260 \mathrm{~nm}$ in einer Mikroküvette (Hellma, QS 1,000) gegen Wasser gemessen. Eine $\mathrm{OD}_{260}$ von 1,0 entspricht dabei einer Konzentration von $50 \mu \mathrm{g} / \mathrm{ml}$. Durch zusätzliche Messung der Lösung bei $280 \mathrm{~nm}$ konnte eine Aussage über die Reinheit der Lösung gemacht werden. Für eine proteinfreie Nukleinsäurelösung sollte das Verhältnis von $\mathrm{OD}_{260} / \mathrm{OD}_{280}$ ungefähr 2:1 sein.

\subsubsection{Isolierung von Plasmid-DNA aus E. coli}

Zur Präparation von Plasmid-DNA im analytischen und präparativen Maßstab kamen Kits verschiedener Firmen zur Anwendung (analytisch: Invitek Invisorb Spin Plasmid Mini Kit, Promega Wizard ${ }^{\circledR}$ Plus SV Minipreps, QUIAGEN QIAprep Spin Miniprep Kit; präparativ: Genomed JetStar Plasmid Midiprep Kit 2.0, QIAGEN Plasmid Midi Kit), die auf dem Prinzip der alkalischen Lyse beruhen. Dabei werden die Zellen zunächst durch Zentrifugation pelletiert und in Resuspensions-Puffer aufgenommen. Im zweiten Schritt werden die Zellen durch Zugabe von Lysis-Puffer (enthält $\mathrm{NaOH}$ und SDS) lysiert und die DNA denaturiert. Durch Zugabe von Neutralisierungs-Puffer (niedriger pH-Wert) wird dann der pH-Wert wieder in den neutralen Bereich abgesenkt; dabei fallen genomische DNA und Proteine aus, während die Plasmid-DNA aufgrund ihrer topologischen Eigenschaften wieder renaturiert. Nach Zentrifugation kann schließlich die Plasmid-DNA über eine Silica-Säule isoliert werden.

\subsubsection{Reinigung von DNA aus Agarosegelen}

Zur Isolierung von DNA-Fragmenten aus Agarosegelen wurde das Invisorb Spin DNA Extraction Kit (Invitek), das QIAquick Gel Extraction Kit (Qiagen) oder das Wizard ${ }^{\circledR}$ SV Gel and PCR Clean-up System (Promega) verwendet. Die aus dem Gel zu isolierende DNA wurde auf dem UV-Durchlicht-Tisch mit einem sterilen Skalpell ausgeschnitten und entsprechend der Instruktionen des jeweiligen Kits gereinigt.

\subsection{Enzymatische Manipulation von DNA}

\subsubsection{Spaltung von DNA mit Restriktionsendonukleasen}

Plasmid-DNA wurde mit Restriktionsendonukleasen unter den vom jeweiligen Hersteller des Enzyms empfohlenen Temperatur- und Pufferbedingungen gespalten. Gleichzeitige Spaltungen mit mehreren Enzymen wurden unter den Pufferbedingungen durchgeführt, bei 
denen laut Hersteller die Endonukleasen mindestens $50 \%$ bis $100 \%$ Spaltaktivität besaßen. War eine Doppelspaltung wegen Inkompatibilität der Enzyme in den mitgelieferten Puffern nicht möglich, wurde die DNA nach der ersten Spaltung mit Ethanol gefällt. In der Regel wurden pro $\mu \mathrm{g}$ DNA 2-3 Einheiten Enzym eingesetzt und der Ansatz für 1-3 h inkubiert. Wurde über Nacht inkubiert, so wurden entsprechend der Herstellerangaben entsprechend geringere Mengen an Enzym verwendet.

\subsubsection{Ligation von DNA-Fragmenten}

Die Ligation von DNA-Fragmenten zu einem zirkulären Ligationsprodukt wurde mit einem bis zu fünffachen molaren Überschuß an DNA-Insert-Fragment gegenüber dem DNA-VektorFragment durchgeführt. Verwendet wurde der T4 DNA-Ligase-Puffer und ca. 2 Einheiten T4 DNA-Ligase in einem Endvolumen von $20 \mu 1$. Die Reaktion erfolgte in der Regel über Nacht bei ca. $12{ }^{\circ} \mathrm{C}$ im Kühlschrank. Der Ligationsansatz wurde vor einer Transformation von $E$. coli-Zellen mit Phenol/Chloroform und mit Chloroform extrahiert (optional zur Erhöhung der Transformationseffizienz, 3.2.3.2.) und mit Ethanol gefällt (3.2.2.1).

\subsubsection{Polymerasekettenreaktion (PCR) [Mullis und Faloona, 1987] [Saiki et al., 1988]}

Mit Hilfe der Polymerasekettenreaktion steht eine potente in vitro-Methode zur enzymatischen Amplifikation spezifischer DNA-Fragmente zur Verfügung. Mit ihr ist es möglich, aus einem komplexen DNA-Gemisch heraus selektiv eine DNA-Matrize zu vervielfachen. Im ersten Schritt wird die doppelsträngige DNA-Vorlage durch Erhitzen in einzelsträngige DNA überführt (Denaturierung). Beim Absenken der Temperatur lagern sich zwei Oligonukleotid-Primer an die Matrizen-DNA an (Primer-Annealing) und flankieren die zu amplifizierenden komplementären Zielregionen. Die Primer werden mit Hilfe einer thermostabilen Polymerase komplementär zur ursprünglichen Duplex-DNA bei hoher Temperatur verlängert (Primer-Extension), um unspezifische Hybridisierung der Primer an die Matrize zu verhindern. Es wird eine bestimmte Anzahl an Amplifikationszyklen durchgeführt, wodurch sich die durch die beiden Primer flankierte DNA-Region akkumuliert.

Die PCR-Bedingungen mussten je nach Länge der zu amplifizierenden Sequenz sowie der Länge und des G/C-Gehaltes der verwendeten spezifischen Primer angepasst werden. Die Reaktionen wurden in einem Gesamtvolumen von $50 \mu 1$ durchgeführt. Als Matrize wurden ca. 5 - 10 ng DNA eingesetzt, in Einzelfällen war die DNA-Menge höher (bis 100 ng). Diente ein Oligonukleotid als Matrize, so wurde 1 fmol von diesem eingesetzt. 
In die PCR-Reaktionsgefäße wurden zunächst $25 \mu 1$ Taq-Puffer (1x) und Template DNA gegeben.

Als Mastermix wurden in einem Eppendorf Reaktionsgefäß zusammenpipettiert:

$2,5 \mu l$ Puffer (10x)

$1 \mu 110 \mathrm{mM}$ dNTPs

je $1 \mu 1$ Primer $(10 \mathrm{pMol} / \mu \mathrm{l})$

ad $25 \mu$ Wasser

Je $25 \mu 1$ des Mastermix wurden in die Reaktionsgefäße gegeben. Zur Vermeidung von Primer-Fehlpaarungen wurde der Mastermix erst nach der initialen zweiminütigen Denaturierungsphase bei $98^{\circ} \mathrm{C}$ zu der Matrizen-DNA gegeben. Diese Abwandlung der $P C R$ wird als Hot Start-PCR bezeichnet. Im Allgemeinen wurde dieser der Vorzug gegenüber der konventionellen PCR gegeben. Die Reaktionsgefäße wurden vor Platzierung in dem PCRCycler mit PCR-Wachs (Chill-out 14, MJ Research) oder Mineralöl überschichtet.

Die Länge und die Temperatur der einzelnen Reaktionsschritte der PCR-Zyklen, sowie deren Anzahl wurde durch die Wahl der Matrize, die Basenzusammensetzung, Länge der Primer und durch die Länge der zu amplifizierenden Sequenz bestimmt. Die Elongationsreaktion (Primer-Extension) wurde bei $72{ }^{\circ} \mathrm{C}$ für $30 \mathrm{~s}$ pro $1000 \mathrm{bp}$ durchgeführt. Die Anzahl der Zyklen betrug zwischen 20 und 30. Die Schmelztemperatur $T_{M}$ eines Oligonukleotids wurde nach folgender empirischer Formel (3.1) berechnet, welche sowohl den relativen G/C-Gehalt $(\% \mathrm{G} / \mathrm{C})$ als auch die Länge der Oligonukleotide $(n)$ berücksichtigt:

$T_{M}\left[{ }^{\circ} \mathrm{C}\right]=69,3+0,41 \cdot(\% \mathrm{G} / \mathrm{C})-\frac{650}{n}$

Die errechnete Temperatur lag in der Regel zwischen $45^{\circ} \mathrm{C}$ und $60{ }^{\circ} \mathrm{C}$. Die optimale Annealing-Temperatur $T_{A}$ für eine Polymerasekettenreaktion wurde nach (2) bestimmt:

$T_{A}=\frac{\left(\mathrm{T}_{\mathrm{M} 1}+\mathrm{T}_{\mathrm{M} 2}\right)}{2}-3^{\circ} \mathrm{C}$

$T_{M 1}$ und $T_{M 2}$ stehen dabei für die Schmelztemperaturen der beiden verwendeten Primer. Die PCR wurde in einem Minicycler (MJ Research) oder einem Primus 96 Thermocycler (MWG Biotech) durchgeführt. Das Programm für die PCRs war:

$98^{\circ} \mathrm{C}$ für $2 \mathrm{~min}$

$85^{\circ} \mathrm{C}$ bis zur Zugabe des Mastermix

$94{ }^{\circ} \mathrm{C} 30 \mathrm{~s}$

annealing Temperatur $\left(\mathrm{T}_{\mathrm{A}}\right) 30 \mathrm{~s}$

$72{ }^{\circ} \mathrm{C} 1 \mathrm{~min}$ pro $\mathrm{kb}$ Produkt (Minimum $30 \mathrm{~s}$ ) 
25 oder 30 Mal nach Schritt 1

Zur direkten Amplifikation von DNA-Bereichen aus Bakterienzellen kam eine modifizierte PCR zur Anwendung ("Kolonie-PCR", [Hofmann und Brian, 1991]). Mit dieser Methode kann schnell und eindeutig das Vorhandensein eines definierten Plasmid-Abschnitts in Bakterienklonen nachgewiesen werden. In PCR-Gefäßen $(0,2 \mathrm{ml})$ wurden $25 \mu 1$ TaqPolymerase-Puffer vorgelegt. Mit einem sterilen Zahnstocher wurden Zellen aus einer Bakterienkolonie aufgenommen, auf einer Mediumplatte ausgestrichen und die restlichen Zellen in dem PCR-Gefäß abgewaschen. Die Bakteriensuspension wurde in die PCRMaschine gestellt, die übrigen Agenzien wurden in Form eines Mastermixes zusammengegeben und der Ansatz wurde mit $25 \mu$ Chill out $14^{\circledR}$ Flüssigwachs überschichtet. Für 10 PCR- Reaktionen wurden $2 \mu \mathrm{l}$ Taq-DNA-Polymerase, $30 \mu 110$ x Taq-PolymerasePuffer , $10 \mu \mathrm{l}$ dNTPs (je $10 \mathrm{mM}$ ), jeweils 50 pmol der zu verwendenden Primer und Wasser bis auf $300 \mu \mathrm{l}$ zusammengegeben. Folgendes PCR-Programm wurde gestartet: 2 min $98{ }^{\circ} \mathrm{C}$, Zugabe von $25 \mu \mathrm{l}$ Mastermix bei $85^{\circ} \mathrm{C}, \quad 30$ Zyklen $\quad \dot{a} \quad 30 \mathrm{~s} \quad 94^{\circ} \mathrm{C}, \quad 30 \mathrm{~s}$ Hybridisierungstemperatur, $1 \mathrm{~min} / \mathrm{kb} 72{ }^{\circ} \mathrm{C}$, danach auf $4{ }^{\circ} \mathrm{C}$. Die Hybridisierungstemperatur wurde wie oben beschrieben ermittelt. Der Erfolg der "Kolonie-PCR" wurde auf einem Agarosegel überprüft (3.2.4.).

In einigen Fällen konnte das zu generierende PCR Produkt nicht in einem Schritt hergestellt werden bzw. es sollte eine Restriktionsschnittstelle in der Mitte des Produktes entfernt werden. Hier wurde eine zweistufige SOE-PCR (Splicing by Overlapping Extension) durchgeführt. In einem ersten Amplifikationsschritt wurden zunächst mit zwei außen und zwei innen liegenden Oligonukleotiden zwei Fragmente generiert. Die beiden inneren Primer wurden dabei so definiert, dass die beiden Fragmente eine Überlappung von 22-24 Basen aufwiesen. Nach Reinigung der Fragmente über 1 bzw. 2\%ige Agarosegele (3.2.7.) wurden diese in etwa gleichen Mengen als Matrize in einem zweiten PCR Schritt mit den beiden äußeren Oligonukleotiden eingesetzt. Das entstehende Endprodukt wurde schließlich mittels Phenol/Chloroform Extraktion (3.2.3.2.) und anschließender Ethanol Fällung (3.2.2.1.) für nachfolgende Anwendungen gereinigt.

\subsubsection{Auffüllen von überhängenden Enden mit T4-DNA-Polymerase}

Zur Erzeugung von „glatten“ DNA-Enden wurde T4-DNA-Polymerase (MBI, Fermentas) benutzt. Die Reaktion erfolgte in einem Gesamtvolumen von $20 \mu 1$ in T4-DNA-PolymerasePuffer (MBI, Fermentas) mit 0,5 mM dNTPs und 1 Einheit (u) Enzym für $20 \mathrm{~min}$ im 
Kühlraum. Anschließend wurde die aufgefüllte DNA mittels Phenol/Chloroform Extraktion (3.2.3.2.) aufgereinigt und mit Ethanol gefällt (3.2.2.1.) .

\subsection{Biochemische Methoden}

\subsubsection{SDS-Polyacrylamid-Gelelektropohorese (SDS-PAGE)}

Proteingemische wurden zur Analyse über denaturierende Polyacrylamidgelektrophorese aufgetrennt. Als Detergenz wurde dabei Natrium-Dodecylsulfat (SDS) zugesetzt, dass die Tertiär- und Sekundästrukturen der Proteine auflöst. Je nach erwarteter Größe der zu trennenden Proteine kam die klassische Methode, wie sie von Lämmli [Laemmli, 1970] beschrieben wurde, oder für die Analyse sehr kleiner Proteine die Methode nach Schägger et al. [Schägger und von Jagow, 1987] zur Anwendung. Das Gießen der Gele erfolgte in einem Gießstand (Hoefer Scientific), mit dem 5 bzw. 10 Gele auf einmal gegossen werden konnten. Die jeweilige Zusammensetzung von Trenn- und Sammelgel ist in Tabelle 3.1. („SchäggerMethode“) und 3.2. („Lämmli-Methode“) angegeben.

\begin{tabular}{|c|c|c|}
\hline Lösung & Trenngel & Sammlegel \\
\hline $30 \%(\mathrm{w} / \mathrm{v})$ Acrylamid, 0,8 \% Bisacrylamid & $20 \mathrm{ml}$ & $1,6 \mathrm{ml}$ \\
\hline $3 \mathrm{M}$ Tris/HCl, 0,3 \% SDS, $\mathrm{pH} 8,45$ & $10 \mathrm{ml}$ & $3,1 \mathrm{ml}$ \\
\hline $\mathrm{H}_{2} \mathrm{O}$ (bidest.) & - & $7,6 \mathrm{ml}$ \\
\hline APS-Stammlösung & $100 \mu \mathrm{l}$ & $100 \mu \mathrm{l}$ \\
\hline TEMED & $10 \mu \mathrm{l}$ & $10 \mu \mathrm{l}$ \\
\hline
\end{tabular}

Tabelle 3.1.: Zusammensetzung von Trenn- und Sammelgel nach Schägger et al. [Schägger und von Jagow, 1987] (,Tris-Tricin Gele“); Angaben für 5 Gele.

\begin{tabular}{|c|c|c|}
\hline Lösung & Trenngel & Sammlegel \\
\hline $30 \%$ (w/v) Acrylamid, 0,8 \% Bisacrylamid & 45 & 5,6 \\
\hline $1,875 \mathrm{M}$ Tris/HCl pH 8,8 & 18 & - \\
\hline $1,25 \mathrm{M}$ Tris/HCl pH 6,8 & - & 3,5 \\
\hline $10 \%$ SDS & $900 \mu 1$ & 350 \\
\hline $\mathrm{H}_{2} \mathrm{O}$ (bidest.) & 25,8 & 25,2 \\
\hline APS-Stammlösung & $300 \mu \mathrm{l}$ & 120 \\
\hline TEMED & $45 \mu \mathrm{l}$ & 35 \\
\hline
\end{tabular}

Tabelle 3.2.: Zusammensetzung von Trenn- und Sammelgel für $15 \%$ ige Polyacrylamidgele nach Lämmli [Laemmli, 1970]; Angaben für 10 Gele.

Das Gel wurde in eine Elektrophoresekammer gestellt und mit Laufpuffer (Nach Lämmli: Lämmli-Puffer; nach Schägger: 0,2 M Tris/ $\mathrm{HCl}$ pH 8,9 in die Anodenkammer, 0,1 M Tris, 0,1 M Tricine, 0,1 \% SDS in die Kathodenkammer) überschichtet. Die Proben wurden mit 1/5 
Volumen Hoechst-Puffer versetzt, $5 \mathrm{~min}$ bei $99^{\circ} \mathrm{C}$ hitzedenaturiert und in die Taschen des Gels gegeben. Die Elektrophorese erfolgte bei maximal 6 Watt pro Gel bis die Bromphenolblau-Bande aus dem Gel gelaufen war. Als Marker diente der Protein Molekulargewichtsmarker von MBI Fermentas.

Der Nachweis der Proteine erfolgte durch unspezifisches Anfärben mit Coomassie [Thompson und Larson, 1992]. Zum Färben wurde das Gel in einem geeigneten Behälter für etwa 10 min in PAG-Färbelösung/ $20 \%$ Essigsäure (1:1 gemischt) geschwenkt. Danach wurde die Färbelösung abgegossen und das Gel zum Entfärben zwei bis drei mal in der Mikrowelle mit Wasser aufgekocht und dann mit PAG Entfärbelösung inkubiert.

\subsubsection{Gewichts- und Konzentrationsbestimmung von Proteinen}

Während die Proteinbestimmung von lyophilisierten Proteinen durch Auswiegen des Feststoffes an der Analysenwaage erfolgte, wurde die Proteinkonzentration einer wässrigen Lösung mit Hilfe eines Spektralphotometers bestimmt.

Zum einen kam dabei die Methode nach Pace et al. [Pace et al., 1995] zur Anwendung, bei der die Proteinkonzentration bei bekannter Zusammensetzung des Proteins über die Absorption von Licht einer Wellenlänge von $280 \mathrm{~nm}\left(\mathrm{OD}_{280}\right)$ bestimmt werden kann. Wesentlich beteiligt an der Absorption eines Proteins bei $280 \mathrm{~nm}$ sind die Seitenketten der aromatischen Aminosäuren Tryptophan und Tyrosin, sowie die Disulfidbrücken des Proteins. Der molare Extinktionskoeffizient des Proteins errechnet sich demnach nach folgender Gleichung:

$$
\varepsilon(\text { Protein })=5500 *\left[\sum \operatorname{Trp}\right]+1490 *\left[\sum \mathrm{Tyr}\right]+125 *\left[\sum \mathrm{S}-\mathrm{S}-\text { Brücken }\right] .
$$

Mit Hilfe des so berechneten molaren Extinktionskoeffizienten lässt sich die Konzentration des Proteins aus der $\mathrm{OD}_{280}$ berechnen.

Zum anderen wurde die Methode nach Bradford [Bradford, 1976] für die Konzentrationsbestimmung von Proteinen in wässriger Lösung verwendet. Dabei wird die Probe mit einem Coomassie-Reagenz versetzt, das sich unspezifisch in das Protein einlagert, und dessen Konzentration über die Messung der optischen Dichte bei $595 \mathrm{~nm}$ bestimmt werden kann. Nachdem Proteinlösungen mit bekannter Konzentration gemessen worden sind, werden die $\mathrm{OD}_{595}$ Werte gegen die Konzentrationen in einem Graph aufgetragen und eine Eichgerade gebildet, auf der man dann die Konzentration der zu bestimmenden Proteinlösung ablesen kann. 


\subsubsection{Dauerhafte Lagerung von Proteinen}

Zur dauerhaften Lagerung von Proteinen wurde die wässrige Lösung entweder direkt bei $20{ }^{\circ} \mathrm{C}$ eingefroren oder zunächst in flüssigen Stickstoff eingetropft und dann bei $-70{ }^{\circ} \mathrm{C}$ gelagert. Mikroproteine können zudem auch in lyophilisierter Form eingefroren und gelagert werden.

\subsubsection{Dialyse}

Zur Umpufferung von Proteinlösungen wurden diese ü.N. im Kühlraum gegen das mindestens 40-fache ihres Volumens Puffer dialysiert. Dazu wurden Dialyseschläuche der Firma Roth mit einer Ausschlußgrenze von ca. $12 \mathrm{kDa}$ verwendet.

\subsubsection{Konzentrierung von Kulturüberständen und Proteinlösungen}

\subsubsection{TCA-Fällung}

Die Fällung von Proteinen mit Trichloressigsäure (TCA) resultiert aus einer irreversiblen Denaturierung der Proteinstruktur. Für die Analyse von $\mathrm{zu}$ gering konzentrierten Kulturüberständen oder Proteinlösungen für die SDS-PAGE wurde 1/5 Volumen 100 \%ige (w/v) TCA Lösung (in $\mathrm{H}_{2} \mathrm{O}$ ) zu der Probe gegeben. Nach 30 min Inkubation auf Eis wurde die Lösung abzentrifugiert (5 min in der Tischzentrifuge, $4{ }^{\circ} \mathrm{C}, 13000 \mathrm{u} / \mathrm{min}$ ), das Pellet einmal mit eiskaltem Aceton gewaschen und anschließend auf dem $37{ }^{\circ} \mathrm{C}$ Heizblock getrocknet. Es konnte dann direkt in Hoechst-Puffer aufgenommen und für die SDS-PAGE (3.4.1.) vorbereitet werden.

\subsubsection{Säure-Fällung mit konzentrierter $\mathrm{HCl}$}

Sollte das Volumen einer Proteinlösung für die chemische Spaltung des Proteins mit Bromcyan (Abschnitt 3.4.9.1.) verringert werden, so wurde eine denaturierende Säurefällung mit konzentrierter Salzsäure durchgeführt. Dazu wurde die Proteinlösung mit 1/20 Volumen $37 \%$ iger $\mathrm{HCl}$ versetzt und für einige min bei Raumtemperatur inkubiert bis sich ein weißlicher Niederschlag ausbildete. Das ausgefallene Protein wurde dann in $50 \mathrm{ml}$ Falcon Röhrchen abzentrifugiert (4000 u/min, 10 min, RT); der Überstand wurde verworfen und das Präzipitat in dem entsprechenden Puffer für die Bromcyan-Spaltung gelöst.

\subsubsection{Konzentration von Proteinlösungen mit Vivaspin-Konzentratoren}

Für die nicht-denaturierende Konzentration von Barnase'-Fusionsprotein-Lösungen wurden Vivaspin Konzentratoren (Vivascience) mit einer molekularen Ausschlussgröße von 10 kDa 
benutzt. Die einzukonzentrierende Lösung wird dabei direkt auf eine PolyethersulfonMembran gegeben und bei der vom Hersteller angegebenen Geschwindigkeit zentrifugiert, bis das gewünschte Volumen erreicht ist.

\subsubsection{Reinigung von Barnase'-Fusionsproteinen}

\subsubsection{Destabilisierung der E. coli Membran mit Essigsäure [Hartley, 1988]}

Das in dieser Arbeit neu aufgelegte Produktionssystem für Mikroproteine sieht die Reinigung als Fusionsprotein mit einer enzymatisch inaktivierten Variante der RNase Barnase (Barnase') aus Bacillus amyloliquefaciens aus dem Kulturüberstand vor. Im E. coli Expressionssystem wird das Fusionsprotein durch eine periplasmatische Signalsequenz ins Periplasma und den Kulturüberstand dirigiert. Durch die Ansäuerung einer E. coli Zellkultur mit Essigsäure kann, vermutlich durch eine Destabilisierung der Zellmembran, das Fusionsprotein vollständig in das umgebende Medium gelangen [Hartley, 1988]. Dazu wurde der Kultur im Kühlraum unter ständigem Rühren 1/20 Volumen konzentrierter Essigsäure zugeführt. Nach etwa 15 minütiger Inkubation wurden die Zellen dann bei $4000 \mathrm{u} / \mathrm{min}\left(4{ }^{\circ} \mathrm{C}, 40 \mathrm{~min}\right)$ pelletiert. Der Kulturüberstand wurde für die sich anschließenden Reinigungsschritte sterilfiltriert.

\subsubsection{Kombinierte Kationenaustausch-/Reversed-phase-Chromatographie an der} Vision Biocad ${ }^{\circledR}$ workstation

Barnase'-Fusionsproteine wurden, sofern das Volumen nicht größer als 1,51 war, an der Vision Biocad workstation über kombinierte Kationenaustausch-/Reversed-phase Chromatographie aus dem Kulturüberstand gereinigt. Der filtrierte Überstand wurde, 1:5 mit $\mathrm{H}_{2} \mathrm{O}$ verdünnt, und mit $10 \% 250 \mathrm{mM}$ Na-Acetat Puffer, pH 5,0 direkt auf eine Perseptive HS20 Säule (1,0 x $10 \mathrm{~cm}, 7.6 \mathrm{ml}$ Volumen) bei einer Flussrate von $8 \mathrm{ml} / \mathrm{min}$ gepumpt. Die Elution erfolgte durch einen $\mathrm{NaCl}$ Gradienten von 0 bis $500 \mathrm{mM} \mathrm{NaCl}$ in $10 \mathrm{~min}$ in $25 \mathrm{mM}$ Na-Acetat Puffer, pH 5,0 bei $8 \mathrm{ml} / \mathrm{min}$. Das Eluat von 166 bis $500 \mathrm{mM} \mathrm{NaCl}$ wurde automatisch auf eine Perseptive R2 RP-Säule geleitet. Nachdem mit $\mathrm{H}_{2} 0 / 0.1 \%$ (v/v) TFA/ $5 \%$ Acetonitril/0.1\% (v/v) TFA für 5 min bei $5 \mathrm{ml} / \mathrm{min}$ Flussgeschwindigkeit gewaschen wurde, erfolgte die Elution des Fusionsproteins mit einem Acetonitril-Gradienten von 5-50 \% in $16 \mathrm{~min}$; das Eluat wurde mit einem automatischen Fraktionssammler in $5 \mathrm{ml}$ Aliquots aufgefangen. Die einzelnen Fraktionen wurden nach Beendigung des Programms durch SDSPAGE (3.4.1.) analysiert, die Fusionsprotein enthaltenen Fraktionen entsprechend vereinigt und ü.N. lyophilisiert (Christ, Alpha 1-4). Die HS-Säule wurde nach jedem Lauf mit 4-5 
Säulenvolumen $1 \mathrm{M} \mathrm{NaCl} / 1 \mathrm{M} \mathrm{NaOH}$ und $1 \%$ TFA in $\mathrm{H}_{2} \mathrm{O}$ gewaschen und anschließend mit $\mathrm{Na}-$ Acetat Puffer und $\mathrm{NaCl}$ wieder regeneriert.

Mussten größere Volumina als 1,51 Kulturüberstand verarbeitet werden, so wurden die Reinigungen von der Göttinger Selecore GmbH über Tropfsäulen aus Glas (72 x 31 cm; $600 \mathrm{ml}$ Säulenmatrixvolumen) durchgeführt.

\subsubsection{Kationenaustauschchromatographie an der Vision Biocad ${ }^{\circledR}$ workstation $^{-}$}

In einigen Fällen war die Reinheit der Fusionsproteine nach dem initialen Reinigungsschritt (3.4.6.2.) nicht ausreichend für die nachfolgenden Applikationen. Insbesondere für die Kristallisation aber auch für die Spaltung der Fusionsproteine mit Bromcyan sollte die Proteinlösung keinerlei Verunreinigungen mehr aufweisen. Daher wurde das Produkt aus 3.4.6.2. zunächst in $0.1 \mathrm{M}$ Tris- $\mathrm{HCl} \mathrm{pH} 7,8$ mit $8 \mathrm{M}$ Harnstoff aufgenommen, ü.N. gegen $50 \mathrm{mM}$ Ammoniumacetat dialysiert (3.4.4.) und noch einmal über Kationenaustauschchromatographie an der Vision Biocad ${ }^{\circledR}$ workstation gereinigt. Dabei wurde wiederum eine Perseptive HS20 Säule (1,0 x $10 \mathrm{~cm}, 7.6 \mathrm{ml}$ Volumen) oder bei größeren Proteinmengen eine XK26 Säule (Pharmacia; 2.6 x $20 \mathrm{~cm}, 79 \mathrm{ml}$ Volumen), gepackt mit SP-Sepharose XL (Amersham Biosciences), verwendet. Die Probe wurde mit 1/10 Volumen $250 \mathrm{mM}$ Na-Acetat pH 5,0 mit einer Flussgeschwindigkeit von 5 (HS20 Säule) bzw. 9 ml/min (XK26 Säule) aufgetragen. Danach wurde solange mit $25 \mathrm{mM}$ Acetat Puffer gewaschen, bis die $\mathrm{OD}_{280}$ wieder den Ausgangswert erreicht hatte. Die Elution erfolgte mit einem zweistufigen $\mathrm{NaCl}$ Gradienten von 90 bis 330 mM in 4 (XK26 Säule) bzw. 20 (HS20 Säule) Säulenvolumen und von 330 bis $2100 \mathrm{mM} \mathrm{NaCl}$ in 1,5 Säulenvolumen. Das Eluat wurde mit dem automatischen Fraktionssammler fraktioniert und anschließend durch SDS-PAGE (3.4.1.) analysiert.

\subsubsection{Präparative Reversed-phase-Chromatographie an der Vision Biocad ${ }^{\circledR}$ workstation $^{(10}$}

In der reversed-phase Chromatographie können Substanzen aufgrund ihres unterschiedlichen hydrophoben Charakters voneinander getrennt werden. Für die Trennung von mit Bromcyan abgespaltenem Mikroproteinen (Abschnitt 3.4.9.1.) von ihrem Fusionspartner wurde zu präparativen Zwecken die reversed-phase Chromatographie an der Vision Biocad ${ }^{\circledR}$ workstation durchgeführt. Dafür wurde eine mit Amberchrom CG-300M RP-Material (Tosoh Bioscience) gepackte XK26 Säule (Amersham Biosciences, $79 \mathrm{ml}$ Volumen) verwendet. Die Probe wurde zunächst 1/10 mit $5 \%$ Acetonitril, $0,1 \%$ (v/v) TFA verdünnt und mit $5 \mathrm{ml} / \mathrm{min}$ aufgetragen. Danach wurde mit $5 \%$ Acetonitril, 0,1\% (v/v) TFA gewaschen, bis die $\mathrm{OD}_{280}$ wieder den Ausgangswert erreicht hatte. Neben der $\mathrm{OD}_{280}$ wurde in diesem Programm auch 
die $\mathrm{OD}_{220}$ (Absorptionsmaximum der Peptidbindung) aufgezeichnet, da die gereinigten Mikroproteine in der Regel keine Aromaten besaßen, die für eine Absorption bei $\mathrm{OD}_{280}$ entscheidend sind. Die Elution erfolgte mit einem zweistufigen Acetonitril/0,1 \% (v/v) TFA Gradienten von 5 bis $30 \%$ in etwa 4 Säulenvolumen und von 30 bis $90 \%$ in etwa 2 Säulenvolumen. Das Eluat wurde mit dem automatischen Fraktionssammler fraktioniert und anschließend durch SDS-PAGE (3.4.1.) analysiert. Die gewünschten Fraktionen wurden zur Entfernung des Lösungsmittels lyophillisiert.

\subsubsection{Reversed-phase HPLC}

Die reversed-phase HPLC beruht auf der unterschiedlich starken Interaktion der zu trennenden Substanzen mit einer Säulenmatrix, der stationären Phase, entlang eines Konzentrationsgradienten in einer mobilen Phase. Polypeptidgemische werden in der Regel über hydrophobe Säulenmaterialien als stationäre Phase aufgetrennt, die aus Kieselgel als Trägermaterial und daran gekoppelten Alkylresten der Länge C2 bis C18 bestehen. In dieser Arbeit wurden analytische und halbpräparative C18 Säulen der Firma Phenomenex verwendet (Synergi 4u Hydro-RP 80Å; 250 x 4.60 mm bzw. 250 x 10,00 mm). Die mobile Phase setzte sich aus Wasser, Acetonitril als hydrophobes Lösungsmittel und $0.1 \%$ Trifluoressigsäure (TFA) zusammen. TFA bindet die geladenen Gruppen des Proteins und verändert damit dessen Hydrophobizität. Es wurden standardmäßig Gradienten von 10 bis $37 \%$ Puffer B (Acetonitril, 0,1 \% TFA) gegen Puffer A $\left(\mathrm{H}_{2} \mathrm{O}, 0,1 \%\right.$ TFA) in 19 min mit Hilfe von Kontron 420 Pumpen bei Flussraten von 1 (analytische Säule) bzw. 3,5 ml/min (halbpräparative Säule) erzeugt. Dabei wurde die $\mathrm{OD}_{217}$ mit einem Kontron Photometer (HPLC Detektor 430) verfolgt und das separierte Protein manuell in Eppendorf-Gefäßen oder Falcon Röhrchen gesammelt. Alternativ zur Kontron HPLC Anlage wurde eine Äcta Explorer HPLC Anlage (Pharmacia Biotech) benutzt; bei größeren aufzureinigenden Proteinmengen bestand zudem die Möglichkeit, die Reinigung über eine präparative YMC J'spere ODS H-80, RP C-18 (250 x 4,6 mm, $4 \mu \mathrm{m}, 8 \mathrm{~nm}$ ) in der Arbeitsgruppe Diederichsen in der Organischen Chemie in Göttingen durchführen zu lassen.

\subsubsection{Gelfiltration}

Bei der Gelfiltration können Proteine nach ihrem Molekulargewicht aufgetrennt werden. Die stationäre Phase besteht aus einem Material mit löchriger, porentragender Oberfläche. In diese Löcher können kleine Moleküle gut und größere weniger gut eindringen. Daher eluieren kleine Moleküle später von der Säule als große und können so voneinander separiert werden. Die Gelfiltration wurde in dieser Arbeit an einer LCC-500 PLUS FPLC Anlage (Pharmacia 
Biotech) für die Trennung von monomeren und dimerisierten (Abschnitt 3.6.1.) Mikroproteinen eingesetzt. Dafür wurde eine Superdex ${ }^{\circledR} 75$ Säule (Pharmacia Biotech) und als Laufpuffer $200 \mathrm{mM}$ Ammoniumacetat benutzt. Die Flussgeschwindigkeit betrug 0,5 ml/min bei einem Rückdruck von etwa 10-15 bar; dabei wurde mit einem Schreiber die $\mathrm{OD}_{280}$ dokumentiert. Der Fraktionssammler wurde auf 10 Tropfen pro Röhrchen eingestellt. Die einzelnen Fraktionen wurden schließlich auf einem Tris-Tricin SDS-Polyacrylamidgel (3.4.1.) analysiert.

\subsubsection{Rückfaltung von reduzierten Mikroproteinen}

Cystin-Knoten Mikroproteine zeichnen sich durch ihre charakteristische Anordnung ihrer drei Disulfidbrücken aus. Durch chemische Synthese erhaltene Mikroproteine liegen in reduzierter Form vor, was eine anschließende Rückfaltung in die native Konformation nötig macht. Die Ausbeute an korrekt gefalteten Protein ist dabei jedoch abhängig von Sequenz und Mikroprotein-Spezies. In dieser Arbeit wurden lineare Varianten von MCoTI-II, die von Olga Avrutina (Organische Chemie Göttingen, Arbeitsgruppe Diederichsen) chemisch synthetisiert worden sind, zurückgefaltet. Dafür wurden die Proteine wie in Wentzel et al. [Wentzel et al., 1999] beschrieben in $10 \mathrm{mM} \mathrm{HCl}(100 \mu \mathrm{l} / \mathrm{mg}$ Protein) und $200 \mathrm{mM}$ Ammoniumcarbonat Puffer pH 9,1 (1 ml/mg Protein) aufgenommen und ü.N. in einem Teflongefäß bei $900 \mathrm{u} / \mathrm{min}$ auf einem Schüttler inkubiert. Das Teflongefäß wurde dabei für die Versorgung mit Sauerstoff mit Parafilm bedeckt, in das mit einer Kanüle mehrere Löcher gestochen wurden. Anschließend erfolgte die Reinigung des oxidierten Mikroproteins mittels RP-HPLC (3.4.6.5.).

\subsubsection{Spaltung von Barnase'-Fusionsproteinen}

\subsubsection{Chemische Spaltung mit Bromcyan}

Die Spaltung von Peptiden und Proteinen mit Bromcyan ist eine etablierte und kostengünstigte Methode. Bromcyan spaltet die Peptidkette selektiv am C-terminalen Ende von Methioninresten unter Ausbildung eines Homoserinlaktons (Abbildung 3.1.). Das zu spaltende Peptid/Protein wird dabei üblicherweise in $70 \%$ iger Ameisensäure gelöst. Da dieses Lösungsmittel jedoch eine reduzierende Wirkung auf Disulfidbrücken besitzt [Villa et al., 1989], wurde im Laufe dieser Arbeit dazu übergegangen, die Proteine in einem adäquaten Volumen $8 \mathrm{M}$ Harnstoff/0,2 $\mathrm{M} \mathrm{HCl}$ oder in $6 \mathrm{M}$ Guanidiniumhydrochlorid/0,2 $\mathrm{M} \mathrm{HCl} \mathrm{zu}$ lösen, nachdem das Fusionsprotein zuvor mittels $\mathrm{HCl}$ gefällt (3.4.5.2.) worden war. Die Spaltung erfolgte dann ü.N. mit 0,6 $\mu 15$ M Bromcyan-Lösung (Fluka) pro mg Protein. 


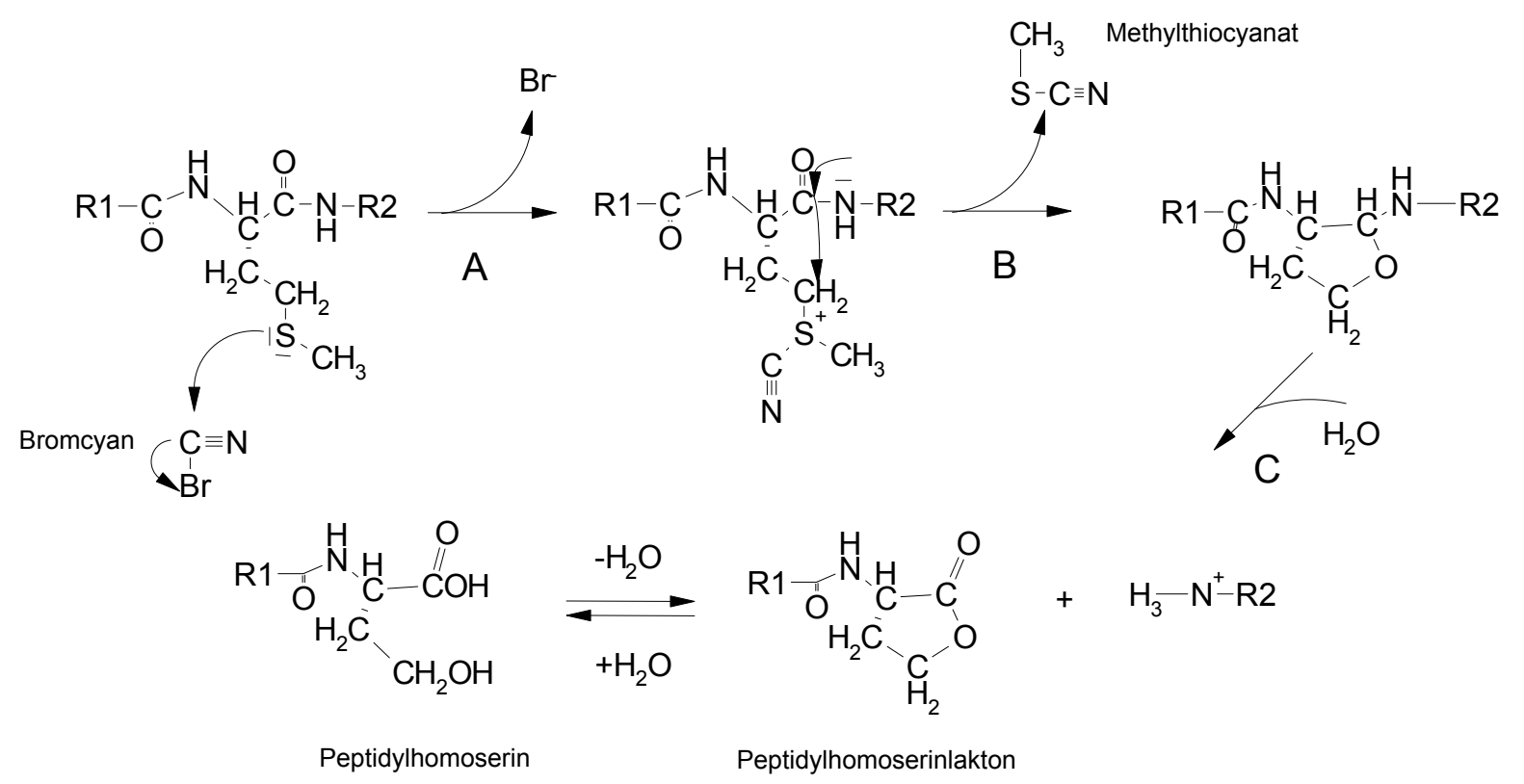

Abbildung 3.1.: Spaltung von Peptiden an Methioninresten mit Bromcyan. (A) Durch den nukleophilen Angriff des Schwefelatoms der Methionin-Seitenkette auf das C-Atom von Bromcyan kommt es zur Ausbildung eines Sulfonium-Ions. (B) Unter Freisetzung von Methylthiocyanat wird ein Imminolakton gebildet. (C) Die Spaltung der Peptidkette erfolgt dann in einer Hydrolyse-Reaktion. Es bildet sich ein C-terminales Homserinlakton aus, das im Gleichgewicht mit einem Homoserin steht [Kaiser und Metzka, 1999].

\subsubsection{Proteolytische Spaltung mit Thrombin}

Thrombin ist das entscheidende Enzym der plasmatischen Blutgerinnung. Es entsteht durch enzymatische Spaltung aus seiner inaktiven Vorstufe, dem Faktor II (Prothrombin) und leitet den letzten Schritt der Gerinnungskaskade und damit die Thrombozytenaggregation ein. Die Serinprotease Thrombin katalysiert die Umwandlung von Fibrinogen zu Fibrin durch proteolytische Abspaltung eines Peptidrestes und ermöglicht damit die Bildung der Fibrinfäden. Thrombin kann aus humanem Plasma isoliert und durch seine hohe Spezifität für die Spaltung von Peptidketten in vitro eingesetzt werden. Das Enzym erkennt die Aminosäuresequenz LVPRGS und spaltet die Peptidbindung zwischen R und G.

In dieser Arbeit wurde die Eignung von Thrombin als Alternative zu Bromcyan für die Spaltung von Barnase'-Fusionsproteinen untersucht. Die lyophilisierten Proteine wurden dafür in $20 \mathrm{mM}$ Tris- $\mathrm{HCl} \mathrm{pH} 8,45,150 \mathrm{mM} \mathrm{NaCl}$ und 2,5 $\mathrm{mM} \mathrm{CaCl}_{2}$ gelöst und mit 1 Einheit Thrombin (Sigma, T-7009) pro mg Fusionsprotein versetzt. Die Reaktion erfolgte ü.N. bei $37^{\circ} \mathrm{C}$ und wurde dann durch SDS-PAGE (3.4.1.) bzw. RP-HPLC (3.4.6.5.) analysiert.

\subsubsection{Proteolytische Spaltung mit Faktor XA}

Neben Thrombin wurde Faktor X zur proteolytischen Spaltung verwendet. Faktor X ist ebenfalls an der Blutgerinnung beteiligt. Seine Aktivierung zu Faktor XA (activated) erfolgt durch den Komplex Faktor IXA, Faktor VIII, Phospholipid, Ca und durch Faktor VII und 
Gewebsthromboplastin. Das Enzym spaltet C-terminal nach der Aminosäuresequenz IEGR. Das zu spaltende Protein wurde gegen $100 \mathrm{mM}$ Tris/ $\mathrm{HCl} \mathrm{pH}$ 8,3 dialysiert (3.4.4.) und für 24$48 \mathrm{~h}$ mit 1 Einheit Faktor XA pro mg Fusionsprotein bei $37{ }^{\circ} \mathrm{C}$ inkubiert. Der Erfolg wurde durch SDS-PAGE (3.4.1.) bzw. RP-HPLC (3.4.6.5.) kontrolliert.

\subsubsection{Bestimmung der Inhibitionskonstante $K_{i}$ gegenüber Trypsin}

Die inhibitorische Aktivität von Mikroproteinvarianten bzw. Barnase'-Mikroprotein-Fusionen wurde nach van Nostrand et al. [Van Nostrand et al., 1990] und Sinha et al. [Sinha et al., 1991] bestimmt. Dazu wurde die verbleibende Aktivität von Trypsin (Fluka, aus Rinder Pankreas) gegenüber dem chromogenen Substrat Boc-Leu-Gly-Arg-pNA (Bachem, gelöst in DMSO) nach 10 min Inkubation mit dem jeweiligen Inhibitor bei $37^{\circ} \mathrm{C}$ gemessen. Die Hydrolyse des Substrats konnte bei $405 \mathrm{~nm}$ im ELISA reader (SLT 340 ATTC) verfolgt werden. Der Assay wurde in einem Gesamtvolumen von $100 \mu$ in Trypsin Puffer $(50 \mathrm{mM}$ Tris/ $\mathrm{HCl}, \mathrm{pH} 7,5,150 \mathrm{mM} \mathrm{NaCl}, 5 \mathrm{mM} \mathrm{CaCl}_{2}$ ) bei $37^{\circ} \mathrm{C}$ mit $5 \mathrm{nM}$ Trypsin, $0,75 \mathrm{mM}$ Substrat und variierten Mengen an Inhibitor $\left(10^{-10}-10^{-6} \mathrm{M}\right)$ durchgeführt. Die gemessene Anfangsgeschwindigkeit der Freisetzung von gespaltenem Substrat ist bei Substratüberschuss gleich der Maximalgeschwindigkeit $\mathrm{v}_{\max }$ und der Enzymaktivität direkt proportional. Aus der erhaltenen Hemmkurve wurde die apparente Dissoziationskonstante $K_{\text {iapp }}$ des Enzym/Inhibitor-Komplexes durch Anpassung der Gleichung 3.3. für festbindende Inhibitoren [Morrison, 1969] mittels nichtlinearer Regression berechnet.

$$
\frac{v_{i}}{v_{0}}=1-\frac{\left[E_{t}\right]+\left[I_{t}\right]+K_{\text {iapp }}-\left\{\left(\left[E_{t}\right]+\left[I_{t}\right]+K_{\text {iapp }}\right)^{2}-4 \cdot\left[E_{t}\right] \cdot\left[I_{t}\right]\right\}^{\frac{1}{2}}}{2 \cdot\left[E_{t}\right]}
$$

$$
\begin{aligned}
& \mathrm{v}_{\mathrm{i}}=\mathrm{v}_{\max } \text { Wert der inhibierten Reaktion } \\
& \mathrm{v}_{0}=\mathrm{v}_{\max } \text { Wert der uninhibierten Reaktion } \\
& {\left[\mathrm{E}_{\mathrm{t}}\right]=\text { Gesamt-Enzym Konzentration (frei und im Komplex) }} \\
& {\left[\mathrm{I}_{\mathrm{t}}\right]=\text { Gesamt-Inhibitor Konzentration (frei und im Komplex) }} \\
& \mathrm{K}_{\text {iapp }}=\text { apparente Dissoziationskonstante des Enzym-Inhibitor-Komplex. }
\end{aligned}
$$

\subsubsection{Bestimmung der Inhibitionskonstante $K_{\mathrm{i}}$ gegenüber Porcine Pankreas Elastase (PPE)}

Die inhibitorische Aktivität gegenüber Porcine Pankreas Elastase (PPE) wurde nach van Nostrand et al. [Van Nostrand et al., 1990] und Sinha et al. [Sinha et al., 1991] bestimmt. Dazu wurde die verbleibende Aktivität von PPE (Serva) gegenüber dem chromogenen 
Substrat Suc-(Ala) 3 -pNA (Sigma, gelöst in DMSO) mit dem jeweiligen Inhibitor bei $37^{\circ} \mathrm{C}$ gemessen. Die Hydrolyse des Substrats konnte bei $405 \mathrm{~nm}$ im ELISA reader (SLT 340 ATTC) verfolgt werden. Der Assay wurde in einem Gesamtvolumen von $100 \mu 1$ in $100 \mathrm{mM}$ Tris/ $\mathrm{HCl}, \mathrm{pH} 8,45$ bei $37^{\circ} \mathrm{C}$ mit $0,1 \mu \mathrm{M}$ PPE, $0,75 \mathrm{mM}$ Substrat und variierten Mengen an Inhibitor $(10 \mathrm{nM}-10 \mu \mathrm{M})$ durchgeführt. Aus der erhaltenen Hemmkurve wurde die apparente Dissoziationskonstante $K_{\text {iapp }}$ des Enzym/Inhibitor-Komplexes wie in 3.4.10. beschrieben bestimmt.

\subsection{Chemische Modifikation von Mikroproteinen}

\subsubsection{Dimerisierung von Mikroproteinen mit Disuccinimidylsuberat (DSS)}

Disuccinimidylsuberat (DSS) ist ein homobifunktionaler N-Hydroxysuccinimid-Ester (NHSEster; Abbildung 3.2.), der mit primären Aminen unter Ausbildung einer Amidbindung und Abspaltung von N-Hydroxysuccinimid reagiert. Diese Eigenschaft kann für die Verknüpfung von Proteinen ausgenutzt werden. Neben der N-terminalen $\alpha$-Aminogruppe reagiert nur die $\varepsilon$ Aminogruppe der Lysin-Seitenkette mit dem NHS-Ester zu einem stabilen Produkt. Daher wurden die zur Dimerisierung vorgesehenen Mikroprotein-Varianten so konzipiert, das sie nur ein singuläres Lysin beinhalteten.

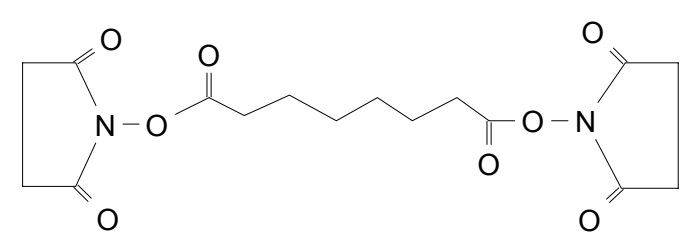

Abbildung 3.2.: Molekülstruktur von DSS.

Die Mikroproteine (1-5 mg) wurden für die Dimerisierung in $985 \mu \mathrm{l}$ Dimethylformamid (DMF), $500 \mu 1$ DMSO und $15 \mu 1$ Triethylamin aufgenommen und mit 1/2 mol Äquivalent DSS (gelöst in DMSO) ü.N. bei RT inkubiert. Der Erfolg der Dimerisierung wurde am nächsten Tag auf einem Tris-Tricin Gel (3.4.1.) kontrolliert. Eine Trennung von Mono-/Di-/Tri- und Tetrameren wurde über Gelfiltration (3.4.7.) oder RP-HPLC (3.4.6.5.) versucht.

\subsubsection{Umsetzung von Homoserinlakton mit Hydrazin-Monohydrat}

Die spezifische Spaltung einer Peptidkette an Methioninresten mit Bromcyan hinterlässt am C-terminalen Ende des Proteins ein im Gleichgewicht mit einem Homoserin stehendes Homoserinlakton (3.4.9.1.). Dieses $\gamma$-Lakton kann mit Hydrazin geöffnet und zu einem Hydrazid umgesetzt werden (Abbildung 3.3.). 
$\mathrm{OH}$

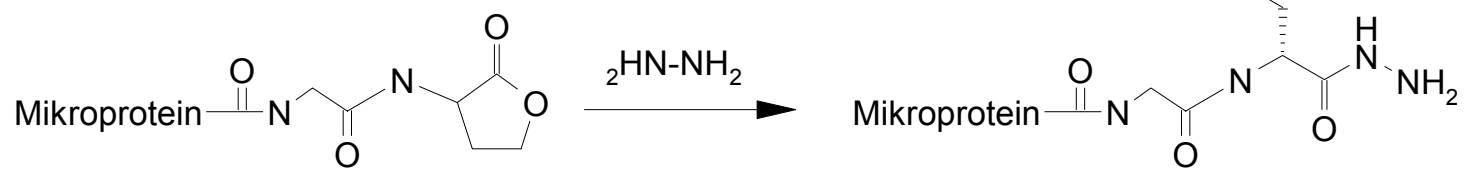

Abbildung 3.3.: Umsetzung von Mikroproteinen mit C-terminalem Homoserinlakton mit Hydrazin.

Für die Umsetzung mit Hydrazin wurde das lyophilisierte Mikroprotein-Homoserinlakton in $\mathrm{H}_{2} \mathrm{O}$ in einer Konzentration von $2-5 \mathrm{mg} / \mathrm{ml}$ aufgenommen und mit einem 100-fach molarem Überschuss an Hydrazin-Monohydrat (Fluka) versetzt. Die Reaktion erfolgte für 90 min bei RT unter leichtem Schütteln. Danach wurde der Ansatz 1:1 mit $\mathrm{H}_{2} \mathrm{O}$ verdünnt und ü.N. lyophilisiert. Um evtl. noch vorhandenes Hydrazin vollständig zu entfernen, wurde das Mikroprotein-Hydrazid anschließend über RP-HPLC (3.4.6.5.) gereinigt.

\subsubsection{Selektive Oxidation von N-terminalen Serinen mit Natrium-Periodat}

Die Oxidation von N-terminalen Serinresten (oder Threoninresten) einer (Poly-) Peptidkette mit Natrium-Periodat zum Aldehyd (Abbildung 3.4.) wurde bereits in den 60er Jahren beschrieben [Fields und Dixon, 1968]. Obwohl auch in später erschienenen Artikeln die Selektivität dieser Methode betont wurde [Gaertner et al., 1992, Geoghegan und Stroh, 1992], ist es nicht trivial, die richtigen Bedingungen für die Oxidation eines spezifischen Peptids/Proteins $\mathrm{zu}$ finden, da bei zu langer Inkubation bzw. zu hoher Konzentration an Periodat auch andere Aminosäureseitenketten oxidiert werden können [Geoghegan und Stroh, 1992]. Bei der Reaktion des Serins zum Serin-Aldehyd kommt es zur Abspaltung von Formaldehyd, zudem wird Ammoniak freigesetzt.

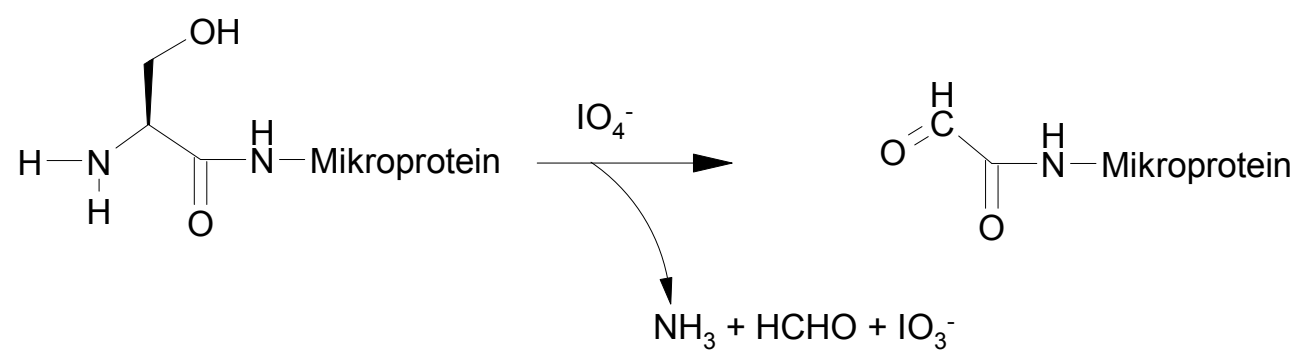

Abbildung 3.4.: Umsetzung N-terminaler Serinreste mit Natrium-Periodat.

In dieser Arbeit wurden Mikroproteine, modifiziert wie in Gärtner et al. [Gaertner et al., 1992] bzw. Geoghegan et al. [Geoghegan und Stroh, 1992] beschrieben, mit $\mathrm{NaIO}_{4}$ zur Oxidation N-terminaler Serinreste umgesetzt. Die Proteine wurden dazu in einer Konzentration von etwa $0,9 \mathrm{mg} / \mathrm{ml}$ in $0,01 \mathrm{M}$ Natrium-Phosphat $\mathrm{pH} \mathrm{7,0}$ aufgenommen und mit 10 mol Äquivalent $\mathrm{NaIO}_{4}$ bei RT inkubiert. Die Reaktion wurde nach 5 min über 
analytische RP-HPLC kontrolliert und das entsprechende Produkt ggf. anschließend über RPHPLC gereinigt. 


\section{Ergebnisse und Diskussion}

\subsection{Entwicklung eines rekombinanten Expressionssystems für die Produktion von Mikroproteinen}

Für die Entwicklung von rational designten Tryptase Inhibitoren und Thrombopoeitin Agonisten auf Basis von Cystin-Knoten Mikroproteinen ist der Aufbau eines robusten Produktionssystems, das in diesem Abschnitt der Arbeit beschrieben werden soll, Grundvoraussetzung.

Ihre geringe Größe von nur etwa 25 bis 40 Aminosäuren macht die Substanzklasse der Cystin-Knoten Mikroproteine sowohl für die automatisierte chemische Synthese [Avrutina et al., 2004, Ay et al., 2003, Daly et al., 1999, Tam et al., 1999] [Le-Nguyen et al., 1989], als auch für die rekombinante Produktion in Mikroorganismen wie Escherichia coli [Chen et al., 1992, Kojima et al., 1996, Molina et al., 1992, Wentzel et al., 1999] zugänglich. Die chemische Boc- bzw. Fmoc-gestützte Festphasensynthese erfordert dabei jedoch die Rückfaltung der Peptide in die native Konformation, bei der die korrekte Verknüpfung der sechs Cystein Reste zu drei Disulfidbrücken erfolgen muss. Diese Rückfaltung gestaltet sich zumindest für einige Varianten schwierig [Daly und Craik, 2000] und lässt sich z.T. nur durch Optimierung der Reaktionsbedingungen bewerkstelligen [Goldenberg, 1992]. Zudem können bestimmte Sequenzen, wie z.B. solche, die $\beta$-Faltblattstrukturen ausbilden oder extrem hydrophobe Abschnitte, die zu Aggregation neigen, zu Problemen in der Festphasen-Synthese führen.

Somit stellt die kosteneffizientere rekombinante Produktion eine interessante Alternative dar. In der Literatur sind bis heute nur sehr wenige Methoden beschrieben, kleine Disulfidbrücken-reiche Proteine in Mikroorganismen zu produzieren [Chen et al., 1992, Döbeli et al., 1998, Fairlie et al., 2002, Kojima et al., 1996, Molina et al., 1992, Wentzel et al., 1999]. Aufgrund der geringen Größe wurden Mikroproteine mit Ausnahme des potato carboxypeptidase inhibitor IIa (PCI-IIa), der solitär über eine Omp A Signal Sequenz in großen Mengen exprimiert (bis zu $80 \mathrm{mg} / \mathrm{l}$ ) und aus dem Kulturüberstand gereinigt werden kann [Molina et al., 1992], bisher in der Regel als Fusionsproteine hergestellt, die zytoplasmatisch als unlösliche inclusion bodies anfallen. Als Fusionspartner dienten dabei z.B. ein Fragment der $\beta$-Galaktosidase [Chen et al., 1992] oder porcine adenylate kinase (ADK) [Kojima et al., 1996]. Die inclusion bodies werden in denaturierenden Agenzien wie z.B. Harnstoff oder Guanidinium-Hydrochlorid aufgenommen und das Fusionsprotein über 
konventionelle Chromatographie gereinigt. Da die inclusion bodies jedoch im Zytoplasma akkumulieren, wo reduzierende Bedingungen herrschen, muss auch in diesem Fall, wie bei der chemischen Synthese, das Mikroprotein nach Abspaltung des Fusionspartners zurückgefaltet werden.

Aus diesem Grund sollte in dieser Arbeit ein neuartiges rekombinantes Expressionssystem für die Produktion von Cystin-Knoten Mikroproteinen entwickelt werden, das die Reinigung von bereits korrekt gefalteten Mikroproteinen aus dem oxidativen Milieu des Periplasmas bzw. des Kulturmediums erlaubt. Als alternative Systeme sollten daher ein E.coli System mit Sekretion ins Periplasma (4.1.2.) und ein eukaryotisches System, für das die methylotrophe Hefe Pichia pastoris ausgewählt wurde (4.1.3.), aufgebaut werden.

\subsubsection{Wahl des Trägerproteins}

Da die solitäre Expression der in der Arbeitsgruppe Kolmar bearbeiteten Mikroproteine in $E$. coli nicht wie bei PCI-IIa möglich ist (H. Kolmar, persönliche Kommunikation), sollte bei dem neu aufzulegenden Expressionssystem auf das Konzept der Fusionierung an ein Trägerprotein zurückgegriffen werden. Das Trägerprotein sollte dabei optimalerweise folgende Eigenschaften aufweisen:

(i) Es sollte ein hohes Expressionslevel in E. coli gewährleisten und leicht zu reinigen sein.

(ii) Es sollte ein Protein ohne Cysteine sein, um eine Interferenz mit der Faltung des fusionierten Mikroproteins in vivo im oxidativen Milieu des Periplasmas auszuschließen.

(iii) Es sollte keine Methionine beinhalten, damit das Trägerprotein mittels Bromcyan an einem Methioninrest zwischen dem Trägerprotein und dem Mikroprotein chemisch abgespalten werden kann.

Nach eingehender Literaturrecherche wurde in Barnase ein Protein mit den gewünschten Eigenschaften gefunden. Es weist zudem nur eine relative molare Masse von etwa 13000 auf, d.h. das Verhältnis von tatsächlich produzierter Masse an Mikroprotein zur Masse an Fusionsprotein ist mit etwa $1 / 5$ relativ gering.

Barnase ist eine extrazelluläre RNase aus Bacillus amyloliquefaciens. Das Protein wirkt innerhalb der Bacillus-Zelle toxisch und wird daher durch die Co-Expression des natürlichen Inhibitors Barstar im Zytoplasma inaktiviert. Barnase wurde intensiv als Modellprotein zur Untersuchung von Proteinfaltungsvorgängen [Corrales und Fersht, 1995] und als Komplex mit dem Inhibitor zur Untersuchung von Protein/Protein Interaktionen beforscht [Hartley, 
2001, Neira et al., 2000]. Barnase kann rekombinant in E. coli entweder zusammen mit dem Inhibitor oder in inaktivierter Form in großen Mengen, d.h. etwa 30-100 mg/l Kultur, hergestellt und aus dem Kulturüberstand über Kationenaustauschchromatographie gereinigt werden [Hartley, 1988].

In den folgenden Abschnitten werden zwei unabhängige Expressionssysteme zur Produktion von Mikroproteinen -in Escherichia coli (4.1.2.) bzw. in Pichia pastoris (4.1.3.)- vorgestellt, bei denen eine enzymatisch inaktivierte Barnase Variante als Fusionspartner dient und die Fusionsproteine jeweils aus dem Kulturüberstand in korrekt gefalteter Form gereinigt werden können.

\subsubsection{Escherichia coli Barnase'-Fusionsprotein-System}

Das entwickelte Barnase-Expressionssystem in E. coli basiert auf den Experimenten von R.W. Hartley [Hartley, 1988], der Barnase in großen Mengen in E. coli exprimiert hat und aus dem Kulturüberstand über Kationenaustauschchromatographie reinigen konnte. Dafür wurde das Plasmid pMT416 benutzt, das die Gene für Barnase und Barstar und eine PhoA Signal Sequenz (dirigiert die Barnase ins Periplasma) unter Kontrolle eines synthetischen tac Promotors trägt. Die wesentlichen Elemente dieses Systems, nämlich tac Promotor und phoA Signal Sequenz, sollten in dem zu entwickelnden Fusionsprotein System erhalten bleiben; im Unterschied zu Hartley sollte aber auf die Co-Expression von Barstar verzichtet werden, d.h. die Barnase sollte durch die Mutation von His ${ }^{102} \mathrm{zu}$ Ala enzymatisch inaktiviert werden [Jucovic und Hartley, 1995], was in der Zukunft neben der klassischen Kationenaustauschchromatographie der Fusionsproteine auch eine Affinitätschromatographie mit Barstar möglich machen könnte. Die enzymatisch inaktivierte His ${ }^{102} \mathrm{zu}$ Ala Variante wird im Folgenden als Barnase' bezeichnet.

\subsubsection{Klonierung der Expressionsvektoren}

Die Klonierung des E. coli Expressionsvektors aus den Ausgangsplasmiden pMT416 (freundlicherweise von L. Levenicki aus Marburg zur Verfügung gestellt) und pASKInt101, einem Derivat des Zelloberflächenpräsentationsvektors pASKInt100 [Wentzel et al., 2001], erfolgte über mehrere Zwischenschritte. Sie wurde in Schmoldt et al. [Schmoldt et al., 2005] beschrieben. Das Grundgerüst des Plasmids, das im Folgenden als pBar100 (Abbildung 4.1.1. A) bezeichnet wird, beinhaltet neben dem Chloramphenicol-Resistenz Gen und dem Tetracyclin Repressor Gen den mit IPTG induzierbaren tac Promotor aus dem pMT416 Vektor, unter dessen Kontrolle die Expression des tripartiten Fusionsgens aus der phoA Signal 
Sequenz (phoAs), des barnase' Gens und des jeweiligen eingeführten Mikroprotein Gens (ICK) steht.

Der Vektor wurde so konstruiert, dass das resultierende Barnase'-Mikroprotein Fusionsprotein durch einen aus drei Serinresten bestehenden linker verknüpft ist. Zudem wurde eine selektive Spaltstelle für die chemische oder proteolytische Abspaltung des Fusionspartners eingeführt. Dabei handelt es sich je nach Konstrukt um ein singuläres Methionin für die chemische Spaltung mit Bromcyan bzw. für den Fall, dass das entsprechende Mikroprotein ein internes Methionin besitzt, um eine Thrombin- (LVPRGS) oder Faktor XA (IEGR) Erkennungssequenz.

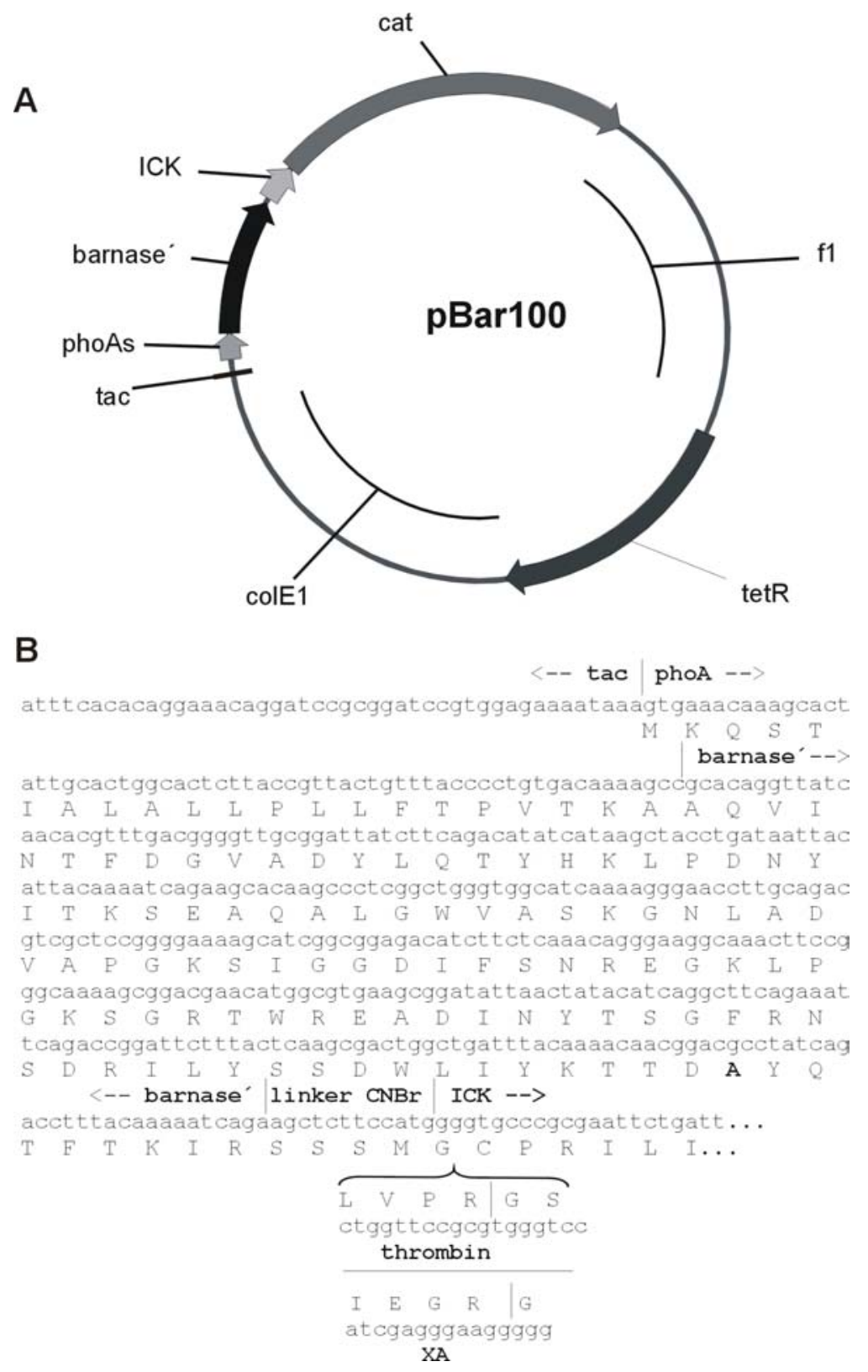

Abbildung 4.1.1. Escherichia coli Barnase'-Fusionsprotein-System.

(A) Schematische Darstellung des Expressionsvektors pBar100. Barnase', His ${ }^{102}$ zu Ala Mutante der RNase Barnase aus Bacillus amyloliquefaciens, das resultierende Barnase' Protein ist durch die Mutation enzymatisch inaktiviert [Jucovic und Hartley, 1995]; f1, Replikationsursprung des Phagen f1; cat, Chloramphenicol Resistenz 
Gen; tetR, kodierende Region für den Tetracyclin Repressor; colE1, colE1 Replikationsursprung; tac, tac Promotor Region; phoAs, Alkalische Phosphatase periplasmatische Signal Sequenz; ICK, Mikroprotein Gen.

(B) DNA and Protein Sequenz von Barnase' und Übergang zum Mikroprotein. Die ausgetauschte Aminosäure an Position \#102 von Barnase' ist fett hervorgehoben. Am Übergang von Barnase' und Mikroprotein (ICK) wurde ein linker aus drei Serinresten und einem Methioninrest eingeführt. Das singuläre Methionin wird für die selektive Spaltung des Fusionsproteins mit Bromcyan benötigt. Als Alternative zur chemischen Spaltung wurden in den Vektoren pBar100Throm und pBar100XA Erkennungssequenzen für die Proteasen Thrombin (LVPRGS) bzw. Faktor XA (IEGR) eingeführt.

Um die Eignung des Barnase'-Expressionssystems in E. coli als robustes System für die Produktion verschiedener Mikroprotein Varianten zu demonstrieren, wurden zunächst vier verschiedene Konstrukte erstellt. Die Bezeichnungen der Plasmide und die Sequenzen der Mikroprotein Varianten sind in Tabelle 4.1.1. aufgelistet. Die Klonierung der Konstrukte wurde in Schmoldt et al. [Schmoldt et al., 2005] beschrieben.

\begin{tabular}{|c|c|c|}
\hline Mikroprotein & Plasmid & Peptid Sequenz \\
\hline EETI-II M7I & pBar100-ETIM7I & GCPRILIRCKQDSDCLAGCVCGPNGFCGS \\
\hline EETI-II & pBar100-XA-ETIw.t. & GCPRILMRCKQDSDCLAGCVCGPNGFCGS \\
\hline McoEeTI & pBar100-McoEeTI & GVCPKILKKCRRDSDCLAGCVCGPNGFCGS \\
\hline ThromMcoEeTI & pBar100-ThromMcoEeTI & GSVCPKILKKCRRDSDCLAGCVCGPNGFCGS \\
\hline
\end{tabular}

Tabelle 4.1.1.: Peptid Sequenzen der erstellten Mikroprotein Varianten.

Bei den Mikroproteinen handelt es sich um den Trypsin Inhibitor EETI-II aus der Spritzgurke Ecbalium elaterium [Heitz et al., 1989, Polanowski et al., 1980], einer EETI-II Mutante mit gegen Isoleucin ausgetauschtem Methionin an Position sieben und McoEeTI, einem linearen Hybrid Protein aus den 13 C-terminalen Aminosäuren von EETI-II und 16 N-terminalen Aminosäuren des Trypsin Inhibitors McoTI-II aus Momordica cochinchinensis [Hernandez et al., 2000]. 


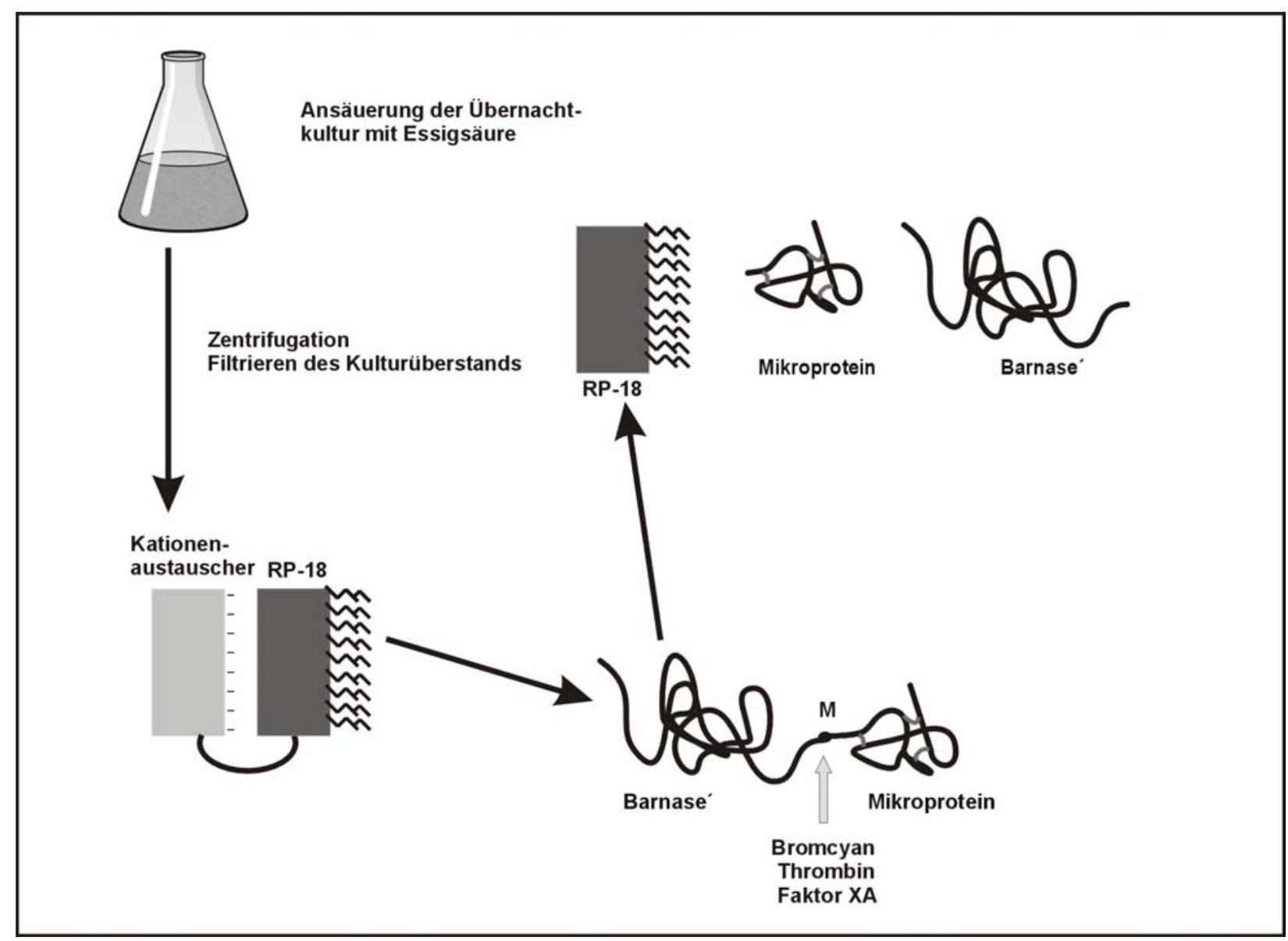

Abbildung 4.1.2.: Schematische Darstellung des Produktions- und Reinigungsprozesses von Barnase'Fusionsproteinen. Beschreibung siehe Text. (Abbildung modifiziert nach Schmoldt et al. [Schmoldt et al., 2005]).

\subsubsection{Produktion und Reinigung der Barnase'-Fusionsproteine}

Das entwickelte Produktions- und Reinigungsschema für Barnase'-Fusionsproteine ist in Abbildung 4.1.2. (siehe oben) zusammenfassend dargestellt. Die Expression der Fusionen erfolgte in E. coli BMH 71-18 mit dem Helferplasmid pRep4, das für eine basale Bereitstellung des Lac Repressors sorgt, um ein kontrolliertes Anschalten der Genexpression über den tac Promotor der pBar100 Vektoren erst bei Induktion mit IPTG zu gewährleisten. Die Fermentation der in Tabelle 4.1.1. aufgelisteten Varianten wurde in 1 bzw. in 51 Gefäßen wie in Abschnitt 3.1.7.2 beschrieben durchgeführt. Der Aufarbeitungsprozess (Abbildung 4.1.2.) beginnt mit der Ansäuerung der induzierten Übernachtkultur mit Essigsäure (3.4.6.1.). Dieser Schritt führt, vermutlich über eine Destabilisierung der Zellmembran, zu einer erhöhten Freisetzung des gebildeten Barnase'-Fusionsproteins in das Kulturmedium [Hartley, 1988], was in der Analyse der Reinigungen von Barnase'-ThromMcoEeTI bzw. Barnase'XA-EETI-II über SDS-PAGE deutlich wird (Abbildung 4.1.3. A Spur 1+2 und B 1+2). 


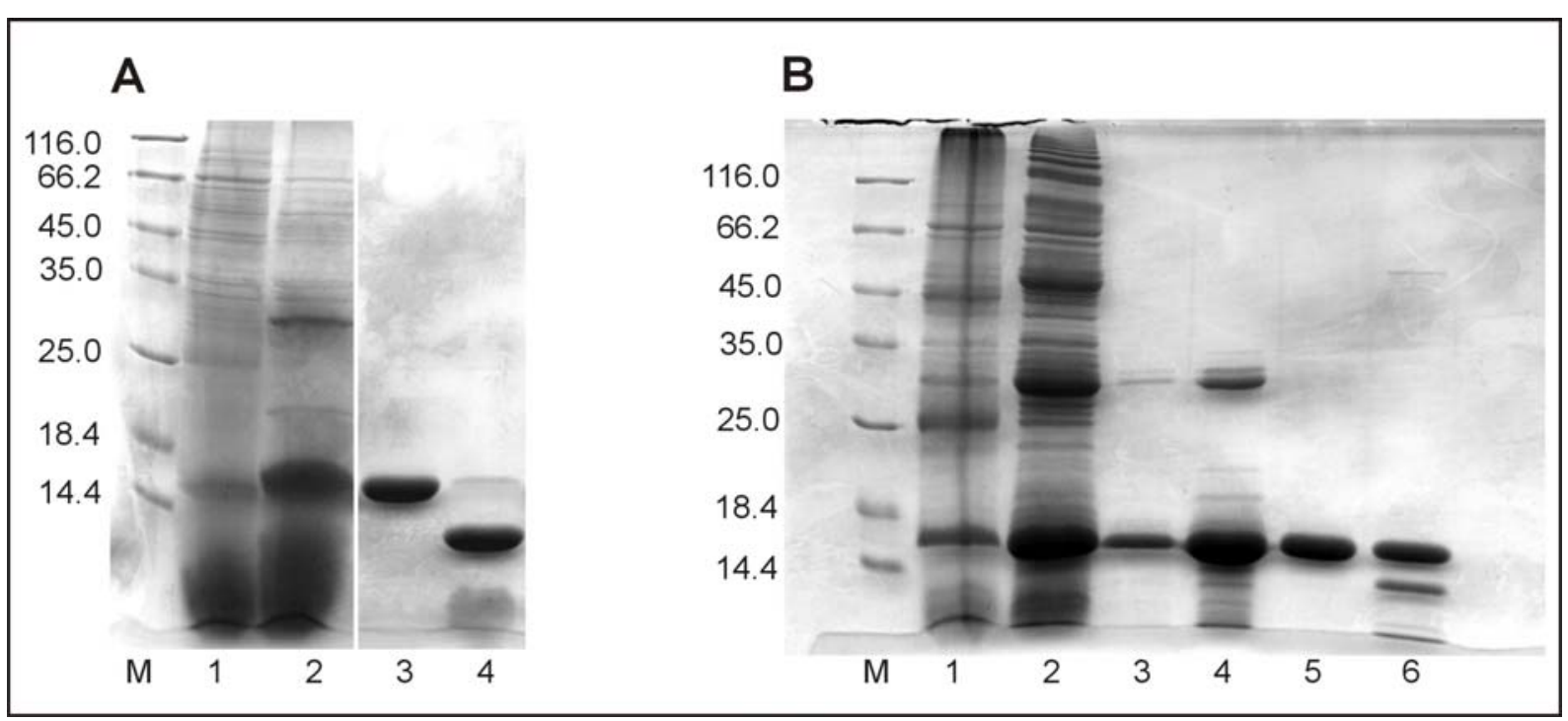

Abbildung 4.1.3.: SDS-PAGE Analyse des Reinigungsprozesses von Barnase'-ThromMcoEeTI (A) bzw. Barnase'-XA-EETI-II (B). (A): M, Molekulargewichts Standard (Größenangabe links in kDa); 1, Kulturüberstand (1,6 ml mit TCA gefällt); 2, Kulturüberstand nach Ansäuerung (1,6 ml mit TCA gefällt); 3, gereinigtes Barnase'-ThromMcoEeTI Protein; 4, Fusionsprotein nach Spaltung mit Thrombin. (B): M, Molekulargewichts Standard (Größenangabe links in kDa); 1, Kulturüberstand (1,6 ml mit TCA gefällt); 2, Kulturüberstand nach Ansäuerung (1,6 ml mit TCA gefällt); 3, Barnase'-XA-EETI-II Protein nach kombinierter Kationenaustausch-/ RP-HPLC; 4, wie 3 nach Denaturierungsschritt mit $8 \mathrm{M}$ Harnstoff und Dialyse; 5, gereinigtes Fusionsprotein; 6, Fusionsprotein nach $48 \mathrm{~h}$ Inkubation mit Faktor XA Protease.

Der saure Kulturüberstand wurde im Folgenden nach Zentrifugation sterilfiltriert und, $1 / 5$ mit $\mathrm{H}_{2} \mathrm{O}$, verdünnt über eine kombinierte Kationenaustausch-/ RP-HPLC an der Perseptive Biocad $^{\circledR}$ workstation (3.4.6.2.) gegeben. Barnase' hat einen vergleichsweise hohen isolelektrischen Punkt von ca. 9 und eluiert daher erst bei einer Konzentration von etwa 250$300 \mathrm{mM} \mathrm{NaCl}$ in der Kationenaustauschchromatographie. Durch die direkt folgende RPHPLC ist das Fusionsprotein in der Regel zu 80-95 \% rein (Abb. 4.1.2. A Spur 3), jedoch war in einigen Fällen eine bräunliche vermutlich aus dem Medium stammende Verunreinigung zu erkennen, die im SDS Gel im unteren molekularen Größenbereich zu erkennen ist (Abb. 4.1.3. B Spur 4). In diesen Fällen wurde das lyophilisierte Fusionsprotein in $8 \mathrm{M}$ Harnstoff denaturiert, mittels Dialyse wieder renaturiert und nochmals über Kationenaustauschchromatographie gereinigt (3.4.6.3. bzw. 3.4.6.4.).

Um die Ausbeute und Reinheit der Fusionsproteine an jedem Schritt der Reinigungsprozedur verfolgen zu können, wurde exemplarisch bei der Reinigung von Barnase'-ThromMcoEeTI an jedem Zwischenschritt mittels Bradford Test (3.4.2.) bzw. durch Auswiegen die Menge des Gesamtproteins und mittels SDS-PAGE Analyse mit bekannten Mengen von bereits gereinigtem Protein (Geltitration) die Menge des Fusionsproteins bestimmt. Die Ergebnisse sind in Tabelle 4.1.2. dargestellt. 


\begin{tabular}{|c|c|c|c|c|c|}
\hline & $\begin{array}{c}\text { Gesamt- } \\
\text { protein } \\
{[\mathrm{mg}]}\end{array}$ & $\begin{array}{c}\text { Fusionsprotein } \\
{[\mathbf{m g}]}\end{array}$ & $\begin{array}{c}\text { Abgespaltenes } \\
\text { Mikroprotein } \\
{[\mathbf{m g}]}\end{array}$ & Ausbeute [\%] & Reinheit [\%] \\
\hline $\begin{array}{c}\text { Angesäuerter } \\
\text { Kulturüberstand }\end{array}$ & $171^{\mathrm{a}}$ & $112,5^{\mathrm{c}}$ & - & - & 65 \\
\hline $\begin{array}{c}\text { Nach kombinierter } \\
\text { HS-RP } \\
\text { Chromatographie }\end{array}$ & $63^{\mathrm{b}}$ & $60^{\mathrm{b}}$ & - & 56 & 95 \\
\hline $\begin{array}{c}\text { Nach Spaltung und } \\
\text { RP-HPLC }\end{array}$ & - & - & $4,2^{\mathrm{b}}$ & 19,6 & $>99$ \\
\hline
\end{tabular}

Tabelle 4.1.2.: Reinigung von McoEeTI.

Angegebene Mengen sind auf 11 Zellkultur (entspricht etwa 19 g Nassgewicht der Zellen) bezogen.

${ }^{a}$ Protein Konzentration mittels Bradford gemessen (3.4.2.).

${ }^{\mathrm{b}}$ Trockengewicht des Proteins.

${ }^{\mathrm{c}}$ Menge durch Geltitration bestimmt.

Die Gesamtausbeute der vier produzierten Barnase'-Fusionsproteine am Ende der Reinigungsprozedur wurde durch Auswiegen des lyophilisierten gereinigten Proteins bestimmt (Tabelle 4.1.3.). Sie lag im Durchschnitt bei $22 \mathrm{mg}$ Protein pro 1 Zellkultur.

\begin{tabular}{|c|c|c|c|}
\hline $\begin{array}{c}\text { Fusionierte } \\
\text { Mikroprotein- } \\
\text { Variante }\end{array}$ & Peptid Sequenz & $\begin{array}{c}\text { Ausbeute } \\
\text { Barnase }^{\prime}- \\
\text { Fusion }^{\mathbf{a}} \text { [mg] }\end{array}$ & $\begin{array}{c}\mathbf{K}_{\mathbf{i}} \text { vs. Trypsin } \\
\text { [M] }\end{array}$ \\
\hline EETI-II M7I & GCPRILIRCKQDSDCLAGCVCGPNGFCGS & 12 & n.b. \\
\hline EETI-II & GCPRILMRCKQDSDCLAGCVCGPNGFCGS & 6,7 & $9.0+-4.2 \times 10^{-9}$ \\
\hline McoEeTI & GVCPKILKKCRRDSDCLAGCVCGPNGFCGS & 63 & $7.1+-0.9 \times 10^{-8}$ \\
\hline ThromMcoEeTI & GSVCPKILKKCRRDSDCLAGCVCGPNGFCGS & 7,4 & n.b. \\
\hline
\end{tabular}

Tabelle 4.1.3.: Liste der als Barnase'-Fusion produzierten Mikroprotein Varianten.

${ }^{a}$ Menge bezogen auf 11 E. coli Kultur, bestimmt nach 3.4.2.

${ }^{\mathrm{b}}$ Bestimmt nach 3.4.10.

n.b. Nicht bestimmt.

\subsubsection{Bestimmung der inhibitorischen Aktivität gegenüber Trypsin}

Ein entscheidendes Element des vorgestellten Expressionssystems ist die Sekretion des gebildeten Barnase'-Fusionsproteins in den periplasmatischen Raum der E.coli Zelle, wo das Mikroprotein im oxidativen Milieu seine native Form ausbilden kann. Die produzierten Mikroprotein Varianten sind Trypsin Inhibitoren. Durch Messung der inhibitorischen Aktivität gegenüber Trypsin lässt sich daher ein sensitiver Nachweis der korrekten Faltung der Fusionsproteine führen, da die Ausbildung der drei Disulfidbrücken Voraussetzung für die Bindung von Trypsin ist [Wentzel et al., 1999]. Dazu wurde die verbleibende Aktivität von Trypsin gegenüber dem chromogenen Substrat Boc-Leu-Gly-Arg-pNA nach Inkubation mit Barnase'-McoEeTI bzw. Barnase'-XA-EETI-II wie in 3.4.10. beschrieben gemessen. Die 
durch nicht-lineare Regression erhaltenen $\mathrm{K}_{\mathrm{i}}$ Werte (Tabelle 4.1.3.) liegen wie erwartet im nanomolaren und damit im publizierten Bereich [Wentzel et al., 1999].

\subsubsection{Abspaltung des Trägerproteins und Isolierung der Mikroproteine}

Durch den Nachweis der inhibitorischen Aktivität konnte gezeigt werden, dass die produzierten Cystin-Knoten Proteine in funktioneller Form als Barnase'-Fusion isoliert werden konnten. Für bestimmte Assays und nachfolgende Anwendungen ist jedoch eine Abspaltung des Trägerproteins nötig. Zu diesem Zweck wurde am Übergang zwischen Barnase' und dem entsprechenden Mikroprotein ein singuläres Methionin bzw., falls das zu reinigende Mikroprotein ein internes Methionin besitzt, eine Protease Schnittstelle (Thrombin in pBar100-Throm bzw. Faktor XA in pBar100-XA Plasmiden) eingeführt.

Bromcyan spaltet die Peptidkette selektiv am C-terminalen Ende von Methioninresten unter Ausbildung eines Homoserinlaktons (3.4.9.1.). Abbildung 4.1.4. B zeigt die RP-HPLC Analyse (3.4.6.5.) vor und nach Spaltung von Barnase'-EETI-II M7I mit Bromcyan. Das Mikroprotein eluiert bei etwa 25-30 \% Acetonitril und kann daher leicht von der Barnase' abgetrennt werden. Die kalkulierte Masse von EETI-II M7I von 2967,35 Dalton konnte durch massenspektrometrische Analyse in der Abteilung Massenspektrometrie der Organischen Chemie in Göttingen bestätigt werden. Hierbei wird die zu analysierende Substanz im hohen Vakuum ionisiert und durch ein starkes Magnetfeld beschleunigt. Dabei trennen sich die Ionen nach ihrem Masse/Ladungsverhältnis (m/z). Das Verhältnis ist gleich der molekularen Masse des Ions. Bei der hier verwendeten Elektronensprayionisierung (ESI-MS, electron spray ionisation) werden die Analyten in Lösung durch eine geladene Nadel mit hohem elektrischem Potential gesprüht, sodass die Lösung in einem feinen Nebel geladener Mikrotröpfchen zerfällt. Das Lösungsmittel verdampft dabei sehr schnell und die resultierenden geladenen Ionen werden dabei in die Gasphase überführt. Die Ionen sind dabei ggf. mit einem oder mehreren Ionen aus dem Lösungsmittel beladen, welches zum Auftreten von, für die ESI-Massenspektrometrie typischen, Quasi-Molekülen wie zum Beispiel $\mathrm{M}+\mathrm{H}^{+}$, $\mathrm{M}+\mathrm{Na}^{+}, 2 \mathrm{M}+\mathrm{H}^{+}, 2 \mathrm{M}+\mathrm{Na}^{+}$oder $\mathrm{M}+\mathrm{H}_{2} \mathrm{O}$ führt. Die Moleküle erhalten ebenfalls durch Protonen, die während des Sprühens durch die Nadel hinzugeführt werden, zusätzliche Ladung.

Neben dem Haupt-Peak waren in der RP-HPLC Analyse jedoch kleinere Nebenprodukte zu erkennen. Diese repräsentieren vermutlich falsch Disulfidbrücken-verknüpfte bzw. teilweise reduzierte EETI-II M7I Moleküle. Diese z.T. reduzierten Spezies können im erhöhten Maße entstehen, wenn die Bromcyan Spaltung in $70 \%$ Ameisensäure durchgeführt wird [Villa et 
al., 1989]. Aus diesem Grund wurde im Laufe der Arbeit zu $6 \mathrm{M}$ Guanidiniumhydrochlorid/0,2 M HCl bzw. $0.2 \mathrm{M}$ HCl/8 M Harnstoff als Lösungsmittel übergegangen.
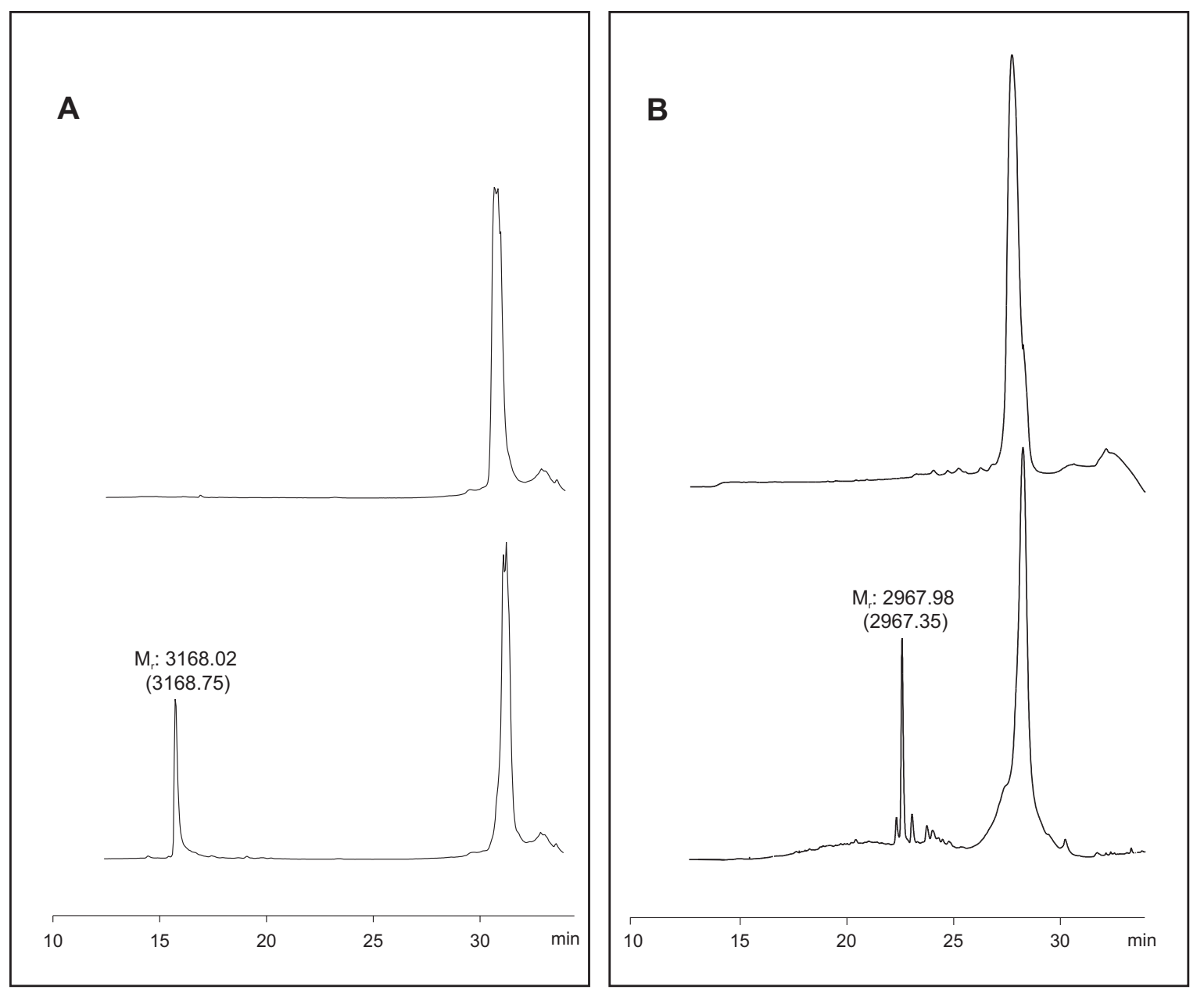

Abbildung 4.1.4.: RP-HPLC Analyse von Barnase'-ThromMcoEeTI (A) bzw. Barnase'-EETI-II M7I (B) Fusionen vor (oberer Graph) und nach (unterer Graph) Spaltung mit Thrombin bzw. Bromcyan. Die durch ESIMS ermittelte molekulare Masse des jeweiligen Mikroproteins ist über dem jeweiligen Peak angegeben, die kalkulierte molekulare Masse steht in Klammern.

Als adäquate Alternative zur chemischen Spaltung der Fusionsproteine mit Bromcyan hat sich lediglich die Spaltung mit Thrombin herausgestellt. Während die Spaltung von Barnase'-XAEETI-II mit Faktor XA Protease (3.4.9.3.) selbst nach 48 h nur zu etwa $10 \%$ erfolgt war (Abbildung 4.1.3. B, Spur 6, Seite 56), wurde Barnase'-ThromMcoEeTI bereits mit 1 Einheit Thrombin pro mg Fusionsprotein (3.4.9.2.) ü.N. bei $37^{\circ} \mathrm{C}$ zu etwa $90 \%$ gespalten (Abbildung 4.1.3. A, Spur 4, Seite 56). Die Analyse in der HPLC (Abbildung 4.1.4. A) zeigt zudem keine Nebenprodukte, was auf eine spezifische Spaltung hinweist. Um die Ausbeute der Thrombin Spaltung näher zu untersuchen, wurden $8 \mathrm{mg}$ Barnase'-ThromMcoEeTI mit Thrombin gespalten, das Mikroprotein über RP-HPLC (3.4.6.5.) abgetrennt und dessen Masse nach Lyophilisieren durch Auswiegen bestimmt. Es wurden 0,9 mg Mikroprotein erhalten, was, bei 
einem kalkulierten Anteil von 1/5 der Masse des Fusionsproteins, etwa $56 \%$ der theoretisch zu erwartenden Menge entspricht.

\subsubsection{Pichia Pastoris Barnase'-Fusionsprotein-System}

Die methylotrophe Hefe Pichia pastoris ist in den letzten Jahren zu einem potenten Expressionssystem für die Produktion rekombinanter Proteine entwickelt worden [Cregg et al., 2000, Hollenberg und Gellissen, 1997, Sreekrishna et al., 1988]. Inzwischen sind weit über 200 verschiedene heterologe Proteine erfolgreich in Pichia pastoris hergestellt worden [Cregg et al., 2000]. Darunter befinden sich eine Reihe bakterieller, viraler, pflanzlicher und vor allem auch humaner Proteine.

Pichia pastoris ist als einzelliger Mikroorganismus genetisch durch etablierte Techniken, die sich in der Regel vom Modellorganismus Sacharomyces cerevisiae übertragen lassen, einfach zu manipulieren und zu kultivieren. Im Gegensatz zu vielen eukaryontischen Systemen kann die Hefe in einfachen, definierten Nährmedien zu hohen Zelldichten fermentiert werden, so dass auch eine Fermentation im industriellen Maßstab möglich ist. Zudem bietet Pichia pastoris die typischen Vorteile eukaryontischer Systeme bei der Protein-prozessierung und faltung und der postranslationalen Modifikation. Auch die Expression Disulfidbrücken haltiger Proteine in korrekt gefalteter Form ist möglich [White et al., 1994], was Pichia pastoris zu einer interessanten Alternative für die Produktion von Mikroproteinen macht.

Für hohe Ausbeuten sorgt in der Regel die Verwendung des starken und Methanolinduzierbaren AOX1 Promoters der primären Alkohol Oxidase (AOX). Da in Pichia pastoris bislang keine replizierenden Plasmide bekannt sind, werden die heterologen Expressionskassetten nach Transformation durch homologe Rekombination in das Genom integriert, was zu einer hohen Stabilität auch unter Expressionsbedingungen führt. Dabei wird in der Regel gezielt entweder der gesamte rekombinante Expressionsvektor oder eine Expressionskassette in das Histidenol-Dehydrogenase-Gen (HIS4) oder das AOX1-Gen inseriert. Zur Selektion rekombinanter Klone nutzt man z.B. die Konvertierung von HISauxotrophen Stämmen zur Prototrophie durch einen HIS4 Marker auf dem Expressionsvektor. Pichia pastoris kann sowohl zur intrazellulären Produktion als auch zur Sekretion durch Verwendung bestimmter Sekretionssignale wie z.B. das Präpropeptid des Pheromons $\alpha 1$ aus S. cerevisiae benutzt werden.

In den folgenden Abschnitten wird die Etablierung des Pichia pastoris Systems als Alternative zum E. coli System für die Produktion von Cystin-Knoten Mikroproteinen als Barnase'-Fusionen vorgestellt. 


\subsubsection{Klonierung von Barnase'-EETI-II M7I}

Für die Expression in Pichia pastoris sind eine Reihe verschiedener käuflich zu erwerbender Expressionsvektoren entwickelt worden. In dieser Arbeit wurde der Vektor pPIC9K (Invitrogen) benutzt (Abbildung 4.1.5.). Er besitzt einen E. coli Repliktionsursprung und ein Ampizillin Resistenz Gen für die Vermehrung in E. coli, die genetischen Elemente für die homologe Rekombination (AOX Fragmente) und einen HIS4 Marker für die Selektion von Pichia pastoris Transformanten. Die Expression in Pichia pastoris (Abschnitt 4.1.3.3) wird über den AOX1 Promotor kontrolliert. Zudem ist ein Kanamycin Resistenzgen vorhanden, welches der transformierten Hefe Resistenz gegenüber Geniticin (G418) vermittelt, und so für die Selektion auf mehrfach inserierte Expressionskassetten verwendet werden kann [Scorer et al., 1994] (Abschnitt 4.1.3.2.).

Es sollte zunächst nur ein Mikroprotein, nämlich EETI-II M7I in den pPIC9K Vektor kloniert werden. Dazu wurde das Barnase'-EETI-II M7I Fusionsgen aus dem Plasmid pBar100-EETIII M7I mit den Oligonukleotiden AvrIIBarnase-up und Eti-NotI-lo mittels PCR (3.3.3.) amplifiziert. Durch die PCR wurde eine Avr II Schnittstelle am 5'-Ende und eine Not I Schnittstelle am 3'-Ende des Produkts eingeführt. Das PCR Produkt wurde nach Reinigung mit diesen Enzymen geschnitten (3.3.1.) und in den mit den gleichen Enzymen geschnittenen Vektor pPIC9K durch Ligation (3.3.2.) eingebracht (Abbildung 4.1.5.). Nach Transformation von E. coli 71-18 mit dem Ligationsprodukt, konnten einzelne Kolonien in dYT-medium angezogen und nach Präparation des Plasmids (3.2.6.) durch Restriktionsverdau (3.3.1.) analysiert werden. Plasmide, die in der Restriktionsanalyse positiv waren, wurden über DNASequenzanalyse (vom Laboratorium für Genomanalyse in Göttingen durchgeführt) verifiziert. 


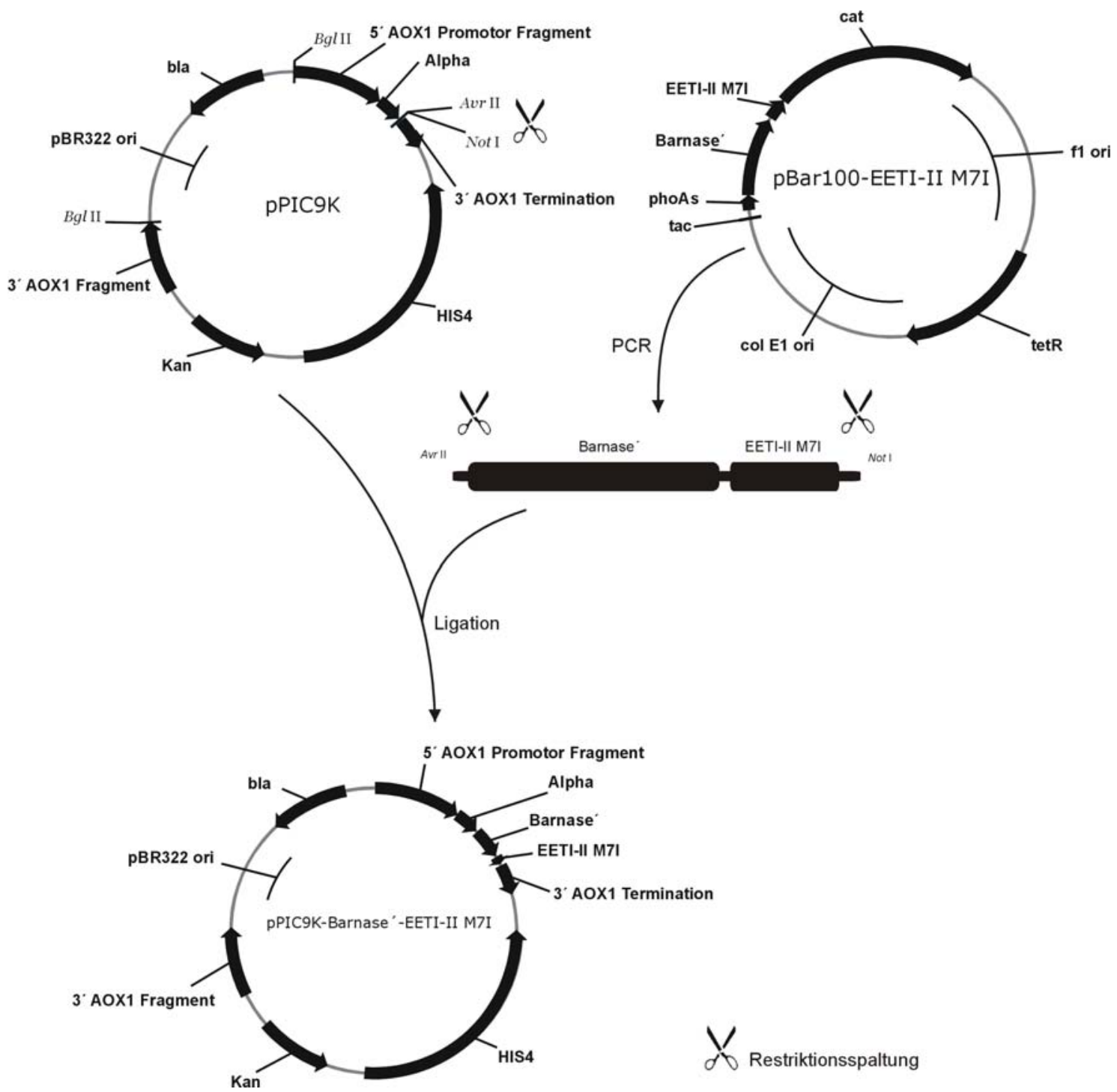

Abbildung 4.1.5.: Schematische Darstellung der Klonierung von pPIC9K-Barnase'-EETI-II M7I. Beschreibung der Klonierung im Text. Die Pfeilrichtungen geben die funktionellen Orientierungen der genetischen Elemente an. Bla, Gen für Beta-Laktamase; HIS4, Histidinol-Dehydrogenase-Gen; Kan, Kanamycin Resistenz Gen; Alpha, Gen für das Präpropeptid des Pheromons $\alpha 1$ aus S. cerevisiae; AOX1, Alkohol-Oxidase 1 Gen; pBR322 ori: E. coli Replikationsursprung; cat, Chloramphenicol Resistenz Gen; Barnase', Gen für Barnase His ${ }^{102} \mathrm{Ala}$; EETI-II M7I, Gen für die M M I Mutante des Trypsin Inhibitor EETI-II; tac, Tac Promotor Region; tetR, Tetrazyklin Repressor Gen; f1, Replikationsursprung des Phagen f1; colE1, colE1 Replikationsursprung; phoAs, Alkalische Phosphatase periplasmatische Signal Sequenz.

\subsubsection{Transformation von Pichia pastoris und Durchmusterung nach Mehrfach-}

\section{Insertionen}

Für die Transformation von Pichia pastoris wurde der in 4.1.3.1. generierte Vektor mit Bgl II linearisiert. Dadurch entsteht eine lineare Expressionskassette, die an beiden Enden AOX1 Fragmente aufweist. Nach Transformation von Pichia pastoris GS115 mittels Elektroporation (3.1.5.) erfolgt die Integration der Expressionskassette durch homologe Rekombination in den AOX1 Lokus. Die Selektion der Transformanten erfolgt durch Konvertierung des HISauxotrophen Stammes zur Prototrophie durch einen HIS4 Marker in der Expressionskassette. Die Zellsuspension aus der Elektroporation wurde daher auf MD-Agarplatten ausgestrichen. 
Nach $48 \mathrm{~h}$ Inkubation im Brutschrank bei $30{ }^{\circ} \mathrm{C}$ hatten sich etwa 200 Transformanten gebildet.

Spontan auftretende Mehrfachinsertionen der Expressionskassette, die durch die höhere Gendosis oftmals auch zu einer höheren Proteinausbeute führen, lassen sich durch ein Kanamycin Resistenzgen auf dem Vektor, das der transformierten Zelle Resistenz gegen Geniticin (G418) vermittelt, identifizieren [Scorer et al., 1994]. Die Histidin prototrophen Transformanten wurden daher auf YPD Platten mit 0,25, 0,5 bzw. 0,6 mg/ml G418 gestempelt (3.1.6.). Von den etwa 200 gestempelten Klonen waren etwa 1/10 in der Lage auch bei der höchsten Konzentration an G418 $(0,6 \mathrm{mg} / \mathrm{ml})$ zu wachsen, während nicht transformierte $P$. pastoris GS115 Zellen auch bei der geringsten G418 Konzentration nicht gewachsen waren (Beispiel Agarplatte siehe Abbildung 4.1.6.).

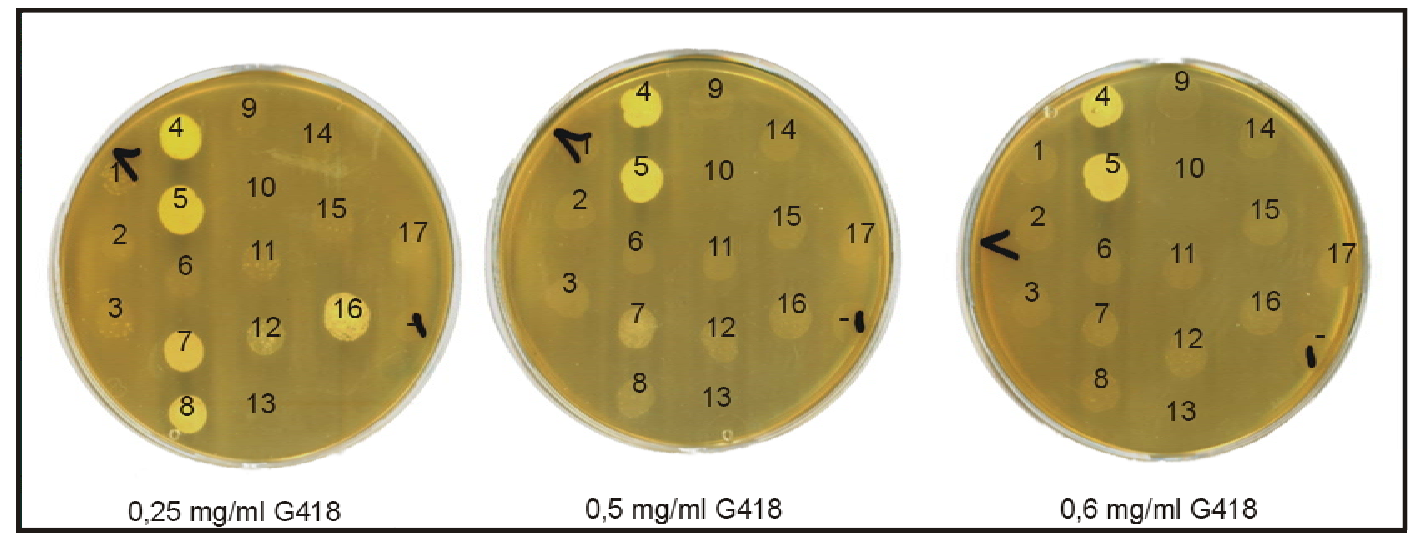

Abbildung 4.1.6.: Durchmusterung der Barnase'-EETI-II P. pastoris Transformanten nach Klonen mit Mehrfachinsertionen über die vermittelte G418 Resistenz. Die Hefe Kolonien wurden von den MD-Platten auf YPD-Platten mit 0,25, 0,5 bzw. 0,6 mg/ml G418 gestempelt (3.1.6.). Zu sehen sind die Klone 1-17 und die Negativkontrolle (-: P. pastoris GS115). Besonders die Klone 4 und 5 sind in der Lage auch bei der höchsten Konzentration an G418 Papillen auzubilden.

So waren z.B. die Klone 4 und 5 (in Abbildung 4.1.6.) noch in der Lage, bei 0,6 mg/ml G418 in den Platten, Papillen auszubilden.

Ob diese durch die Mehrfachinsertionen erhöhte Gendosis jedoch tatsächlich auch zu einer höheren Produktion des Barnase'-EETI-II M7I Fusionsproteins führte, wurde im Folgenden durch eine Expressionsanalyse untersucht.

\subsubsection{Expressionsanalyse}

Die Expression des Fusionsgens über die pPIC9K Kassette wird über den enthaltenen starken AOX1 Promotor der primären Alkohol-Oxidase kontrolliert. Da das rekombinante pPIC9KBarnase'-EETI-II M7I Plasmid vor der Transformation von P. pastoris mit Bgl II linearisert wurde, wird durch Bildung einer Kassette mit zwei AOX1 Fragmenten am 3'- und 5'-Ende eine Insertion im AOX1 Lokus und damit ein Ausschalten des AOX1 Gens favorisiert. 
Aufgrund der Verwendung des Stamms GS115, der neben AOX1 die weniger stark exprimierte AOX2 besitzt, sollte trotzdem der sogenannte $\mathrm{Mut}^{+}$Phänotyp favorisiert sein, bei dem im Gegensatz zum sogenannten Mut ${ }^{\mathrm{S}}$ Phänotyp ein Wachstum mit Methanol als einziger C-Quelle möglich ist. Der verwendete AOX1 Promotor ist katabolitreprimiert, d.h. zusätzlich zur Induktion mit Methanol ist die Abwesenheit weiterer C-Quellen notwendig.

Zur Analyse wurden die Klone 1-6 zunächst im 3 ml Maßstab in Glukose-haltigem Medium für zwei Tage bei $30^{\circ} \mathrm{C}$ angezogen (3.1.8.). Um die Genexpression zu starten, wurden die Zellkulturen im Folgenden abzentrifugiert und die Zellen in Methanol-haltigem Medium aufgenommen. Während der dreitägigen Induktionszeit bei $30{ }^{\circ} \mathrm{C}$ wurde durch kräftiges Schütteln $(250 \mathrm{u} / \mathrm{min})$ und mit Löchern im Deckel des Kulturgefäßes für eine für die Expression wichtige hohe Sauerstoffzufuhr gesorgt. Zudem wurden an jedem Tag $15 \mu 1$ Methanol hinzugegeben.

Nach drei Tagen wurde die Expression von Barnase'-EETI-II M7I untersucht. Da das Protein über den sogenannten Alpha-Faktor, das Präpropeptid des Pheromons $\alpha 1$ aus S. cerevisiae, in das umgebende Medium sekretiert werden sollte, wurden $20 \mu 1$ Kulturüberstand direkt auf ein 15 \%iges SDS Polyacrylamidgel (3.4.1.) aufgetragen (Abbildung 4.1.7.).

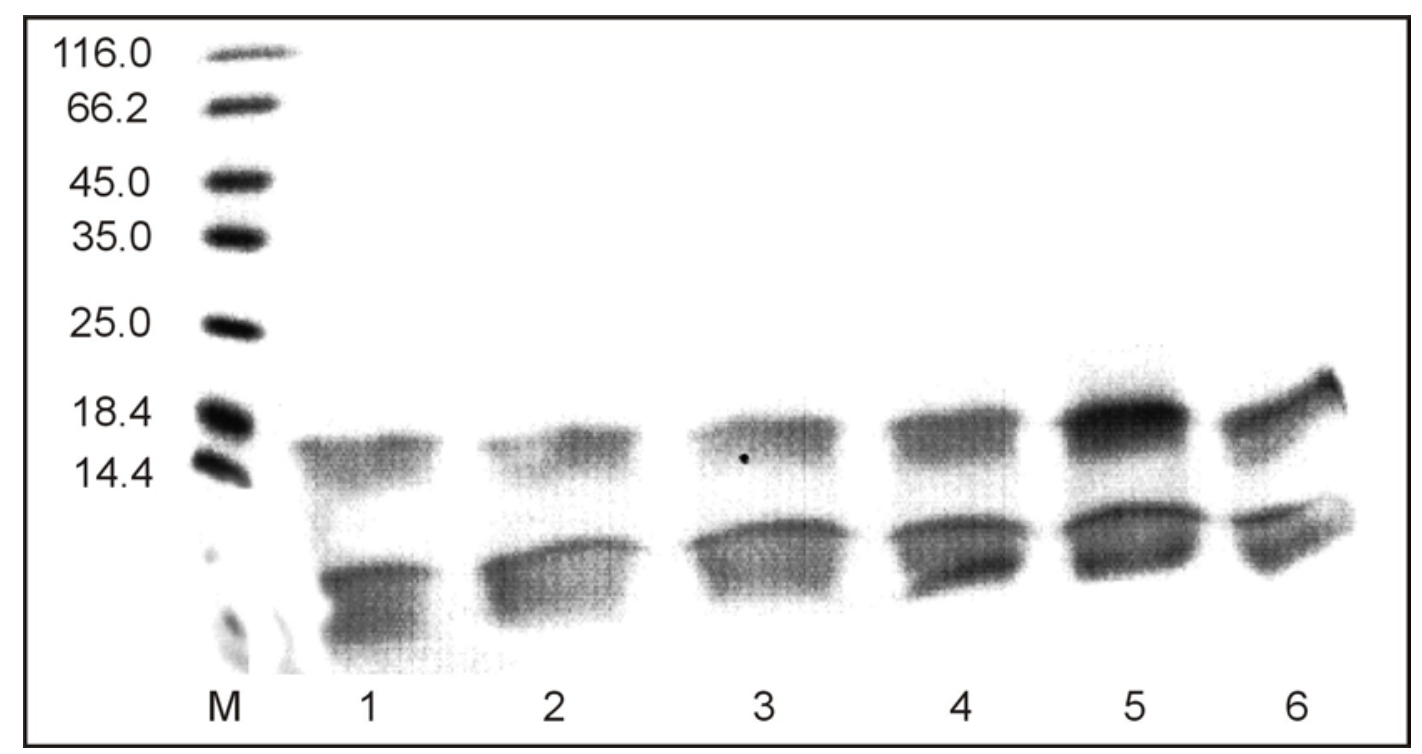

Abbildung 4.1.7.: Barnase'-EETI-II M7I Expressionsanalyse durch SDS-PAGE. M, Molekulargewichts Standard (Größenangabe links in kDa); 1-6, P. pastoris Klone 1 bis 6, $20 \mu 1$ Kulturüberstand.

Wie aus Abbildung 4.1.7. ersichtlich, haben alle sechs untersuchten P. pastoris Klone das Barnase'-EETI-II M7I Fusionsprotein produziert und in das umgebende Medium sekretiert (Größe etwa $15 \mathrm{kDa}$ ). Zudem scheint $P$. pastoris nur wenige andere Proteine zu sekretieren, da, abgesehen von Molekülen im unteren molekularen Massenbereich, kaum andere Banden auf dem Gel zu erkennen sind. Auffällig ist jedoch, dass es kaum Unterschiede in der Expression zwischen den einzelnen Klonen gibt. So scheinen z.B. die Klone 4 und 5, die sich 
als resistent gegen die höchste getestete G418 Konzentration herausgestellt haben (Abbildung 4.1.6.), kaum besser in der Expression zu sein als z. B. die Klone 1-3, die kaum resistent gegen G418 waren.

\subsubsection{Expression im größeren Maßstab}

Pichia pastoris lässt sich in einfachen, definierten Nährmedien zu hohen Zelldichten fermentieren. Die Fermentation von P. pastoris Barnase'-EETI-II M7I wurde von Dr. Joop Van den Heuvel an der GBF (Gesellschaft für biotechnologische Forschung) in Braunschweig im 51 Maßstab durchgeführt. Es konnte nach Reinigung von der Selecore $\mathrm{GmbH}$ eine Ausbeute von insgesamt $1100 \mathrm{~g}$, also $220 \mathrm{mg} / \mathrm{l}$ Fusionsprotein erreicht werden. Zudem wurden in Kooperation mit der Göttinger Selecore GmbH zwei weitere Mikroprotein Varianten, nämlich McoEeTI und eine Variante von AGRP', einem Cystin Knoten Mikroprotein, das aus einem Fragment der Melanocortin Binde-Domäne des Agouti related protein (AGRP) besteht [McNulty et al., 2001], als Barnase'-Fusionen in P. pastoris GS115 eingebracht und an der GBF fermentiert. Auch hierbei wurden Ausbeuten von etwa $200 \mathrm{mg}$ Fusionsprotein pro 1 Kultur erreicht.

\subsubsection{Barnase'-Fusionierung von Mikroproteinen als Werkzeug für die Röntgenstrukturanalyse}

Die strukturelle Charakterisierung ist ein unerlässliches Werkzeug für die Entwicklung von Wirkstoffen auf der Basis von Cystin-Knoten Mikroproteinen durch rationales Protein Design und die Optimierung gewünschter Eigenschaften. Kleine, Disulfidbrücken-reiche Proteine sind sehr schwer zu kristallisieren [Craik et al., 2001]. Daher stammen die zur Zeit in den Datenbanken erhältlichen Strukturinformationen über Cystin-Knoten Mikroproteine fast ausschließlich aus der Analyse durch NMR. NMR-Daten sind jedoch auch für kleine Proteine im Bereich von Mikroproteinen sehr schwer zu generieren und sind im Vergleich zur Röntgenstrukturanalyse ungenau (G. Sheldrick, persönliche Kommunikation).

In den vorangegangenen Abschnitten wurde die Entwicklung eines Verfahrens zur Expression und Produktion von Mikroproteinen über die Fusionierung an Barnase', einer enzymatisch inaktivierten Variante der extrazellulären RNase Barnase aus Bacillus amyloliquefaciens, vorgestellt. Barnase ist ein strukturell sehr gut untersuchtes und leicht kristallisierendes Protein, was sich in einer Zahl von mehr als 20 verschiedenen Einträgen in der Protein-DatenBank ausdrückt. 
Es wäre konzeptionell daher möglich, dass die Fusionierung der Mikroproteine an Barnase' nicht nur für deren Expression und Reinigung dienlich ist, sondern auch als Werkzeug für die Generierung von Kristallen für die Röntgenstrukturanalyse. Zudem könnte man auf diesem Wege die Lösung der Struktur durch molekularen Ersatz mit Barnase als Suchmodell vereinfachen.

Um das Konzept der Erleichterung der Kristallisation durch Fusionierung der Mikroproteine an Barnase' experimentell umzusetzen, sollte in Zusammenarbeit mit Dr. Hartmut Niemann (Abteilung Strukturbiologie an der GBF Braunschweig) McoEeTI als Barnase'Fusionsprotein kristallisiert und dessen Struktur aufgeklärt werden. McoEeTI (Abbildung 4.1.8.) ist ein Hybridprotein aus den Trypsininhibitoren EETI-II [Heitz et al., 1989, Polanowski et al., 1980] und MCoTI-II [Heitz et al., 2001, Hernandez et al., 2000], welches in dieser Arbeit als Grundgerüst für die Entwicklung von Inhibitoren der humanen $\beta$-Tryptase (Abschnitt 4.2.2.) verwendet wurde. Die Aufklärung der 3-D Struktur von McoEeTI hat also nicht nur methodischen Wert, sondern wird zudem für die Verbesserung der inhibitorischen Eigenschaften des Mikroproteins gegenüber Tryptase eingesetzt.

MCOTI-II

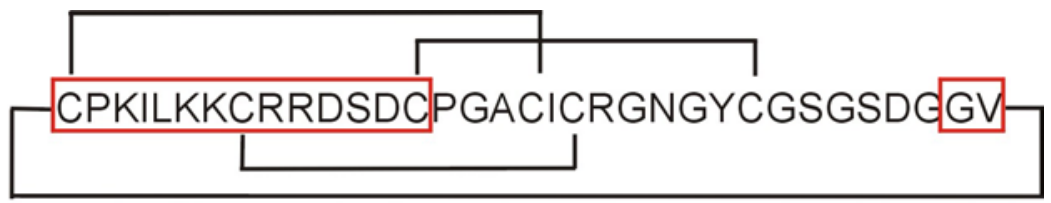

EETI-II

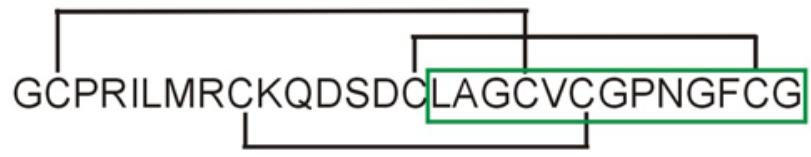

McoEeTI

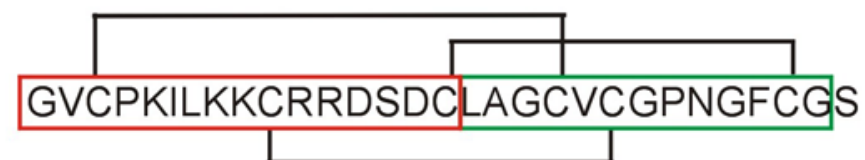

Abbildung 4.1.8.: Aminosäuresequenz und Disulfidverknüpfung des Cyklotids MCoTI-II, EETI-II und des Hybridproteins McoEeTI, das aus den 16 N-terminalen Resten von MCoTI-II (rot) und den 13 C-terminalen Aminosäuren von EETI-II (grün) zusammengesetzt ist.

\subsubsection{Klonierung, Expression und Reinigung von Barnase'-McoEeTI}

Barnase'-McoEeTI sollte über das in Abschnitt 4.1.2. beschriebene E. coli System produziert und gereinigt werden. Die Klonierung des Vektors pBar100-McoEeTI wurde in Schmoldt et al. [Schmoldt et al., 2005] beschrieben und wird daher hier nicht näher erläutert.

Auf die Produktion und Reinigung von McoEeTI als Barnase' Fusion wurde bereits in Abschnitt 4.1.2.2. eingegangen, soll aber im Folgenden noch einmal näher dargestellt werden. Nach Transformation des E.coli Stammes 71-18, der bereits das Helferplasmid pRep4 
enthielt, mit dem Vektor pBar100-McoEeTI erfolgte die Fermentation bei der Selecore GmbH im 51 Maßstab (3.1.7.2.). Auch die initialen Reinigungsschritte wurden von der Selecore GmbH durchgeführt: Nach Ansäuerung der Fermentationskultur (3.4.6.1.), Zentrifugieren und Sterilfiltrieren des Überstands wurde der Kulturüberstand, 1:5 mit Wasser verdünnt, in 25 mM Na-Acetat Puffer pH 5 zunächst über eine große Kationenaustauschersäule gegeben (Tropfsäule aus Glas mit SP-SEpharose XL) und das Fusionsprotein mit $\mathrm{NaCl}$ eluiert. Das Eluat wurde dann über eine zweite Säule, gefüllt mit Amberchrom CG-300 M reversed phase Material, gegeben und das Fusionsprotein mit einem Acetonitril Gradienten eluiert. Barnase'McoEeTI enthaltene Fraktionen wurden nach SDS-PAGE Analyse vereinigt.

Nach diesen initialen Reinigungsschritten war das Protein jedoch für Kristallisationszwecke nicht rein genug. Insbesondere war ein Anteil dimerer und trimerer Fusionsproteine enthalten. Die Fraktionen aus der RP Reinigung wurden nach Verunreinigungsgrad in zwei Aliquots (Fraktion A: wenig Di- und Trimer; Fraktion B: relativ viel Di- und Trimer) geteilt und zunächst separat lyophilisiert, um das Acetonitril zu entfernen. Das lyophilisierte Protein wurde dann in 0,1 M Tris- $\mathrm{HCl}$ Puffer $\mathrm{pH}$ 7,8 mit $8 \mathrm{M}$ Harnstoff gelöst, über Nacht gegen $50 \mathrm{mM}$ Ammoniumacetat dialysiert (3.4.4.) und an der Vision Biocad ${ }^{\mathbb{R}}$ workstation erneut präparativ über Kationenaustauschchromatographie (3.4.6.3.) gereinigt (Abbildung 4.1.9.). Die Elution erfolgte, um die di- und trimeren Spezies abzutrennen, mit einem sehr flachen $\mathrm{NaCl}$ Gradienten von $0-750 \mathrm{mM} \mathrm{NaCl}$ in 40 Säulenvolumen.

A

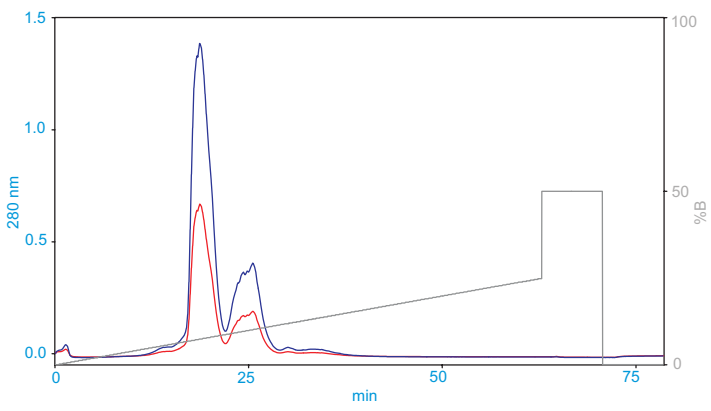

B

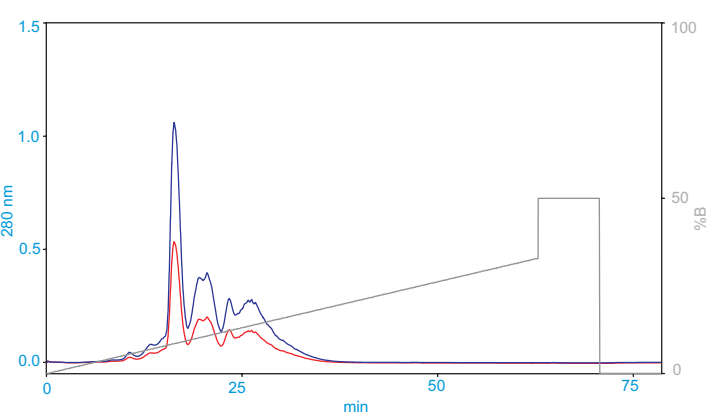

C

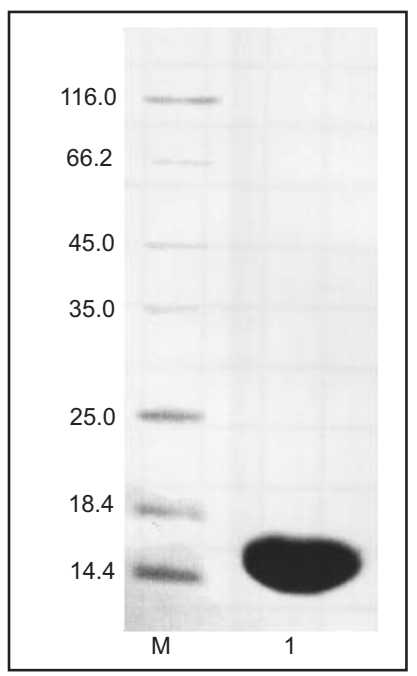

Abbildung 4.1.9.: Reinigung von Barnase'-McoEeTI über Kationenaustauschchromatographie. (A) Chromatogramm der Reinigung von Fraktion A, enthielt wenig Di- und Trimere; (B) Chromatogramm der 
Reinigung Fraktion B, enthielt mehr Di- und Trimere. In blau dargestellt ist der Verlauf der $\mathrm{OD}_{280}$, in rot der $\mathrm{OD}_{260}$ über die Zeit in min. In grau: $\mathrm{NaCl}$ Gradient in \% einer $3 \mathrm{M}$ Stammlösung. (C) Analyse des gereinigten Barnase'-McoEeTI Fusionsproteins auf einem $15 \%$ igem SDS-Polyacrylamidgel. M, Molekulargewichts Standard (Größenangabe links in kDa); 1, Barnase'-McoEeTI Fusionsprotein nach Dialyse gegen gegen $25 \mathrm{mM}$ Tris- $\mathrm{HCl} \mathrm{pH}$ 8,0, $10 \mathrm{mM} \mathrm{NaCl}$.

Man erkennt in Abbildung 4.1.9. (A, B) jeweils einen Hauptpeak bei etwa 20 min, der dem monomeren Barnase'-McoEeTI Fusionsprotein entspricht, und einem (A) bzw. zwei (B) Nebenpeaks, den trimeren bzw. dimeren Spezies. Die einzelnen Fraktionen wurden mittels SDS-PAGE (3.4.1.) analysiert. Die Fraktionen, die das Fusionsprotein in der gewünschten Reinheit enthielten, wurden vereinigt und gegen $25 \mathrm{mM}$ Tris- $\mathrm{HCl} \mathrm{pH} 8,0,10 \mathrm{mM} \mathrm{NaCl}$ dialysiert. Abbildung 4.1.9. C zeigt das saubere Endprodukt der Reinigung auf einem $15 \%$ igen SDS-Polyacrylamidgel. Die Konzentration des gereinigten Proteins wurde photometrisch bestimmt (3.4.2.). Es ergab sich eine Gesamtmenge von ca. $50 \mathrm{mg}$ Fusionsprotein, das für die Kristallisation an der GBF eingesetzt wurde.

\subsubsection{Kristallisation und Röntgenstrukturanalyse von Barnase'-McoEeTI}

Die Kristallisation und Röngenstrukturanalyse von Barnase'-McoEeTI wurde von Dr. Hartmut Niemann durchgeführt. Das Testen verschiedener Kristallisationsbedingungen führte zum Wachstum kleiner Kristalle unter verschiedenen Konditionen. Nach Optimierung konnten geeignete Kristalle mit der sitting drop vapour diffusion Methode bei $4{ }^{\circ} \mathrm{C}$ mit $1,3 \mathrm{M}$ Ammoniumsulfat, 7 \% PEG 400 (v/v), 0,1 M MES pH 6,5 als Reservoir Puffer erhalten werden. Dabei wurden die Tropfen aus $4 \mu \mathrm{l}$ Reservoir Puffer und $8 \mu 1$ Proteinlösung (30 mg/ml) zusammengemischt. Die für die Datenaufnahme benutzten Kristalle wuchsen über einige Wochen zu einer Größe von ca. 500 x 500 x $35 \mu \mathrm{m}$ heran (Abbildung 4.1.10.).

Die Aufnahme des Datensatzes der optimierten Kristalle wurde von H. Niemann an der DESY beamline BW6 bei $100 \mathrm{~K}$ und einer Wellenlänge von 1,050 Á durchgeführt. Es konnte dabei eine Auflösung von 1,3 ̊́ erreicht werden. Die Statistiken sind in Niemann et al. (Manuskript in Vorbereitung) nachzulesen.

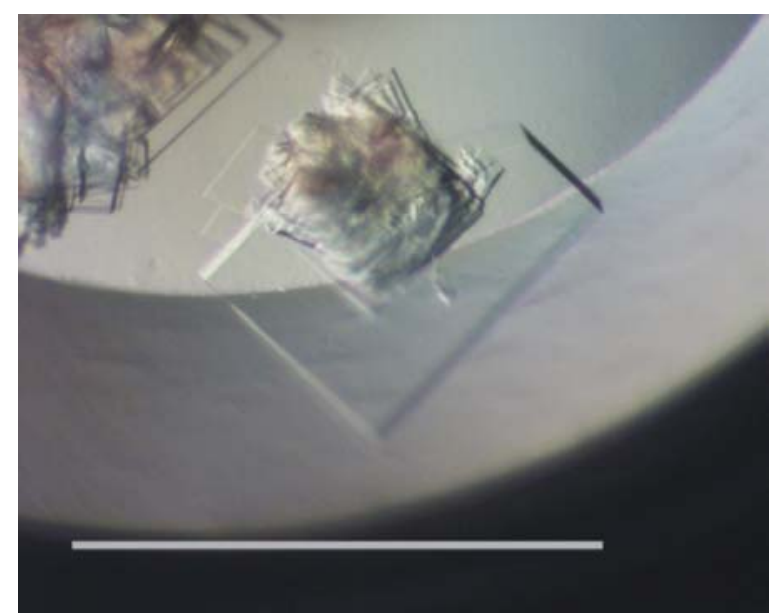

Abbildung 4.1.10.: Photographie der für die Datensatzaufnahme verwendeten Barnase'-McoEeTI Kristalle (Quelle: H. Niemann). Der graue Strich entspricht etwa $1 \mathrm{~mm}$. 
Die Struktur des Barnase'-McoEeTI Fusionsproteins konnte durch molekularen Ersatz mit einem Monomer von Barnase w.t. [Mauguen et al., 1982] als Suchmodell gelöst werden. In der asymetrischen Einheit befinden sich zwei unabhängige Moleküle des Fusionsproteins (Abbildung 4.1.11.).

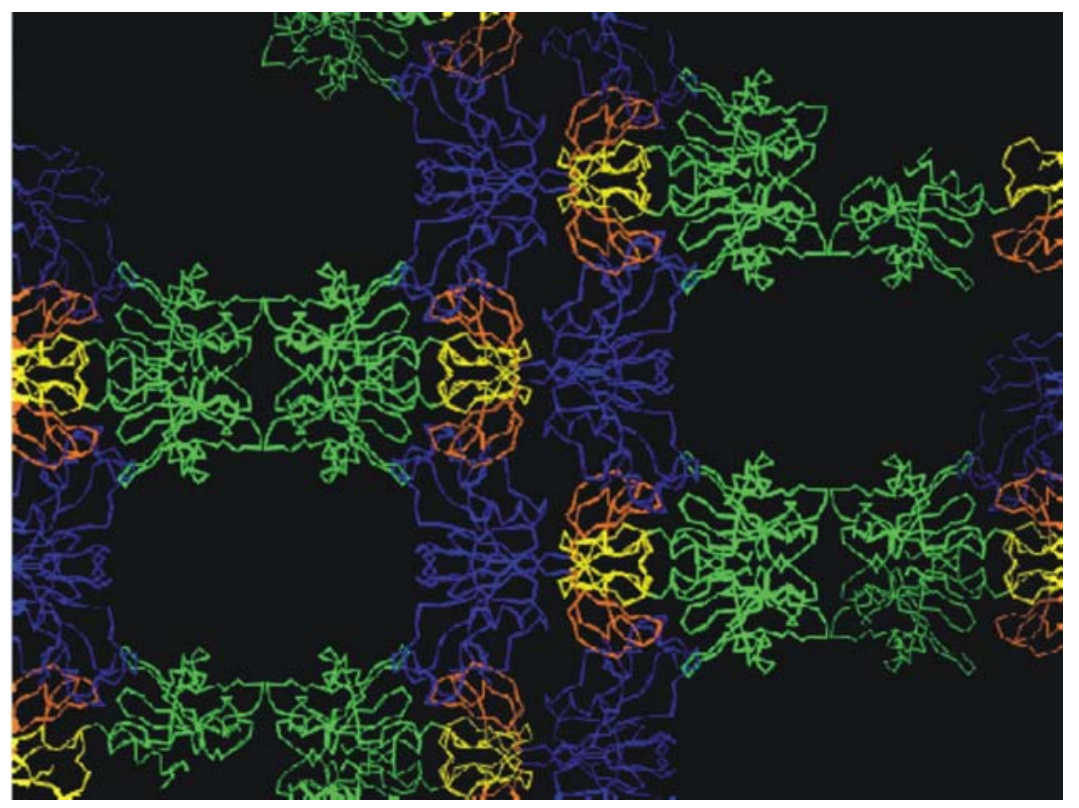

Abbildung 4.1.11.: Schematische Darstellung der Kristallpackung von Barnase'-McoEeTI (Quelle: H. Niemann). Barnase' und McoEeTI des ersten Moleküls in der asymetrischen Einheit sind in blau und orange, Barnase' und McoEeTI des zweiten Moleküls in grün und gelb dargestellt.

Die zwei unabhängigen Moleküle des Fusionsproteins kommen im Wesentlichen durch eine unterschiedliche Orientierung der Fusionspartner durch Drehung um den linker SSSM zustande, der Barnase' und McoEeTI verbindet (Abbildung 4.1.12. A).

Die Struktur von McoEeTI (Abbildung 4.1.12. B) zeigt das erwartete Cystin-Knoten Motiv, bei dem das erste Cystein mit dem vierten, das zweite mit dem fünften und das dritte mit dem sechsten Cystein verknüpft ist. Es gibt nur zwei $\beta$-Faltblattstränge in McoEeTI, die den $\beta$ hairpin formenden Strängen zwei und drei des Inhibitor-Cystin Knoten FaltungsMotivs [Chiche et al., 2004, Pallaghy et al., 1994] entsprechen, wobei die Strang eins bildende Region in McoEeTI von dem verwendeten Programm formal nicht als $\beta$-Strang erkannt wird. Der loop zwischen Cystin II und III beinhaltet eine kurze $3_{10}$ Helix.

Im Vergleich zu den NMR Strukturen von MCoTI-II [Felizmenio-Quimio et al., 2001, Heitz et al., 2001] fehlt McoEeTI der flexible SGSDG loop, der in dem zyklischen Protein N- und C-Terminus verknüpft. Zusätzlich sind einige kleinere Unterschiede zu erkennen (Niemann et al., Manuskript in Vorbereitung). Lysin 119 (Lys 10 in MCoTI-II) ist nach Analogie mit Strukturen von Cystin-Knoten Trypsin Inhibitoren im Komplex mit Trypsin [Bode et al., 1989, Helland et al., 1999] der P1 Rest, der in das aktive Zentrum der Protease inseriert wird. 
Vergleicht man die Lysin Seitenkette mit den P1 Resten solcher Kristallstrukturen, die im Komplex mit Trypsin generiert wurden (z.B. [Bode et al., 1989]), so erkennt man, dass die Stellung der Kette deutlich verschieden ist, d.h. die genaue Positionierung erfolgt offensichtlich erst nach Kontakt mit der Ziel-Protease.

A
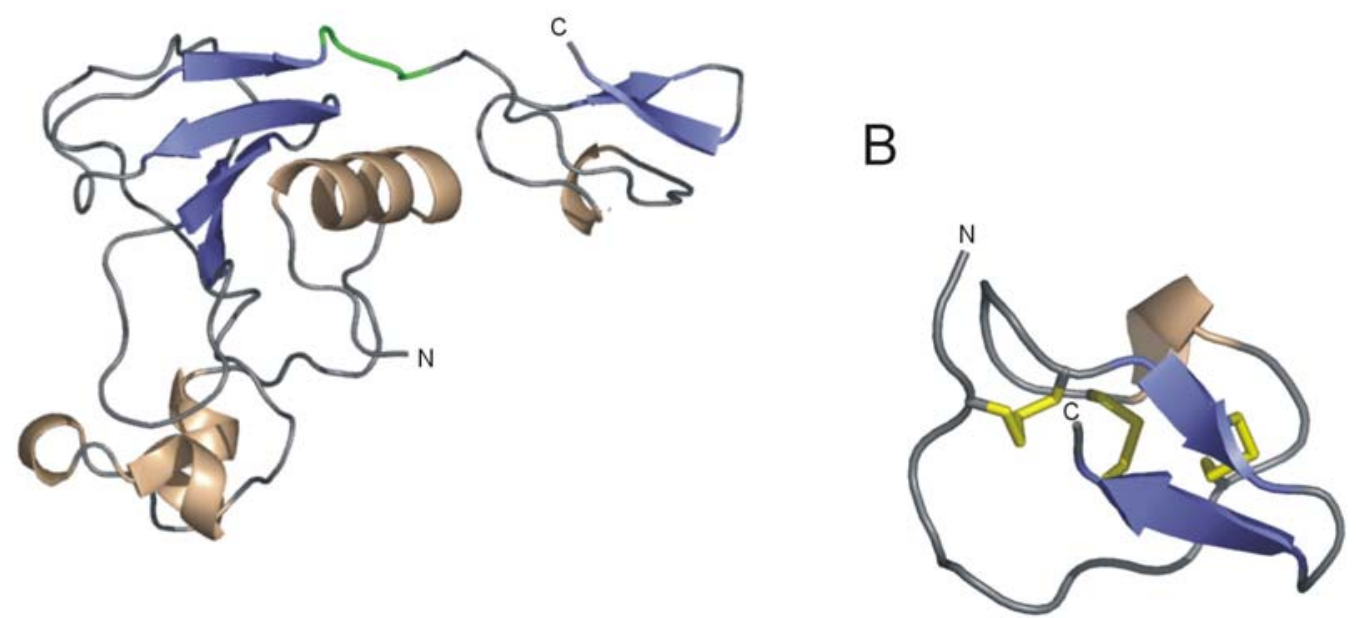

Abbildung 4.1.12.: Darstellung des Barnase'-McoEeTI Fusionsproteins (A) und von McoEeTI (B). Die linker Sequenz (SSSM) ist in grün, $\beta$-Stränge in beige und $\alpha$-helikale Bereiche in blau dargestellt. Der Bereich des fusionierten McoEeTI Mikroproteins beginnt C-terminal nach dem linker. Disulfidbrücken sind in gelb dargestellt. Die Abbildung wurde mit dem Programm PyMOL (http://www.pymol.org) erstellt.

\subsubsection{Diskussion und Ausblick}

In den vorangegangenen Abschnitten wurde ein neuartiges Expressionssystem für die Produktion und Reinigung von Cystin-Knoten Mikroproteinen in Escherichia coli [Schmoldt et al., 2005] bzw. in Pichia pastoris vorgestellt. Das Verfahren sieht die Expression der Mikroproteine als Fusion mit einer enzymatisch inaktivierten Variante (Barnase') der extrazellulären RNase Barnase aus Bacillus amyloliquefaciens und die Reinigung des löslichen Fusionsproteins aus dem Kulturüberstand von E. coli bzw. P. pastoris vor. Im Gegensatz zur chemischen Synthese von Mikroproteinen [Avrutina et al., 2004, Daly et al., 1999, Le-Nguyen et al., 1989] und der rekombinanten Synthese, bei der das Protein aus inclusion bodies aufgearbeitet wird [Bolewska et al., 1995, Kojima et al., 1996, Wentzel et al., 1999], können die Mikroproteine im vorgestellten System als Barnase'-Fusion in korrekt gefalteter Form isoliert werden. Damit wird die oft schwierige Rückfaltung der Varianten in die native Konformation überflüssig. Der Nachweis für die korrekte Faltung konnte durch Bestimmung der inhibitorischen Aktivität zweier produzierter Trypsin Inhibitor Varianten erbracht werden (4.1.2.3.). Damit konnte zudem gezeigt werden, dass die Fusionierung an Barnase' nicht zu einer Aufhebung der biologischen Funktion, z.B. durch sterische Effekte, 
der Varianten führt, was eine Eignung für gewisse biochemische Tests als Fusionsprotein nahe legt.

Für die Produktion in E. coli 71-18 wurde der Vektor pBar100 [Schmoldt et al., 2005] ausgehend von den Plasmiden pMT416 [Hartley, 1988] und pASKInt101 [Wentzel et al., 2001] konstruiert (4.1.2.1.). Es konnten mit dem E. coli System zunächst insgesamt vier verschiedene Varianten der Trypsin Inhibitoren EETI-II [Heitz et al., 1989, Polanowski et al., 1980] und McoEeTI, einem Hybrid Protein aus EETI-II und MCoTI-II [Felizmenio-Quimio et al., 2001, Hernandez et al., 2000], produziert und gereinigt werden. Die durchschnittliche Ausbeute der gereinigten Fusionsproteine betrug $22 \mathrm{mg} / 1$ Zellkultur bzw. pro $19 \mathrm{~g}$ Nassgewicht und liegt damit unter der von Fairlie et al. [Fairlie et al., 2002] von 25-75 mg/l Zellkultur bzw. von Döbili et al. [Döbeli et al., 1998] von 400-4800 mg pro $100 \mathrm{~g}$ ZellNassgewicht, die jedoch mit ihrem jeweiligen System keine Cystin-Knoten Mikroproteine, sondern lediglich Peptide mit einer Disulfidbrücke produzieren und reinigen konnten.

Mit dem Aufbau eines alternativen Barnase'-Expressiossystems in der methylotrophen Hefe Pichia pastoris (4.1.3.) konnte die durchschnittliche Ausbeute auf etwa $200 \mathrm{mg}$ Fusionsprotein pro 1 Zellkultur und damit auf einen etwa 10-fach höheren Wert im Vergleich zur Produktion in E. coli erhöht werden. Es konnten von Joop Van den Heuvel an der GBF in Braunschweig drei verschiedene Barnase'-Mikroprotein Fusionen produziert und von der Selecore GmbH gereinigt werden. Für die Expression in P. pastoris wurde der pPIC9K Vektor von Invitrogen benutzt, der den starken AOX1 Promotor der primären Alkoholoxidase trägt. Über ein enthaltenes Tn903 kanr Gen, das den Hefen Resistenz gegen Geniticin (G418) vermittelt, können die transformierten Hefen nach multi copy Transformanten (eine erhöhte Gendosis führt oft zu einer höheren Proteinproduktion) durchmustert werden. Das Barnase'Fusionsprotein wird über das Präpropeptid des Pheromons $\alpha 1$ aus $S$. cerevisiae in das Kulturmedium sekretiert und kann von dort wie im E. coli System in korrekt gefalteter Form durch Kationenaustausch- und RP-Chromatographie isoliert werden.

In dieser Arbeit wurde damit zum ersten Mal die Produktion von Cystin-Knoten Mikroproteinen in einem eukaryontischen Expressionssystem beschrieben. Trotz der erhöhten Ausbeute an Barnase'-Fusionsprotein ist jedoch das E. coli System aufgrund der vergleichsweise hohen Generationszeit der Hefen effizienter. Demgegenüber steht als Vorteil der Produktion in Pichia die fehlende Bildung von Endotoxinen, was in Zukunft hinsichtlich der Entwicklung eines GMP (good manufacturing practice) konformen Prozesses für die 
Herstellung von Mikroproteinen für therapeutische Applikationen von Relevanz werden könnte.

Für Applikationen, bei denen das solitäre Mikroprotein benötigt wird, wurden zwei alternative Möglichkeiten für die Abspaltung des Barnase'-Trägerproteins dargelegt (4.1.2.4.). Zum einen steht die selektive chemische Spaltung des Fusionsproteins an Methioninresten mit Bromcyan [Villa et al., 1989] [Kaiser und Metzka, 1999] zur Verfügung, die seit Jahren etabliert und extrem kosteneffizient ist. Zum anderen wurde, als Alternative für die Abspaltung von Mikroproteinen mit internen Methioninen, die proteolytische Spaltung mit Thrombin bzw. mit Faktor XA Protease untersucht. Während sich Faktor XA Protease als ungeeignet für die effektive Spaltung von Barnase'-Fusionsproteinen herausstellte, erwies sich Thrombin als spezifische und effiziente Alternative zu Bromcyan. Die Trennung des Mikroproteins vom abgespalteten Trägerprotein kann mittels RP-HPLC geschehen.

In Abschnitt 4.1.4. wurde die Reinigung und die Aufklärung der Struktur von Barnase'McoEeTI beschrieben. Es sollte in Zusammenarbeit mit Hartmut Niemann von der GBF an diesem Beispiel untersucht werden, ob sich die zur Expression und Reinigung gedachte Fusionierung der Mikroproteine an Barnase' für die Erleichterung der Kristallisation von (solitär schlecht kristallisierenden) Cystin-Knoten Mikroproteinen eignet.

Die Struktur des Fusionsproteins konnte von H. Niemann in kurzer Zeit durch molekularen Ersatz mit einem Monomer von Barnase w.t. [Mauguen et al., 1982] als Suchmodell mit einer Auflösung von 1,3 $\AA$ gelöst werden. Sie stellt eine von nur wenigen Kristallstrukturen von nicht komplexierten Cystin-Knoten Mikroproteinen und die einzige als Fusion mit einem Trägerprotein dar. McoEeTI zeigt die für Cystin-Knoten Mikroproteine charakteristische Verknüpfung der sechs Cystein Reste zu drei Disulfibrücken. Die erfolgreiche Lösung der Struktur bestätigt den konzeptionellen Ansatz und legt eine generelle Eignung der Fusionierung von Barnase' für die Kristallisation von Cystin-Knoten Mikroproteinen nahe. Zudem stellt die erhaltene McoEeTI Struktur die Grundlage für die struktur-basierte Weiterentwicklung der Tryptase-inhibitorischen Eigenschaften des Moleküls dar (Kapitel 4.2.2.).

Für die Zukunft können noch einige Optimierungen des beschriebenen Expressions- und Reinigungsprozess vorgenommen werden. So könnten z.B., um die den Reinigungsprozess erschwerenden Peptide aus dem Medium zu entfernen, Minimalmedien verwendet oder das verwendete TB-Medium durch Ultrafiltration vor dem Autoklavieren vorfraktioniert werden. Des weiteren könnte die starke Bindung von Barnase an seinen natürlichen Inhibitor Barstar, 
der mit Barnase einen Komplex mit einer sehr hohen Dissoziationskonstante von ca. $10^{-14} \mathrm{M}$ ausbildet [Hartley, 2001, Schreiber und Fersht, 1996], für eine alternative Reinigungsstrategie ausgenutzt werden. Unter der Voraussetzung, dass die His ${ }^{102}$ Ala Mutation in Barnase' diese starke Bindung nicht zerstört, wäre eine affinitätschromatographische Reinigung mit immobilisiertem Barstar Protein, das wie Barnase gut in E. coli exprimiert werden kann [Hartley, 1988], denkbar. Solch eine Strategie wurde kürzlich von Deyev et al. [Deyev et al., 2003] in umgekehrter Konstellation (Barnase wurde immobilisiert) für die Reinigung von scFV Antikörperfragmenten beschrieben.

Zusammenfassend lässt sich sagen, dass mit dem in diesem Kapitel beschriebenen Barnase'Expressionssystem die Grundlagen für die Generierung rational designter Protease Inhibitoren bzw. Thrombopoietin mimetischer Mikroprotein Varianten gelegt worden sind. 


\subsection{Design von Protease Inhibitoren}

Ziel dieser Arbeit ist es, die Möglichkeit einer Neufunktionalisierung von Cystin-Knoten Mikroproteinen in einem rationalen Ansatz an zwei Beispielen zu untersuchen. In diesem Kapitel soll zunächst ein konzeptionell vergleichsweise simplerer Zugang zur gezielten funktionellen Modulation von Mikroproteinen untersucht werden, nämlich die Umwandlung der Wirkspezifität eines Protease Inhibitors hin zu einer anderen Protease. Als Grundgerüste werden die Trypsin Inhibitoren EETI-II [Favel et al., 1989, Heitz et al., 1989, Polanowski et al., 1980] und McoEeTI [Schmoldt et al., 2005] verwendet. Im ersten Abschnitt (4.2.1.) dieses Kapitels wird die Transformation von EETI-II von einem Trypsin Inhibitor in einen Inhibitor von Porcine Pankreas Elastase (PPE) beschrieben, während in Abschnitt 4.2.2. die Verwendung von McoEeTI, dessen Kristallstruktur als Barnase' Fusionsprotein gelöst werden konnte (4.1.4.), als Ausgangsmolekül zur Generierung potenter Tryptase-Inhibitoren aufgezeigt wird.

\subsubsection{Transformation eines Trypsin in einen Elastase Inhibitor}

Serinproteasen spalten die peptidische Bindung ihrer Substrate in charakteristischer Weise durch die Verwendung einer katalytischen Triade bestehend aus einem Histidin, einem Aspartat und einem Serin. Dabei übernimmt das Histidin ein Proton der Hydroxylgruppe des Serins, um dessen nukleophilen Angriff auf das Substrat zu ermöglichen, während das ebenfalls in räumlicher Nähe befindliche Aspartat die positiv geladene Form des Histidins stabilisiert. Die Proteasen Trypsin und Elastase gehören zu dieser Familie von Serinproteasen. Sie unterscheiden sich unter anderem durch ihre Substratspezifität, die im Wesentlichen von der Art der Bindungstasche bestimmt wird [Czapinska und Otlewski, 1999]. Während Trypsin Arginin oder Lysin auf der Aminoseite der zu spaltenden Peptidbindung benötigt, greifen Elastasen spezifisch an Aminosäuren mit kleineren, hydrophoben Seitenketten in der sogenannten P1 Position an.

Elastasen kommen vor allem in polymorphkernigen neutrophilen Granulozyten (PMN), Makrophagen und Endothelzellen vor. Der durch Neutrophilen bedingte Abbau von Proteoglykanen beruht hauptsächlich auf der proteolytischen Aktivität der Elastase. Ferner ist Elastase maßgeblich z.B. an der Gewebezerstörung bei Emphysemen, bei cystischer Fibrose und Rheumatoider Arthritis beteiligt. Autoantikörper (pANCA) gegen dieses Antigen sind assoziiert mit entzündlichen rheumatischen Erkrankungen wie rheumatoider Arthritis, Vaskulitis, Sjögren Syndrom und systemischem Lupus erythematodes (SLE). Elastase 
Inhibitoren könnten daher eine Anwendung als anti-immflamatorische Wirkstoffe finden [Tremblay et al., 2003].

Vertreter der Cystin-Knoten Mikroproteine zählen zu den kleinsten bekannten natürlichen Protease Inhibitoren. Vor allem aus den Samen verschiedener Pflanzen konnte eine Vielzahl verschiedener Trypsin Inhibitoren isoliert und charakterisiert werden [Favel et al., 1989, Hamato et al., 1995, Hernandez et al., 2000, Miura und Funatsu, 1995, Otlewski et al., 1984, Polanowski et al., 1980, Wieczorek et al., 1985]. Hamato et al. [Hamato et al., 1995] gelang es, neben einem Trypsin Inhibitor, drei Cystin-Knoten Mikroproteine mit inhibitorischer Aktivität gegenüber Porcine Pankreas Elastase, die neben humaner Leukozyten Elastase zu den am besten charakterisierten Elastasen gehört [Bode et al., 1989], aus den Samen von Momordica charantia zu isolieren. Diese sind zwar sequenzhomolog zu den bekannten Trypsin Inhibitoren, besitzen jedoch statt eines Arginin oder Lysin ein Leucin in der P1 Position. Der potenteste dieser drei Elastase Inhibitoren ist MCEI-III mit einer Inhibitionskonstante von $4 \times 10^{-9} \mathrm{M}$.

In diesem Abschnitt soll, um die strukturelle Plastizität von Cystin-Knoten Mikroproteinen zu untersuchen, durch Transplantation des aminoterminalen Teils von MCEI-III auf den carboxyterminalen Teil von EETI-II ein Hybrid aus beiden Molekülen generiert werden (Abbildung 4.2.1.). Dieses als McEeTI bezeichnete Hybrid sollte daher in den Vektor pBar100 kloniert, über das vorgestellte Expressionssystem als Barnase'-Fusion produziert und gereinigt und dessen inhibitorische Aktivität gegenüber PPE bestimmt werden.

MCEI-III

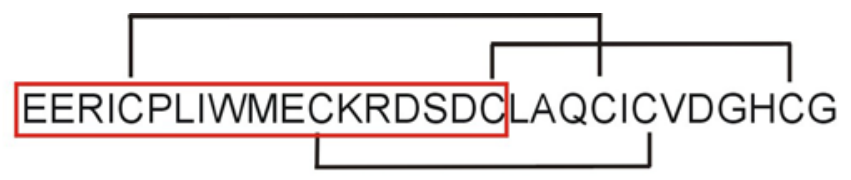

EETI-II

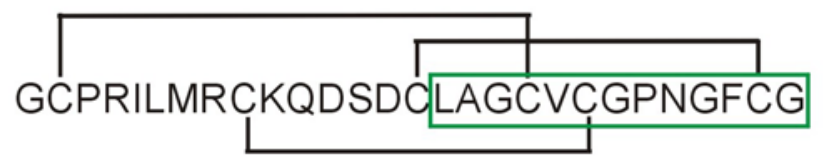

McEeTI

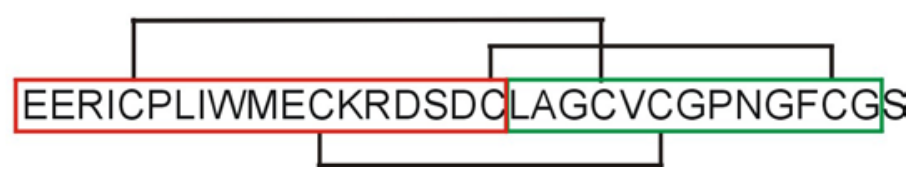

\begin{abstract}
Abbildung 4.2.1.: Aminosäuresequenz und Disulfidverknüpfung des PPE Inhibitors MCEI-III aus Momordica charantia, des Trypsin Inhibitors EETI-II aus Ecbalium elaterium und des Hybridproteins McEeTI, das aus den 18 N-terminalen Resten von MCEI-III (rot) und den 13 C-terminalen Aminosäuren von EETI-II (grün) zusammengesetzt ist. Das C-terminale Serin wird aus Klonierungsgründen eingeführt.
\end{abstract}




\subsubsection{Klonierung von pBar100-XA-McEeTI}

Für die Produktion und Reinigung von McEeTI über das in Abschnitt 4.1.2. vorgestellte $E$. coli Expressionssystem wurde McEeTI zunächst mittels PCR (3.3.3.) amplifiziert. Als Matrize diente der Vektor pBar100-XA-EETI-II. Die PCR wurde in abgewandelter Form zunächst für 10 Zyklen mit je $1 \mathrm{pMol}$ der Oligonukleotide MCETIup1 und cat-Hind-Mitte-lo und dann für weitere 20 Zyklen nach Zugabe von je 10 pMol cat-Hind-Mitte-lo und MCEIUpNco durchgeführt. Dabei wurde ein Fusionsgen aus McEeTI mit Nco I Schnittstelle am 5'-Ende und halbem Chloramphenicol Resistenzgen amplifiziert. Das PCR Produkt wurde mittels Phenol/Chloroform Extraktion (3.2.3.2.) und anschließender Ethanol Fällung (3.2.2.1.) gereinigt, mit Nco I und Hind III gespalten (3.3.1.) und mit dem gleichermaßen geschnittenen Vektor pBar100-EETI-II M7I ligiert (3.3.2.). Ein Schema der Klonierung ist in Abbildung 4.2.2. dargestellt.

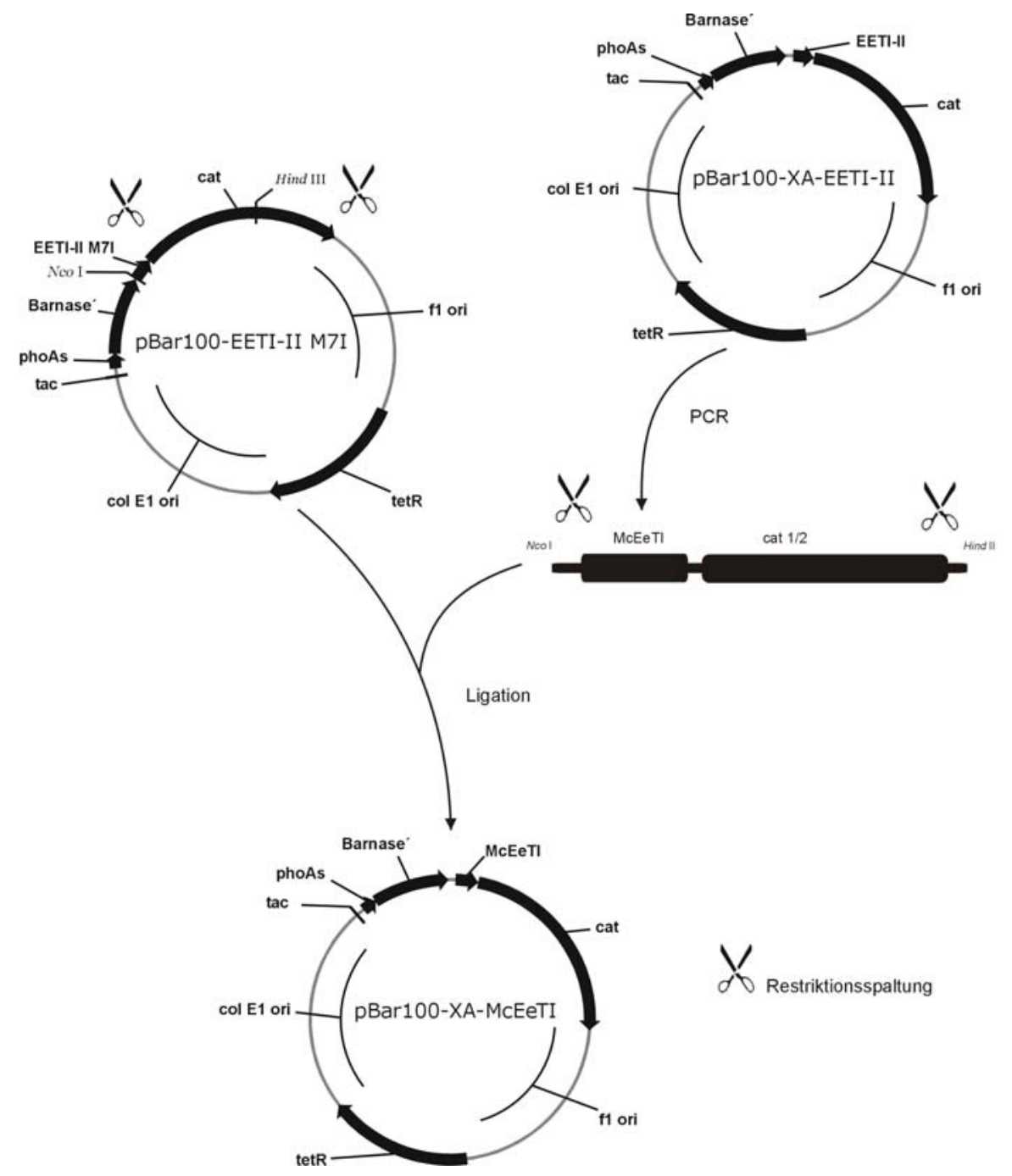

Abbildung 4.2.2.: Schematische Darstellung der Klonierung von pBar100-XA-McEeTI. Beschreibung der Klonierung im Text. Die Pfeilrichtungen geben die funktionellen Orientierungen der genetischen Elemente an. Cat, Chloramphenicol Resistenz Gen; Barnase', Gen für Barnase His ${ }^{102}$ Ala; EETI-II, Gen für den Trypsin Inhibitor EETI-II; tac, Tac Promotor Region; tetR, Tetrazyklin Repressor Gen; f1 ori, Replikationsursprung des 
Phagen f1; col E1 ori, col E1 Replikationsursprung; phoAs, Alkalische Phosphatase periplasmatische Signal Sequenz; McEeTI, Gen für das Hybrid Protein aus EETI-II und MCEI-III.

Nach Transformation von E. coli 71-18 pRep4 (3.1.5.) konnten insert-tragende Transformanten mittels Kolonie PCR (3.3.3.) mit den Oligonukleotiden cat-Hind-Mitte-lo und MCEIUPNco und anschließender Restriktionsanalyse (3.3.1.) der präparierten Plasmid DNA (3.2.6.) von in der PCR positiven Klonen ermittelt werden. Die Sequenz eines Klons konnte durch DNA-Sequenzierung im Laboratorium für Genomanalyse verifiziert werden.

\subsubsection{Produktion und Reinigung von Barnase'-McEeTI}

Die Expression von Barnase'-McEeTI erfolgte nach Transformation von E coli 71-18 pRep4 mit dem in 4.2.1.1. erstellten Plasmid pBar100-XA-McEeTI im Schüttelkolben (3.1.7.1.). Es wurden 2 x 31 Kolben mit je 11 TB Medium und den entsprechenden Antibiotika mit 25 ml frischer Übernachtkultur angeimpft. Bei einer $\mathrm{OD}_{600}$ von 0,7 wurde die Genexpression durch Zugabe von IPTG angeschaltet und die Kultur ü.N. bei $30^{\circ} \mathrm{C}$ unter Schütteln inkubiert.

Die Aufarbeitung der induzierten Kultur erfolgte wie in Kapitel 4.1.2. beschrieben nach Ansäuerung mit Essigsäure aus dem Kulturüberstand. Das Barnase'-McEeTI Fusionsprotein wurde in einem ersten Schritt über kombinierte Kationenaustausch-/RP-Chromatographie (3.4.6.2.) gereinigt. Nach SDS-PAGE Analyse (3.4.1.) wurden Fusionsprotein enthaltene Fraktionen vereinigt und lyophilisiert. Das Protein wurde dann in $0,1 \mathrm{M}$ Tris- $\mathrm{HCl} \mathrm{pH}$ 7,8 mit $8 \mathrm{M}$ Harnstoff aufgenommen, ü.N. gegen $50 \mathrm{mM}$ Ammoniumacetat dialysiert (3.4.4.) und zur vollständigen Entfernung von Verunreinigungen erneut über Kationenaustausch-

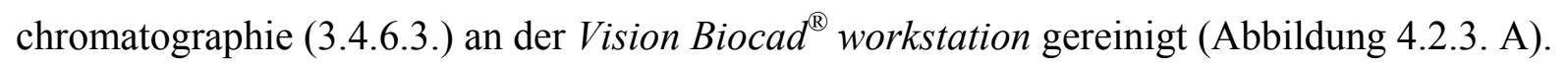

A

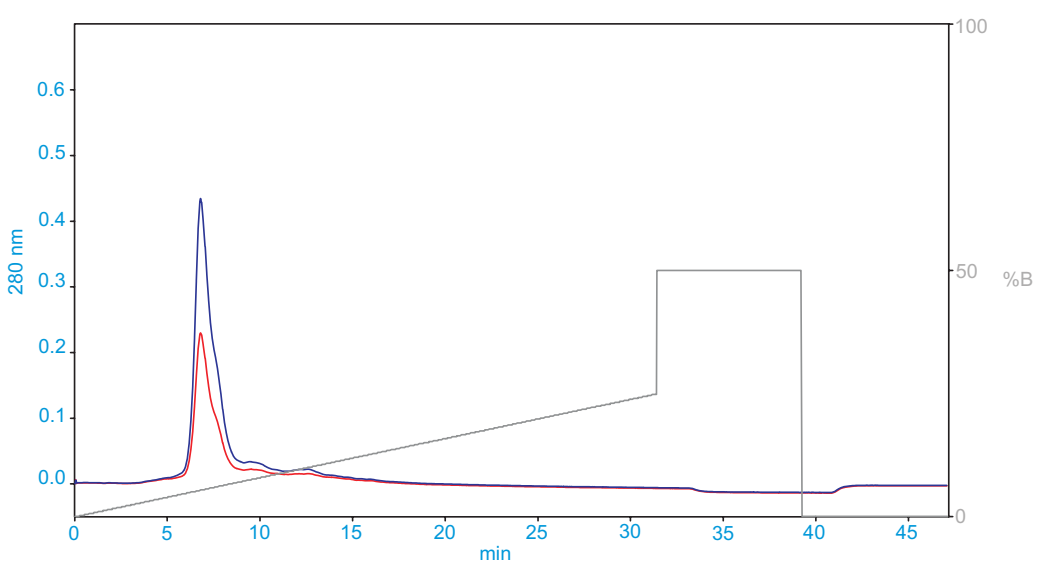

B

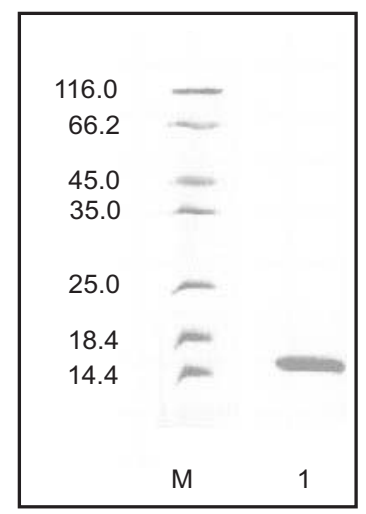

Abbildung 4.2.3.: Reinigung von Barnase'-McEeTI. (A) Chromatogramm der Kationenaustauschchromatographie. In blau dargestellt ist der Verlauf der $\mathrm{OD}_{280}$, in rot der $\mathrm{OD}_{260}$ über die Zeit in min.

In grau: $\mathrm{NaCl}$ Gradient in $\%$ einer $3 \mathrm{M}$ Stammlösung. (B) Analyse des gereinigten Barnase'-McEeTI Fusionsproteins auf einem 15 \%igem SDS-Polyacrylamidgel. M, Molekulargewichts Standard (Größenangabe links in kDa); 1, gereinigtes Barnase'-McEeTI Fusionsprotein. 
Die einzelnen Fraktionen der Reinigung wurden mittels SDS-PAGE (3.4.1.) analysiert. Fraktionen, die das reine Fusionsprotein enthielten, wurden vereinigt und gegen $50 \mathrm{mM}$ Ammoniumacetat dialysiert (3.4.4.). Abbildung 4.2.3. B zeigt das gereinigte Barnase'McEeTI Fusionsprotein auf einem 15 \%igem Polyacrylamidgel.

\subsubsection{Untersuchung der inhibitorischen Aktivität von McEeTI}

In den vorangegangenen Abschnitten wurde die Generierung und Reinigung eines Hybridproteins aus dem N-terminalen Bereich des PPE Inhibitors MCEI-III und dem Cterminalen Bereich des Trypsin Inhibitors EETI-II beschrieben. Unter der Voraussetzung, dass sich trotz der Zusammensetzung aus zwei verschiedenen Mikroproteinen eine stabile dreidimensionale Struktur ausbildet, sollte das generierte Mikroprotein die PPE Spezifität von MCEI-III übernommen haben, da mit dem N-terminalen Teil die Inhibitorschleife mit eingebracht wurde. Daher wurde die inhibitorische Aktivität von McEeTI als Barnase'Fusionsprotein gegenüber PPE wie in Abschnitt 3.4.11. beschrieben durch Messung der verbleibenden Aktivität von PPE gegenüber dem chromogenen Substrat Suc-(Ala) $)_{3}$-pNA mit und ohne Inhibitor gemessen. Aus der erhaltenen Hemmkurve wurde die apparente Dissoziationskonstante $K_{\text {iapp }}$ des Enzym/Inhibitor-Komplexes bestimmt. Es ergab sich ein $\mathrm{K}_{\mathrm{i}}$

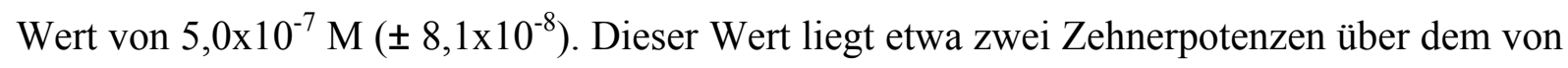
Hamato et al. [Hamato et al., 1995] gemessenen Wert für die Inhibition von PPE durch MCEI-III. Obwohl nicht ausgeschlossen werden kann, dass nicht korrekt Disulfid-verknüpfte Moleküle die dominante Form der Präparation darstellen, legt der ermittelte $\mathrm{K}_{\mathrm{i}}$ Wert jedoch nahe, dass das Hybridprotein eine geordnete dreidimensionale Struktur mit der korrekten Verknüpfung der Cystin Reste angenommen hat. Der im Vergleich höhere $\mathrm{K}_{\mathrm{i}}$ Wert könnte zum einen durch die im Hybridprotein nicht optimale Positionierung der Inhibitorschleife bzw. des P1 Restes in die PPE Bindungstasche zu erklären sein. Zum anderen könnten jedoch auch unterschiedliche Assays zur Bestimmung des $\mathrm{K}_{\mathrm{i}}$ Wertes bzw. eine gewisse sterische Beeinträchtigung des Mikroproteins durch den Barnase'-Fusionspartner mögliche Gründe für den im Vergleich hohen $\mathrm{K}_{\mathrm{i}}$ Wert sein.

Mit dem in diesem Abschnitt dargestellten Experiment konnte gezeigt werden, dass eine Neufunktionalisierung eines Cystin-Knoten Mikroproteins durch Austausch einer Schleife bzw. wie in diesem Fall durch Ersetzung des gesamten aminoterminalen Bereiches möglich ist. Diese Neufunktionalisierung bedeutet in diesem Fall die Transformation eines Trypsin in einen Elastase Inhibitor. Es könnte aber konzeptionell durch Transplantation entsprechender Sequenzen in das Cystin-Knoten Grundgerüst die Modulation verschiedener biomolekularer 
Wechselwirkungen möglich sein, wie etwa die in Kapitel 4.3. beschriebene Generierung von Thrombopoeitin Rezeptor Agonisten.

\subsubsection{Inhibitoren der humanen $\beta$-Tryptase}

Die Familie der humanen Mastzell Tryptasen umfasst eine Gruppe sequenz-homologer Trypsin-ähnlicher Serinproteasen (Abschnitt 1.2.2.). Zumindest die Isoenzyme $\alpha 1, \beta 1, \beta I I$ und $\beta I I I$ werden in großen Mengen selektiv in Mastzellen und in geringerem Maße in Basophilen exprimiert [Jogie-Brahim et al., 2004, Schwartz et al., 1987, Xia et al., 1995]. Jedoch werden nur die $\beta$-Tryptasen intrazellulär aktiviert und in größeren Mengen als jede andere Granulaassoziierte Serinprotease in Leukozyten oder Lymphozyten in sekretorischen Granula gespeichert [Sakai et al., 1996, Schwartz et al., 1995]. Nach Aktivierung der Mastzellen wird Tryptase im Zuge verschiedener allergischer sowie inflammatorischer Prozesse wie z.B. Asthma, Rhinitis oder Multiple Sklerose [Levi-Schaffer und Piliponsky, 2003, Payne und Kam, 2004] als nicht kovalent verbundenes Tetramer sekretiert. Diese ungewöhnliche Struktur (Abschnitt 1.2.2.) wurde 1998 anhand der $\beta$ II-Tryptase aufgeklärt [Pereira et al., 1998]. Das Heparin-stabilisierte Tetramer bildet dabei eine etwa 50 x $30 \AA$ große Pore aus. Die aktiven Zentren jedes Monomers sind in die Pore gerichtet. Aufgrund der speziellen Architektur der Tryptase konzentrierte sich die Entwicklung von Tryptase Inhibitoren bisher fast ausschließlich auf small-molecules [Burgess et al., 1999, Costanzo et al., 2003, Zhao et al., 2004]. Einige der entwickelten Inhibitoren konnten mit der Indikation Asthma im Tierversuch [Clark et al., 1995, Krishna et al., 2001] bzw. mit der Indikation Ulcerative Colitis in der klinischen Phase II [Tremaine et al., 2002] Wirksamkeit zeigen. Viele der entwickelten small-molecule Inhibitoren erwiesen sich jedoch entweder in der Toxikologie, in der Pharmakokinetik oder in der Bioverfügbarkeit bzw. Darreichungsform als unbrauchbar (C. Sommerhoff, persönliche Kommunikation).

Aufgrund der tetrameren Architektur und der relativ kleinen zentralen Pore ist bisher, abgesehen von Heparin-Antagonisten [Hallgren et al., 2001] wie z.B. Lactoferrin [Elrod et al., 1997], nur ein „proteinerger“ Inhibitor der humanen Mastzell-Tryptase bekannt. Dabei handelt es sich um LDTI (leech derived trypsin inhibitor), einem 46 Aminosäuren großen Protein aus dem Blutegel Hirudo medicinalis [Auerswald et al., 1994, Mühlhahn et al., 1994, Sommerhoff et al., 1994]. LDTI hat, wie Cystin-Knoten Mikroproteine, drei Disulfidbrücken, gehört jedoch zur Familie der Kazal-type Inhibitoren [Fink et al., 1986, Friedrich et al., 1993]. Die Inhibitionskonstante von rekombinant hergestelltem LDTI gegenüber humaner Tryptase 
beträgt 1,5 nM [Pohlig et al., 1996], aufgrund der Größe von LDTI können jedoch nur zwei der vier Tryptase Monomere gebunden und inhibiert werden [Sommerhoff et al., 1994].

Angesichts der Nachteile von Tryptase Inhibitoren auf small molecule Basis und angesichts der Ähnlichkeit von Tryptase und Trypsin sollte eine Entwicklung von Tryptase Inhibitoren auf Basis von Cystin-Knoten Trypsin Inhibitor Mikroproteinen möglich sein. Zudem erfüllen Cystin-Knoten Mikroproteine die weiteren Anforderungen hinsichtlich ihrer Größe, Stabilität und evtl. hinsichtlich einer Bioverfügbarkeit.

In diesem Abschnitt soll die Entwicklung von Tryptase Inhibitoren auf Basis von McoEeTI [Schmoldt et al., 2005] (Abbildung 4.1.12.) und McoTI [Avrutina et al., 2004], einer linearen Variante von MCoTI-II, beschrieben werden. Diese Grundgerüste wurden ausgewählt, da sie vor allem in der Inhibitorschleife Sequenzähnlichkeiten zu LDTI aufweisen (Abbildung 4.2.4.).

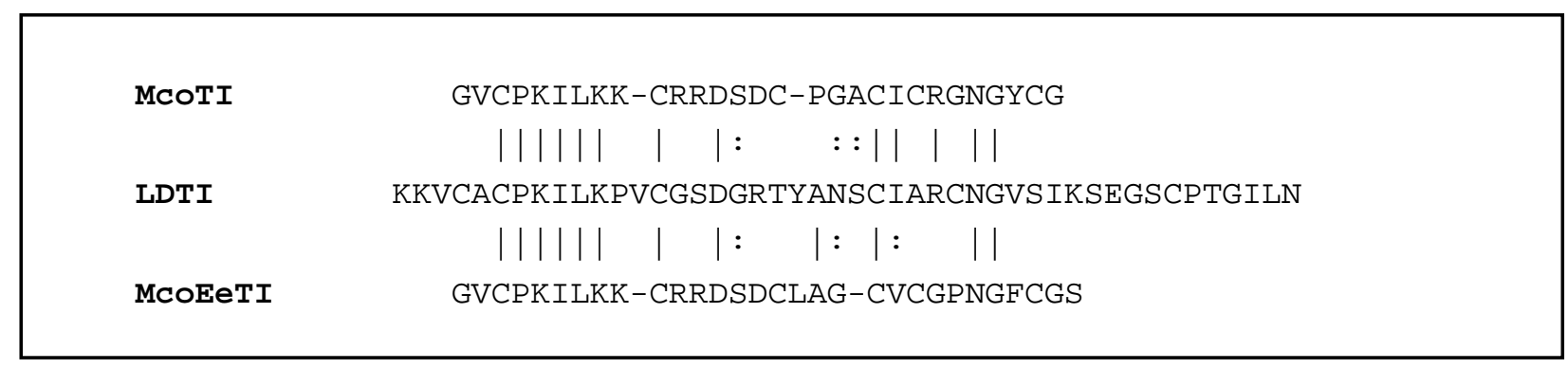

Abbildung 4.2.4.: Vergleich der Aminosäuresequenz des leech-derived-tryptase-inhibitors (LDTI), des HybridProteins McoEeTI aus EETI-II und MCoTI-II [Schmoldt et al., 2005] und der linearen MCoTI-II Variante McoTI [Avrutina et al., 2004] mittels FASTA. Striche symbolisieren identische, Punkte ähnliche Aminosäuren.

Erste Tryptase Inhibitionstests, die in der Arbeitsgruppe von Prof. Dr. Sommerhoff (LMU, München) mit Barnase'-McoEeTI Fusionsprotein durchgeführt wurden, waren vielversprechend (Daten folgen in Abschnitt 4.2.2.3.). Daher sollte im Folgenden eine systematische Analyse verschiedener zu generierender Varianten erfolgen. Ein Teil der generierten Varianten wurde von Olga Avrutina (Organische Chemie, Göttingen) chemisch synthetisiert und dann in die native Form zurückgefaltet (4.2.2.1.) während der andere Teil als Barnase'-Fusion in E. coli exprimiert wurde (4.2.2.2.). Alle generierten Varianten wurden schließlich in der Arbeitsgruppe von Prof. Dr. Sommerhoff hinsichtlich ihrer Tryptase inhibierenden Eigenschaften untersucht (4.2.2.3.), um dann die gewonnenen Erkenntnisse anhand der Strukturen der humanen BII-Tryptase [Pereira et al., 1998] und des Barnase'McoEeTI Fusionsproteins (Niemann et al., Manuskript in Vorbereitung) zu vertiefen. 


\subsubsection{Chemische Synthese und Rückfaltung von McoTI Varianten}

Cystin-Knoten Mikroproteine sind durch ihre geringe Größe sowohl der rekombinanten Produktion in Mikroorganismen als auch der chemischen Synthese zugänglich. Von O. Avrutina wurde ein Fmoc gestütztes Protokoll für die chemische Synthese von McoTI Varianten entwickelt [Avrutina et al., 2004]. Als McoTI wurde das lineare Grundgerüst aus MCoTI-II ohne den flexiblen SGSDG linker bezeichnet. Folgende McoTI Varianten wurden von O. Avrutina synthetisiert (Tabelle 4.2.1.):

\begin{tabular}{|c|c|}
\hline McoTI Variante & Peptid Sequenz \\
\hline McoTI-K & GVCPKILKKCRRDSDCPGACICRGNGYCG \\
\hline McoTI-R & GVCPRILKKCRRDSDCPGACICRGNGYCG \\
\hline McoTI-LAKC & GVCPKILAKCRRDSDCPGACICRGNGYCG \\
\hline McoTI-LKAC & GVCPKILKACRRDSDCPGACICRGNGYCG \\
\hline McoTI-LRKC & GVCPKILRKCRRDSDCPGACICRGNGYCG \\
\hline McoTI-LKRC & GVCPKILKRCRRDSDCPGACICRGNGYCG \\
\hline McoTI-KKV & KKVGVCPKILKKCRRDSDCPGACICRGNGYCG \\
\hline McoTI-A & GVCPAILKKCRRDSDCPGACICRGNGYCG \\
\hline
\end{tabular}

Tabelle 4.2.1.: Chemisch synthetisierte McoTI Varianten. Die rot markierten Aminosäuren wurden im Vergleich zu McoTI-K ausgetauscht.

Die in Tabelle 4.2.1. aufgelisteten Varianten dienten im Wesentlichen der Analyse der Inhibitorschleife des Mikroproteins zwischen den ersten beiden Cysteinen. Dabei wurden alle Lysine einzeln zum einen gegen Arginin und zum anderen gegen Alanin ausgetauscht, um zu analysieren, ob die gegebene Position mit einem Lysin oder einer anderen positiv geladenen Aminosäure besetzt sein muss, oder ob diese Ladung nicht entscheidend für die Inhibition von Tryptase ist. Bei der Variante -KKV wurden die drei N-terminalen Reste von LDTI, die an der Bindung der Tryptase beteiligt sein könnten, übernommen.

Da die generierten Varianten nach der chemischen Synthese in reduzierter Form vorlagen, wurde eine Rückfaltung in die native Cystin-Knoten Form durchgeführt (3.4.8.). Dazu wurden die Proteine wie in Wentzel et al. [Wentzel et al., 1999] beschrieben in $10 \mathrm{mM} \mathrm{HCl}$ (100 $\mu \mathrm{l} / \mathrm{mg}$ Protein) und $200 \mathrm{mM}$ Ammoniumcarbonat Puffer $\mathrm{pH} \mathrm{9,1} \mathrm{(1} \mathrm{ml/mg} \mathrm{Protein)}$ aufgenommen und ü.N. in einem Teflongefäß bei $900 \mathrm{u} / \mathrm{min}$ auf einem Schüttler inkubiert. Die Reinigung der korrekt gefalteten Spezies erfolgte über RP-HPLC (3.4.6.5.). Abbildung 4.2.5. zeigt die RP-HPLC Analyse vor und nach Rückfaltung der jeweiligen McoTI Variante. 
A McoTI-R

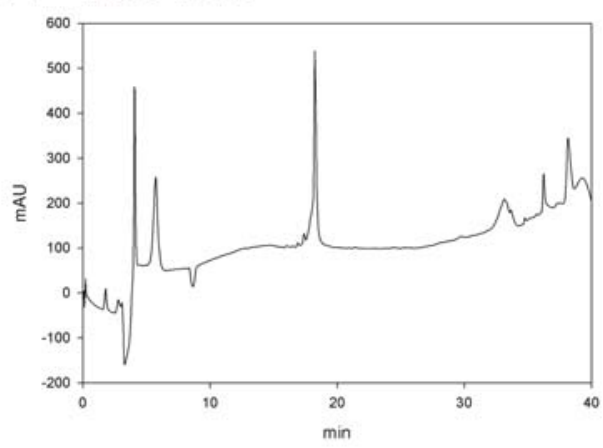

B McoTI-KKV

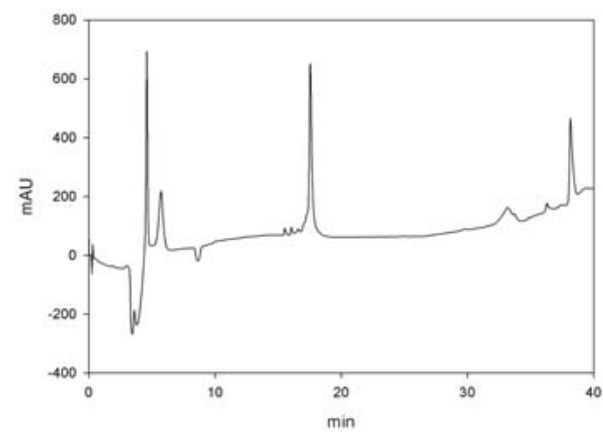

C MCOTI-LAKC

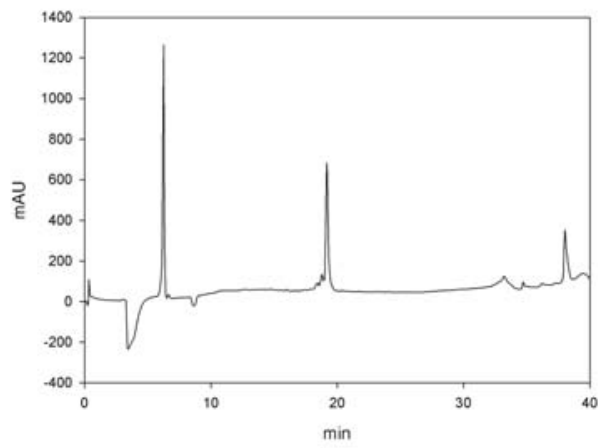

D McoTI-LKAC

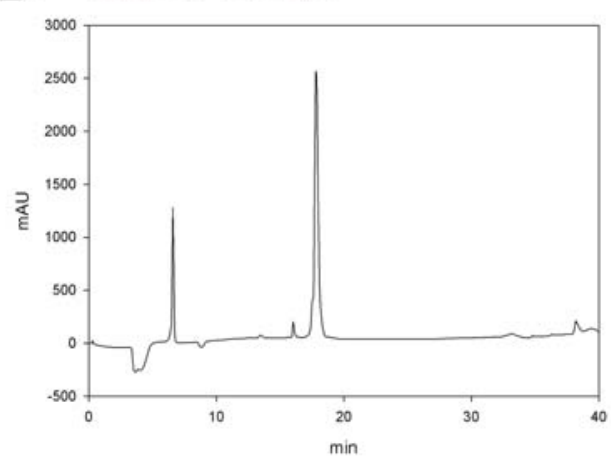

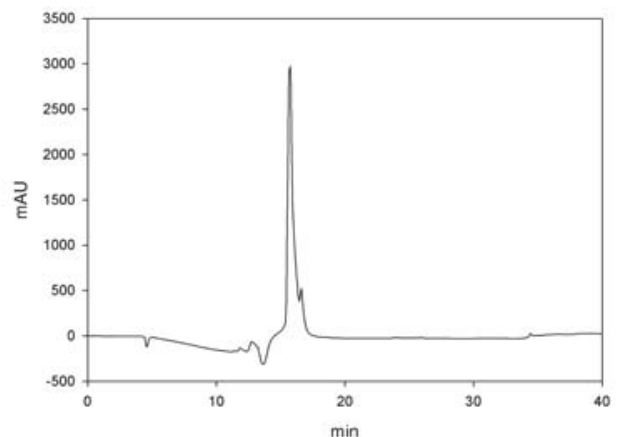
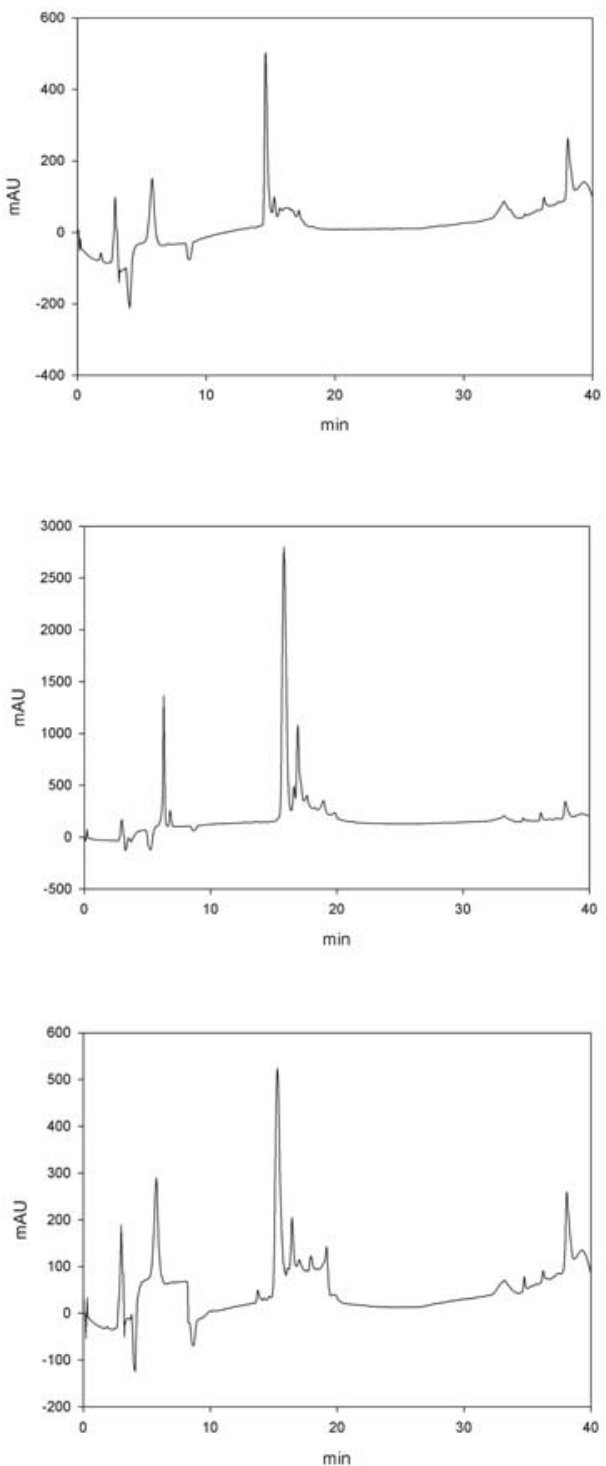

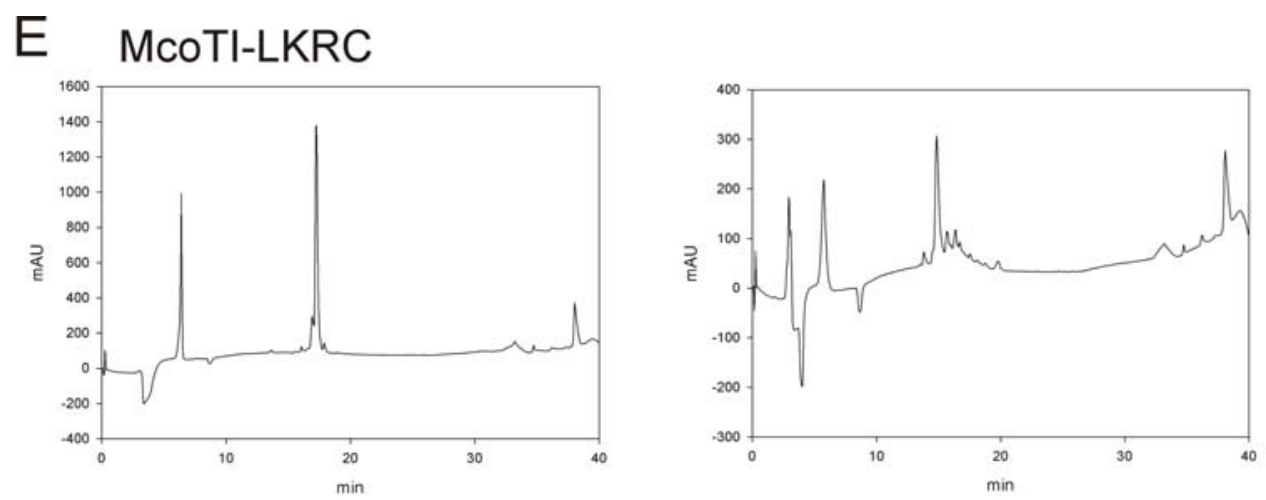

F McoTI-LRKC
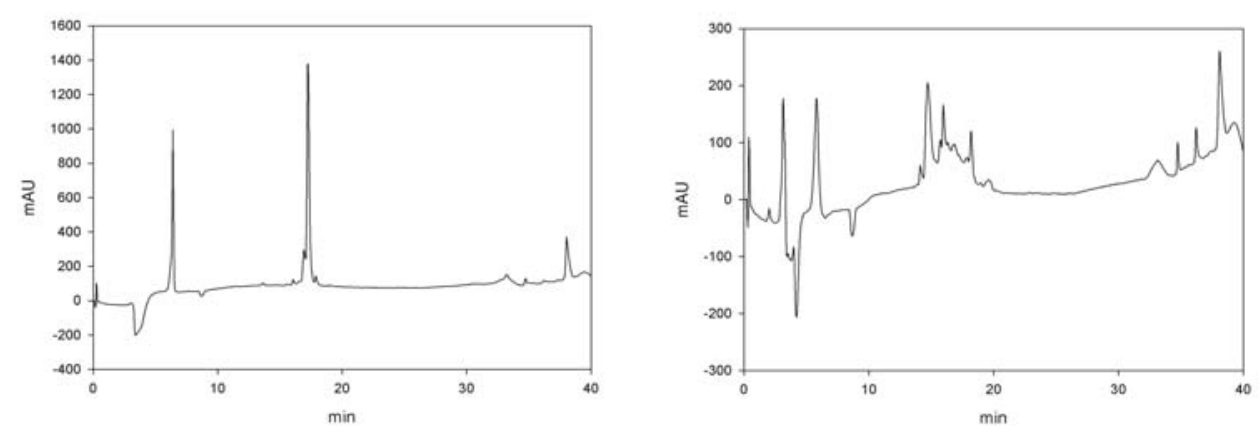

G McoTI-A
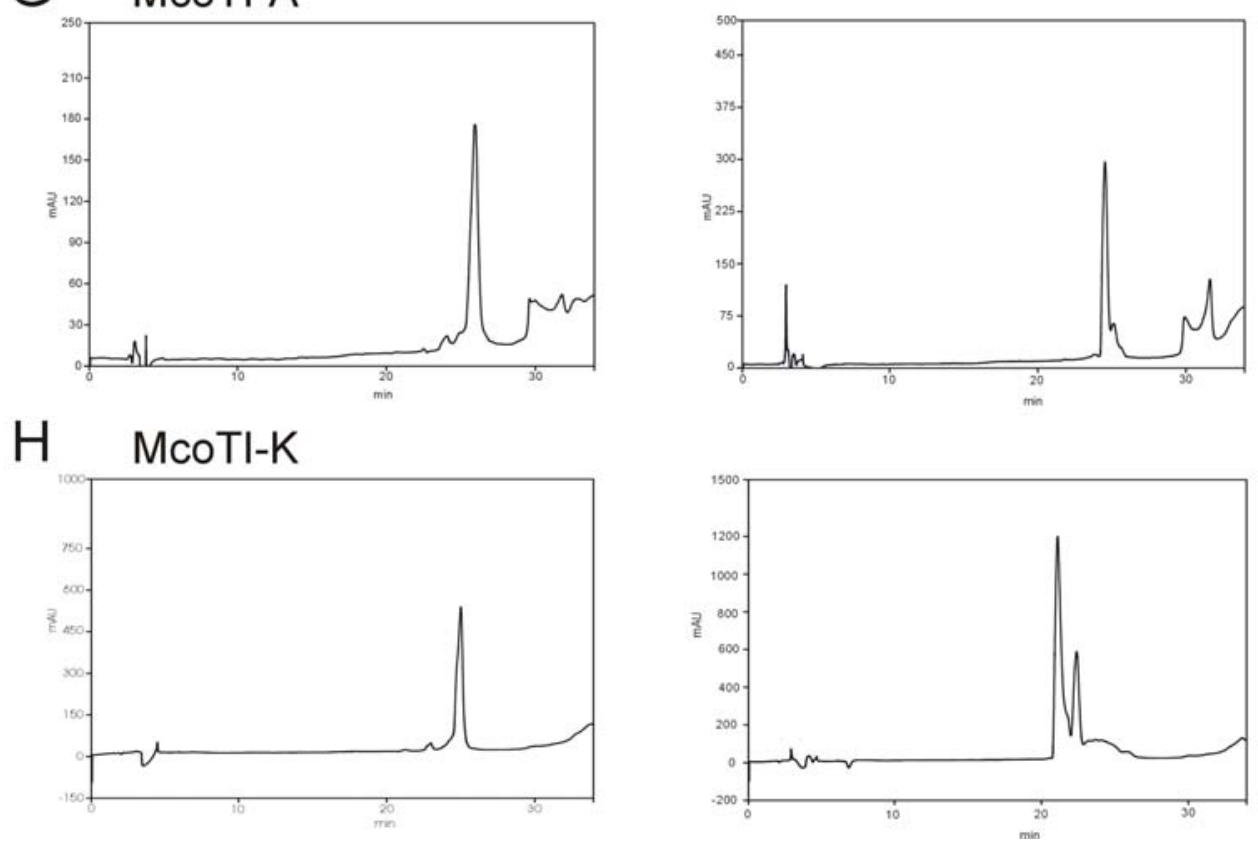

Abbildung 4.2.5.: Analyse der Rückfaltungen der McoTI Varianten über RP-HPLC. Dargestellt ist jeweils im linken Diagramm die Analyse der reduzierten Variante und im rechten Diagramm die Analyse nach Rückfaltung. Aufgetragen ist der Verlauf der $\mathrm{OD}_{217}$ (in mAU) über die Zeit in min. (A) McoTI-R; (B) McoTI-KKV; (C) McoTI-LAKC; (D) McoTI-LKAC; (E) McoTI-LKRC; (F) McoTI-LRKC; (G) McoTI-A; (H) McoTI-K.

Wie aus Abbildung 4.2.5. ersichtlich, ließen sich die unterschiedlichen McoTI Varianten unterschiedlich gut in die native Form zurückfalten. So sind z.B. nach Oxidation von McoTI$\mathrm{R}$ und $-\mathrm{A}$ (Abbildung 4.2.5. A bzw. G, rechts) kaum Nebenprodukte in der RP-HPLC Analyse zu erkennen, während sich z.B. die Variante-LRKC (Abbildung 4.2.5. F, rechts) nur mit schlechten Ausbeuten zurückfalten ließ. Die oxidierten Varianten wurden mittels RP- 
HPLC (3.4.6.5.) gereinigt und lyophilisiert. Die jeweilige erwartete Masse der oxidierten Spezies konnte durch ESI-Massenspektroskopie verifiziert werden.

\subsubsection{Klonierung, Expression und Reinigung von McoEeTI Varianten}

Folgende McoEeTI Varianten wurden für die Tryptase Inhibitionstests rekombinant über das in Kapitel 4.1. vorgestellte Barnase'-Expressions- und Reinigungssystem hergestellt (Tabelle 4.2.2.):

\begin{tabular}{|c|c|}
\hline McoEeTI Variante & Peptid Sequenz \\
\hline McoEeTI & Barnase'-SSSMGVCPKILKKCRRDSDCLAGCVCGPNGFCGS \\
\hline McoEeTI-2R & Barnase'-SSSMGVCPRNRQKCRRDSDCLAGCVCGPNGFCGS \\
\hline McoEeTI-3R & Barnase'-SSSMGVCPRILRRCRRDSDCLAGCVCGPNGFCGS \\
\hline McoEeTI-QRT & Barnase'-SSSMGVCPRNRQRCRRDSDCLAGCVCTNNKFCGS \\
\hline McoEeTI-KKV & Barnase'-SSSMGKKVGVCPKILKKCRRDSDCLAGCVCGPNGFCGS \\
\hline McoEeTI-ARD & Barnase'-SSSMGVCPKILKACARDSDCLAGCVCGPNGFCGS \\
\hline McoEeTI-LKA & Barnase'-SSSMGVCPKILKACRRDSDCLAGCVCGPNGFCGS \\
\hline McoEeTI-3RT & Barnase'-SSSMGVCPRILRRCRRDSDCLAGCVCTNNKFCGS \\
\hline McoEeTI-T & Barnase'-SSSMGVCPKILKKCRRDSDCLAGCVCTNNKFCGS \\
\hline McoEeTI-ARDs & Barnase'-SSSMGVCPKILKKCARDSDCLAGCVCGPNGFCGS \\
\hline McoEeTI-RAD & Barnase'-SSSMGVCPKILKKCRADSDCLAGCVCGPNGFCGS \\
\hline McoEeTI-KKV-3R & Barnase'-SSSMGKKVCPRILRRCRRDSDCLAGCVCGPNGFCGS \\
\hline
\end{tabular}

Tabelle 4.2.2.: Rekombinant herzustellende McoEeTI Varianten. Die rot markierten Aminosäuren wurden im Vergleich zu McoEeTI ausgetauscht.

Die in Tabelle 4.2.2. aufgelisteten Varianten basieren auf dem Hybridprotein McoEeTI, das bereits in Abschnitt 4.1.3. beschrieben wurde. Eine Gruppe dieser Varianten (-ARD, -LKA, ARDs und -RAD) deckt den Austausch der positiven Ladungen im mittleren Teil des Proteins gegen Alanin ab. Bei der in den Varianten $-2 \mathrm{R}$ bzw. QRT eingeführten Sequenz RNRQK/R handelt es sich um eine von Richard L. Stevens und Chifu Huang patentierte Sequenz [Stevens und Huang, 1999], die Tryptase inhibitorisch wirken soll. Die Varianten T, -3RT und -QRT enthalten statt GPNG die Sequenz TNNK [Wentzel et al., 1999] an Position 23-26 von McoEeTI; zudem wurden bei diesen Varianten alle Lysine gegen Arginin ausgetauscht. Diese Austausche wurden zum Zwecke einer möglichen Dimerisierung (Abschnitt 4.2.2.5.) über das dann singuläre Lysin zur Generierung bivalenter Inhibitoren gemacht.

Die Klonierung, Expression und Reinigung von Barnase'-McoEeTI wurde bereits in Abschnitt 4.1.4.1. beschrieben. Alle weiteren Varianten sollten ebenfalls in E. coli 
rekombinant hergestellt werden und wurden daher in den Vektor pBar100 kloniert (Abbildung 4.2.6.).

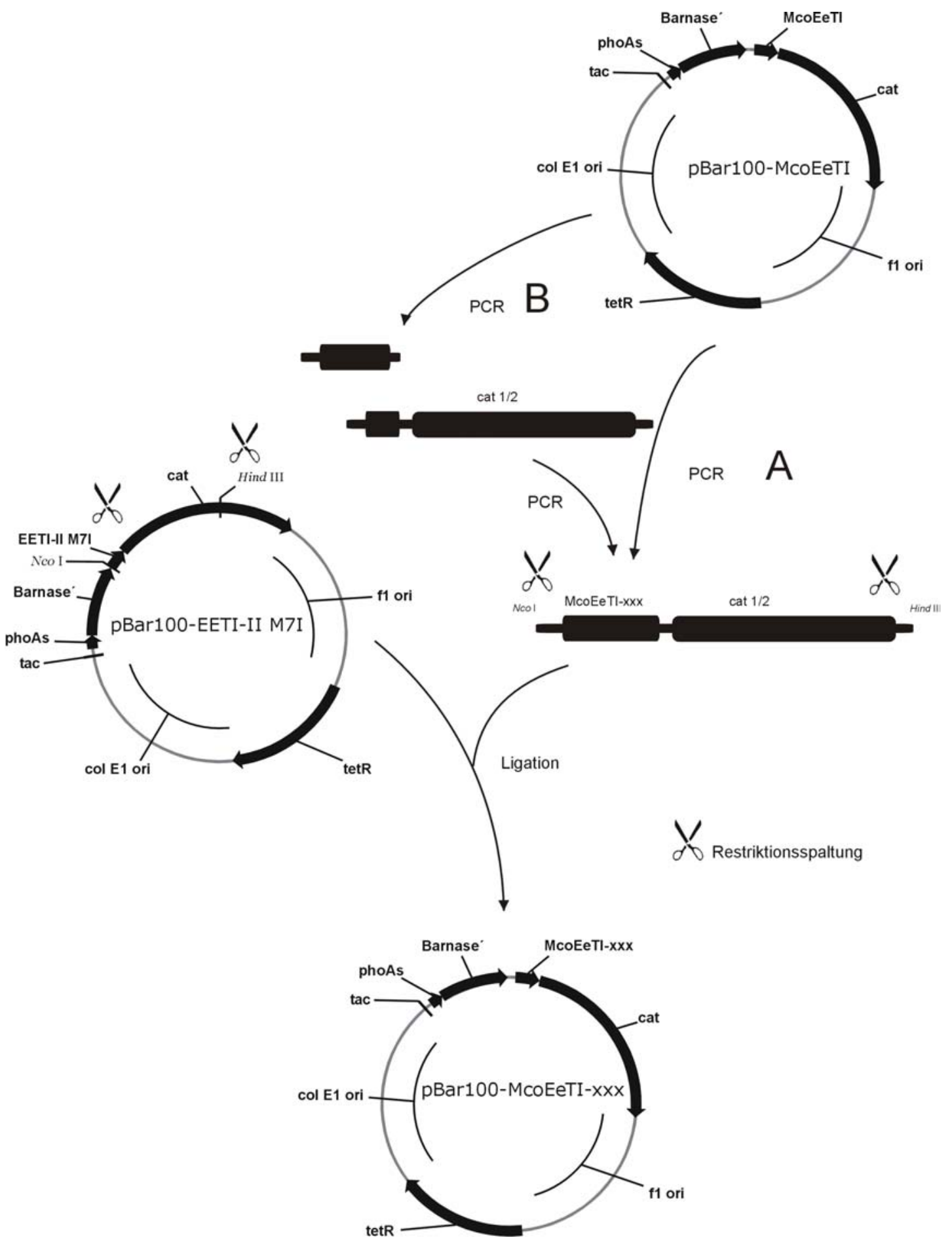

Abbildung 4.2.6.: Schematische Darstellung der Klonierung der McoEeTI Varianten in den pBar100 Vektor. Beschreibung der Klonierungen im Text. Die Pfeilrichtungen geben die funktionellen Orientierungen der genetischen Elemente an. Cat, Chloramphenicol Resistenz Gen; Barnase', Gen für Barnase His ${ }^{102}$ Ala; EETI-II M7I, Gen für die $M^{7} I$ Variante des Trypsin Inhibitors EETI-II; tac, Tac Promotor Region; tetR, Tetrazyklin Repressor Gen; f1, Replikationsursprung des Phagen f1; col E1 ori , col E1 Replikationsursprung; phoAs, Alkalische Phosphatase periplasmatische Signal Sequenz; McoEeTI, Gen für das Hybrid Protein aus EETI-II und MCoTI-II; McoEeTI-xxx, Gen für die jeweilige McoEeTI Variante. (B) Die Varianten McoEeTI-KKV, LKA, -ARD und -KKV-3R wurden über eine zweistufige SOE PCR amplifiziert. (A) Alle anderen Varianten wurden in einem PCR Schritt amplifiziert. 
Dazu wurde das Gen der entsprechenden Variante zunächst analog zu McEeTI (4.2.1.1.) mitsamt des halben cat Gens mittels PCR amplifiziert (3.3.3.). Als Matrize diente dabei das Plasmid pBar100-McoEeTI; nur bei der Variante McoEeTI-KKV-3R wurde eine andere Matrize, nämlich das zu dem Zeitpunkt bereits erstellte Plasmid pBar100-McoEeTI-3R verwendet. Die PCR erfolgte bei den Varianten -KKV, -LKA, -ARD und -KKV-3R jeweils mit einem spezifischen up-Primer, der eine Nco I Schnittstelle einführte, und dem Oligonukleotid cat-Hind-Mitte-lo (Abbildung 4.2.6. A). Bei allen anderen Varianten wurde eine zweistufige SOE-PCR (3.3.3.) mit einem spezifischen up-Primer, der eine Nco I Schnittstelle einführte, zwei innen liegenden Primern und dem Oligonukleotid cat-HindMitte-lo (Abbildung 4.2.6. B) durchgeführt. Auf beiden Wegen wurde ein Fragment aus dem jeweiligen McoEeTI Gen und dem halben cat Gen mit einer Nco I Schnittstelle am 5'- und einer Hind III Schnittstelle am 3'-Ende generiert. Dieses wurde mit den beiden Enzymen gespalten (3.3.1.), mittels Phenol/Chloroform Extraktion (3.2.3.2.) und anschließender Ethanol Fällung (3.2.2.1.) gereinigt, und mit dem gleichermaßen geschnittenen Vektor pBar100-EETI-II M7I ligiert (3.3.2.). Nach Transformation von E. coli 71-18 pRep4 (3.1.5.) konnten insert-tragende Transformanten mittels Kolonie PCR (3.3.3.) und anschließender Restriktionsanalyse (3.3.1.) der präparierten Plasmid DNA (3.2.6.) von in der PCR positiven Klonen ermittelt werden. Die jeweiligen Sequenzen konnten durch DNA-Sequenzierung im Laboratorium für Genomanalyse verifiziert werden.

Die Expression der Barnase'-McoEeTI Varianten erfolgte nach Transformation von E coli 7118 pRep4 mit dem jeweiligen Plasmid im 11 Fermenter (3.1.7.2.). Die Aufarbeitung der induzierten Kulturen erfolgte wie in Kapitel 4.1.2. beschrieben nach Ansäuerung mit Essigsäure aus dem Kulturüberstand. Die Barnase'-McoEeTI Fusionsproteine wurden in einem ersten Schritt über kombinierte Kationenaustausch-/RP-Chromatographie (3.4.6.2.) gereinigt. Nach SDS-PAGE Analyse (3.4.1.) wurden Fusionsprotein enthaltene Fraktionen vereinigt und lyophillisiert. Die Proteine wurden dann in $0,1 \mathrm{M}$ Tris- $\mathrm{HCl} \mathrm{pH} 7,8$ mit $8 \mathrm{M}$ Harnstoff aufgenommen, ü.N. gegen $50 \mathrm{mM}$ Ammoniumacetat dialysiert (3.4.4.) und zur vollständigen Entfernung von Verunreinigungen erneut über Kationenaustauschchromatographie (3.4.6.3.) an der Vision Biocad ${ }^{\circledR}$ workstation gereinigt (Abbildung 4.2.7.). Die einzelnen Fraktionen der Reinigungen wurden mittels SDS-PAGE (3.4.1.) analysiert. Fraktionen, die das reine Fusionsprotein enthielten, wurden vereinigt und gegen PBS Puffer dialysiert (3.4.4.). 

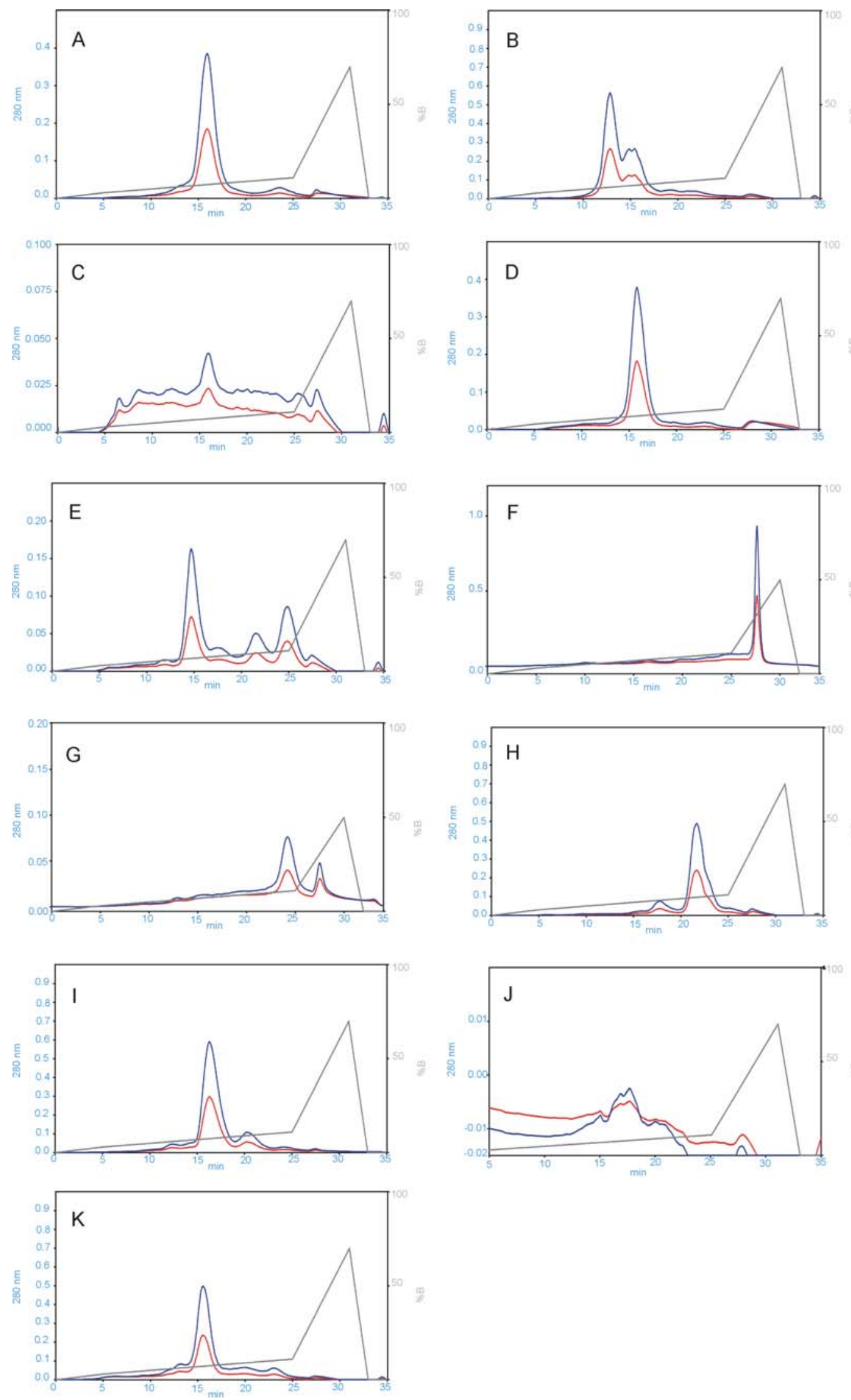

Abbildung 4.2.7.: Chromatogramme der Reinigung der Barnase'-McoEeTI Varianten über Kationenaustauschchromatographie. In blau dargestellt ist der Verlauf der $\mathrm{OD}_{280}$, in rot der $\mathrm{OD}_{260}$ über die Zeit in min. In grau: $\mathrm{NaCl}$ Gradient in \% einer $3 \mathrm{M}$ Stammlösung. (A) Barnase'-McoEeTI-KKV-3R; (B) -ARD; (C) -3RT; (D) ARDs; (E)-KKV; (F)-QRT; (G) -T; (H)-2R; (I)-RAD; (J)-3R; (K) LKA. 


\subsubsection{Inhibition der humanen $\beta$-III Tryptase}

Die Messungen der Inhibitionskonstanten der generierten McoTI- bzw. McoEeTI-Varianten gegenüber humaner $\beta$-III Tryptase erfolgte in der Abteilung von Prof. Dr. C. Sommerhoff (LMU, München). Um die jeweilige Konzentration an aktivem Inhibitor $\mathrm{zu}$ bestimmen, wurden zunächst active site Titrationen mit Trypsin durchgeführt. Die $\mathrm{K}_{\mathrm{i}}$ Werte gegenüber Trypsin sowie Tryptase wurden wie in Sommerhoff et al. [Sommerhoff et al., 1994] beschrieben, nach Inkubation des Enzyms mit dem jeweiligen Inhibitor, durch photometrische Messung des Umsatzes des Substrates Tosyl-Gly-Pro-Arg-pNA bestimmt.

In Abbildung 4.2.8. ist exemplarisch die Hemmkurve von Barnase'-McoEeTI gegenüber Tryptase dargestellt. Es zeigt sich, dass das Enzym bei einer Inhibitor Konzentration von etwa $0,8 \mu \mathrm{M}$ fast vollständig gehemmt wird, d.h. trotz Fusionierung an Barnase' ist McoEeTI im Gegensatz zu LDTI [Sommerhoff et al., 1994] in der Lage, alle vier Monomere der Tryptase zu besetzen und zu inhibieren. Für den Komplex aus Tryptase und Barnase'-McoEeTI wurde eine Inhibitionskonstante $K_{i}$ von $100 \mathrm{nM}$ errechnet. Die bestimmten $K_{i}$ Werte, die Sequenzen sowie die produzierte Mengen aller Varianten sind in Tabelle 4.2.3. zusammengefasst.
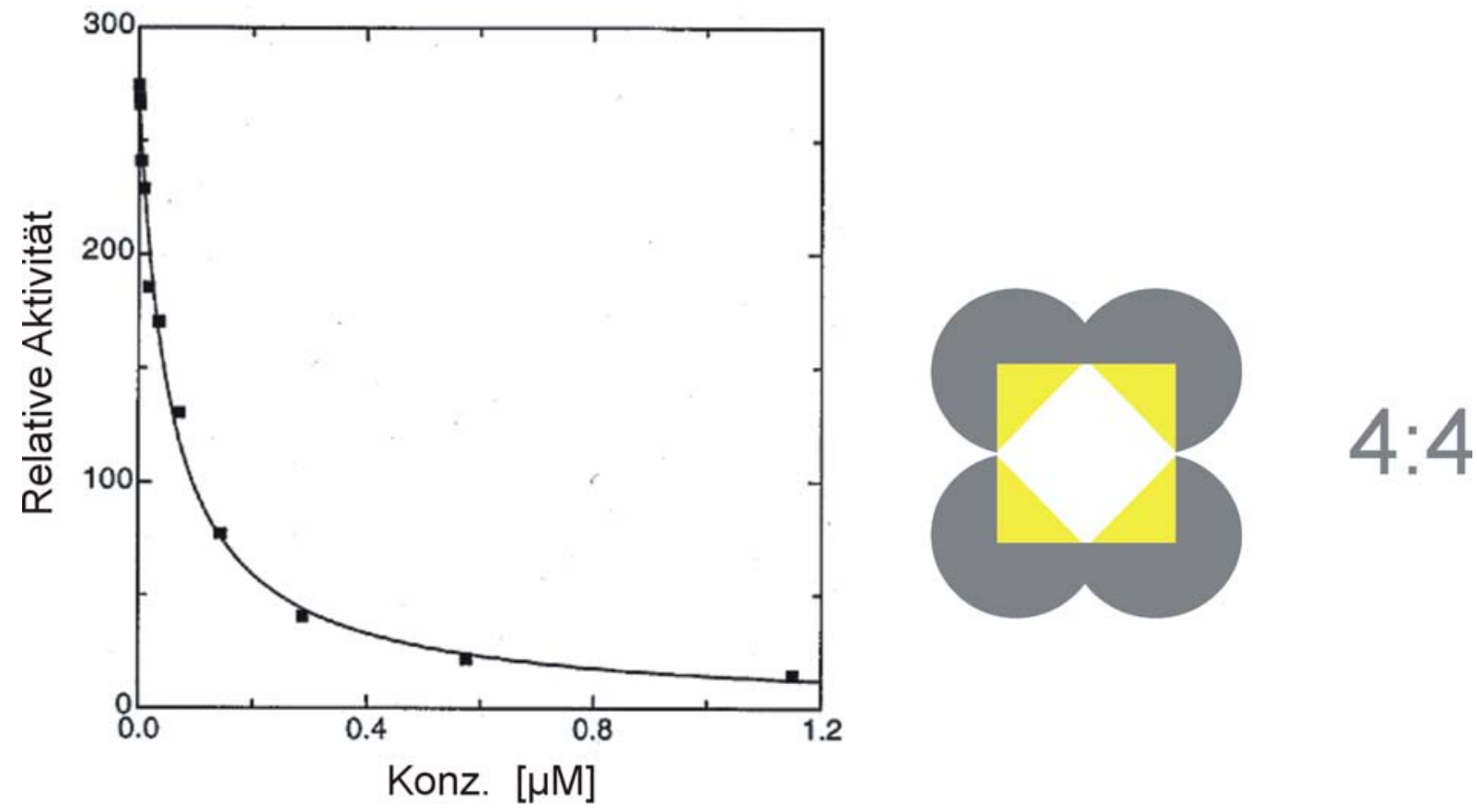

Abbildung 4.2.8.: Inhibition von humaner Tryptase durch Barnase'-McoEeTI. Aufgetragen ist die relative Aktivität der Tryptase gegen die Konzentration des Inhibitors Barnase'-McoEeTI (Quelle: C. Sommerhoff). 


\begin{tabular}{|c|c|c|c|c|c|c|c|c|c|c|c|c|c|c|c|c|c|c|c|c|}
\hline 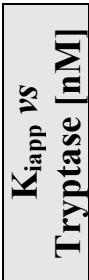 & 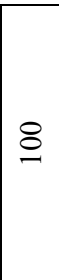 & 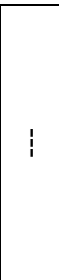 & in & ! & ¿ & 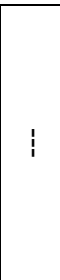 & 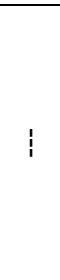 & ! & $\stackrel{8}{n}$ & $\begin{array}{l}8 \\
\text { n్ } \\
m\end{array}$ & \&ু & $!$ & तి & ¿ి & $\nsubseteq$ & ల & 으 & 은 & $\sim$ & 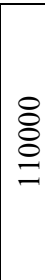 \\
\hline 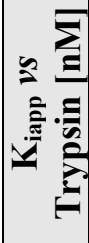 & $\vec{v}$ & $\stackrel{m}{ }$ & $\tilde{o}$ & - & $\tilde{o}$ & $\tilde{o}$ & $\tilde{o}$ & ?. & $\overrightarrow{0}$ & ?. & ô & $\overrightarrow{0}$ & ?. & $\stackrel{\infty}{\circ}$ & ô & $\stackrel{t}{0}$ & $\because$ & $\stackrel{t}{0}$ & $\stackrel{t}{0}$ & 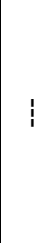 \\
\hline 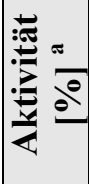 & & ' & $\stackrel{ \pm}{\sim}$ & $\stackrel{6}{6}$ & ले & in & 8 & $\stackrel{\sim}{ }$ & ిల & 8 & $g$ & in & $\stackrel{\infty}{\infty}$ & $\hat{n}$ & $\approx$ & $\stackrel{\circ}{\sim}$ & 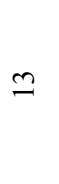 & নి & $I$ & \\
\hline 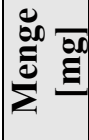 & & $\begin{array}{l}0 \\
\infty\end{array}$ & $\stackrel{t}{0}$ & $\hat{n}$ & $\hat{i}$ & $\bar{\infty}^{\circ}$ & $\stackrel{\nabla_{n}}{\sim}$ & $\stackrel{0}{=}$ & $\approx$ & ఫु & $\begin{array}{l}m \\
n\end{array}$ & $\hat{\sigma}$ & $\stackrel{ }{=}$ & & $n$ & $\because$ & $\because$ & $\tilde{o}$ & $\stackrel{+}{\sigma}$ & \\
\hline 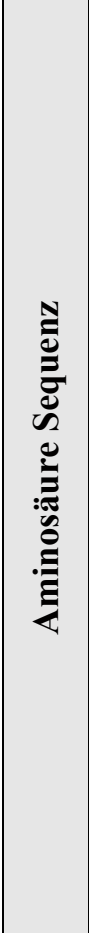 & 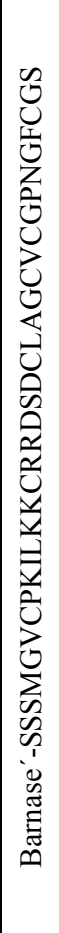 & 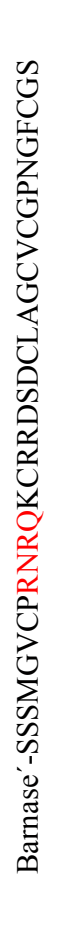 & 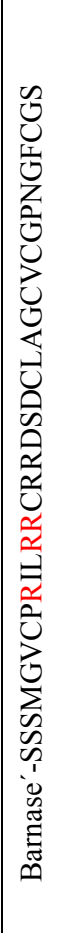 & 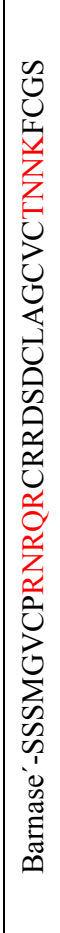 & 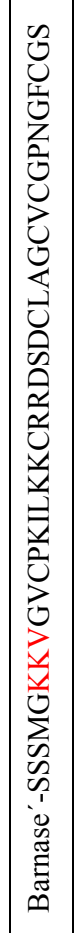 & 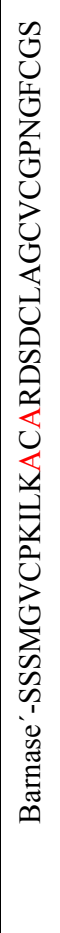 & 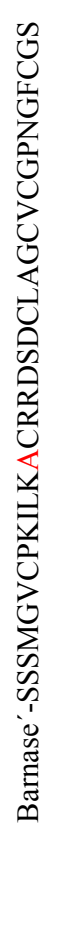 & 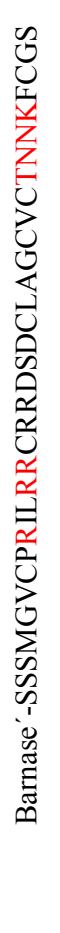 & 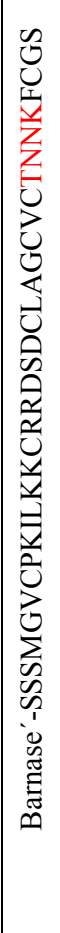 & 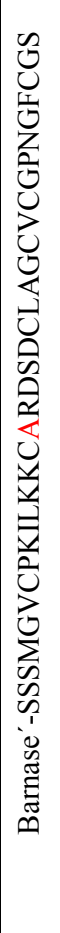 & 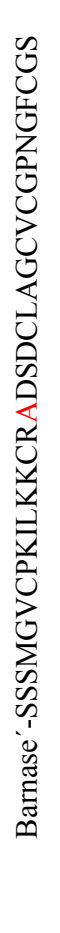 & 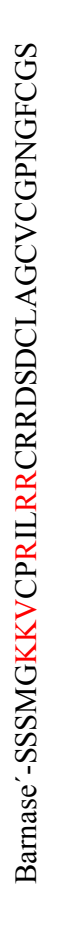 & 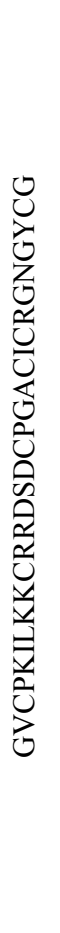 & 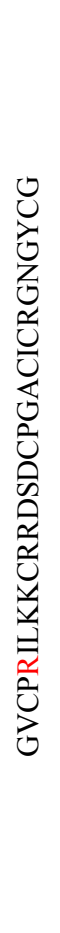 & 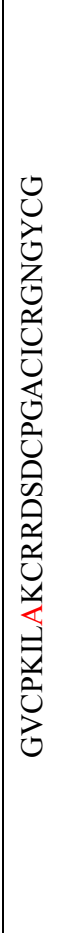 & 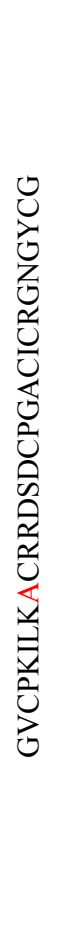 & 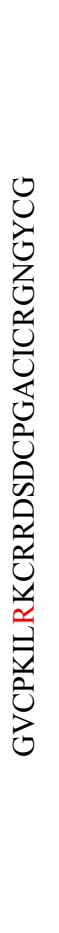 & 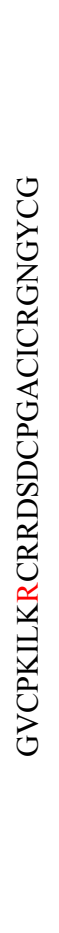 & 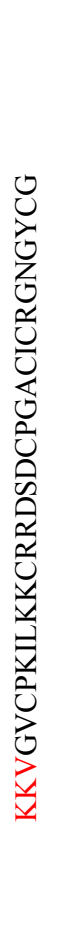 & 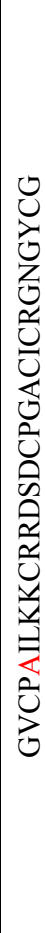 \\
\hline 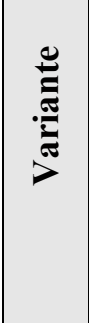 & $\begin{array}{l}\overrightarrow{0} \\
\text { W0 } \\
\text { ¿ }\end{array}$ & 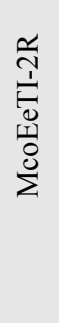 & 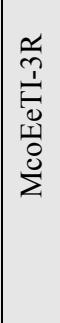 & 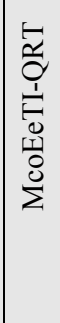 & 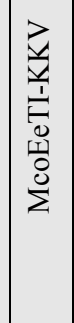 & 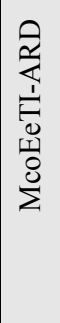 & 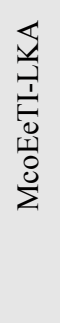 & 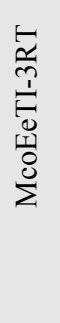 & 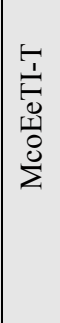 & 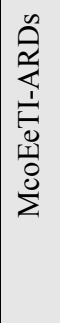 & 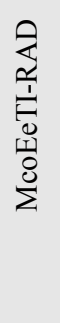 & 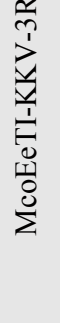 & 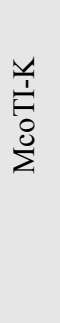 & 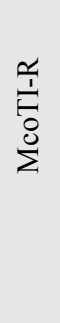 & 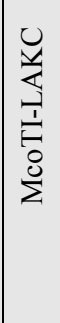 & 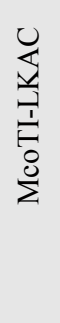 & 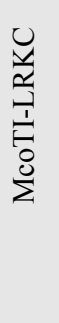 & 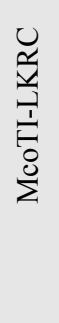 & 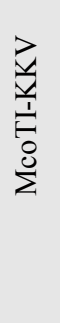 & 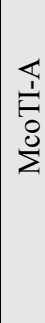 \\
\hline
\end{tabular}


Die beste Variante bzgl. der Inhibition von Tryptase stellt McoTI-KKV mit einem Wert von $2 \mathrm{nM}$ dar, was im Bereich von LDTI und anderer monovalenter veröffentlichter Tryptase Inhibitoren auf small-molecule Basis liegt [Costanzo et al., 2003, Gangloff, 2000, Sommerhoff et al., 1994, Zhao et al., 2004]. Andere Varianten, wie die Varianten McoEeTI2R und $-Q R T$, bei denen die von Richard L. Stevens und Chifu Huang patentierte Sequenz [Stevens und Huang, 1999] eingeführt wurde, inhibieren Trypsin aber nicht Tryptase.

Im Folgenden soll, unter Einbeziehung der vorhandenen Kristallstrukturen von Barnase'McoEeTI (Niemann et al., Manuskript in Vorbereitung) und der humanen $\beta$-II Tryptase [Pereira et al., 1998] eine Analyse der anhand der Inhibitionskonstanten gewonnenen Erkenntnisse gemacht werden. Da Barnase'-McoEeTI und Tryptase nicht im Komplex kristallisiert worden sind, wurde McoEeTI von Dr. H. Kolmar unter Verwendung des Programms Insight II (Biosym Technologies) in das Tryptase Tetramer modelliert. Dazu wurde zunächst der Komplex aus Porcine Trypsin mit einer EETI-II Mutante (PDB Accession $N r: 3.4 .21 .4)$ mit der Trypsin-ähnlichen Tryptase und anschließend McoEeTI (ohne Barnase') mit der EETI-II Mutante superpositioniert.
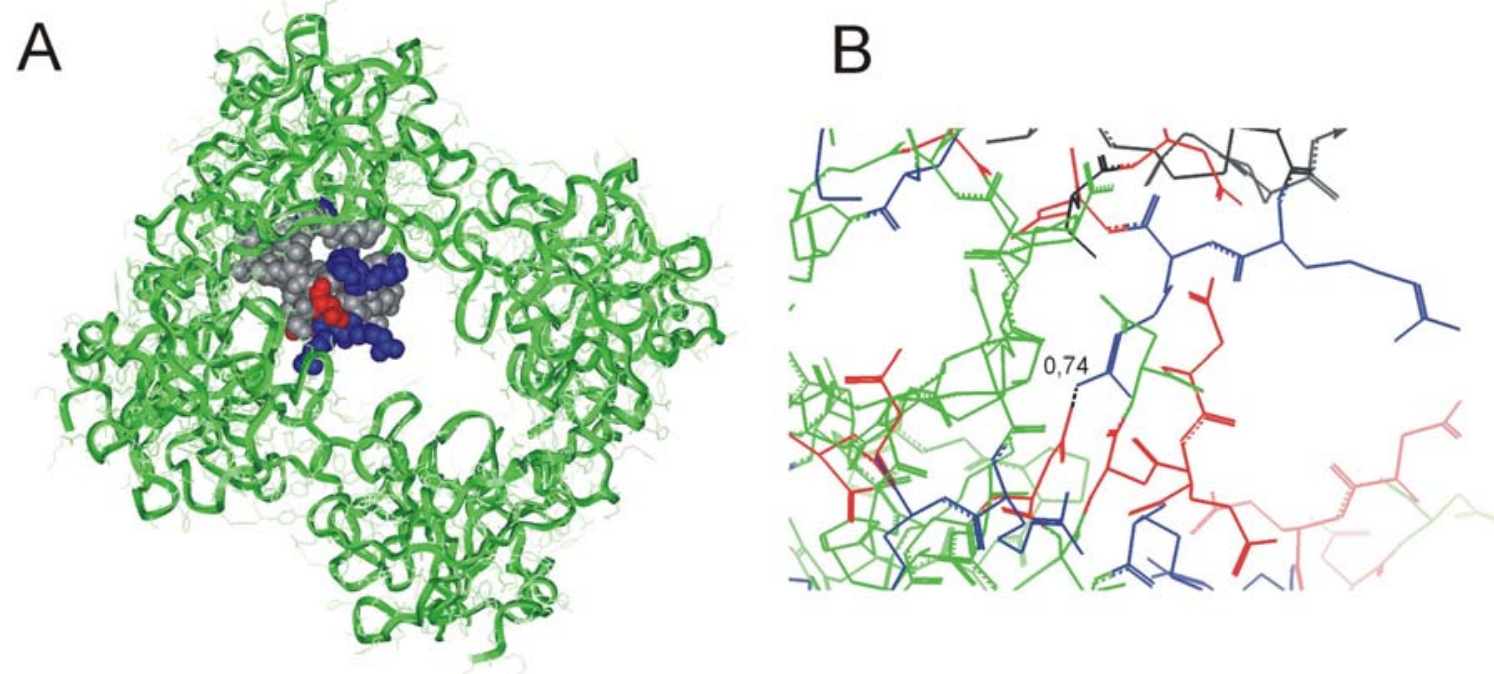

\begin{abstract}
Abbildung 4.2.9.: Modell der Bindung von McoEeTI und $\beta$-II Tryptase. (A) Darstellung eines McoEeTI Moleküls im Tryptase Tetramer. McoEeTI ist in grau als Oberflächen-Modell gezeigt, negativ geladene Aminosäuren sind in rot, positiv geladene in blau hervorgehoben. Tryptase (grün) ist im Ribbon Modell mit Seitenketten dargestellt. (B) Zoom in das Interface zwischen einem Tryptase Monomer (grün) und dem positiv geladenen Rückgrat von McoEeTI (grau). Negativ geladene Aminosäuren sind jeweils in rot, positiv geladene in blau hervorgehoben. Das Arginin an Position \#12 von McoEeTI bildet nach diesem Modell eine Salzbrücke mit einem Aspartat des benachbarten Tryptase Monomers aus. Der Abstand zwischen Amino- und Hydroxylgruppe beträgt 0,74 Á. Die Abbildung wurde mit dem Programm Insight II erstellt.
\end{abstract}

In Abbildung 4.2.9. $\mathrm{A}$ ist ein in das $\beta$-II Tryptase Tetramer modelliertes McoEeTI Molekül dargestellt. Neben einem negativ geladenem Bereich zeichnet sich McoEeTI vor allem durch drei in blau dargestellte Abschnitte positiver Ladung aus. Bei den konstruierten Varianten wurden diese positiv geladenen Reste systematisch gegen Lysin bzw. Alanin ausgetauscht. 
Offensichtlich haben alle ausgetauschten positiven Reste Auswirkungen auf die Inhibition der $\beta$-II Tryptase, da die inhibitorische Aktivität bei Austausch gegen Alanin bei allen Varianten negativ beeinflußt ist bzw. vollkommen verloren geht, während die Austausche gegen Arginin die Aktivität nicht bzw. sogar positiv beeinflussen. Erklärbar ist dieser Effekt durch eine Vielzahl negativer Reste, die von dem jeweiligen Tryptase Monomer in die zentrale Pore gerichtet sind. Eine dieser negativ geladenen Aminosäuren eines „benachbarten“ Tryptase Monomers befindet sich dabei nach diesem Modell in einem Abstand zum Arginin an Position \#12 von McoEeTI, der die Ausbildung einer Salzbrücke erlaubt (Abbildung 4.2.9. B). Die Genauigkeit dieses Modells ist jedoch nicht klar, da es nicht gelang, vier Mikroprotein Moleküle gleichzeitig in das Tetramer $\mathrm{zu}$ modellieren, obwohl diese 4:4 Stöchometrie experimentell nachgewiesen werden konnte. Eine Erklärung könnte sein, daß die Kristallisation des Tryptase Tetramers ohne Heparin erfolgte [Pereira et al., 1998], d.h. die „wahre“ Struktur könnte in vivo durch Assoziation von Heparin anders aussehen.

Superpositioniert man McoEeTI mit dem Tryptase Inhibitor LDTI (Modell nicht gezeigt) so fällt auf, daß die Hauptkettenverläufe der Inhibitorschleifen beider Moleküle nahezu identisch sind. Die Schleife von LDTI (-PKILKPV-) ist um eine Aminosäure länger als die von McoEeTI (-PKILKK-), wird jedoch durch ein zusätzliches Prolin entsprechend gekrümmt. Es wäre daher interessant eine McoEeTI bzw. McoTI Variante mit dem gesamten aminoterminalen Bereich von LDTI herzustellen und den Einfluß auf die inhibitorischen Eigenschaften des Moleküls zu messen.

Zusammenfassend läßt sich sagen, daß McoTI bzw. McoEeTI aufgrund der geringen Größe in der Lage ist, alle vier Untereinheiten des Tryptase Tetramers zu blockieren. Selbst als Fusionsprotein werden (im Vergleich etwa um den Faktor 10 höhere) $\mathrm{K}_{\mathrm{i}}$ Werte im nanomolarem Bereich gegenüber Tryptase erreicht, d.h. vermutlich ragt in diesem Fall der Barnase'-Fusionsteil aus dem Tetramer hinaus. Essentielle Bestandteile des Inhibitors sind neben einem Lysin oder Arginin in P1 Position offensichtlich eine generelle positiv geladene Oberflächenstruktur des Mikroproteins. Zudem ließ sich durch Transplantation der aminoterminalen Aminosäuren -KKV von LDTI die Inhibitionskonstante gegenüber der $\beta$-II Tryptase auf einen Wert von $2 \mathrm{nM}$ verbessern.

\subsubsection{Analyse der Selektivität}

Bei der Entwicklung eines Protease Inhibitors für eine spätere therapeutische Applikation sind neben der potenten Blockierung der Ziel-Protease eine Reihe weitere Faktoren zu berücksichtigen. Neben der Stabilität des Inhibitors und einer eventuellen oralen 
Bioverfügbarkeit stellt sich vor allem die Frage der Selektivität. So wäre ein potenter Tryptase Inhibitor nicht verwendbar, wenn er gleichzeitig andere wichtige Prozesse im menschlichen Körper wie z.B. die Blutgerinnung hemmt. Aus diesem Grund wurden in der Arbeitsgruppe von Prof. Dr. Sommerhoff erste Selektivitätsstudien dreier ausgewählter Varianten gegenüber verschiedenen relevanten anderen Proteasen durchgeführt (Tabelle 4.2.4.). Es wurden die Varianten McoTI-KKV, McoTI-R und McoEeTI und Enzyme aus dem Pankreas, der Blutgerinnung, aus dem Bereich der Immunabwehr und zwei Vertreter der Kallikreine für die Untersuchungen ausgewählt.

\begin{tabular}{|c|c|c|c|c|c|}
\hline & & & \multicolumn{3}{|c|}{$K_{\text {iapp }}[n \mathbf{M}]$} \\
\hline Gruppe & Protease & Spezies & McoEeTI & McoTI-KKV & McoTI-R \\
\hline \multirow[t]{4}{*}{ Tryptase } & $\beta$-III & Mensch & 100 & 2 & 20 \\
\hline & $\beta$-Ia & Mensch & 70 & 3 & 40 \\
\hline & $\beta$-II & Mensch & 70 & 4 & 40 \\
\hline & ST2 & Schaf & 4000 & 100 & 1000 \\
\hline \multirow[t]{3}{*}{ Pankreas } & Trypsin & Schwein & 0,3 & 0,4 & 0,8 \\
\hline & Chymotrypsin & Schwein & $>1000$ & $>1000$ & $>1000$ \\
\hline & Elastase & Schwein & $>1000$ & $>1000$ & $>1000$ \\
\hline \multirow[t]{2}{*}{ Koagulation } & Thrombin & Mensch & $>1000$ & $>1000$ & $>1000$ \\
\hline & Faktor XA & Mensch & $>1000$ & $>1000$ & $>1000$ \\
\hline \multirow[t]{2}{*}{ Fibrinolyse } & Plasmin & Mensch & $\sim 600$ & $\sim 400$ & $>1000$ \\
\hline & tPA & Mensch & $>1000$ & $>1000$ & $>1000$ \\
\hline \multirow[t]{2}{*}{ Neutrophile } & Elastase & Mensch & $>1000$ & $>1000$ & $>1000$ \\
\hline & Cathepsin G & Mensch & $>1000$ & $>1000$ & $>1000$ \\
\hline \multirow[t]{2}{*}{ Kallikreine } & $\mathrm{pK} 1$ & Schwein & $>1000$ & $>1000$ & $>1000$ \\
\hline & $\mathrm{hK} 3$ & Mensch & $>1000$ & $>1000$ & $\sim 100$ \\
\hline
\end{tabular}

Tabelle 4.2.4.: Erste Ergebnisse der Selektivitätsstudien von McoEeTI, McoTI-KKV und McoTI-R (Messungen durchgeführt in der Abteilung Sommerhoff).

Wie aus Tabelle 4.2.4. ersichtlich, werden alle getesteten $\beta$-Tryptase Isomere von dem jeweiligen Inhibitor in vergleichbarer Weise gehemmt. Nur gegenüber Trypsin ergaben sich noch niedrigere $\mathrm{K}_{\mathrm{i}}$ Werte im Bereich von unter $1 \mathrm{nM}$. Die Inhibition aller anderen getesteten Proteasen ist dagegen nur gering. $\mathrm{Zu}$ beachten ist, dass bei allen Messungen, wo der Wert $>1000 \mathrm{nM}$ angegeben ist, bisher bei den ersten Experimenten keine Inhibition bei $1 \mu \mathrm{M}$ Inhibitor gemessen wurde.

Die Selektivität eines Tryptase Inhibitors kann man als das Verhältnis zwischen dem $\mathrm{K}_{\mathrm{i}}$ Wert gegenüber der jeweiligen Protease und dem jeweiligen $K_{i}$ Wert gegenüber Tryptase ( $\beta$-III) definieren. Die Selektivitäten der drei getesteten Inhibitoren gegenüber Trypsin, Kallekrein, 
uPA, Plasmin und Thrombin sind in Tabelle 4.2.5. im Vergleich zu den veröffentlichten Daten der Tryptase Inhibitoren RWJ-56423, APC-366 und Babim [Costanzo et al., 2003, Katz et al., 1998, Rice et al., 1998] aufgelistet. Alle drei Inhibitoren sind hinsichtlich der Selektivität gegenüber den getesteten Proteasen in einem in etwa vergleichbaren Bereich mit Babim, APC-366 und RWJ-56423. Zu beachten ist jedoch, dass diese Selektivitäten aus den vorläufigen Messungen, in denen bei mehreren Proteasen bei $1 \mu \mathrm{M}$ Inhibitorkonzentration keine Inhibition messbar war (Tabelle 4.2.4.), berechnet sind.

\begin{tabular}{|c|c|c|c|c|c|c|}
\hline \multicolumn{2}{|c|}{ K $_{\text {iapp }}[\mathbf{n M}]$} & \multicolumn{5}{c|}{ Selektivität $^{\text {a }}$} \\
\hline Inhibitor & Tryptase & Trypsin & Kallikrein & uPA & Plasmin & Thrombin \\
\hline McoEeTI & 100 & 0,003 & $>10$ & n.b. & 6 & $>10$ \\
\hline McoTI-KKV & 2 & 0,2 & $>500$ & n.b. & 200 & $>500$ \\
\hline McoTI-R & 20 & 0,04 & 5 & n.b. & $>50$ & $>50$ \\
\hline & & & & & & \\
\hline RWJ-56423 & 10 & 0,8 & 32 & 220 & 810 & 31000 \\
\hline APC-366 & 330 & 0,5 & $>3000$ & n.b. & $>3000$ & 1,3 \\
\hline Babim & 140 & 1,3 & 0,7 & 7,5 & 20 & 32 \\
\hline
\end{tabular}

Tabelle 4.2.5.: Selektivitäten der getesteten Varianten gegenüber Trypsin, Kallikrein, uPA (uPA= urokinasetype plasminogen activator), Plasmin und Thrombin und Vergleich zu anderen Tryptase Inhibitoren [Costanzo et al., 2003, Katz et al., 1998, Rice et al., 1998]. Selektivität ist definiert als das Verhältnis zwischen den $\mathrm{K}_{\mathrm{i}}$ Werten gegenüber der jeweiligen Protease und dem jeweiligen $\mathrm{K}_{\mathrm{i}}$ Wert gegenüber Tryptase ( $\beta$-III).

\subsubsection{Bivalente Inhibitoren}

Die spezielle tetramere Architektur der aktiven humanen Tryptase ermöglicht eine Potenzierung der inhibitorischen Aktivität und damit verbunden eine deutliche Erhöhung der Selektivität durch Generierung bivalenter Inhibitoren [Schaschke et al., 2001]. Diese Potenzierung der inhibitorischen Aktivität, die bereits anhand chemisch synthetisierter dibasischer Moleküle gezeigt werden konnte [Schaschke et al., 2002, Schaschke et al., 2001, Selwood et al., 2003], lässt sich durch eine Erhöhung der freien Energie bei der Bindung von bivalenten Inhibitoren durch Erhöhung der Translations- und Rotations-Entropie [Schaschke et al., 2001] erklären. Für die Verknüpfung der Inhibitormoleküle sind dabei aus energetischen Gründen starre linker vorzuziehen, die jedoch eine optimale Passung der beiden Kopfgruppen in die S1 Tasche der Tryptase erfordern [Schaschke et al., 2001].

Aus den genannten Gründen sollte ein bivalenter Tryptase Inhibitor auf Cystin-Knoten Mikroprotein Basis generiert werden. Bis dato ist die Dimerisierung von Cystin-Knoten Mikroproteinen in der Literatur nicht beschrieben. Eine Strategie für die chemische Verknüpfung zweier Mikroproteine stellt die Verbindung über in das Mikroprotein 
einzuführende singuläre Lysinreste dar, die mittels eines homobifunktionalem NHydroxysuccinimid-Esters (NHS-Ester) wie z.B. Disuccinimidylsuberat (DSS) verlinkt werden sollen. Da die für die Dimerisierung ursprünglich vorgesehene McoEeTI Variante 3RT keine inhibitorische Aktivität gegenüber Tryptase aufwies (Tabelle 4.2.3.), sollte als proof of concept ein Dimer auf Basis von EETI-II M7I erstellt werden (Barnase'-EETI-II M7I hat einen Ki Wert von 1,3 $\mu \mathrm{M}$ gegenüber Tryptase, die Daten wurden noch nicht gezeigt). Die Sequenz der $\mathrm{zu}$ erstellenden nur ein Lysin enthaltenden Variante und die Dimerisierungsstrategie ist in Abbildung 4.2.10. dargestellt.

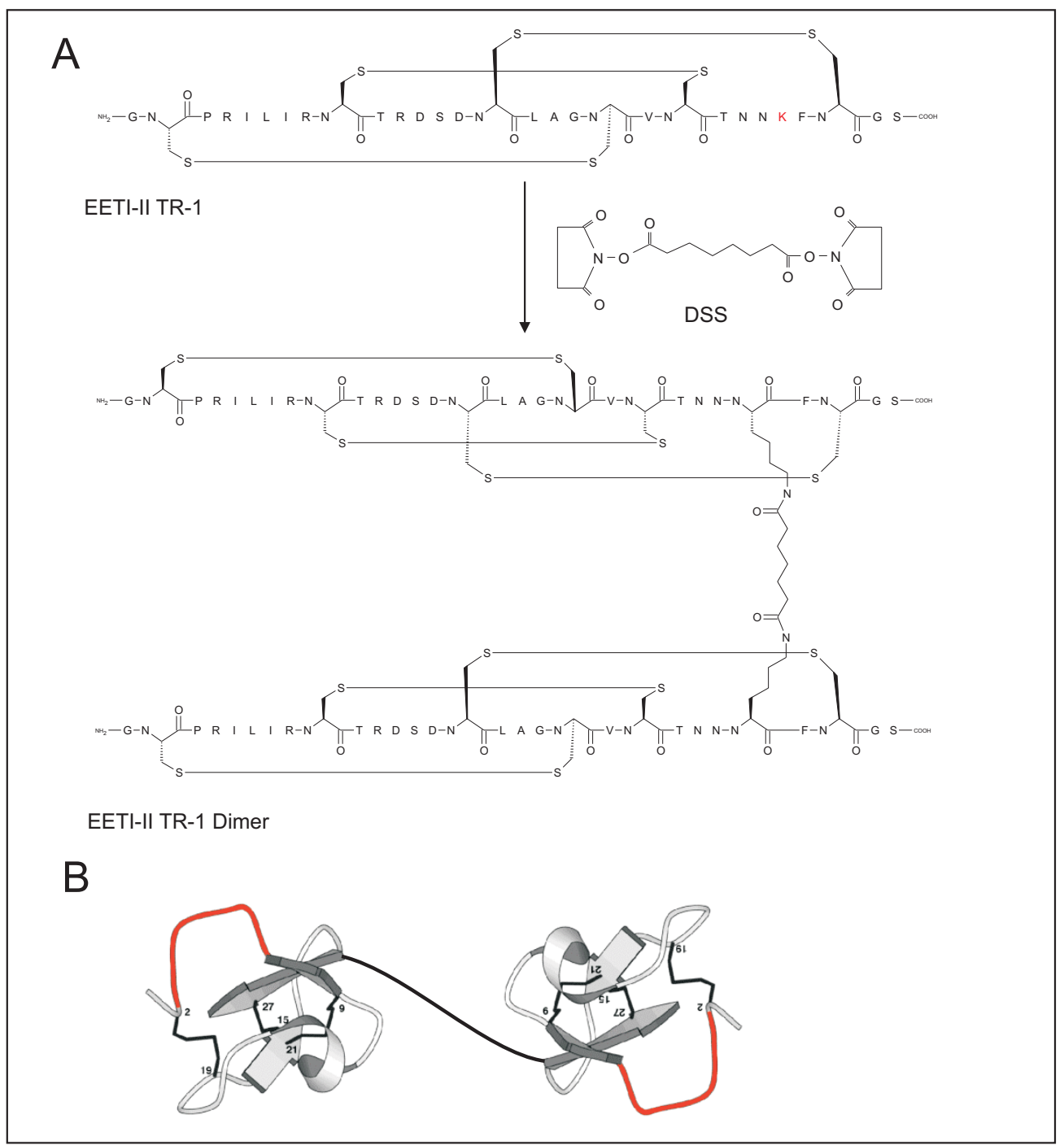

Abbildung 4.2.10.: Schematische Darstellung der Dimerisierung der EETI-II Variante TR-1. (A) Aminosäuresequenz von EETI-II TR-1 und dem durch Verknüpfung zweier Monomere über ein singuläres Lysin entstehenden Dimer. Die Cysteine sind jeweils im Detail ausgeschrieben und durch Disulfidbrücken verbunden. (B) Schematische dreidimensionale Darstellung eines EETI-II Dimers. Die Inhibitorschleife ist in rot hervorgehoben.

\subsection{Klonierung, Expression und Reinigung von EETI-II TR-1}

Die für die Dimerisierung vorgesehene EETI-II Variante -TR-1 sollte über das vorgestellte Expressionssystem in E. coli als Barnase' Fusion produziert werden. Dazu wurde das EETI-II 
TR-1 Gen zunächst in einer zweistufigen SOE-PCR (3.3.3.) amplifiziert. Als Matrize diente der Vektor pBar100-EETI-II M7I. Dabei wurden im ersten Schritt mit den Oligonukleotiden ETI-TNNKSOEup und cat-Hind-Mitte-lo sowie Barmitte-up und ETI-TR-SOE-lo zwei überlappende Fragmente generiert. Diese wurden in einem zweiten PCR Schritt zu einem Fusionsgen aus dem halben Barnase' Gen, EETI-II TR-1 und dem halbem Chloramphenicol Resistenzgen zusammengefügt. Das PCR Produkt wurde mittels Phenol/Chloroform Extraktion (3.2.3.2.) und anschließender Ethanol Fällung (3.2.2.1.) gereinigt, mit Nco I und Hind III gespalten (3.3.1.) und mit dem gleichermaßen geschnittenen Vektor pBar100-EETIII M7I ligiert (3.3.2.). Ein Schema der Klonierung ist in Abbildung 4.2.11. dargestellt.

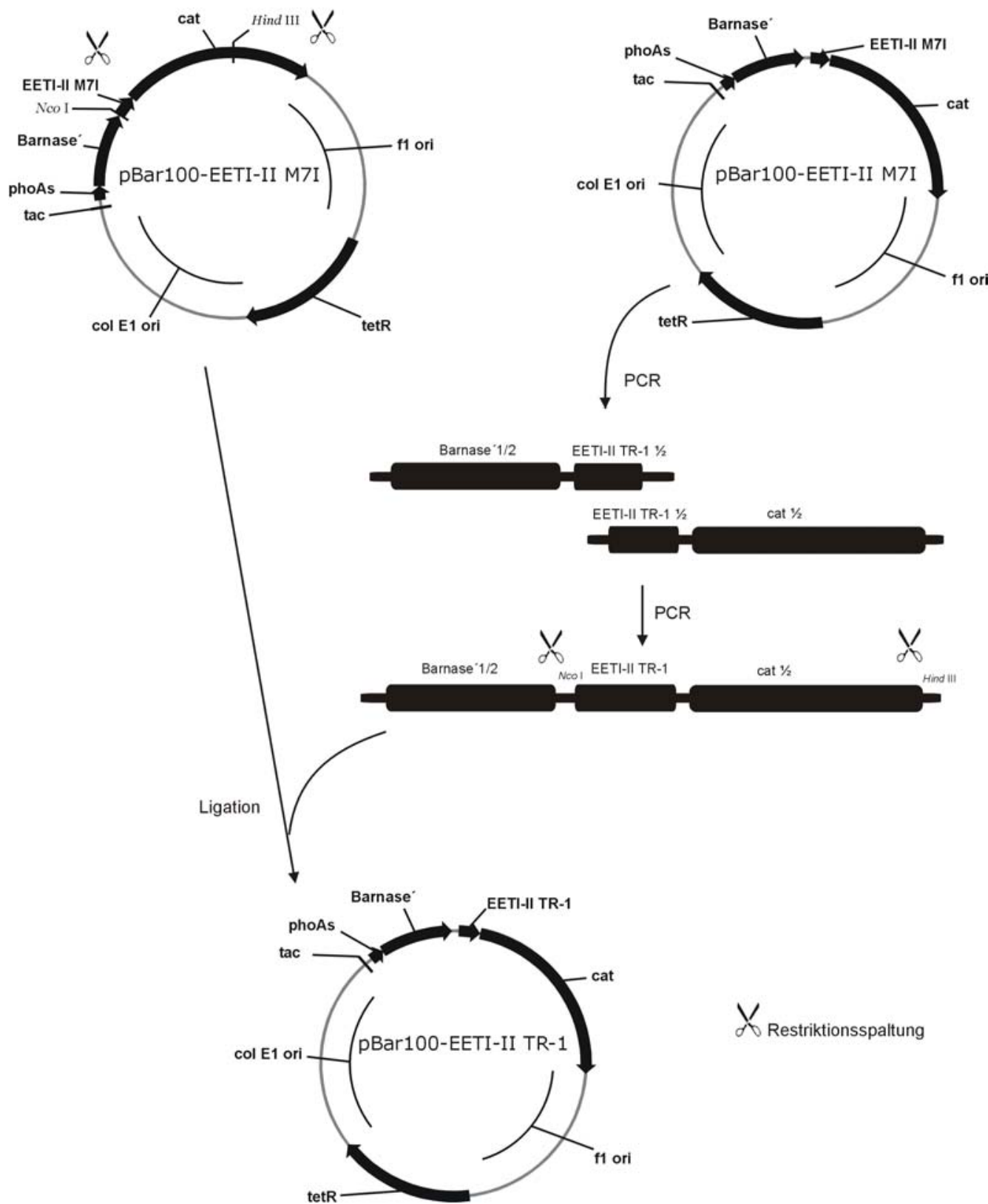

Abbildung 4.2.11.: Schematische Darstellung der Klonierung von pBar100-EETI-II TR-1. Beschreibung der Klonierung im Text. Die Pfeilrichtungen geben die funktionellen Orientierungen der genetischen Elemente an. Cat, Chloramphenicol Resistenz Gen; Barnase', Gen für Barnase His ${ }^{102}$ Ala; EETI-II M7I, Gen für die $M^{7}$ I Mutante des Trypsin Inhibitors EETI-II; tac, Tac Promotor Region; tetR, Tetrazyklin Repressor Gen; f1 ori, 
Replikationsursprung des Phagen f1; col E1 ori, col E1 Replikationsursprung; phoAs, Alkalische Phosphatase periplasmatische Signal Sequenz; EETI-II TR-1, Gen der für die Dimerisierung vorgesehene EETI-II Variante TR-1.

Die Expression von Barnase'-EETI-II TR-1 in E. coli 71-18 pRep4 erfolgte wie in Abschnitt 4.2.2.2. beschrieben im 11 Fermenter. Auch die Reinigung des Fusionsproteins erfolgte analog wie in 4.2.2.2. beschrieben durch kombinierte Kationenaustausch-/RP-HPLC als ersten Reinigungsschritt (3.4.6.2.) und einer weiteren Kationenaustauschchromatographie (3.4.6.3.) als zweiten Reinigungsschritt. Das Chromatogramm der finalen Reinigung ist in Abbildung 4.2.12. A dargestellt.

A

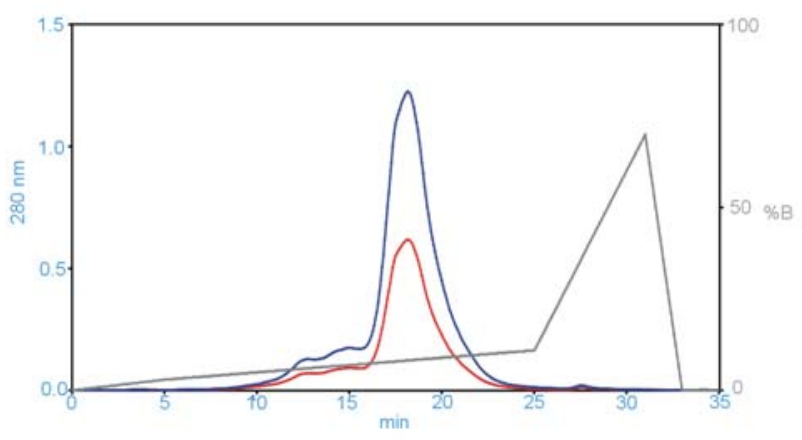

B

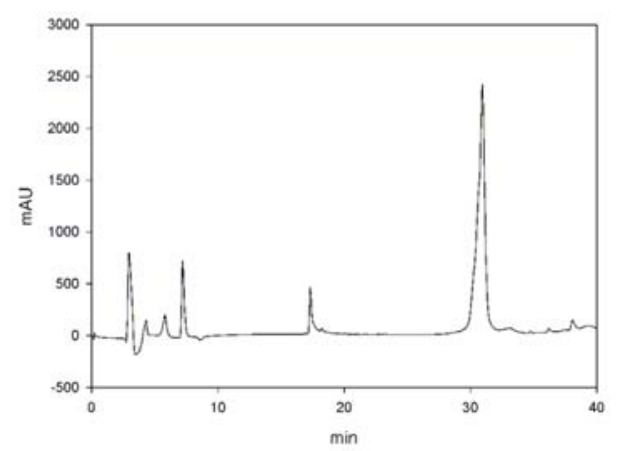

Abbildung 4.2.12. Chromatographische Reinigung von EETI-II TR-1. (A) Chromatogramm der Reinigung von Barnase'-EETI-II TR-1 über Kationenaustauschchromatographie. In blau dargestellt ist der Verlauf der OD $\mathrm{OD}_{280}$, in rot der $\mathrm{OD}_{260}$ über die Zeit in min. In grau: $\mathrm{NaCl}$ Gradient in \% einer $3 \mathrm{M}$ Stammlösung. (B) Analyse der BrCN Spaltung von Barnase-EETI-II TR-1 über RP-HPLC. Aufgetragen ist der Verlauf der $\mathrm{OD}_{217}$ (in mAU) über die Zeit in min. Das abgespaltene Mikroprotein ( bei $17 \mathrm{~min})$ eluiert bei einer deutlich geringeren Acetonitril Konzentration als das Barnase' Trägerprotein.

Die einzelnen Fraktionen der Reinigung wurden mittels SDS-PAGE (3.4.1.) analysiert. Fraktionen, die das reine Fusionsprotein enthielten, wurden vereinigt. Das Protein wurde mittels Säurefällung (3.4.5.2.) und anschließender Zentrifugation präzipitiert, und mit Bromcyan gespalten (3.4.9.1.). Die Spaltung wurde am nächsten Tag zunächst über RP-HPLC (3.4.6.5.) analysiert (Abbildung 4.2.12. B) und das abgespaltene Mikroprotein dann über präparative RP-HPLC an der Vision Biocad ${ }^{\circledR}$ workstation (3.4.6.4.) isoliert. Es folgte eine Analyse der einzelnen Fraktionen der Reinigung mittels SDS-PAGE (3.4.1.). Mikroprotein enthaltene Fraktionen wurden vereinigt und lyophilisiert. Die Ausbeute betrug $5 \mathrm{mg}$ reines EETI-II TR-1 Mikroprotein. Das entspricht bei $41 \mathrm{mg}$ gespaltenem Fusionsprotein (aus 21 Zellkultur) etwa $61 \%$ der theoretisch erwarteten Menge (das Massenverhältnis von Mikroprotein zum Fusionsprotein beträgt etwa 1:5). Die molekulare Masse des abgespalteten und gereinigten Mikroproteins konnte mittels ESI-MS verifiziert werden. 


\subsection{Dimerisierung von EETI-II TR-1}

Disuccinimidylsuberat (DSS) ist ein homobifunktionaler N-Hydroxysuccinimid-Ester, der mit primären Aminen unter Ausbildung einer Amidbindung und Abspaltung von NHydroxysuccinimid reagiert. Diese Reaktion sollte für die Dimerisierung von EETI-II TR-1 über das singuläre Lysin an Position \#25 des Mikroproteins ausgenutzt werden (Abbildung 4.2.10). Dazu wurden 3,5 mg des Mikroproteins wie in Abschnitt 3.6.1. beschrieben in DMF/Triethylamin mit 0,5 Moläquivalenten DSS versetzt und ü.N. bei RT inkubiert. Da neben der $\varepsilon$-Aminogruppe der Lysin-Seitenkette auch die N-terminale $\alpha$-Aminogruppe des Mikroproteins mit dem NHS-Ester zu einem stabilen Produkt reagiert, ist auch die Bildung von tri- und tetrameren Spezies möglich. Aus diesem Grund wurde eine Reinigung des Dimerisierungsansatzes über RP-HPLC (3.4.6.5.) oder Gelfiltration (3.4.7.) angeschlossen. Durch keine der beiden Methoden konnte jedoch das Dimer vollständig von den mono-, triund tetrameren Mikroprotein Spezies abgetrennt werden (Abbildung 4.2.13.). Es wurden daher für die anschließenden Tryptase Inhibitionstests drei verschiedene Fraktionen mit unterschiedlichem Anteil an Verunreinigungen eingesetzt. Von Fraktion 1 (Abbildung 4.2.13. A Spur 2) waren $100 \mu \mathrm{g}$, von Fraktion 2 (Abbildung 4.2.13. B Spur 4) $200 \mu \mathrm{g}$ und von Fraktion 3 (Abbildung 4.2.13. B Spur 5) $700 \mu \mathrm{g}$ für die anschließenden Tests vorhanden.

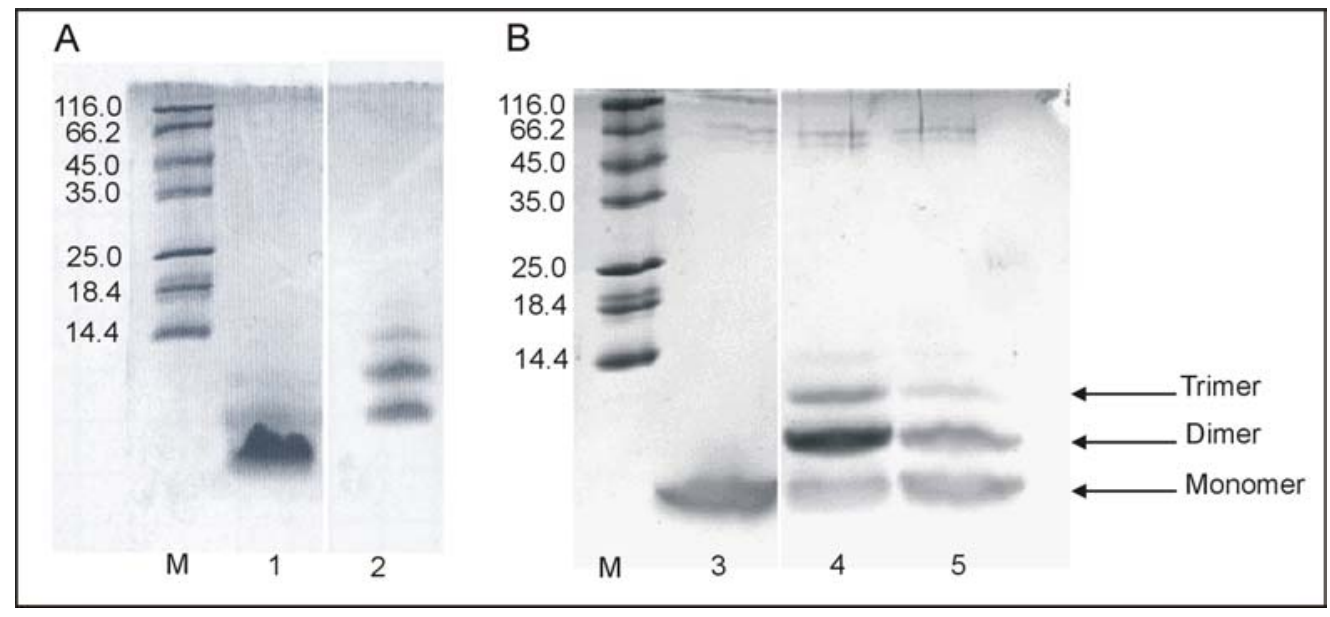

Abbildung 4.2.13.: SDS-PAGE Analyse der Dimerisierung von EETI-II TR-1 nach Gelfiltration (A) bzw. nach RP-HPLC (B). M: Molekulargewichts Standard (Größenangabe jeweils links in kDa); 1, 3: EETI-II TR-1 vor Dimerisierung; 2: Fraktion nach Dimerisierung und Gelfiltration; 4,5: Fraktionen nach Dimerisierung und RPHPLC.

\subsection{Inhibition der humanen $\beta$-III Tryptase mit dem dimerisierten EETI-II TR-1}

\section{Protein}

Im vorangehenden Abschnitt konnte gezeigt werden, dass es möglich ist, Mikroproteine über eingeführte singuläre Lysin Reste mittels bifunktionaler NHS-Ester zu dimerisieren. Für die Dimerisierung von EETI-II TR-1 wurde DSS benutzt, was zu einem sieben C-Atome langen linker zwischen den beiden Stickstoffatomen der Lysine führt (Abbildung 4.2.10.). Ob sich 
dieser linker für eine optimale Passung der beiden Mikroprotein Kopfgruppen in zwei gegenüberliegende S1 Taschen der Tryptase Monomere eignet, sollte über die Messung der inhibitorischen Aktivität von monomerem und dimerem EETI-II TR-1 bestimmt werden. Wie aus Tabelle 4.2.6. ersichtlich, hat sich der $\mathrm{K}_{\mathrm{i}}$ Wert gegenüber Trypsin des monomeren EETIII TR-1 im Vergleich zur Ausgangsvariante -M7I durch die Modifikationen nicht verschlechtert. Jedoch zeigte sich bei keiner der drei getesteten Dimer Fraktionen ein positiver Effekt, d.h. offensichtlich konnten die Mikroprotein Kopfgruppen mit dem verwendeten linker nicht in optimaler Weise positioniert werden.

\begin{tabular}{|c|c|c|c|}
\hline Variante & Aktivität [\%] $^{\mathbf{a}}$ & $\mathbf{K}_{\text {iapp }} \boldsymbol{v s}$ Trypsin [nM] & $\mathbf{K}_{\text {iapp }} \boldsymbol{v s}$ Tryptase [nM] \\
\hline Barnase-EETI-II M7I & 65 & 0,1 & 1300 \\
\hline EETI-II TR-1 & 38 & 0,1 & 1000 \\
\hline EETI-TR-1 Dimer Fr.1 & 3 & 0,1 & $>1500$ \\
\hline EETI-TR-1 Dimer Fr.2 & 78 & 0,2 & 1100 \\
\hline EETI-TR-1 Dimer Fr.3 & 31 & 0,1 & 1100 \\
\hline
\end{tabular}

Tabelle 4.2.6.: Ergebnisse der Tryptase Inhibitionstests. ${ }^{a}$, bestimmt mittels active site Titration mit Trypsin. Die Werte wurden in der Abteilung Dr. Sommerhoff bestimmt.

Schaschke et al. machten bei ihren Untersuchungen mit bivalenten chemisch synthetisierten Inhibitoren die Beobachtung, dass schon der Austausch eines Glycin gegen ein $\beta$-Alanin zu einer deutlichen Veränderung in der inhibitorischen Aktivität gegenüber Tryptase führte [Schaschke et al., 2001]. Bei der Dimerisierung von EETI-II TR-1 mit DSS handelte es sich lediglich um einen ersten sondierenden Versuch. Weiterführende Untersuchungen sollten auf die Variation der Länge des linkers und der Position des Verknüpfungspunktes in der Peptidkette abzielen.

\subsubsection{Diskussion und Ausblick}

In dem zurückliegenden Kapitel wurde das Konzept der Neufunktionalisierung von CystinKnoten Mikroproteinen anhand zweier Beispiele eingeführt. Da es sich bei den als Grundgerüst verwendeten Proteinen EETI-II, McoEeTI bzw. McoTI um Trypsin Inhibitoren handelt, wurde zunächst die naheliegende Möglichkeit einer Generierung von Inhibitoren therapeutisch interessanter Serinproteasen ergründet.

Im ersten Abschnitt konnte gezeigt werden, dass durch Transplantation des N-terminalen Bereichs des Elastase Inhibitors MCEI-III in das Grundgerüst von EETI-II auch dessen Funktion auf das entstehende Hybridprotein übertragbar ist. Nach Produktion und Reinigung

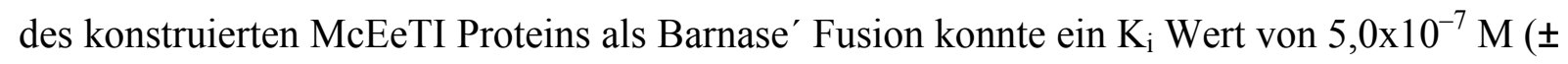
$8,1 \times 10^{-8}$ ) gegenüber Porcine Pankreas Elastase (PPE) bestimmt werden. Dieser Wert liegt 
zwar um etwa zwei Zehnerpotenzen über dem von Hamato et al. bestimmten Wert für MCEIIII [Hamato et al., 1995], was z.B. auf eine sterische Behinderung durch die Fusionierung an Barnase' zurückzuführen sein könnte. Er zeigt jedoch, dass die transplantierte Inhibitorschleife durch das Cystin-Knoten Grundgerüst von EETI-II in einer konformationellen Struktur positioniert wurde, die die Inhibition der Elastase ermöglichte.

Tryptasen sind die mengenmäßig dominierenden Proteine humaner Mastzellen. Die Trypsinähnlichen Serinproteasen wurden in den letzten Jahren in den Kontext verschiedener pathophysiologischer Prozesse gebracht. So wird der Tryptase eine Mediator Rolle in allergischen und inflammatorischen Prozessen wie z.B. Rhinitis, Conjunctivitis und vor allem Asthma [Tanaka et al., 1995] zugesprochen. Durch die tetramere Struktur der Tryptase in der aktiven Form, deren zentrale Pore nur den Eintritt kleinerer Moleküle ermöglicht, wurden bisher hauptsächlich kleine chemisch synthetisierte Inhibitoren entwickelt. Obwohl die Wirksamkeit der entwickelten Tryptase Inhibitoren in vitro bzw. z.B. bei dem Inhibitor APC366 [Krishna et al., 2001] im Tierexperiment nachgewiesen werden konnte [Clark et al., 1995], scheiterten zahlreiche Inhibitoren auf small-molecule Basis aus verschiedenen Gründen in der weiteren Entwicklung [Newhouse, 2002]. Die einzige Verbindung, die bisher die klinische Phase II durchlaufen hat, ist der dibasische Inhibitor APC-2059 [Rice et al., 2000, Tremaine et al., 2002].

Cystin-Knoten Mikroproteine besitzen im Vergleich zu small-molecules möglicherweise verschiedene Vorteile z.B. hinsichtlich ihrer Stabilität und Paßgenauigkeit. Es sollten daher im Rahmen dieser Arbeit Tryptase Inhibitoren auf Mikroprotein Basis generiert werden.

Insgesamt konnten 15 verschiedene EETI-II bzw. McoEeTI Varianten und in Zusammenarbeit mit Olga Avrutina 8 verschiedene McoTI Varianten hergestellt werden. Diese wurden in der Abteilung von Prof. Dr. Sommerhoff auf ihre inhibitorische Aktivität gegenüber Tryptase getestet. Es zeigte sich, dass sich McoEeTI bzw. McoTI als Grundgerüst für die Generierung potenter Tryptase Inhibitoren eignet. Aufgrund ihrer geringen Größe werden im Gegensatz zum leech-derived-trypsin-inhibitor (LDTI) [Auerswald et al., 1994, Pohlig et al., 1996, Sommerhoff et al., 1994] alle vier Monomere der Tryptase besetzt und inhibiert. Neben der obligaten positiv geladenen Aminosäure in der P1 Position scheint eine generelle positiv geladene Oberflächenstruktur wichtig für die inhibitorische Funktion von McoEeTI bzw. McoTI zu sein. Durch Einfügen der aminoterminalen Reste KKV von LDTI konnte der $\mathrm{K}_{\mathrm{i}}$ Wert gegenüber $\beta$-III Tryptase von 20 (McoTI-K) auf $2 \mathrm{nM}$ (McoTI-KKV) 
gesenkt werden, was im Bereich veröffentlichter Daten von Inhibitoren auf chemischer Basis liegt.

Neben einer starken Inhibition der humanen Tryptase stellt insbesondere die Selektivität gegenüber anderen Proteasen einen entscheidenden Aspekt für therapeutische Applikationen dar. Daher wurden die drei generierten Inhibitoren McoTI-R, McoTI-KKV und McoEeTI auf inhibitorische Aktivität gegenüber anderen wichtigen Serinproteasen aus dem Pankreas, der Blutgerinnung, aus dem Bereich der Immunabwehr und zwei Vertreter der Kallikreine getestet (Tabelle 4.2.4.). Aus den (bisher nur vorläufigen) Werten wurde die Selektivität des jeweiligen Inhibitors gegenüber der jeweiligen Protease bestimmt und ein Vergleich mit den small-molecule Inhibitoren RWJ-56423, APC-366 und Babim (Tabelle 4.2.5.) angestellt. Alle drei Inhibitoren sind hinsichtlich der Selektivität gegenüber den getesteten Proteasen in einem vergleichbaren Bereich zu Babim, APC-366 und RWJ-56423.

Die spezielle tetramere Architektur der humanen Tryptase macht wie bereits mehrfach gezeigt wurde [Schaschke et al., 2002, Schaschke et al., 2001, Selwood et al., 2003] das rationale Design bivalenter Inhibitoren möglich. Durch die energetischen Vorteile dieser bivalenten Inhibitoren können theoretisch im Vergleich zum Monomer potenzierte Inhibitionskonstanten und damit verbunden auch drastisch erhöhte Selektivitäten erreicht werden. In Abschnitt 4.2.2.5. wurde erstmals die Dimerisierung eines Cystin-Knoten Mikroproteins beschrieben und damit die Grundlage für die Herstellung bivalenter Inhibitoren gelegt. Auf Basis von EETI-II wurde eine Variante mit einem singulärem Lysin Rest an Position \#25 des Mikroproteins konstruiert. Diese als EETI-II TR-1 bezeichnete Variante wurde als Barnase'Fusion produziert und gereinigt. Nach Abspaltung des Trägerproteins konnte das Mikroprotein mittels DSS, einem homobifunktionalen N-Hydroxysuccinimid-Ester, über die Lysin Seitenkette erfolgreich dimerisiert werden. Eine Verbesserung der inhibitorischen Aktivität des generierten Dimers gegenüber Tryptase konnte jedoch nicht gemessen werden, was vermutlich auf eine ungeeignete Länge des verwendeten linkers zurückzuführen ist.

Es sollte daher für die Dimerisierung in Zukunft unter Verwendung der Kristallstrukturen von Barnase'-McoEeTI (Niemann et al., Manuskript in Vorbereitung) und der humanen $\beta$-II Tryptase [Pereira et al., 1998] eine genaue Analyse der für die optimalen Positionierung der Mikroprotein Kopfgruppen erforderlichen linker Länge durchgeführt werden. Des weiteren sollte in Zukunft neben der Optimierung der bestehenden McoEeTI bzw. McoTI Inhibitoren ein Nachweis der biologischen Wirksamkeit in vivo erfolgen. 


\subsection{Generierung Thrombopoietin mimetischer Mikroproteine}

Eine Vielzahl von Hormonen und Zytokinen initiieren Signaltransduktionskaskaden, indem sie durch agonistische Bindung die Dimerisierung zweier Rezeptormoleküle auslösen. Die Agonisten sind entweder als Dimer wirksam, wobei jedes Monomer ein Monomer des Rezeptors bindet, oder sie agieren als Monomer mit zwei verschiedenen Binderegionen [Frank, 2002, Grötzinger, 2002, Mellado et al., 2001].

Ein bekanntes Beispiel für die Aktivierung eines in der Zelloberfläche verankerten Rezeptors durch die Liganden-vermittelte Dimerisierung zweier Rezeptormoleküle ist das TPO/TPOR System [Dower et al., 1998, Geddis et al., 2002]. Thrombopoietin (TPO) ist ein aus 332 Aminosäuren bestehendes glykosyliertes Protein, das eine Schlüsselrolle in der Regulation der Bildung von Thrombozyten aus Megakaryozyten, der Megakaryozytopoese, einnimmt [de Sauvage et al., 1994, Kaushansky und Drachman, 2002]. TPO wird hauptsächlich in der Leber produziert, nimmt aber seine Hauptfunktion im Knochenmark wahr, wo es die Differenzierung von Stammzellen zu Megakaryozyten-Vorläufern und Wachstum und Differenzierung von Megakaryozyten stimuliert. Damit ist das Zytokin der primäre Regulator in Thrombozyten-Mangelsituationen, sogenannter Thrombozytopenie. Häufigste Ursachen der Thrombozytopenie sind myelosuppressive Chemotherapien, Radiotherapien, Infektionen oder allergische Reaktionen auf das blutgerinnungshemmende Medikament Heparin und das Antibiotikum Chloramphenicol sowie seltene Erbkrankheiten wie das TAR-Syndrom (Thrombocytopenia with Absent Radius). Die therapeutische Applikation von TPO bei Thrombozytopenie ist daher naheliegend. Erste klinische Studien untersuchen die Wirksamkeit von rekombinantem TPO für die Rückbildung der Thrombozyten bei Krebspatienten, die mit myelosuppressiver oder myeloablativer Therapie behandelt wurden [Jones et al., 1998]. Weitere Studien wurden zudem mit an Polyethylenglykol (PEG) gekoppeltem megakaryocyte differentiation factor (peg-MGDF, ein an PEG gekoppeltes aminoterminales TPO Fragment) [Fanucchi et al., 1997] durchgeführt. Bei den Studien traten jedoch Probleme bzgl. der Antigenizität der rekombinanten Proteine auf [Basser et al., 2002, Li et al., 2001]. Obwohl „,nur“ die Bildung transienter und nicht neutralisierender Antikörper beschrieben wurde, besteht dabei die Gefahr einer Antikörperbildung gegen endogenes TPO. Eine Alternative für die Applikation von rekombinantem TPO stellen TPO Mimetika dar. Neben der kürzlich veröffentlichten Entwicklung von agonistisch wirkenden Antikörpern [Orita et al., 2005] konnten bereits 1997 von Cwirla et al. [Cwirla et al., 1997] TPOPeptidmimetika aus einer phage display Bibliothek isoliert werden. Diese Peptide sind nicht 
sequenz-homolog zu TPO, binden jedoch mit hoher Affinität an den TPO Rezeptor. Durch chemische Dimerisierung der Peptide konnte die agonistische Aktivität bis auf ein mit dem natürlichen Zytokin vergleichbares Level gesteigert werden. Der therapeutische Einsatz von peptidischen Wirkstoffen ist jedoch durch die geringe proteolytische Stabilität limitiert, was zu einer kurzen Plasma-Halbwertzeit führt und zudem eine orale Applikation verhindert.

Die angeführten Nachteile der peptidischen Agonisten könnten durch den Einbau in ein stabiles Grundgerüst, wie es Cystin-Knoten Mikroproteine bereitstellen können, umgangen werden. Zudem sollte in diesem zweiten Beispiel einer Neufunktionalisierung von Mikroproteinen die Möglichkeit ergründet werden, ob nicht nur die bindende, sondern auch die aktivierende Funktion der Peptide durch Einführung in ein konformationell starres Gerüst zwischen zwei Cysteine erhalten bleibt. Es sollten daher in dieser Arbeit Varianten der in Cwirla et al. [Cwirla et al., 1997] beschriebenen Peptide in die Cystin-Knoten Grundgerüste von EETI-II [Heitz et al., 1989, Polanowski et al., 1980] und AGRP', einem Fragment der Melanocortin Rezeptor Bindedomäne des human agouti related proteins AGRP [McNulty et al., 2001] eingesetzt werden. Folgende EETI-II bzw. AGRP' Varianten (Tabelle 4.3.1.) sollten daher generiert und über das in Kapitel 4.1. vorgestellte Barnase' Expressionssystem produziert und gereinigt werden:

\begin{tabular}{|c|c|}
\hline Variante & Aminosäure Sequenz \\
\hline 1 lin & SSSMGGCADGPTLREWISFCGG \\
\hline 2 lin & SSSMIEGPTLRQWLAARA \\
\hline A11 & SSSMGCVRLHESCLGQQVPCCDPAATCGGCADGPTLREWISFCGGCKGS \\
\hline A12 & SSSMGCVRLHESCLGQQVPCCDPAATCYCADGPTLREWISFCYCKGS \\
\hline A21 & SSSMGCVRLHESCLGQQVPCCDPAATCIEGPTLRQWLAARACKGS \\
\hline A31 & SSSMGCVRLHESCLGQQVPCCDPAATCGGTALAIEGPTLRQWLAARACKGS \\
\hline A41 & SSSMGCVRLHESCLGQQVPCCDPAATCGGTCLAIEGPTLRQWLCARACKGS \\
\hline A51 & SSSMGCVRLHESCLGQQVPCCDPAATCYCIEGPTLRQWLAACYCKGS \\
\hline E11 & SSSMGCGGCADGPTLREWISFCGGCKQDSDCLAGCVCGPNGFCGS \\
\hline E21 & SSSMGCIEGPTLRQWLAARACKQDSDCLAGCVCGPNGFCGS \\
\hline E51 & SSSMGCIEGPTLRQWLAACKQDSDCLAGCVCGPNGFCGS \\
\hline
\end{tabular}

Tabelle 4.3.1.: Aminosäuresequenzen der als Barnase'-Fusion herzustellenden AGRP' (Axx) und EETI-II (Exx) Varianten und der als Referenz als Barnase'-Fusion herzustellenden linearen TPO mimetischen Peptide aus Cwirla et al. [Cwirla et al., 1997]. Die in rot hervorgehobenen Bereiche in den Mikroprotein Varianten stammen aus Cwirla et al. [Cwirla et al., 1997]. Blau hervorgehoben sind Aminosäuren, die als spacer eingeführt wurden, bzw. die Cysteine, die wie in AGRP eine vierte S-S Brücke ausbilden.

Für die Transplantation in die Mikroprotein Grundgerüste wurden zwei verschiedene Peptide bzw. Variationen dieser Peptide ausgewählt. Für Peptid 1 (GGCADGPTLREWISFCGG) wurde von Cwirla et al. in einem Kompetitions-ELISA mit einem TPO Fragment (MBP- 
$\mathrm{TPO}_{156}$, als Maltose Binde Protein Fusion) ein $\mathrm{IC}_{50}$ Wert von $60 \mathrm{nM}$, für Peptid 2 (IEGPTLRQWLAARA) ein Wert von $2 \mathrm{nM}$ als Monomer bzw. 0,5 nM als Dimer bestimmt. Die Transplantation der beiden Peptide in das EETI-II Grundgerüst sollte in die flexible Schleife zwischen den Cysteinen I und II, die in EETI-II natürlicherweise die Trypsin Inhibitor Schleife-PRILMR- bildet, erfolgen (Varianten E11, E21 und E51). Bei E51 wurden die beiden carboxyterminalen Aminosäuren des Peptids 2 entfernt, um den von Cwirla et al. vermuteten $\beta$-turn (in der Sequenz GPTL) in dem Peptid symmetrisch zwischen die beiden Cystein Reste zu positionieren. In AGRP' sollte die für die Bindung des Melanocortin Rezeptors verantwortliche Schleife (-CYCRFFNAFCYC-) [Joseph et al., 2003], gegen die jeweilige Peptidsequenz ausgetauscht werden (Varianten A11-A51). Da keine strukturelle Information der Peptide im Komplex mit dem TPO Rezeptor vorhanden ist, sollten verschiedene Varianten konstruiert werden, bei denen das eingeführte Peptid in verschiedene strukturelle Konformationen „gezwängt“ wird. Dies sollte zum einen durch das Einfügen zusätzlicher Aminosäuren in die Schleife (Konstrukt A31) bzw. wie bei den Konstrukten A11, A12, A41 und A51 durch das Einfügen einer vierten Disulfidbrücke (wie in AGRP) erreicht werden (siehe Tabelle 4.3.1.). Als Referenz sollten die linearen Peptide ebenfalls als Barnase'-Fusion (Klone 1lin und 2lin) produziert werden.

Die Aktivität der generierten Varianten sollte im Anschluss von Kooperationspartnern am Institut für Biochemie I in Jena in einem Zell-basierten Lumineszenz Assay und schließlich von Kooperationspartnern in der Abteilung Päd. Hämatologie und Onkologie an der Medizinischen Hochschule Hannover in Zellkultur untersucht werden.

\subsubsection{Klonierung, Produktion und Reinigung der Varianten}

Für die Produktion und Reinigung der Varianten über das in Abschnitt 4.1.2. vorgestellte $E$. coli Expressionssystem wurden die entsprechenden Gene in den Vektor pBar100 kloniert (Abbildung 4.3.1.). Dazu wurde das Gen der entsprechenden Variante zunächst in einer zweistufigen SOE-PCR (3.3.3.) mit dem Oligonukleotid Barmitte-up, zwei innen liegenden Primern und dem Oligonukleotid cat-Hind-Mitte-lo amplifiziert. Als Matrize diente dabei das Plasmid pBar100-AGRP' (A. Wentzel, unveröffentlicht) für alle AGRP' Varianten bzw. das Plasmid pBar100-EETI-II M7I [Schmoldt et al., 2005] für alle weiteren Konstrukte. In der PCR Reaktion wurde dabei jeweils ein Fragment aus dem halben barnase' Gen, dem jeweiligen Gen der zu konstruierenden Variante und dem halben cat Gen generiert. Die Produkte wurden mit Nco I und Hind III gespalten (3.3.1.), mittels Phenol/Chloroform Extraktion (3.2.3.2.) und anschließender Ethanol Fällung (3.2.2.1.) gereinigt, und mit dem 
gleichermaßen geschnittenen Vektor pBar100-EETI-II M7I ligiert (3.3.2.). Nach Transformation von E. coli 71-18 pRep4 (3.1.5.) konnten insert-tragende Transformanten mittels Kolonie PCR (3.3.3.) und anschließender Restriktionsanalyse (3.3.1.) der präparierten Plasmid DNA (3.2.6.) von in der PCR positiven Klonen ermittelt werden. Die jeweiligen Sequenzen konnten durch DNA-Sequenzierung im Laboratorium für Genomanalyse verifiziert werden. Lediglich beim Konstrukt 2lin wurde kein Klon mit der richtigen Sequenz gefunden. Einer der Klone hatte jedoch eine „,tolerierbare“ Insertion von zwei Codons (GlyCys) C-terminal der linker Sequenz (SSSM) und damit N-terminal vor der Sequenz des TPO mimetischen Peptids 2 (siehe Tabelle 4.3.1.).

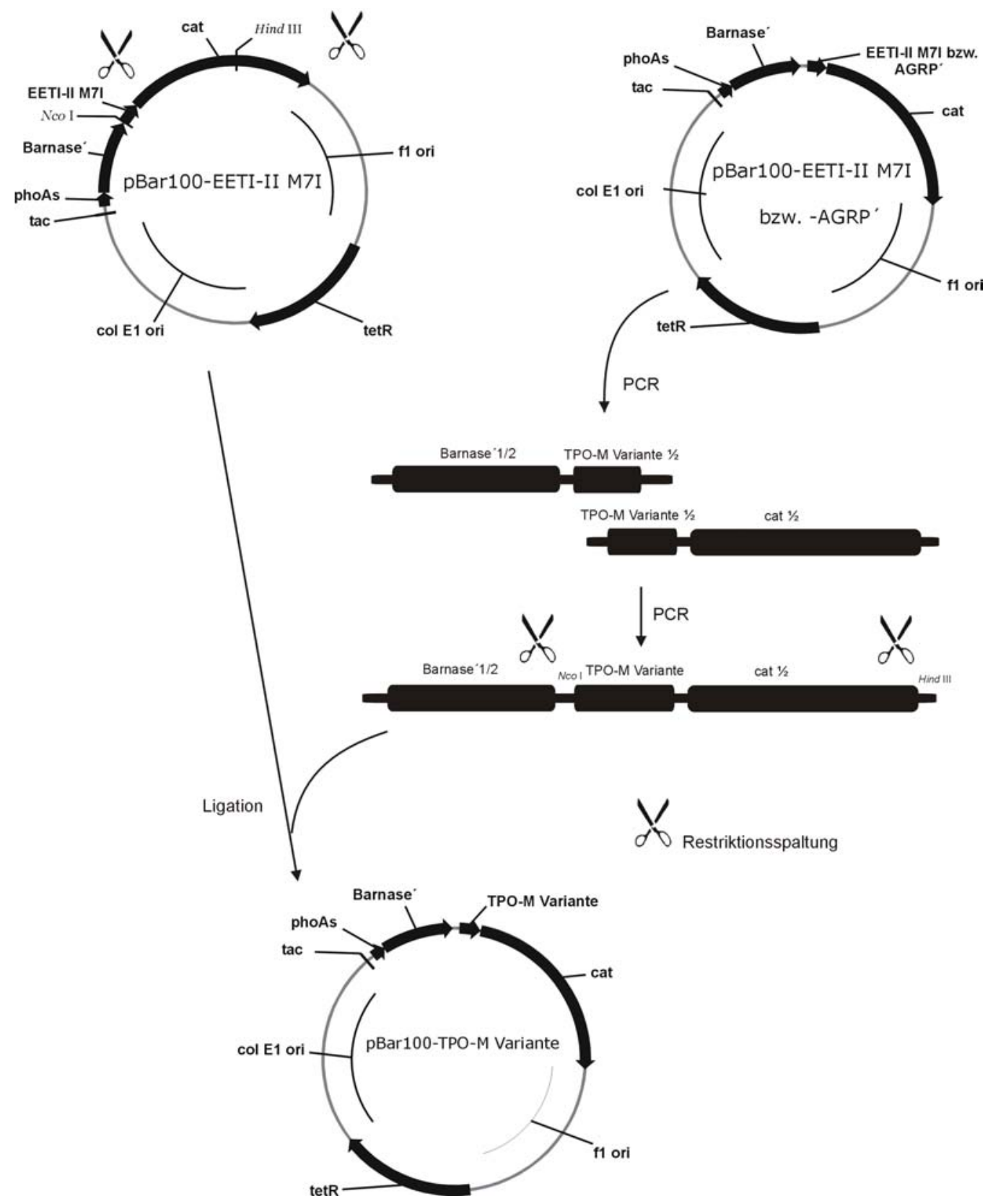

Abbildung 4.3.1.: Schematische Darstellung der Klonierung der TPO Mimetika (TPO-M) Varianten in den Expressionsvektor pBar100. Beschreibung der Klonierung im Text. Die Pfeilrichtungen geben die funktionellen 
Orientierungen der genetischen Elemente an. Cat, Chloramphenicol Resistenz Gen; Barnase', Gen für Barnase His ${ }^{102}$ Ala; EETI-II M7I, Gen für die M $^{7}$ I Mutante des Trypsin Inhibitors EETI-II; tac, Tac Promotor Region; tetR, Tetrazyklin Repressor Gen; f1 ori, Replikationsursprung des Phagen f1; col E1 ori, col E1 Replikationsursprung; phoAs, Alkalische Phosphatase periplasmatische Signal Sequenz; AGRP', Gen für das Cystin-Knoten Mikroprotein AGRP', abgeleitet von der Melanocortin Rezeptor Bindedomäne des human agouti related proteins AGRP [McNulty et al., 2001].

Die Expression der Barnase'-Fusionen erfolgte nach Transformation von E coli 71-18 pRep4 mit dem jeweiligen Plasmid im 11 Fermenter (3.1.7.2.). Die Aufarbeitung der induzierten Kulturen wurde wie in Kapitel 4.1.2. beschrieben nach Ansäuerung mit Essigsäure aus dem Kulturüberstand durchgeführt. Die Barnase' Fusionsproteine wurden zunächst über kombinierte Kationenaustausch-/RP-Chromatographie (3.4.6.2.) gereinigt. Nach SDS-PAGE Analyse (3.4.1.) wurden Fusionsprotein enthaltene Fraktionen vereinigt und lyophilisiert. Die Proteine wurden dann in 0,1 M Tris- $\mathrm{HCl}$ pH 7,8 mit $8 \mathrm{M}$ Harnstoff aufgenommen, ü.N. gegen $50 \mathrm{mM}$ Ammoniumacetat dialysiert (3.4.4.) und zur vollständigen Entfernung von Verunreinigungen erneut über Kationenaustauschchromatographie (3.4.6.3.) an der Vision Biocad $^{\circledR}$ workstation gereinigt (Abbildung 4.3.2.). Die einzelnen Fraktionen der Reinigungen wurden mittels SDS-PAGE (3.4.1.) analysiert. Fraktionen, die das reine Fusionsprotein enthielten, wurden vereinigt und gegen PBS Puffer dialysiert (3.4.4.). 

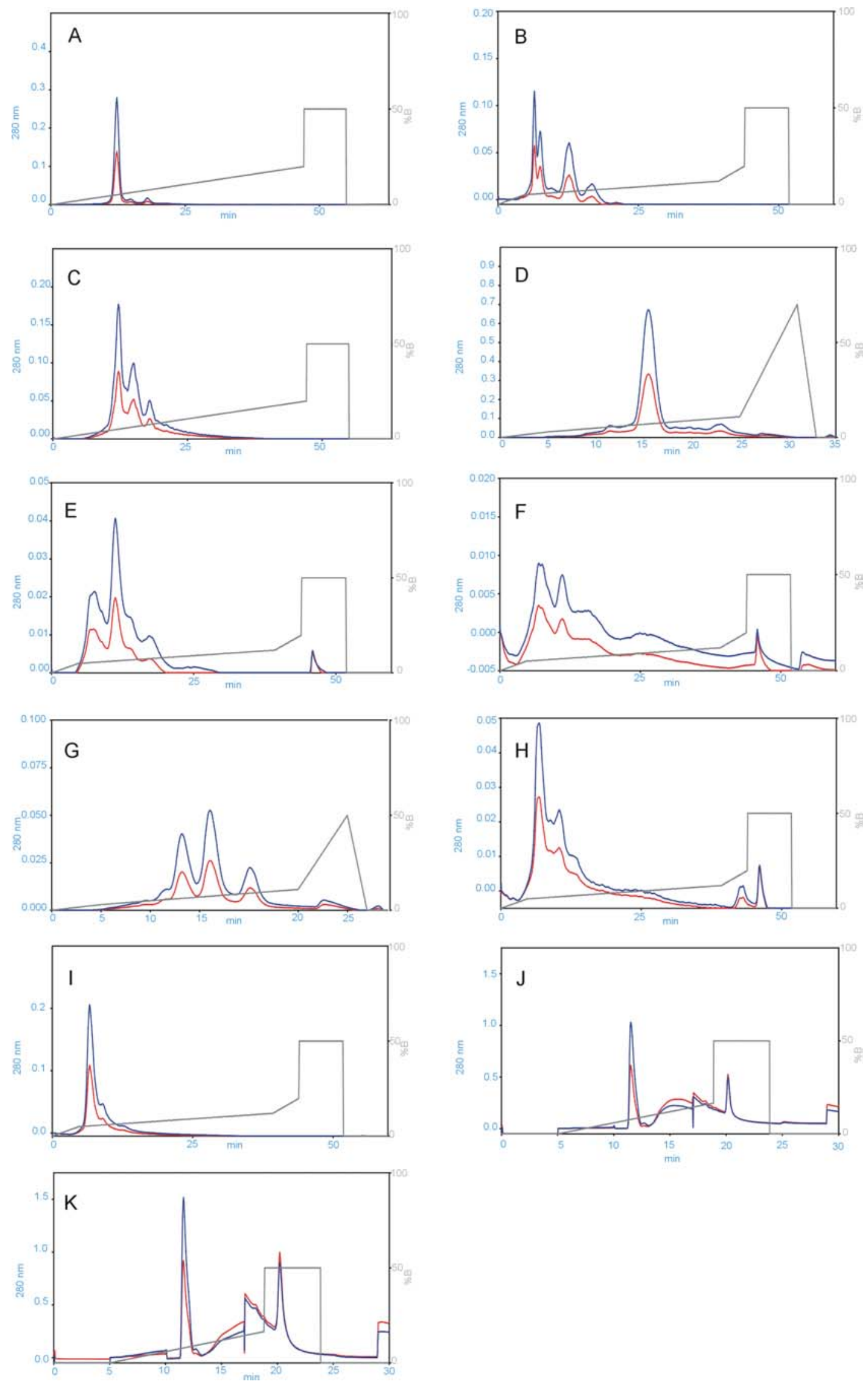

Abbildung 4.3.2.: Chromatogramme der Reinigung der Barnase' Fusionen über Kationenaustauschchromatographie. In blau dargestellt ist der Verlauf der $\mathrm{OD}_{280}$, in rot der $\mathrm{OD}_{260}$ über die Zeit in min. In grau: $\mathrm{NaCl}$ Gradient in \% einer $3 \mathrm{M}$ Stammlösung. (A) Barnase'-1lin; (B) -2lin; (C) -A11; (D) -A12; (E) -A21; (F) A31; (G) -A41; (H) -A51; (I) -E11; (J)-E21; (K) -E51. 


\subsubsection{Inhibition der Aktivierung des TPO Rezeptors}

Für den Nachweis der Bindung der konstruierten Varianten an den TPO Rezeptor wurde von Sebastian Krause vom Institut für Biochemie I in Jena ein Reporter-Gen-Assay entwickelt. Die Grundlage dafür bildet ein Fusionsgen aus der extrazellulären Domäne des humanen TPO Rezeptors und der intrazellulären 4R $\alpha$ Domäne des humanen Interleukin-4 Rezeptors (IL-4R), das in die murine Zelllinie Ba/F3 eingebracht wurde. Zusätzlich wurden die Zellen mit einem Plasmid transfiziert, das das STAT6 responsive IL-4 spezifische Reportergenkonstrukt pIETATALuc [Krause et al., 2004] trägt. Die ligandenvermittelte Aktivierung des TPO Rezeptors führt dabei über eine IL-4 spezifische Signaltransduktionskaskade zur Induktion des STAT6 abhängigen Promotors des pIETATALuc und ist somit durch Messung der Lumineszenz auslesbar (Abbildung 4.3.3.).

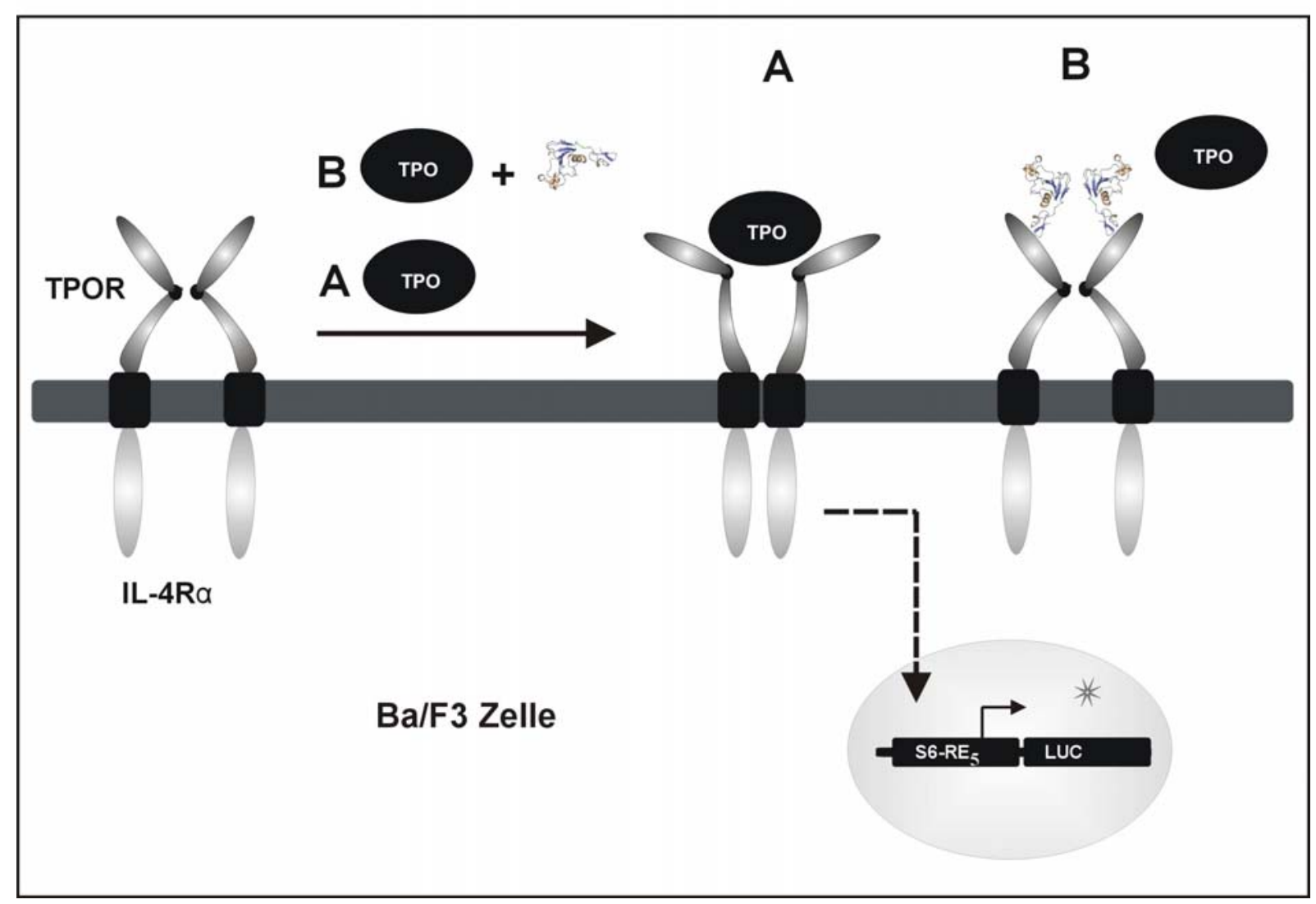

Abbildung 4.3.3.: Schematische Darstellung des Reporter-Gen Assays. Ein Komplex aus dem Fusionsprotein aus der extrazellulären Domäne des humanen TPO Rezeptors und der intrazellulären 4R $\alpha$ Domäne des humanen Interleukin-4 Rezeptors (IL-4R) wird transient in Ba/F3 Zellen exprimiert. Die ligandenvermittelte Aktivierung des TPO Rezeptors führt zu einer Dimerisierung der intrazellulären IL-4R Ketten. Über den IL-4 spezifischen Signaltransduktionsweg erfolgt dann die Induktion des STAT6 responsiven Promotors eines stabil in das Genom integrierten Reporter Gen Konstrukts (S6-RE 5 -luc), wodurch die Rezeptor Aktivierung durch Messung der Lumineszenz auslesbar wird. (A) Aktivierung durch TPO; (B) Kompetition mit Barnase'-Mikroprotein Fusionsprotein. 
Die antagonistische Wirkung der generierten Barnase'-Fusionsproteine wurde von S. Krause in einem Kompetitions-Assay mit humanem TPO gemessen. Dazu wurden die transfizierten Zellen zunächst eine Stunde mit $500 \mathrm{nM}$ der jeweiligen Variante vorinkubiert. Nach Zugabe von $5 \mathrm{nM}$ TPO wurden die Zellen dann für $12 \mathrm{~h}$ bei $37^{\circ} \mathrm{C}$ und $5 \% \mathrm{CO}_{2}$ inkubiert und die Luziferase Aktivität wie in Krause et al. [Krause et al., 2004] beschrieben gemessen. Die Ergebnisse des Assays sind in Abbildung 4.3.4. dargestellt.

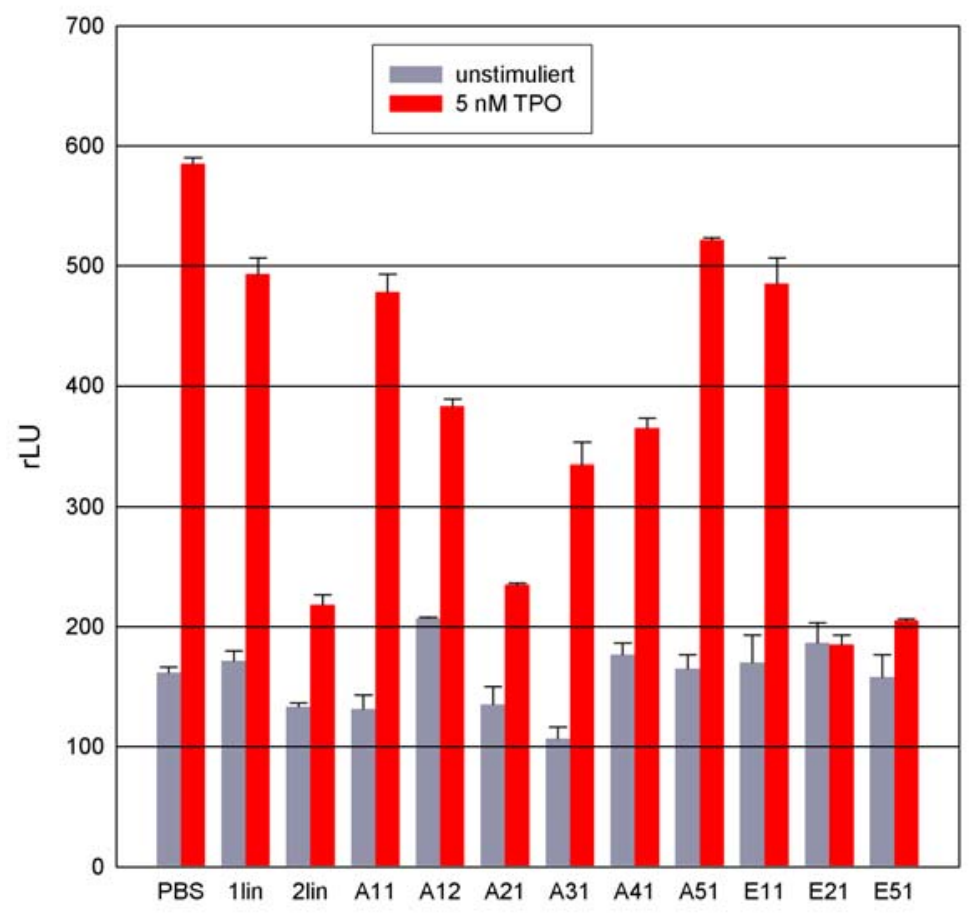

\begin{abstract}
Abbildung 4.3.4.: Antagonistische Wirkung der erstellten Varianten gemessen im Reporter-Gen-Assay (S. Krause). Grau: Relative Lumineszenz (rLU) mit $500 \mathrm{nM}$ der jeweiligen Variante. Rot: Relative Lumineszenz mit $500 \mathrm{nM}$ der jeweiligen Variante (nur bei A31 $100 \mathrm{nM}$ ) und $5 \mathrm{nM}$ TPO. PBS: Kontrolle mit PBS Puffer ohne Fusionsprotein.
\end{abstract}

Wie aus Abbildung 4.3.4. ersichtlich, kommt es ohne die Zugabe von TPO nicht zu einem Anstieg der Lumineszenz. Wie zu erwarten, vermag also keine der Varianten, den Rezeptor in monomerer Form $\mathrm{zu}$ aktivieren. Bei Zugabe von TPO steigt die Lumineszenz ohne Vorinkubation mit Fusionsprotein. Die Konstrukte 2lin, A21, E21 und E51 binden offensichtlich an den TPO Rezeptor und verhindern dadurch die Aktivierung durch TPO. Während die Varianten A31 und A41 offenbar noch zu einer schwachen Bindung fähig sind, führt die Vor-Inkubation der Zellen mit allen weiteren Varianten nicht bzw. kaum zu einer Abnahme der Lumineszenz. Beim Blick auf die Sequenzen der Varianten (Tabelle 4.3.3.) fällt zum einen auf, dass alle Varianten, bei denen Peptid 1 (GGCADGPTLREWISFCGG) eingeführt wurde, keine bzw. kaum antagonistische Aktivität aufweisen. Selbst das lineare Peptid als Barnase'-Fusion zeigt kaum inhibitorische Aktivität. Von den Varianten, bei denen Peptid 2 (IEGPTLRQWLAARA) eingeführt wurde, sind die lineare Variante 2lin, E21 und 
E51 „starke Antagonisten“. Die Ergebnisse zeigen, dass offensichtlich nur eine spezielle Konformation der in das Cystin-Knoten Grundgerüst eingeführten Peptide die Bindung an den Rezeptor ermöglicht. Das einige der Varianten in dem Assay antagonistische Aktivität zeigten, ist daher nicht trivial, da die konformationellen Freiheitsgrade eines freien solitären Peptids ungleich größer sind als die eines Peptids, das in das Cystin-Knoten Grundgerüst eingespannt ist.

\subsubsection{Dimerisierung der Variante E21}

Die liganden-vermittelte Aktivierung des TPO Rezeptors durch Dimerisierung erfordert eine dimere Struktur des Zytokins bzw. zwei Rezeptor-Bindestellen auf einem Monomer des Liganden [Feese et al., 2004]. Um die antagonistische Bindung der generierten Mikroprotein Varianten an den TPO Rezeptor in einen aktivierenden Bindungsmodus umzuwandeln, wurden in Kooperation mit der Selecore $\mathrm{GmbH}$ in Göttingen die im ersten Assay antagonistisch wirkenden Varianten (Abbildung 4.3.4.) E21, E51, A21 und A41 dimerisiert. Die Varianten wurden so konzipiert, dass sie nur ein singuläres Lysin in ihrer Sequenz aufweisen (Tabelle 4.3.1.). Das Konzept der Dimerisierung von Mikroproteinen über die Aminogruppe der Lysin-Seitenkette mittels eines homobifunktionalem NHydroxysuccinimid-Esters (NHS-Ester) wie z.B. Disuccinimidylsuberat (DSS) wurde bereits in Abschnitt 4.2.2.5. eingeführt. Aus diesem Grund soll hier nur die Produktion und Dimerisierung der Variante E21, die im Lumineszenz-Assay die stärkste antagonistische Aktivität aufwies (Abbildung 4.3.4.), im Detail beschrieben werden.

Nach Transformation des E.coli Stammes 71-18, der bereits das Helferplasmid pRep4 enthielt, mit dem Vektor pBar100-E21 erfolgte die Fermentation bei der Selecore GmbH im $51 \mathrm{Maßstab}$ (3.1.7.2.). Auch die initialen Reinigungsschritte wurden von der Selecore GmbH durchgeführt: Nach Ansäuerung der Fermentationskultur (3.4.6.1.), Zentrifugieren und Sterilfiltrieren des Überstands wurde der Kulturüberstand, 1:5 mit Wasser verdünnt, in 25 mM Na-Acetat Puffer pH 5 zunächst auf eine Kationenaustauschersäule gegeben $(72 \times 31$ cm Tropfsäule aus Glas mit $600 \mathrm{ml}$ SP-Sepharose XL) und das Fusionsprotein mit $\mathrm{NaCl}$ eluiert. Das Eluat wurde dann über eine zweite Säule, gefüllt mit Amberchrom CG-300 M reversed phase Material, gegeben und das Fusionsprotein mit einem Acetonitril Gradienten eluiert. Barnase'-E21 enthaltene Fraktionen wurden nach SDS-PAGE Analyse vereinigt und lyophilisiert, um das Acetonitril zu entfernen.

Das lyophilisierte Protein wurde dann in 0,1 M Tris-HCl Puffer $\mathrm{pH}$ 7,8 mit $8 \mathrm{M}$ Harnstoff gelöst, über Nacht gegen $50 \mathrm{mM}$ Ammoniumacetat dialysiert (3.4.4.) und an der Vision 
Biocad $^{\circledR}$ workstation erneut präparativ über Kationenaustauschchromatographie (3.4.6.3.) gereinigt (Abbildung 4.3.5. A).

A

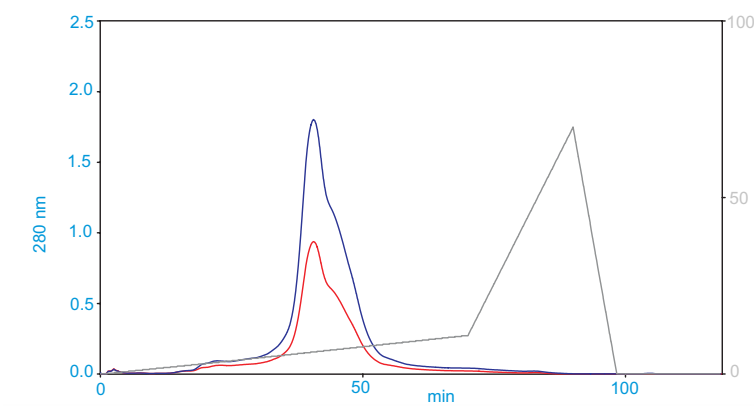

B

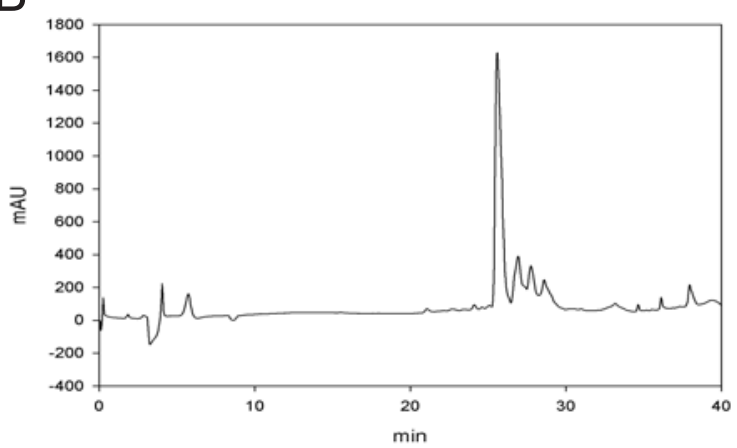

C

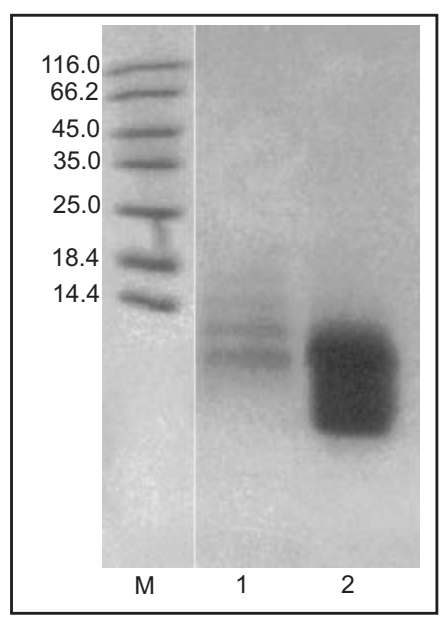

Abbildung 4.3.5.: Reinigung der Variante E21. (A) Chromatogramm der Reinigung von Barnase'-E21 über Kationenaustauschchromatographie. In blau dargestellt ist der Verlauf der $\mathrm{OD}_{280}$, in rot der $\mathrm{OD}_{260}$ über die Zeit in min. In grau: $\mathrm{NaCl}$ Gradient in \% einer $3 \mathrm{M}$ Stammlösung. (B) Analyse des mit Bromcyan abgespaltenen und gereinigten E21 Mikroproteins über RP-HPLC. (C) SDS-PAGE Analyse der Dimerisierung der Variante E21. M: Molekulargewichts Standard (Größenangabe links in kDa); 1, E21 nach Dimerisierung und RP-HPLC Reinigung; 2, E21 vor Dimerisierung.

Die Fraktionen aus der Kationenaustauschchromatographie wurden mittels SDS-PAGE (3.4.1.) analysiert. Fraktionen, die das Fusionsprotein enthielten, wurden vereinigt. Um die Menge für die anschließende Bromcyanspaltung abzuschätzen, wurde die $\mathrm{OD}_{280}$ spektrophotometrisch gemessen (3.4.2.). Es wurde eine Menge von etwa $100 \mathrm{mg}$ Fusionsprotein errechnet. Das Protein wurde anschließend mit $\mathrm{HCl}$ gefällt (3.4.5.2.) und in $6 \mathrm{M}$ Guanidiniumhydrochlorid, 0,2 M HCl mit Bromcyan gespalten (3.4.9.1.). Am nächsten Tag konnte das Mikroprotein über präparative RP-Chromatographie an der Vision Biocad ${ }^{\circledR}$ workstation (3.4.6.4.) vom Fusionspartner separiert werden. Die anschließende Analyse des gereinigten Mikroproteins über RP-HPLC (3.4.6.5.) zeigte noch leichte Verunreinigungen (Abbildung 4.3.5. B). Abbildung 4.3.5. C zeigt eine SDS-PAGE Analyse des E21 Monomers nach Dimerisierung mit DSS (3.6.1.) und RP-HPLC Reinigung. Wie aus Abbildung 4.3.5. C ersichtlich, läuft das E21 Monomer in der SDS-PAGE als breite Bande. Das Dimer konnte, wie schon in Abschnitt 4.2.2.5. bei EETI-II TR-1 beschrieben, durch RP-HPLC nicht von trimeren und tetrameren Spezies getrennt werden, die durch Verknüpfung über den NTerminus entstehen können. 


\subsubsection{Aktivierung des TPO Rezeptors}

Die dimerisierten Mikroprotein Varianten wurden im Folgenden erneut von Sebastian Krause im beschriebenen Zell-basierten Lumineszenz Assay getestet. Im Unterschied zur ersten Messung (4.3.2.) sollten jedoch die agonistischen, d.h. die Rezeptor aktivierenden Eigenschaften der Varianten untersucht werden. Daher wurden die Dimere nicht in Kompetition mit TPO zu den Zellen gegeben, sondern der Anstieg der Lumineszenz bei Inkubation mit verschiedenen Konzentrationen der entsprechenden Variante gemessen. Abbildung 4.3.6. zeigt die agonistischen Eigenschaften der Varianten E21 und A41, gemessen im $\mathrm{Ba} / \mathrm{F} 3$ TPO Reporter Gen Assay, im Vergleich zu rekombinanten humanen Thrombopoietin. Dazu wurde von S. Krause die relative Stimulation bestimmt, bei der die Werte relativ zur maximalen Stimulation mit TPO (= $100 \%)$ angegeben werden. Wie aus Abbildung 4.3.6. ersichtlich, kommt es nach Inkubation der Zellen sowohl mit TPO als auch mit der dimerisierten E21 und A41 Variante Dosis-abhängig zu einem Anstieg der relativen Stimulation. Dabei liegt die agonistische Aktivität der dimerisierten Mikroproteine und von TPO im vergleichbarem Konzentrationsbereich (im nanomolarem Bereich). Es ist also nicht nur gelungen, die bindenden Eigenschaften des Peptids 2 durch Inkorporation in das Grundgerüst auf die Mikroproteine zu übertragen, sondern durch Generierung zweier Bindungsstellen auf einem Ligandenmolekül, auch die agonistische Wirkung im Bereich des natürlichen Zytokins TPO zu erhalten.

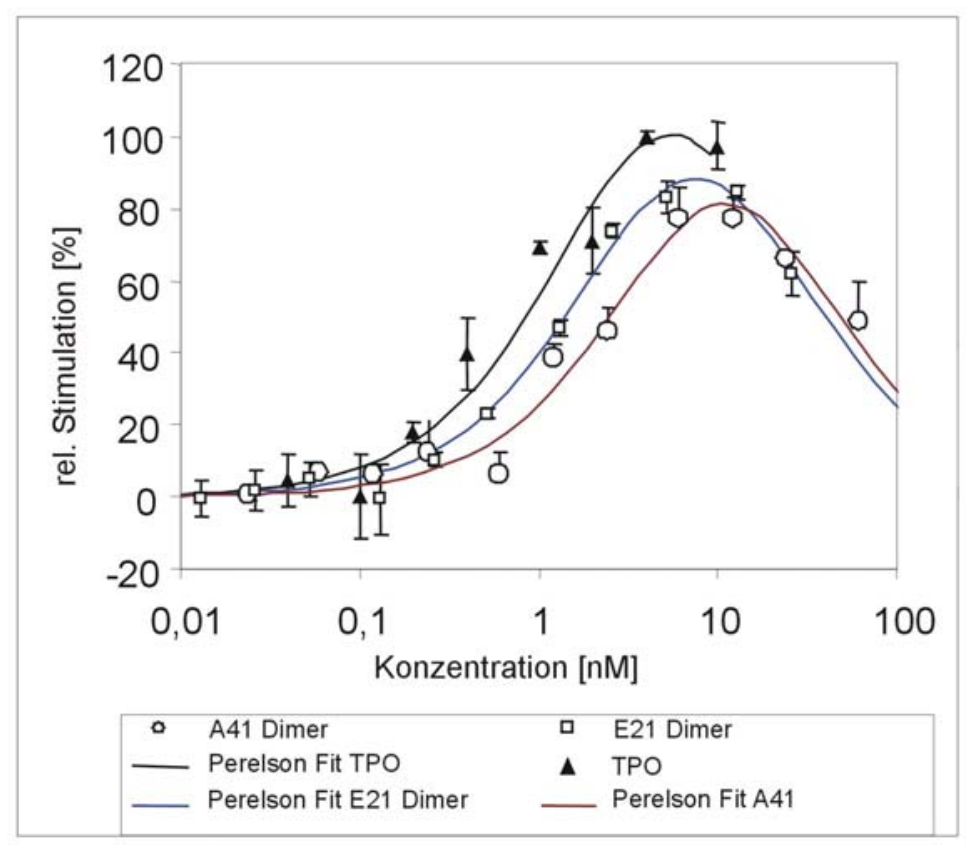

Abbildung 4.3.6.: Messung der agonistischen Eigenschaften der dimerisierten E21 und A41 Variante im Vergleich mit rekombinantem humanen TPO gemessen im Ba/F3 TPO Reporter-Gen-Assay (Quelle S. Krause). Die Relative Stimulation von TPO und den Mikroprotein Varianten wurde nach dem von Perelson und DeLisi [Perelson und DeLisi, 1980] beschriebenen Model der Bildung von Rezeptor Clustern durch bivalente Liganden angepasst. 
Neben den Varianten E21 und A41 wurde bisher von S. Krause die dimerisierte Variante E51 im Reporter Gen Assay auf ihre agonistische Aktivität untersucht. Aus den erhaltenen Werten wurde die Konzentration bei halb-maximaler Stimulation $\left(\mathrm{EC}_{50}\right.$ Wert) bestimmt. Eine Zusammenfassung der Ergebnisse aus den von S. Krause durchgeführten Lumineszenz Assays ist in Tabelle 4.3.2. dargestellt.

\begin{tabular}{|c|c|c|c|}
\hline Variante & Aminosäure Sequenz & $\begin{array}{c}\text { Antagonist } \\
{[\%]}\end{array}$ & $\begin{array}{c}\text { Agonist } \\
\mathrm{EC}_{50}[\mathrm{nM}]^{\mathrm{a}}\end{array}$ \\
\hline $1 \operatorname{lin}$ & -SSSMGGCADGPTLREWISFCGG & - & \\
\hline $2 \operatorname{lin}$ & -SSSMIEGPTLRQWLAARA & ++ & \\
\hline A11 & -SSSMGCVRLHESCLGQQVPCCDPAATCGGCADGPTLREWISFCGGCKGS & - & \\
\hline A12 & -SSSMGCVRLHESCLGQQVPCCDPAATCYCADGPTLREWISFCYCKGS & - & \\
\hline A21 & -SSSMGCVRLHESCLGQQVPCCDPAATCIEGPTLRQWLAARACKGS & + & n.b. \\
\hline A31 & -SSSMGCVRLHESCLGQQVPCCDPAATCGGTALAIEGPTLRQWLAARACKGS & +- & \\
\hline A41 & -SSSMGCVRLHESCLGQQVPCCDPAATCGGTCLAIEGPTLRQWLCARACKGS & + & 2,52 \\
\hline A51 & -SSSMGCVRLHESCLGQQVPCCDPAATCYCIEGPTLRQWLAACYCKGS & - & \\
\hline E11 & -SSSMGCGGCADGPTLREWISFCGGCKQDSDCLAGCVCGPNGFCGS & - & \\
\hline E21 & -SSSMGCIEGPTLRQWLAARACKQDSDCLAGCVCGPNGFCGS & ++ & 1,41 \\
\hline E51 & -SSSMGCIEGPTLRQWLAACKQDSDCLAGCVCGPNGFCGS & ++ & 25 \\
\hline
\end{tabular}

Tabelle 4.3.2.: Zusammenfassung der Ergebnisse aus den Ba/F3 TPO Reporter-Gen-Assays (S. Krause). Die in rot hervorgehobenen Bereiche in den Aminosäure Sequenzen stammen aus Cwirla et al. [Cwirla et al., 1997]. Blau hervorgehoben sind Aminosäuren, die als spacer eingeführt wurden, bzw. die Cysteine, die wie in AGRP eine vierte S-S Brücke ausbilden. Das für die Dimerisierung verwendete singuläre Lysin ist jeweils in grün hervorgehoben. ${ }^{\text {a}}$ : Konzentration bei halb-maximaler Stimulation, der in diesem Assay bestimmte Wert für rekombinantes humanes TPO beträgt 0,85. -: kaum/keine antagonistische Aktivität; +-widersprüchliche Ergebnisse (Aktivität wurde in zweiter Messung nicht bestätigt); +: schwache Aktivität; ++: starke Aktivität.

Obwohl die Variante A41 als Monomer nur schwache antagonistische Eigenschaften aufwies (Abbildung 4.3.4.), konnte das dimerisierte A41 Mikroprotein eine Aktivierung des TPO Rezeptors hervorrufen. Diese Beobachtung könnte man mit einer nur schwachen Bindung des A41 Monomers an den Rezeptor erklären, die aber dann aufgrund einer besonders guten Positionierung der dimerisierten Monomere zueinander im AGRP' Kontext zu einer Aktivierung des Rezeptors ausreicht. Das Gegenteilige ist für die Variante E51 der Fall, die als Monomer stark antagonistisch wirkt, als Dimer jedoch einen relativ hohen $\mathrm{EC}_{50}$ Wert von $25 \mathrm{nM}$ bzgl. der Aktivierung des TPO Rezeptors aufweist. Der einzige Unterschied zwischen E51 und dem starken Agonisten E21 ist das Fehlen der Aminosäuren R und A in E51 am CTerminus der in das Mikroprotein Grundgerüst transplantierten Peptidsequenz. Das Fehlen der beiden Aminosäuren scheint auf die Bindung des Monomers an den TPO Rezeptor keinen Einfluss zu haben. Warum jedoch nach Dimerisierung die Aktivierung deutlich schlechter 
erfolgt, ist unklar und müsste durch Wiederholen der Messungen und Kontrollexperimente wie z.B. die Messung der antagonistischen Aktivität des Dimers ergründet werden.

\subsubsection{Stimulation der Proliferation von Knochenmarkszellen}

Seine primäre biologische Funktion nimmt das Zytokin Thrombopoietin (TPO) hauptsächlich im Knochenmark war, wo es z.B. die Differenzierung von Stammzellen zu MegakaryozytenVorläufern und die Bildung von Thrombozyten [de Sauvage et al., 1994, Kaushansky et al., 1994] stimuliert. Um den Effekt der im Lumineszenz Assay agonistisch auf die Aktivierung des TPO Rezeptors wirkenden dimeren E21 Variante auf die Proliferation von Knochenmarkszellen zu untersuchen, wurden von Dr. Matthias Ballmaier von der Medizinischen Hochschule Hannover primäre humane CD34+ Knochenmarkszellen (BMMNCs, bone marrow mononuclear cells) mit verschiedenen Konzentrationen von E21 bzw. rekombinanten humanen TPO (rhuTPO ) inkubiert. Dazu wurden wie in Ballmaier et al. [Ballmaier et al., 2001] beschrieben $10^{5}$ BMMNCs in semi-solid Medium entweder ohne Zugabe von Zytokinen, mit $50 \mathrm{ng} / \mathrm{ml}$ oder $10 \mathrm{ng} / \mathrm{ml}$ rhuTPO bzw. mit $30 \mathrm{nM}, 10 \mathrm{nM}$ oder $3 \mathrm{nM}$ dimerem E21 Mikroprotein kultiviert. Nach $10-12$ Tagen in Kultur bei $37^{\circ} \mathrm{C}$ und $5 \%$ $\mathrm{CO}_{2}$ wurde die Stimulation der Proliferation durch Auszählen der Kolonien [CFU(colony forming unit)-Megakaryozyten] gemessen. Die Ergebnisse sind in Abbildung 4.3.7. zusammengefasst.

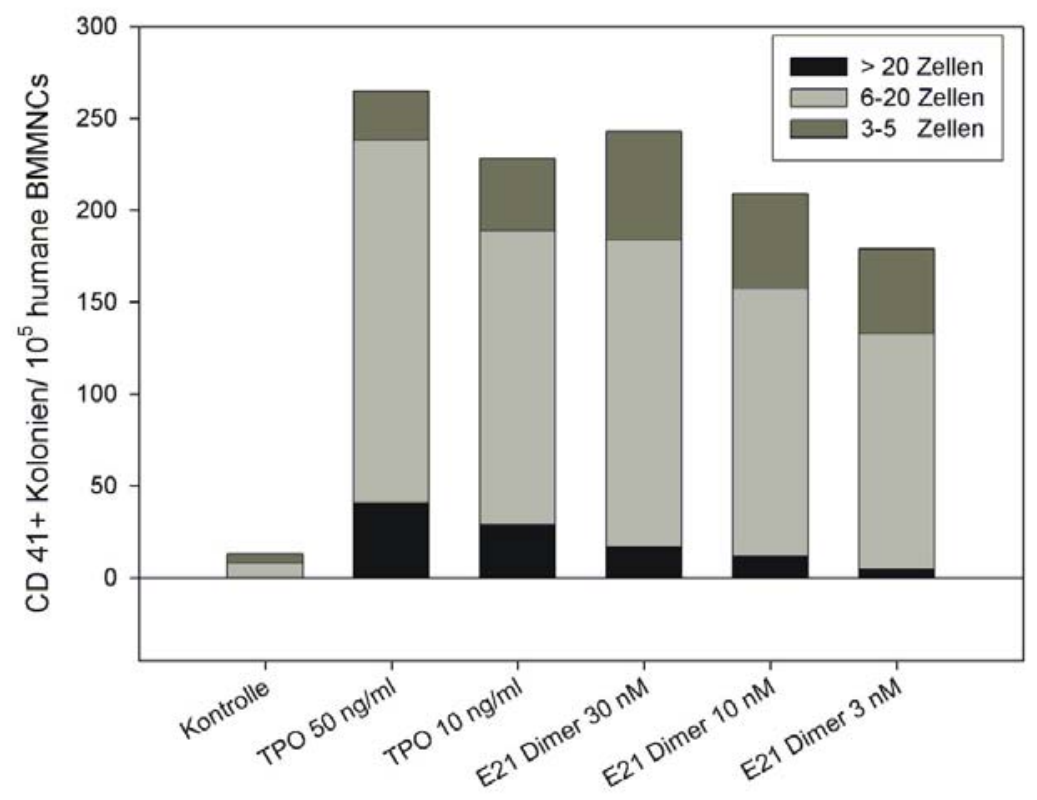

Abbildung 4.3.7.: Induktion der Proliferation von primären Knochenmarkszellen (BMNNCs) durch Kultivierung von $10^{5}$ Zellen mit den angegebenen Konzentrationen von rekombinantem humanen TPO, E21 Mikroprotein bzw. ohne die Zugabe von Zytokin (Kontrolle). Angegeben ist die Zahl der Megakaryozyten Kolonien und die Größe der Kolonien (Quelle: M. Ballmaier). Rekombinantes humanes TPO besteht nur aus der 
aminoterminalen Domäne von TPO und hat etwa eine relative molare Masse von 18500, $10 \mathrm{ng} / \mathrm{ml}$ würden daher einer Konzentration von etwa 0,55 $\mathrm{nM}$ entsprechen.

In der Kontrolle, bei der die Zellen ohne Zugabe von Zytokinen kultiviert wurden, konnten wie erwartet nur wenige Megakaryozyten Kolonien gezählt werden. Nach Inkubation mit 50 bzw. $10 \mathrm{ng} / \mathrm{ml}$ rhuTPO hingegen kommt es zu einem etwa 15-fachen Anstieg der gezählten Kolonien. In einem ähnlichen Bereich bewegt sich die Zunahme der Zellen nach Kultivierung mit dimeren E21 Mikroprotein. Das dimere Mikroprotein ist also wie TPO in der Lage, die Proliferation der Megakaryozyten Vorläufer-Zellen $\mathrm{zu}$ stimulieren. Verglichen mit der Stimulation durch Zugabe von rhuTPO (10 ng/ml entsprechen etwa 0,55 nM) ist die Zunahme der Zellen nach Inkubation mit dimerem E21 Protein jedoch weniger stark. Ein gewisser Unterschied besteht zudem in der Größe der gebildeten Zellverbände, d.h. TPO vermag im Vergleich zum dimeren E21 Mikroprotein die Bildung größerer Kolonien besser zu stimulieren.

\subsubsection{Diskussion und Ausblick}

Thrombopoietin (TPO) ist der primäre Regulator der Bildung, Proliferation und Differenzierung von Megakaryozyten [Kaushansky und Drachman, 2002]. Das Zytokin bindet an einen spezifischen Zelloberflächen Rezeptor, den TPO-Rezeptor (TPOR), der auf Thrombozyten, Megakaryozyten und deren Vorläufer Zellen zu finden ist. TPOR gehört wie z.B. auch der Erythropoietin Rezeptor zur Typ I Familie von Zytokin Rezeptoren [Bazan, 1990]. Obwohl die Struktur des TPO/TPOR Komplexes nicht bekannt ist, gibt es fundierte Hinweise, dass die Aktivierung des Rezeptors und der nachgeschalteten Signaltransduktionskaskade durch Dimerisierung zweier Rezeptorketten nach Bindung eines TPO Moleküls erfolgt [Feese et al., 2004].

Das Fehlen von TPO bzw. externe Einwirkungen wie z.B. myelosuppressive Chemotherapien führen zu tiefgreifender Thrombozytopenie, einem Mangel an Thrombozyten. Dieser Mangelzustand kann durch die Applikation von TPO, die zu einem Wiederanstieg des Blutplättchen Levels führt, therapiert werden [Bartley et al., 1994, de Sauvage et al., 1994, Kaushansky et al., 1994]. Daher wurden inzwischen klinische Studien zur Behandlung von iatrogener Thrombozytopenie mit verschiedenen Formen von rekombinanten humanem TPO initiiert [Fanucchi et al., 1997, Jones et al., 1998], bei denen es jedoch Probleme bzgl. der Antigenizität des TPOs gab [Basser et al., 2002, Li et al., 2001]. Eine Alternative zu rekombinantem TPO stellen TPO Mimetika dar. Ein solcher Ansatz konnte mit Antikörpern [Orita et al., 2005], small molecules [Erickson-Miller et al., 2005, Inagaki et al., 2004] und mimetischen Peptiden [Cwirla et al., 1997] als Basis bereits umgesetzt werden. 
Cystin-Knoten Mikroproteine sind sehr kleine Proteine mit einer Größe von nur etwa 28-35 Aminosäuren, die jedoch eine geordnete Faltung in eine äußerst stabile dreidimensionale Struktur aufweisen. Ihre Stabilität, hohe Passgenauigkeit und orale Verfügbarkeit machen sie zu idealen Leitstrukturen für die Generierung therapeutischer Wirkstoffe [Craik et al., 2001, Craik et al., 2002].

In diesem Kapitel wurde die Generierung Thrombopoietin mimetischer Mikroproteine durch Transplantation der von Cwirla et al. [Cwirla et al., 1997] veröffentlichten Peptidsequenzen in das Cystin-Knoten Grundgerüst beschrieben. Es wurden drei Varianten durch Einbringen der Peptide in das Grundgerüst des Trypsin Inhibitors EETI-II [Heitz et al., 1989, Polanowski et al., 1980] und sechs durch Transplantation in AGRP', einem Fragment der Melanocortin Rezeptor Bindedomäne des human agouti related proteins AGRP [McNulty et al., 2001], konstruiert und als Barnase'-Fusion über das in Kapitel 4.1. vorgestellte Expressionssystem produziert. Zusätzlich wurden als Referenz die beiden linearen Ausgangspeptide kloniert und als Barnase'-Fusion produziert.

Durch die Einführung der Peptide in das strukturell rigide Cystin-Knoten Grundgerüst werden die konformationellen Freiheitsgrade deutlich verringert. Trotzdem konnte in einem Zellbasiertem Lumineszenz Assay die antagonistische Bindung einiger Varianten nachgewiesen werden. Der Assay basiert auf einem Fusionsgen aus der extrazellulären Domäne des humanen TPO Rezeptors und der intrazellulären 4R $\alpha$ Domäne des humanen Interleukin-4 Rezeptors (IL-4R). Das Konstrukt wurde in die murine Zelllinie Ba/F3 eingebracht und kann auf das Signaltransduktionsnetzwerk der Zelle zugreifen. Die ligandenvermittelte Aktivierung des Rezeptors wurde durch die Verwendung des zusätzlich in die murine Zelle eingebrachten IL-4 spezifischen Reportergenkonstrukts pIeTATALuc [Krause et al., 2004] nachgewiesen. Es stellte sich heraus, dass offensichtlich nur die Peptid 2 (IEGPTLRQWLAARA) enthaltenen Varianten und nicht die Peptid 1 (GGCADGPTLREWISFCGG) enthaltenen an den TPO Rezeptor binden können. Daß nicht alle Varianten in dem durchgeführten Assay die Aktivierung des Rezeptors durch TPO unterbinden konnten, weist darauf hin, dass tatsächlich eine spezielle Konformation der TPO mimetischen Peptide für die Bindung an TPOR erforderlich ist.

Das Zytokin TPO besitzt höchstwahrscheinlich zwei Bindungsstellen in der Rezeptorbindedomäne, die vermutlich durch Bindung an zwei Rezeptorketten die Aktivierung durch Dimerisierung des Rezeptors vermitteln [Feese et al., 2004]. Bereits Cwirla et al. [Cwirla et al., 1997] machten daher die Beobachtung, dass erst nach Dimerisierung ihres an 
den TPO Rezeptor bindenden Peptids, eine Stimulation der Proliferation einer TPO responsiven $\mathrm{Ba} / \mathrm{F} 3$ Zelllinie im Bereich von TPO erreicht wurde.

Aus diesem Grund wurden in Zusammenarbeit mit Dr. Alexander Wentzel (Selecore GmbH, Göttingen) die Mikroprotein Varianten E21, E51, A21 und A41 in größeren Mengen produziert, vom Fusionspartner Barnase' abgespalten und separiert und mittels Disuccinimidylsuberat (DSS) über die Aminogruppen singulärer Lysine dimerisiert. Obwohl die dimeren Mikroproteine durch RP-HPLC nicht vollständig von tri- und tetrameren Spezies, die durch Verknüpfung über die aminoterminale $\mathrm{NH}_{2}$-Gruppe entstehen können, getrennt werden konnten, konnte von Sebastian Krause im Lumineszenz Assay für die Varianten A41 und E21 eine Aktivierung des TPO Rezeptors festgestellt werden. Diese agonistische Aktivität ist Dosis-abhängig und liegt im Konzentrationsbereich, der im selben Assay für humanes rekombinantes TPO gemessen wurde. Es ist also nicht nur gelungen, die bindenden Eigenschaften der TPO mimetischen Peptide durch Transplantation auf die Mikroproteine zu übertragen, sondern zudem durch Dimerisierung der Varianten, einen agonistischen Bindungsmodus anzunehmen.

Im Weiteren ging es darum, zu eruieren, inwiefern die generierten Mikroprotein Varianten in der Lage sind, die biologischen Funktionen von TPO wahrzunehmen. Es wurde daher zunächst von Dr. Matthias Ballmaier die Stimulation der Proliferation von Knochenmarkszellen durch die dimere E21 Variante in einem CFU-(colony forming unit) Assay [Ballmaier et al., 2001] untersucht. Dazu wurden $10^{5}$ primäre humane CD34+ Knochenmarkszellen (BMMNCs, bone marrow mononuclear cells) mit verschiedenen Konzentrationen von E21 bzw. rekombinanten humanen TPO (rhuTPO ) für 10-12 Tage inkubiert und der stimulierende Effekt durch Auszählen der entstandenen CD41+ Megakaryozyten Kolonien gemessen. Es zeigte sich, dass das dimere Mikroprotein in zu TPO vergleichbarer Weise die Proliferation der Megakaryozyten Vorläufer Zellen stimulierte. Ein gewisser Unterschied ergab sich jedoch in der Größe der gebildeten Zellverbände, d.h. TPO vermag im Vergleich zum dimeren E21 Mikroprotein die Bildung größerer Kolonien besser zu stimulieren.

Während des Schreibens dieser Arbeit wurde im Frauenhofer Institut Hannover in einem ersten Experiment die Wirkung von dimerem E21 Mikroprotein auf die Thrombozyten Bildung in Mäusen untersucht. Bei subcutaner Gabe von 0,2 bzw. $20 \mu \mathrm{g}$ des Mikroproteins pro kg Körpergewicht, konnte eine Verdopplung der Blutplättchenzahl im Vergleich zu einer Gabe von Placebo nachgewiesen werden. 
Mit der in diesem Kapitel beschriebenen Generierung Thrombopoietin mimetischer CystinKnoten Mikroproteine ist es zum ersten Mal gelungen, Varianten aus dieser Proteinfamilie mit agonistischer Wirkung herzustellen. Für die dimere Variante E21 konnte in Zusammenarbeit mit den Kooperationspartnern aus Jena und Hannover die biologische Wirksamkeit, d.h. die Stimulation der Proliferation von Knochenmarkszellen und der Bildung von Thrombozyten, in Zellkultur und inzwischen auch im Tier gezeigt werden. 


\subsection{Zyklisierung von Cystin-Knoten Mikroproteinen}

Proteine sind in der Regel aus Aminosäuren zusammengesetzte lineare Ketten, die nach Faltung in eine dreidimensionale Struktur ihre spezifische biologische Funktion wahrnehmen. In den letzten Jahren wurden jedoch in zunehmender Zahl Peptide und Proteine entdeckt, deren N- und C-Termini durch eine zusätzliche Peptidbindung verknüpft sind und die daher ein zyklisches Grundgerüst aufweisen [Trabi und Craik, 2002]. Zyklische Peptide, wie z.B. Cyclosporin A [Lautz et al., 1989], enthalten oftmals modifizierte Aminosäuren und sind keine „wahren“ Genprodukte, sondern werden in multifunktionellen Enzymkomplexen synthetisiert. Es kommen hingegen „wahre“ zyklische Proteine von einer Größe von 14-70 Aminosäuren in der Natur vor, die geordnete dreidimensionale Strukturen einnehmen. Die größte Gruppe natürlich vorkommender zyklischer Proteine, die jedoch auch in Mikroorganismen [Gonzalez et al., 2000, Martinez-Bueno et al., 1994] und in Säugern [Trabi et al., 2001] zu finden sind, nehmen die pflanzlichen Zyklotide ein [Craik, 2001, Craik et al., 1999, Craik et al., 2004, Craik et al., 2003]. Die Vertreter der Familie der Zyklotide wurden haupsächlich aus Rubiaceae und Violaceae isoliert und haben neben einem zirkulären Grundgerüst und ihrer geringen Größe von nur etwa 30 Aminosäuren sechs Cystein Reste gemein, die einen Cystin Knoten bilden. Dieses als cyclic cystine knot (CCK) bezeichnete Faltungsmotiv [Craik et al., 1999] ist abgesehen von der Verknüpfung der Termini durch eine zusätzliche Peptidbindung identisch zu dem der Vertreter der Cystin-Knoten Mikroproteine mit dem inhibitor cystine knot (ICK) Motiv [Le Nguyen et al., 1990]. Obwohl die Funktion und der Mechanismus der Zyklisierung bisher nicht komplett verstanden ist, scheint das zirkuläre Rückgrat dem Protein eine hohe Stabilität zu verleihen [Colgrave und Craik, 2004]. Diese hohe Stabilität wird am besten durch das erste bekannte Mitglied der Zyklotide, Kalata B1, illustriert, das von afrikanischen Frauen aus der Pflanze Oldenlandia affinis durch Kochen extrahiert und als Uterus kontrahierendes Medikament verwendet wurde [Gran, 1973].

Während immer mehr natürliche Zyklotide entdeckt wurden, konnten bereits einige Verfahren für die synthetische Herstellung zyklischer (Mikro-)Proteine entwickelt werden [Evans et al., 1999, Scott et al., 1999, Tam und Lu, 1998], um dadurch potentiell stabilere Proteine zu generieren. Im Prinzip gibt es bisher zwei wesentliche Strategien für die Verknüpfung von Nund C-Terminus eines gegebenen Proteins (Abbildung 4.4.1.): Der erste Ansatz nutzt die Eigenschaft von modifizierten Protein Splicing Elementen, sogenannten Inteinen, aus, die in der Lage sind, Peptidbindungen jeweils an ihrem N- bzw. C-terminalen Ende zu spalten 
[Evans et al., 1999, Williams et al., 2002]. Werden die Inteine jeweils in frame mit dem Nund C-Terminus eines zu zyklisierenden Proteins kloniert, so wird durch die Spaltung ein Nterminales Cystein und ein C-terminaler Thioester auf dem Zielprotein generiert, was spontan zur Ausbildung einer Peptidbindung führt.

Der zweite Ansatz (Native chemical ligation), der für die Zyklisierung von Mikroproteinen eingesetzt wird, basiert auf der chemischen Synthese des Proteins mit einem N-terminalen Cystein und einem C-terminalen $\alpha$-Thioester [Davies, 2003]. Befinden sich die beiden Termini in räumlicher Nähe zueinander, so bildet sich zunächst ein Thioester-verknüpftes Intermediat, das sich durch spontane intramolekulare Umlagerungen in das zyklische Produkt mit einer nativen Peptidbindung umwandelt [Muir, 2003, Tam und Lu, 1998].

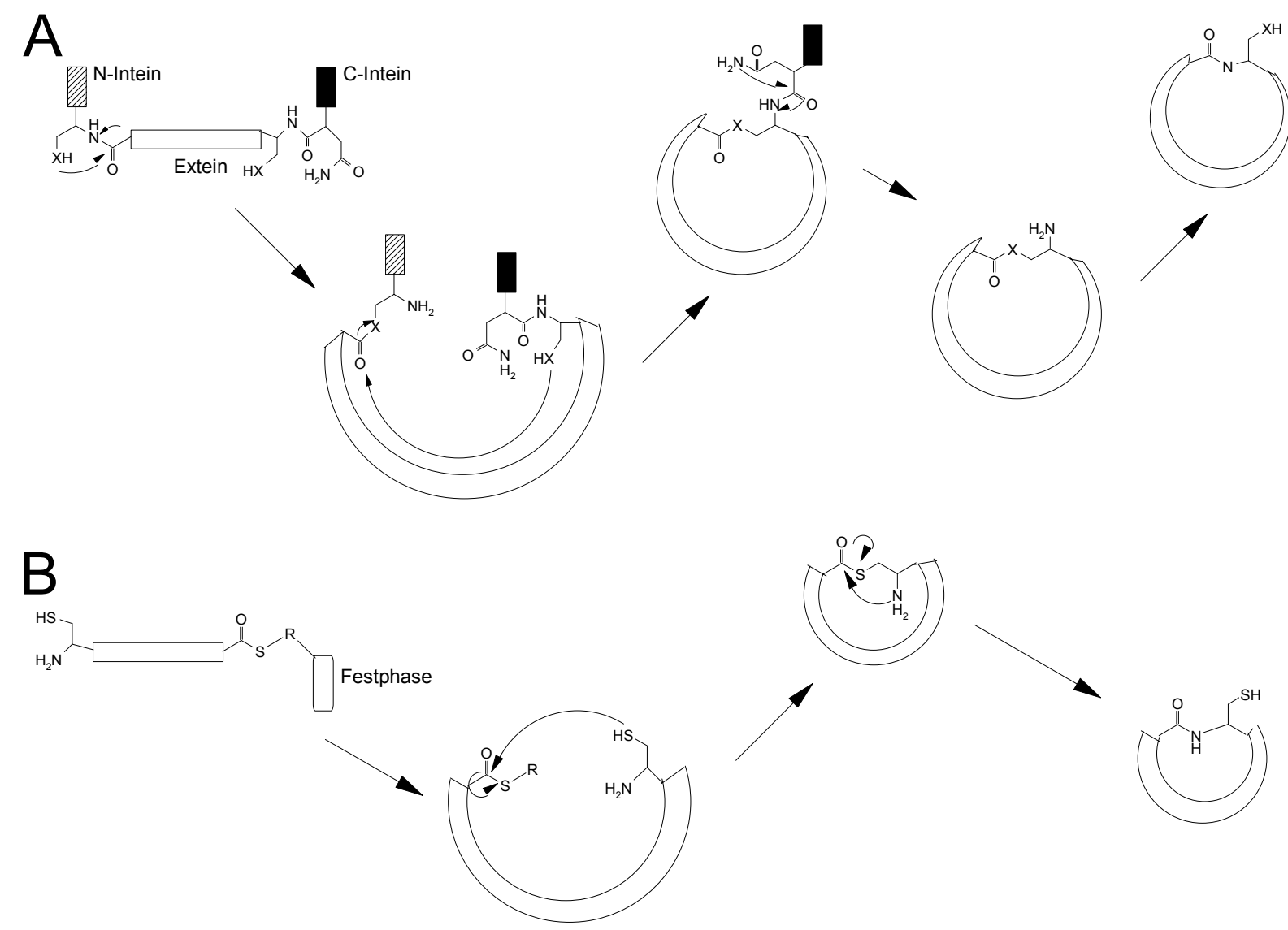

Abbildung 4.4.1.: Bisherige Strategien zur Generierung synthetischer zyklischer Proteine (nach [Trabi und Craik, 2002]). (A) Split-Intein Mechanismus. Nach Aktivierung durch eine N-S bzw. N-O Acyl Umlagerung bildet sich ein Ester- bzw. ein Thioester-Intermediat. Dieses wird dann in einem zweiten Schritt durch die OHbzw. SH-Gruppe eines S, T oder C Restes vom C-terminalen Ende angegriffen. Dabei bildet sich ein verzweigtes zyklisches Zwischenprodukt. Die Verzweigung wird durch die Zyklisierung eines konservierten Asparagin Restes am C-Intein aufgelöst. Dabei erfolgt die Abspaltung des C-Inteins. Schließlich findet eine spontane O-N bzw. S-N Acyl Umlagerung statt, die zur Bildung eines zirkularen Exteins mit einer natürlichen Peptidbindung führt; ( $\mathrm{X}=\mathrm{S}$ oder O Atom der Seitenkette des S, T oder C Restes). (B) Native chemical ligation. Das zu zyklisierende Peptid wird an der Festphase mit einem N-terminalen Cystein und einem C-terminalen $\alpha$-Thioester synthetisiert. Die beiden Gruppen reagieren unter Ausbildung eines Thioester-verknüpften Intermediats miteinander, das sich durch spontane intramolekulare Umlagerungen in das zyklische Endprodukt umwandelt. 
Beide vorgestellten Verfahren wurden erfolgreich zur Generierung zyklischer Peptide eingesetzt. Sie weisen jedoch für die Zyklisierung von Cystin-Knoten Mikroproteinen einige Nachteile auf. Chemische Synthesen erfordern die Rückfaltung der Proteine in die native Konformation in vitro, was sich für verschiedene Mikroprotein Varianten als schwierig herausgestellt hat [Goldenberg, 1992]. Dieses Problem einer erforderlichen Rückfaltung besteht auch beim Intein Verfahren, da die Intein Fusionsproteine aus dem Zytoplasma gereinigt werden, wo sich durch die reduzierenden Bedingungen keine Disulfidbrücken ausbilden können.

In dieser Arbeit sollte daher ein Verfahren für die Zyklisierung von Cystin-Knoten Mikroproteinen entwickelt werden, das mit der rekombinanten Produktion der Mikroproteine über das in Abschnitt 4.1. vorgestellte Barnase'-Expressionssystem kompatibel ist. Es wurde ein Verfahren konzipiert, das zunächst am Beispiel des Hybrid-Mikroproteins McoEeTI [Schmoldt et al., 2005] getestet werden sollte. Dieses Protein wurde für den ersten proof of concept ausgewählt, da es zum einen aus dem natürlicherweise zyklischen MCoTI-II [Hernandez et al., 2000] abstammt und weil die Funktionalität des zu generierenden zyklischen Konstrukts (im Folgenden als cyclo-McoEeTI bezeichnet) einfach durch Messung der Trypsin bzw. Tryptase inhibitorischen Aktivität untersucht werden kann. Im Vergleich zu McoEeTI wurde die zu zyklisierende Variante cyclo-McoEeTI so konstruiert, dass ein Teil des flexiblen linkers aus MCoTI-II (SDGG) eingeführt wurde, so dass der Abstand zwischen den Cysteinen I und VI im am Ende zyklischen Protein wie in MCoTI-II acht Aminosäuren beträgt. Zudem wurden N- und C-terminal Methioninreste zur Spaltung mit BrCN eingeführt. Die konzeptionelle Struktur des Zyklisierungs Verfahrens stellt sich wie folgt dar (Abbildung 4.4.2): Das cyclo-McoEeTI Konstrukt soll über das in Kapitel 4.1. beschriebene Expressionssystem als Barnase'-Fusion produziert und gereinigt werden (A). Nach Spaltung des Fusionsproteins an den eingeführten Methionin Resten mit Bromcyan bildet sich am Cterminalen Ende ein Homoserinlakton aus, am N-Terminus befindet sich nach der Spaltung ein Serin (B). Der Homoserinlaktonring kann mit Hydrazin geöffnet werden, wodurch ein „Mikroprotein-Hydrazid“ entsteht (C). Das aminoterminale Serin kann im Folgenden, wie in Geoghegan et al. [Geoghegan und Stroh, 1992] beschrieben, selektiv durch Oxidation mit Natriumperiodat aktiviert werden. Dabei entsteht ein Aldehyd aus der Hydroxygruppe des Serins, das mit dem C-terminalen Hydrazid unter Ausbildung eines Hydrazons reagieren kann (D) [King et al., 1986]. Damit wäre der Ringschluss vollzogen; Voraussetzung ist jedoch, dass N- und C-Terminus in räumlicher Nähe zueinander stehen. Schließlich könnte das Hydrazon durch Reduktion mit Natrium-Cyano-Borhydrid stabilisiert werden (E). 


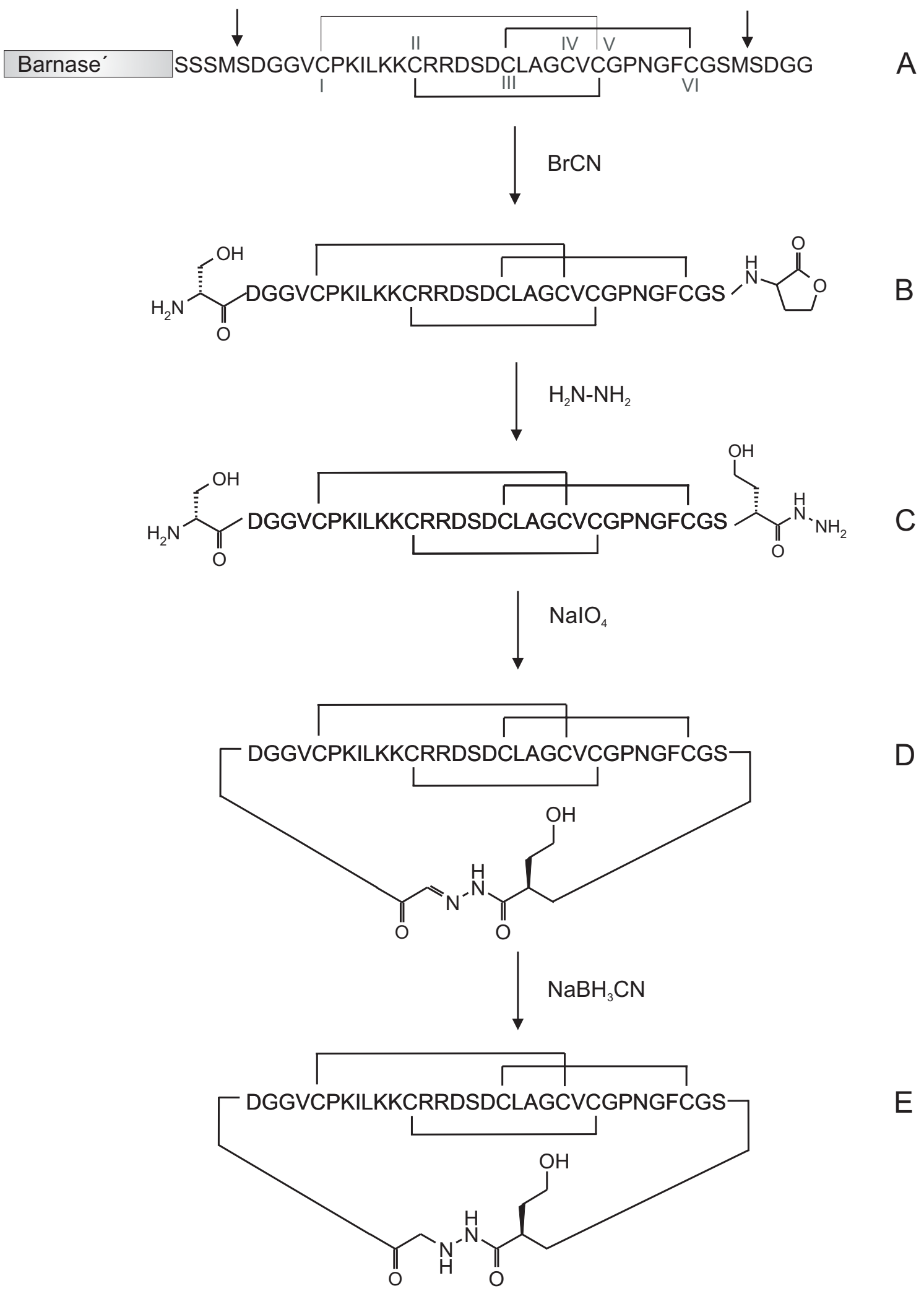

Abbildung 4.4.2.: Schematische Darstellung der Zyklisierung von Cystin-Knoten Mikroproteinen am Beispiel von cyclo-McoEeTI durch Bromcyan Spaltung gefolgt von Hydrazid Bildung, selektiver Oxidation des Nterminalen Serins und intramolekularer Zyklisierung. Erklärungen im Text. Die Cysteine sind startend vom NTerminus mit I-VI numeriert. 


\subsubsection{Klonierung von pBar100-cyclo-McoEeTI}

Die für die Zyklisierung vorgesehende McoEeTI Variante sollte über das in Kapitel 4.1. vorgestellte Barnase'-Expressionssystem in E. coli produziert und anschließend gereinigt werden. Das cyclo-McoEeTI Konstrukt wurde daher in den pBar100 Vektor kloniert (Abbildung 4.4.3.).

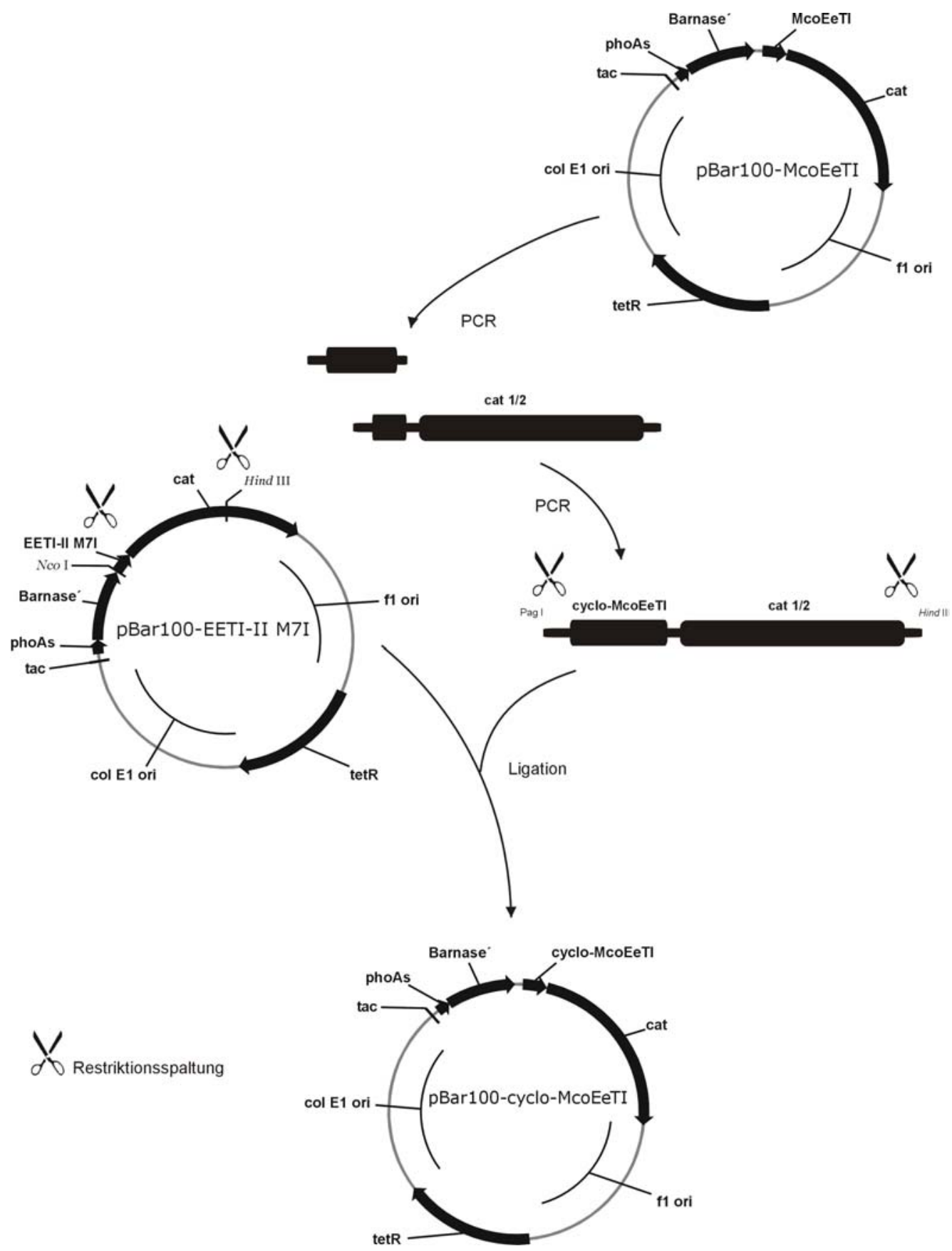

Abbildung 4.4.3.: Schematische Darstellung der Klonierung des Vektors pBar100-cyclo-McoEeTI. Beschreibung der Klonierung im Text. Die Pfeilrichtungen geben die funktionellen Orientierungen der genetischen Elemente an. Cat, Chloramphenicol Resistenz Gen; Barnase', Gen für Barnase His ${ }^{102}$ Ala; EETI-II M7I, Gen für die M7I Variante des Trypsin Inhibitors EETI-II; tac, Tac Promotor Region; tetR, Tetrazyklin Repressor Gen; f1, Replikationsursprung des Phagen f1; col E1 ori , col E1 Replikationsursprung; phoAs, Alkalische Phosphatase periplasmatische Signal Sequenz; McoEeTI, Gen für das Hybrid Protein aus EETI-II und MCoTI-II; cyclo-McoEeTI, Gen für die zu zyklisierende McoEeTI Variante. 
Dazu wurde das Mikroprotein Gen zunächst in einer zweistufigen SOE-PCR (3.3.3.) mit dem Oligonukleotid BspHI-McoTI-MSDGG-up, den beiden innen liegenden Primern McoTIMSDGGhinten-SOE-lo und -up und dem Oligonukleotid cat-Hind-Mitte-lo amplifiziert. Als Matrize diente dabei das Plasmid pBar100-McoEeTI [Schmoldt et al., 2005]. In der zweiten PCR Reaktion wurde dabei ein Fragment aus dem halben cat Gen und dem cyclo-McoEeTI Gen generiert. Das Produkt wurde mit Pag I (Isoschizomer von BspH I und kompatibel zu Nco I) und Hind III gespalten (3.3.1.), mittels Phenol/Chloroform Extraktion (3.2.3.2.) und anschließender Ethanol Fällung (3.2.2.1.) gereinigt, und mit dem mit Nco I und Hind III geschnittenen Vektor pBar100-EETI-II M7I ligiert (3.3.2.). Nach Transformation von E. coli 71-18 pRep4 (3.1.5.) konnten insert-tragende Transformanten mittels Kolonie PCR (3.3.3.) und anschließender Restriktionsanalyse (3.3.1.) der präparierten Plasmid DNA (3.2.6.) von in der PCR positiven Klonen ermittelt werden. Die Sequenz eines Klons konnte durch DNASequenzierung im Laboratorium für Genomanalyse verifiziert werden.

\subsubsection{Rekombinante Produktion und Reinigung von cyclo-McoEeTI}

Nach Transformation von E.coli 71-18 pRep4 mit dem Vektor pBar100-cyclo-McoEeTI erfolgte die Fermentation bei der Selecore GmbH im 51 Maßstab (3.1.7.2.). Auch die ersten Reinigungsschritte wurden von der Selecore GmbH durchgeführt: Nach Ansäuerung der Fermentationskultur (3.4.6.1.), Zentrifugieren und Sterilfiltrieren des Überstands wurde der Kulturüberstand, 1:5 mit Wasser verdünnt, in $25 \mathrm{mM}$ Na-Acetat Puffer pH 5 zunächst über eine große Kationenaustauschersäule gegeben (Tropfsäule aus Glas mit SP-Sepharose XL, $600 \mathrm{ml}$ Säulenvolumen) und das Fusionsprotein mit einem $\mathrm{NaCl}$ Stufengradienten eluiert. Die entsprechenden Fraktionen des Eluats wurden dann über eine zweite Säule, gefüllt mit Amberchrom CG-300 M reversed phase Material, gegeben und das Fusionsprotein mit einem Acetonitril Gradienten eluiert. Barnase'-cyclo-McoEeTI enthaltene Fraktionen wurden nach SDS-PAGE Analyse vereinigt.

Anschließend wurde das Eluat aus der RP-Chromatographie zunächst lyophilisiert, um das Acetonitril zu entfernen. Das lyophilisierte Protein wurde dann in 0,1 M Tris-HCl Puffer pH 7,8 mit $8 \mathrm{M}$ Harnstoff aufgenommen, über Nacht gegen $50 \mathrm{mM}$ Ammoniumacetat dialysiert (3.4.4.) und an der Vision Biocad ${ }^{\circledR}$ workstation präparativ über Kationenaustauschchromatographie (3.4.6.3.) gereinigt (Abbildung 4.4.4. A). Nach Elution mit $\mathrm{NaCl}$ und Analyse mittels SDS-PAGE (3.4.1.) wurden die Fusionsprotein enthaltenden Fraktionen vereinigt. Das Protein wurde mittels Säurefällung (3.4.5.2.) und anschließender Zentrifugation präzipitiert, und mit Bromcyan in 70 \%iger Ameisensäure gespalten (3.4.9.1.). 
Das abgespaltene Mikroprotein konnte über präparative RP-HPLC an der Vision Biocad ${ }^{\mathbb{R}}$ workstation (3.4.6.4.) isoliert werden (Abbildung 4.4.4. B). Man sieht an den beiden Peaks am Ende des Gradienten (Barnase' Trägerprotein und ungespaltenes Fusionsprotein), daß die Spaltung nur zu etwa 50-70 \% komplett war. Es folgte eine Analyse der einzelnen Fraktionen der Reinigung mittels SDS-PAGE (3.4.1.). Mikroprotein enthaltene Fraktionen wurden vereinigt und lyophilisiert.
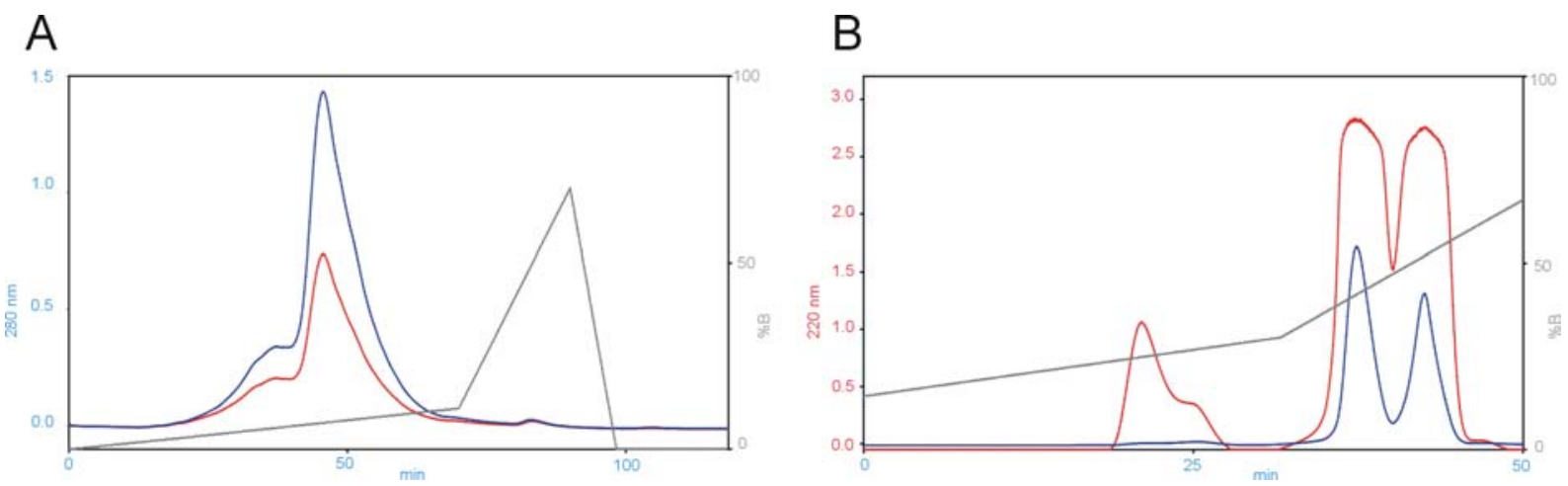

Abbildung 4.4.4.: Reinigung von cyclo-McoEeTI. (A) Chromatogramm der Reinigung von Barnase'-cycloMcoEeTI über Kationenaustauschchromatographie. In blau dargestellt ist der Verlauf der $\mathrm{OD}_{280}$, in rot der $\mathrm{OD}_{260}$ über die Zeit in min. In grau: $\mathrm{NaCl}$ Gradient in \% einer $3 \mathrm{M}$ Stammlösung. (B) Reinigung des mit Bromcyan abgespaltenen Mikroproteins cyclo-McoEeTI (eluiert nach etwa 20-25 min) über präparative RPChromatographie. In blau dargestellt ist der Verlauf der $\mathrm{OD}_{280}$, in rot der $\mathrm{OD}_{220}$ über die Zeit in min. In grau: Acetonitril/ $0,1 \%$ TFA Gradient in $\%$.

Eine finale Reinigung von cyclo-McoEeTI wurde schließlich von Olga Avrutina über RPHPLC mit einer präparativen YMC J'Sphere ODS H-80 Säule durchgeführt. Insgesamt konnten $5 \mathrm{mg}$ reines Mikroprotein, das nach Bromcyan Spaltung N-terminal ein Serin und Cterminal ein Homoserinlakton aufweist, (Abbildung 4.4.2. B) isoliert werden. Die erwartete Masse des Peptids von 3422 konnte mittels ESI-MS verifiziert werden.

\subsubsection{Hydrazinolyse und Ringschluß durch Natrium-Periodat Oxidation}

Das gereinigte cyclo-McoEeTI Mikroprotein wurde im Folgenden durch Hydrazinolyse Cterminal aktiviert (3.5.2.). Dafür wurden $4,7 \mathrm{mg}$ (ca. 1,4 $\mu \mathrm{mol}$ ) Protein in $2 \mathrm{ml}$ Wasser aufgenommen und mit einem 100-fachen molaren Überschuß an Hydrazin-Monohydrat versetzt. Aufgrund der hohen Reaktivität des Hydrazins kann dadurch der Homoserinlaktonring am C-terminalen Ende des Proteins unter Ausbildung eines Hydrazids geöffnet werden (Abbildung 4.4.2. C). In der RP-HPLC Analyse der Reaktion (Abbildung 4.4.5.) sieht man, daß sich der Haupt-Peak von cyclo-McoEeTI nach Umsetzung mit Hydrazin im Vergleich mit dem Homoserinlakton in einen Bereich niedrigerer Acetonitril Konzentration verschiebt. 
A

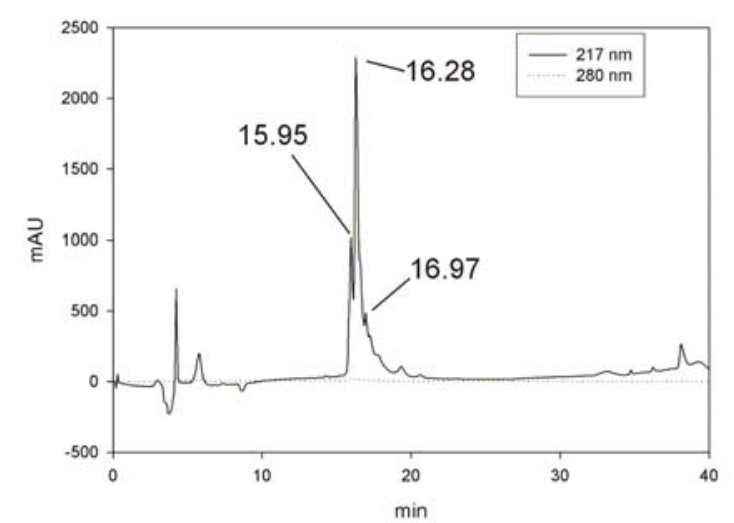

B

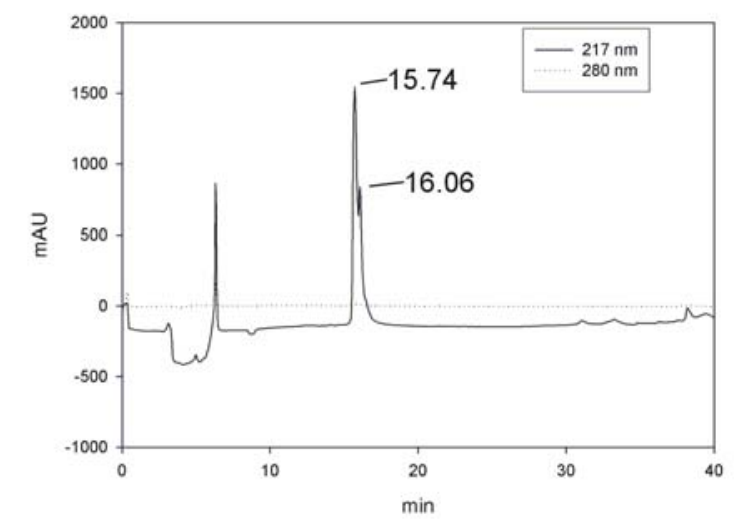

Abbildung 4.4.5.: RP-HPLC Analyse der Umsetzung des cyclo-McoEeTI Homoserinlaktons (A) zum cycloMcoEeTI Hydrazid (B). Dargestellt ist der Verlauf der $\mathrm{OD}_{217}$ (durchgezogene Linie) und der $\mathrm{OD}_{280}$ (gestrichelte Linie) in mAU (relative Absorption) über die Zeit in min. Die Elutionszeit des jeweiligen Peaks ist in min angegeben.

Nach einstündiger Inkubation mit Hydrazin wurde der Reaktionsansatz zunächst lyophilisiert und das cyclo-McoEeTI Hydrazid anschließend von O. Avrutina mittels RP-HPLC gereinigt, um das Hydrazin vollständig $\mathrm{zu}$ entfernen. Es wurden nach Reinigung 2,1 mg des Mikroproteins erhalten, also etwa $44 \%$ des Ausgangsmaterials. Die erwartete Masse des cyclo-McoEeTI Hydrazids von 3456 konnte mittels ESI-MS verifiziert werden.

Im Gegensatz zu bisher in der Literatur beschriebenen Verfahren zur Zyklisierung von Mikroproteinen wird das zu zyklisierende Protein in dem hier vorgestellten Ansatz in bereits korrekt gefalteter Form isoliert und anschließend der Zyklisierungsreaktion unterzogen. Der Vorteil dieser Vorgehensweise liegt darin, daß auf diese Weise durch die Wahl eines adäquaten linkers N- und C-Terminus bereits in räumliche Nähe zueinander gebracht werden, wodurch der Ringschluß enthropisch begünstigt wird.

A

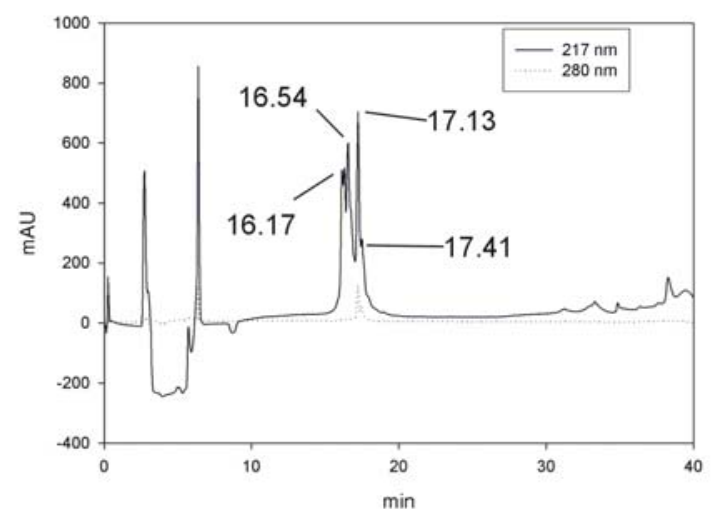

B

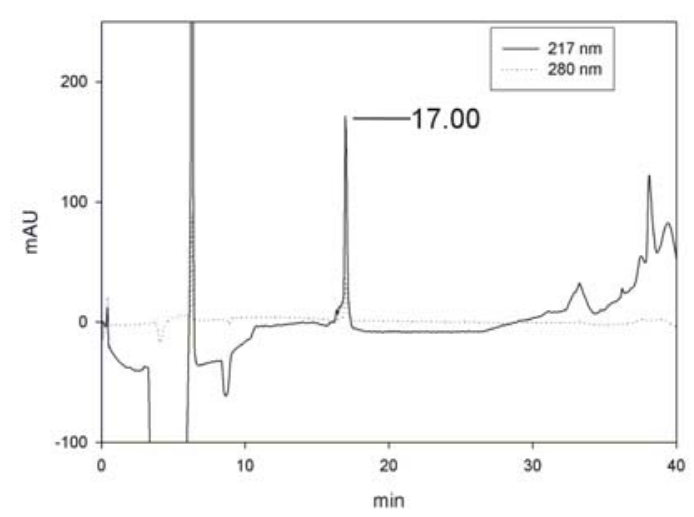

Abbildung 4.4.6.: (A) RP-HPLC Analyse der Umsetzung von cyclo-McoEeTI Hydrazid mit Natrium-Periodat nach 10 min Inkubation (B) ) RP-HPLC Analyse von cyclo-McoEeTI nach Zyklisierung und Reinigung. Dargestellt ist der Verlauf der $\mathrm{OD}_{217}$ (durchgezogene Linie) und der $\mathrm{OD}_{280}$ (gestrichelte Linie) in $\mathrm{mAU}$ (relative Absorption) über die Zeit in min. Die Elutionszeit des jeweiligen Peaks ist in min angegeben. 
Für die Aktivierung des N-Terminus wurden $1,6 \mathrm{mg}(0,46 \mu \mathrm{mol})$ des generierten cycloMcoEeTI Hydrazids mit einem 10-fach molarem Überschuß an Natrium-Periodat in $100 \mathrm{mM}$ Natrium-Phosphat Puffer pH 7 umgesetzt (3.5.3.). Dabei kann das N-terminale Serin zum Aldehyd oxidiert werden [Gaertner et al., 1992, Geoghegan und Stroh, 1992]. Da Periodat im Prinzip verschiedene Aminosäure Seitenketten oxidieren kann [Geoghegan und Stroh, 1992], wurde die Reaktion mittels RP-HPLC Anaylse kontrolliert. Abbildung 4.4.6. A zeigt die Analyse nach 10 min Inkubation bei RT.

Wie aus Abbildung 4.4.6. A ersichtlich, bildet sich bereits nach 10 min Inkubation mit Periodat eine Spezies aus, die in der RP-HPLC später eluiert als das Hydrazid und die im Gegensatz zu dem Mikroprotein-Homoserinlakton und dem -Hydrazid auch eine Absorption bei $280 \mathrm{~nm}$ aufweist. Die massenspektrometrische Analyse dieser Spezies mittels ESI wies eine Masse von 3407 aus (Abbildung 4.4.7.), was der erwarteten Masse des zu generierenden zyklischen Produkts (Abbildung 4.4.2. D) entspricht.

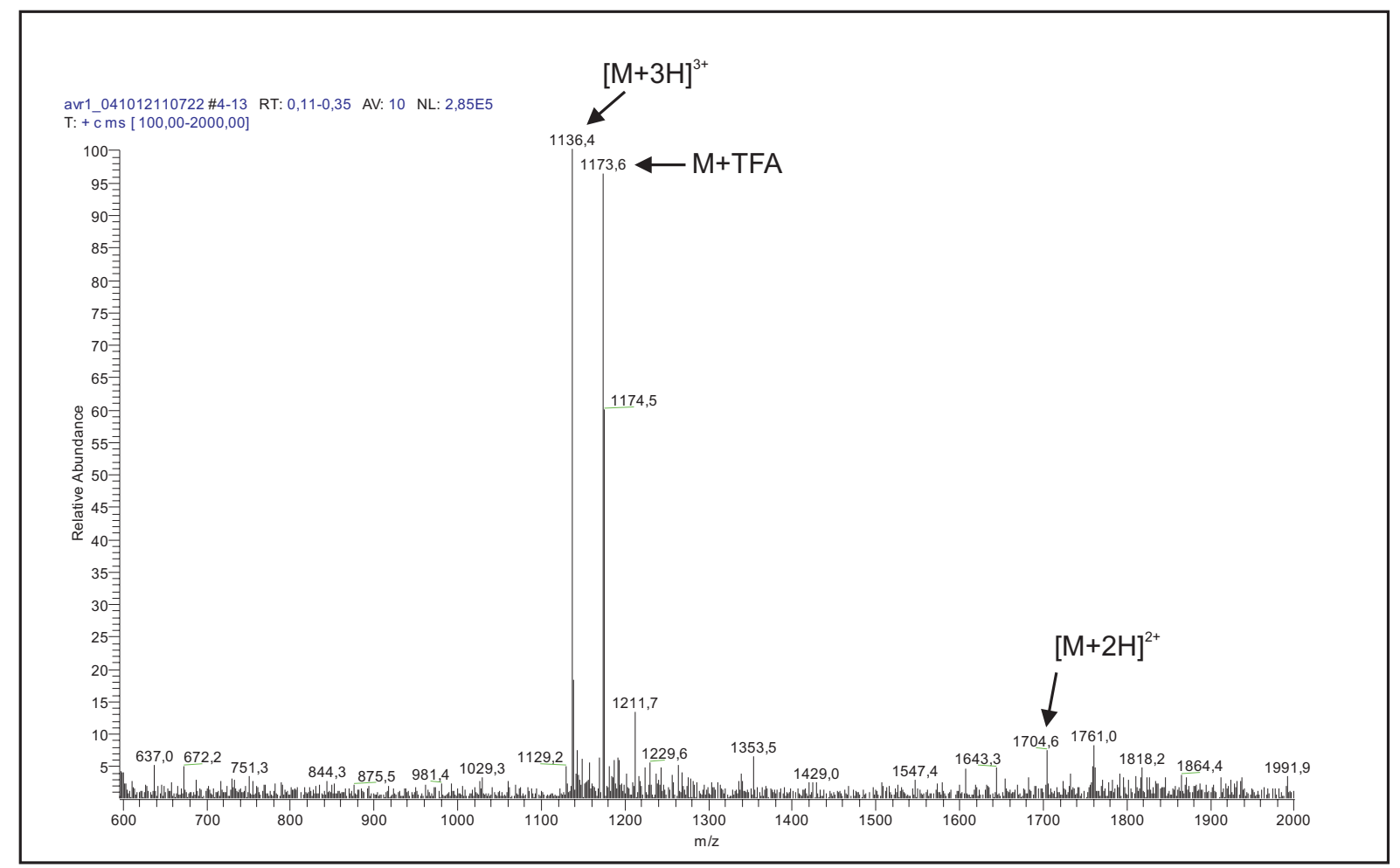

Abbildung 4.4.7.: Massenspektrometrische Analyse des putativen cyclo-McoEeTI Hydrazons mittels electrospray ionisation (ESI). Dargestellt ist die relative Häufigkeit der Signale gegen das Masse/Ladung Verhältnis (m/z) des Moleküls. Das errechnete Molekulargewicht des putativen Hydrazons liegt bei $3407 \mathrm{~g} / \mathrm{mol}$. Es konnte sowohl die dreifach als auch die zweifach geladene Masse detektiert werden. Zudem ist ein Signal einer mit Trifluoressigsäure (TFA) komplexierten Spezies zu erkennen.

Offensichtlich ist also die Zyklisierungsreaktion zwischen dem C-terminalen Hydrazid und dem N-terminalen Aldehyd unter Bildung des Hydrazons so schnell, daß das Glyoxal Zwischenprodukt der Oxidation des Serins nicht mehr detektiert werden konnte. Das gebildete Hydrazon wurde im Folgenden von O. Avrutina präparativ über RP-HPLC 
gereinigt. Abbildung 4.4.6. B zeigt das gereinigte putative cyclo-McoEeTI Hydrazon Produkt in der Analyse. Es konnte insgesamt $1 \mathrm{mg}$ des putativen Hydrazons isoliert werden, was einer Ausbeute bzgl. der eingesetzten Menge an Hydrazid von etwa 64 \% entspricht.

\subsubsection{Charakterisierung des putativen Hydrazons}

Die in Abschnitt 4.4.3. beschriebene Isolierung einer cyclo-McoEeTI Spezies mit verändertem Laufverhalten in der RP-HPLC, verändertem Absorptionsverhalten bei $280 \mathrm{~nm}$ und einer Masse, die der des zu generierenden Hydrazons entspricht, sind bereits gute Evidenzen für den Erfolg der Zyklisierung des Mikroproteins. Im Folgenden muß jedoch eine genaue Charakterisierung des Produkts erfolgen.

Aus Zeitgründen konnte bisher lediglich eine Untersuchung der Funktionalität des generierten Produkts begonnen werden. Das Hybridprotein McoEeTI ist ein potenter Trypsin Inhibitor [Schmoldt et al., 2005] und ein Inhibitor von humaner Mastzell-Tryptase (Kapitel 4.2.). Das putative Hydrazon wurde daher in der Arbeitsgruppe von Prof. Dr. C. Sommerhoff hinsichtlich seiner inhibitorischen Eigenschaften gegenüber Trypsin und der humanen $\beta$-III Tryptase untersucht. Die Ergebnisse sind in Tabelle 4.4.1. dargestellt.

\begin{tabular}{|c|c|c|c|}
\hline Variante & ${\text { Aktivität }[\%]^{\mathbf{a}}}$ & $\mathbf{K}_{\mathbf{i}} \boldsymbol{v s}$ Trypsin $[\mathbf{n M}]$ & $\mathbf{K}_{\mathbf{i}} \boldsymbol{v s}$ Tryptase $[\mathbf{n M}]$ \\
\hline McoEeTI & 73 & 0,3 & 100 \\
\hline Cyclo-McoEeTI & 45 & 0,2 & 4000 \\
\hline
\end{tabular}

Tabelle 4.4.1.: Inhibitorische Aktivität des putativen cyclo-McoEeTI Hydrazons gegenüber Trypsin und der humanen $\beta$-III Tryptase im Vergleich zu McoEeTI. ${ }^{a}$, bestimmt mittels active site Titration mit Trypsin.

Wie aus Tabelle 4.4.1. ersichtlich, weist das putative Hydrazon im Vergleich zu McoEeTI sogar eine leicht bessere inhibitorische Aktivität gegenüber Trypsin auf, während die Inhibitionskonstante gegenüber der Tryptase auf $4 \mu \mathrm{M}$ steigt. Das generierte Produkt hat also seine Funktionalität in Bezug auf die Inhibition von Trypsin behalten. Der deutliche Anstieg der Inhibitionskonstante gegenüber der Tryptase läßt sich durch die Veränderung des NTerminus im Vergleich zu McoEeTI erklären. Wie in Kapitel 4.2. beschrieben, ließ sich durch Transplantation des positiv geladenen N-Terminus (KKV) von LDTI auf McoTI die Inhibitionskonstante gegenüber der Tryptase von 20 auf $2 \mathrm{nM}$ senken. In cyclo-McoEeTI befindet sich N-terminal der Inhibitorschleife jedoch ein Aspartat, also eine negativ geladene Aminosäure, die offensichtlich $\mathrm{zu}$ der deutlich schlechteren inhibitorischen Aktivität gegenüber Tryptase führt. 


\subsubsection{Diskussion und Ausblick}

In den letzten Jahren wurden insbesondere in Pflanzen zahlreiche kleine Proteine mit dem sogenannten CCK (cyclic cystine knot) Faltungsmotiv entdeckt [Craik, 2001, Craik et al., 1999]. Dieses Motiv zeichnet sich strukturell durch die Ausbildung eines Cystin-Knoten Grundgerüsts, wie es auch in Mikroproteinen mit dem ICK (inhibitor cystine knot) Motiv zu finden ist, und die Verknüpfung von $\mathrm{N}$ - und C-Terminus durch eine zusätzliche Peptidbindung aus. Obwohl die Rolle des zyklischen Rückgrats bisher kaum systematisch untersucht wurde, scheint es dem ohnehin schon rigiden Cystin-Knoten Grundgerüst zusätzliche Stabilität zu verleihen [Colgrave und Craik, 2004]. Vor allem sollte durch die Zyklisierung Resistenz gegenüber Exoproteasen vermittelt werden, da zirkuläre Proteine keine freien Termini aufweisen.

Für die synthetische Generierung zyklischer Proteine und Peptide wurden mehrere Verfahren entwickelt [Scott et al., 1999, Tam und Lu, 1998, Williams et al., 2002], die jedoch hinsichtlich einer Anwendung für die Zyklisierung von Cystin-Knoten Mikroproteinen verschiedene Nachteile aufweisen. In diesem Kapitel wurde ein Verfahren für die Herstellung zyklischer Mikroproteine vorgestellt, das auf der rekombinanten Produktion des Proteins über das in Kapitel 4.1. beschriebene Barnase'-Expressionssystem basiert. Das zu zyklisierende Protein wird so konzipiert, daß es nach Abspaltung vom Barnase'-Träger mittels Bromcyan über zwei eingeführte Methioninreste C-terminal ein Serin und N-terminal ein Homoserinlakton aufweist. Im Folgenden kann das Homoserinlakton mit Hydrazin umgesetzt werden, wodurch ein reaktives Hydrazid entsteht. Das N-terminale Serin wiederum kann mit Natrium-Periodat zum Aldehyd oxidiert werden. Befinden sich $\mathrm{N}$ - und C-Terminus in räumlicher Nähe zueinander, so können Aldehyd und Hydrazid unter Ausbildung eines Hydrazons miteinander reagieren und der Ringschluß ist vollzogen. Im Unterschied zu anderen Zyklisierungsstrategien bzw. zu natürlich vorkommenden Zyklotiden entsteht hier also keine Peptidbindung, sondern ein Hydrazon. Dieses Hydrazon ist unter sauren pH Bedingungen labil, kann jedoch durch Reduktion mit Natrium-Cyano-Borhydrid stabilisiert werden.

Dieses Konzept der Zyklisierung von Cystin-Knoten Mikroproteinen konnte in den Grundzügen an dem Beispiel Protein McoEeTI illustriert werden. Dafür wurde das Hybrid Mikroprotein McoEeTI durch Einführen zusätzlicher Aminosäuren so modifiziert, daß sich in dem gefalteten zyklischen Endprodukt die Termini in räumlicher Nähe befinden sollten. Das als cyclo-McoEeTI bezeichnete Konstrukt konnte in den Expressionsvektor pBar100 kloniert und in E. coli als Barnase'-Fusion produziert werden. Nach Reinigung des Fusionsproteins 
wurde der Barnase'-Träger mit Bromcyan abgespalten und durch präparative RPChromatographie abgetrennt. Das gereinigte Mikroprotein wurde dann der Zyklisierungsreaktion unterzogen, bei der zunächst der C-Terminus mit Hydrazin aktiviert und anschließend das N-terminale Serin mit Periodat zum Aldehyd oxidiert wird. Es wurde letztlich ein Produkt generiert, das ein verändertes Laufverhalten in der RP-HPLC, ein verändertes Absorptionsverhalten bei $280 \mathrm{~nm}$ und eine Masse aufwies, die der des zu generierenden Hydrazons entsprach.

Eine erste Charakterisierung des Produkts erfolgte im Labor von Prof. Dr. Sommerhoff durch Bestimmung der inhibitorischen Aktivität gegenüber Trypsin und humaner $\beta$-III MastzellTryptase. Es zeigte sich, daß das putative Hydrazon trotz der Modifikationen seine Funktion als Trypsin Inhibitor beibehalten hatte, während die Inhibitionskonstante gegenüber der Tryptase vermutlich aufgrund des Einführens einer negativ geladenen Aminosäure in die linker Sequenz im Vergleich zu McoEeTI deutlich höher war.

Obwohl es erste Evidenzen für die erfolgreiche Zyklisierung gibt, konnte bisher kein eindeutiger Nachweis für die Existenz der zyklischen Struktur des generierten cyclo-McoEeTI Proteins erbracht werden. Ein solcher Nachweis könnte zum einen durch die Aufklärung der dreidimsionalen Struktur mittels NMR oder Röntgenstrukturanalyse erfolgen. Zum anderen könnte man das Endprodukt mit Hydroxylamin spezifisch an Asparagin-Glycin Resten [Bornstein und Balian, 1970, Bornstein und Balian, 1977] spalten, wobei im Falle einer erfolgreichen Zyklisierung nur ein Fragment statt zwei entstünde. Im Zuge einer weiteren Charakterisierung sollten zudem die Auswirkungen der Zyklisierung auf die Stabilität des Mikroproteins insbesondere gegenüber Proteasen untersucht werden. Für die praktische Umsetzung dieser Experimente müßte jedoch zunächst eine Synthese des zyklischen Peptids im größeren Maßstab als bisher erfolgen.

In Zukunft wäre eine weitere Applikation des hier vorgestellten Konzepts vorstellbar. So wäre es denkbar, das Mikroprotein Grundgerüst rekombinant so herzustellen, das sich am Nterminalen Ende der Inhibitorschleife ein Methionin und am C-terminalen Ende der Inhibitorschleife ein Methioninrest gefolgt von einem Serin befindet. Die Schleife könnte mit Bromcyan „herausgeschnitten“ werden. Parallel könnte man chemisch beliebige Peptide mit N-terminalem Serin und C-terminalem Hydrazid herstellen und diese durch aufeinanderfolgende Aktivierung der Termini von Mikroprotein und Peptid mit Hydrazin bzw. Periodat in das Cystin-Knoten Grundgerüst ,einligieren“. 
Zusammenfassend läßt sich sagen, daß in diesem Kapitel die Grundlagen für ein neues Verfahren für die Zyklisierung von Mikroproteinen aufgezeigt wurden. Das Verfahren kombiniert die kosteneffiziente und im großen Maßstab anwendbare rekombinante Produktion des Mikroproteins in korrekt gefalteter Form mit einem postsynthetischen chemischen Verfahren für die Verknüpfung von N- und C-Terminus. Die Zyklisierung von Mikroproteinen könnte ein interessanter Weg für die weitere Erhöhung der Stabilität der Proteine im Zuge einer Entwicklung dieser Protein Familie als Wirkstoffkandidaten sein. 


\section{Zusammenfassung}

Cystin-Knoten Mikroproteine sind peptidische Biomoleküle mit einer Größe von etwa 28-40 Aminosäuren. Sie sind in der Lage, konformationell extrem stabile dreidimensionale Strukturen einzunehmen, die sich durch die charakteristische Verknüpfung von sechs Cysteinen $\mathrm{zu}$ einem Cystin-Knoten und ein dreisträngiges antiparalleles $\beta$-Faltblatt auszeichnen. Die Vertreter dieser Proteinfamilie sind untereinander kaum sequenz- aber dafür extrem strukturhomolog und sind in der Natur sowohl in linearer Form als auch mit zyklischem Grundgerüst (Zyklotide) als Modulatoren biomolekularer Wechselwirkungen mit verschiedensten biologischen Aktivitäten zu finden.

Im Rahmen dieses Promotionsvorhabens wurden auf der Basis des Cystin-Knoten Grundgerüsts durch rationales Protein Design neue Varianten generiert, die vorgegebenen Ansprüchen an die Wechselwirkung mit vorzugsweise therapeutisch relevanten Interaktionspartnern genügen.

Als technische Basis für diese Funktionalisierung wurde ein neuartiges rekombinantes Expressions- und Reinigungssystem zur Produktion variierter Cystin-Knoten Mikroproteine entwickelt, das auf der Fusion an Barnase', einer enzymatisch inaktivierten RNase aus Bacillus amyloliquefaciens beruht. Als alternative Expressionsorganismen wurde neben Eschericchia coli mit der Hefe Pichia pastoris zum ersten Mal ein eukaryontischer Einzeller für die Expression von Cystin-Knoten Mikroproteinen erschlossen. Dabei konnten Ausbeuten von über 20 (E. coli) bzw. $200 \mathrm{mg}$ (P. pastoris) Fusionsprotein pro Liter Zellkultur erreicht werden. Die Produktion durch Fusion an Barnase' ermöglichte zudem in Kooperation mit Dr. H. Niemann (GBF, Braunschweig) die Kristallisation und die Aufklärung der dreidimensionalen Struktur des Mikroproteins McoEeTI, die dann Grundlage für das rationale Design von Proteaseinhibitoren war.

In dieser Arbeit wurden erstmals durch rationales Protein Design Mikroproteine synthetisiert, die als Monomere mit hoher Affinität an den humanen Thrombopoietin-Rezeptor binden und als linkerverbrückte Homodimere potente Thrombopoietin-Rezeptor Agonisten sind. Zudem konnten durch strukturbasiertes Design neue Cystin-Knoten Mikroprotein Varianten entwickelt werden, die mit hoher Spezifität und Selektivität die mit Asthma assoziierte humane Mastzell-Tryptase blockieren. Diese Varianten sind zur Zeit die potentesten proteinergen Inhibitoren dieser tetrameren Serinprotease und sollten sich durch Herstellung bivalenter Homodimere weiter verbessern lassen. 
Schließlich wurde in Zusammenarbeit mit Olga Avrutina (Institut für Organische Chemie, Georg-August Universität Göttingen) ein Verfahren entwickelt, das durch rekombinante Produktion und postsynthetische chemische Modifizierung einen Zugang zu zyklischen Mikroproteinen schafft. Die prinzipielle Gangbarkeit dieser Synthesestrategie wurde anhand des Beispiels McoEeTI im analytischen Maßstab illustriert und könnte die Grundlage für eine weitergehende Stabilisierung in Hinblick auf eine potentielle therapeutische Anwendung von Varianten aus der Familie der Cystin-Knoten Mikroproteine und insbesondere der Zyklotide legen. 


\section{Literaturverzeichnis}

1. Auerswald, E.A., Morenweiser, R., Sommerhoff, C.P., Piechottka, G.P., Eckerskorn, C., Gurtler, L.G. \& Fritz, H., Recombinant leech-derived tryptase inhibitor: construction, production, protein chemical characterization and inhibition of HIV1 replication. Biol Chem Hoppe Seyler, 1994. 375(10): p. 695-703.

2. Avrutina, O., Schmoldt, H.U., Kolmar, H. \& Diederichsen, U., Fmoc-Assisted Synthesis of a 29Residue Cystine-Knot Trypsin Inhibitor Containing a Guaninyl Amino Acid at the P1-Position. Eur $J$ Org Chem, 2004(23): p. 49314935.

3. Ay, J., Hilpert, K., Krauss, N., Schneider-Mergener, J. \& Höhne, W., Structure of a hybrid squash inhibitor in complex with porcine pancreatic elastase at $1.8 \mathrm{~A}$ resolution. Acta Crystallogr D Biol Crystallogr, 2003. 59(Pt 2): p. 24754.

4. Ballmaier, M., Germeshausen, M., Schulze, H., Cherkaoui, K., Lang, S., Gaudig, A., Krukemeier, S., Eilers, M., Strauss, G. \& Welte, K., c-mpl mutations are the cause of congenital amegakaryocytic thrombocytopenia. Blood, 2001. 97(1): p. 139-46.

5. Bartley, T.D., Bogenberger, J., Hunt, P., Li, Y.S., Lu, H.S., Martin, F., Chang, M.S., Samal, B., Nichol, J.L., Swift, S. \& et al., Identification and cloning of a megakaryocyte growth and development factor that is a ligand for the cytokine receptor Mpl. Cell, 1994. 77(7): p. 1117-24.

6. Basser, R.L., O'Flaherty, E., Green, M., Edmonds, M., Nichol, J., Menchaca, D.M., Cohen, B. \& Begley, C.G., Development of pancytopenia with neutralizing antibodies to thrombopoietin after multicycle chemotherapy supported by megakaryocyte growth and development factor. Blood, 2002. 99(7): p. 2599-602.

7. Battinelli, E., Willoughby, S.R., Foxall, T., Valeri, C.R. \& Loscalzo, J., Induction of platelet formation from megakaryocytoid cells by nitric oxide. Proc Natl Acad Sci U S A, 2001. 98(25): p. 14458-63.

8. Bazan, J.F., Structural design and molecular evolution of a cytokine receptor superfamily. Proc Natl Acad Sci U S A, 1990. 87(18): p. 6934-8.

9. Beasley, J.R. \& Hecht, M.H., Protein design: the choice of de novo sequences. $J$ Biol Chem, 1997. 272(4): p. 2031-4.

10. Becker, S., Schmoldt, H.U., Adams, T.M., Wilhelm, S. \& Kolmar, H., Ultra-high-throughput screening based on cell-surface display and fluorescence-activated cell sorting for the identification of novel biocatalysts. Curr Opin Biotechnol, 2004. 15(4): p. 323-9.

11. Benoist, C. \& Mathis, D., Mast cells in autoimmune disease. Nature, 2002. 420(6917): p. 875-8.

12. Bode, W., Greyling, H.J., Huber, R., Otlewski, J. \& Wilusz, T., The refined 2.0 A X-ray crystal structure of the complex formed between bovine beta-trypsin and CMTI-I, a trypsin inhibitor from squash seeds (Cucurbita maxima). Topological similarity of the squash seed inhibitors with the carboxypeptidase A inhibitor from potatoes. FEBS Lett, 1989. 242(2): p. 285-92.

13. Bode, W. \& Huber, R., Natural protein proteinase inhibitors and their interaction with proteinases. Eur J Biochem, 1992. 204(2): p. 433-51. 
14. Bode, W., Meyer, E., Jr. \& Powers, J.C., Human leukocyte and porcine pancreatic elastase: $\mathrm{X}$ ray crystal structures, mechanism, substrate specificity, and mechanism-based inhibitors. Biochemistry, 1989. 28(5): p. 1951-63.

15. Bolewska, K., Krowarsch, D., Otlewski, J., Jaroszewski, L. \& Bierzynski, A., Synthesis, cloning and expression in Escherichia coli of a gene coding for the Met8-$>$ Leu CMTI I--a representative of the squash inhibitors of serine proteinases. FEBS Lett., 1995. 377(2): p. 172-4.

16. Bolin, K.A., Anderson, D.J., Trulson, J.A., Thompson, D.A., Wilken, J., Kent, S.B., Gantz, I. \& Millhauser, G.L., NMR structure of a minimized human agouti related protein prepared by total chemical synthesis. FEBS Lett, 1999. 451(2): p. 125-31.

17. Bornstein, P. \& Balian, G., The specific nonenzymatic cleavage of bovine ribonuclease with hydroxylamine. J Biol Chem, 1970. 245(18): p. 4854-6.

18. Bornstein, P. \& Balian, G., Cleavage at Asn-Gly bonds with hydroxylamine. Methods Enzymol, 1977. 47: p. 132-45.

19. Bradford, M.M., A rapid and sensitive method for the quantitation of microgram quantities of protein utilizing the principle of protein-dye binding. Anal Biochem, 1976. 72: p. 248-54.

20. Brakmann, S. \& Schwienhorst, A., eds. Evolutionary Methods in Biotechnology. 1. Edition ed. 2004, Wiley-VCH: Weinheim.

21. Brown, J.K., Jones, C.A., Rooney, L.A., Caughey, G.H. \& Hall, I.P., Tryptase's potent mitogenic effects in human airway smooth muscle cells are via nonproteolytic actions. Am J Physiol Lung Cell Mol Physiol, 2002. 282(2): p. L197-206.
22. Bunting, S., Widmer, R., Lipari, T., Rangell, L., Steinmetz, H., Carver-Moore, K., Moore, M.W., Keller, G.A. \& de Sauvage, F.J., Normal platelets and megakaryocytes are produced in vivo in the absence of thrombopoietin. Blood, 1997. 90(9): p. 3423-9.

23. Burgess, L.E., Newhouse, B.J., Ibrahim, P., Rizzi, J., Kashem, M.A., Hartman, A., Brandhuber, B.J., Wright, C.D., Thomson, D.S., Vigers, G.P. \& Koch, K., Potent selective nonpeptidic inhibitors of human lung tryptase. Proc Natl Acad Sci U S A, 1999. 96(15): p. 8348-52.

24. Cairns, J.A., Inhibitors of mast cell tryptase beta as therapeutics for the treatment of asthma and inflammatory disorders. Pulm Pharmacol Ther, 2005. 18(1): p. 55-66.

25. Cairns, J.A. \& Walls, A.F., Mast cell tryptase is a mitogen for epithelial cells. Stimulation of IL-8 production and intercellular adhesion molecule-1 expression. $J$ Immunol, 1996. 156(1): p. 275-83.

26. Caughey, G.H., Of mites and men: trypsin-like proteases in the lungs. Am J Respir Cell Mol Biol, 1997. 16(6): p. 621-8.

27. Caughey, G.H., Raymond, W.W., Bacci, E., Lombardy, R.J. \& Tidwell, R.R., Bis(5-amidino-2benzimidazolyl)methane and related amidines are potent, reversible inhibitors of mast cell tryptases. $J$ Pharmacol Exp Ther, 1993. 264(2): p. 676-82.

28. Chen, X.M., Qian, Y.W., Chi, C.W., Gan, K.D., Zhang, M.F. \& Chen, C.Q., Chemical synthesis, molecular cloning, and expression of the gene coding for the Trichosanthes trypsin inhibitor--a squash family inhibitor. J. Biochem. (Tokyo), 1992. 112(1): p. 4551.

29. Chiche, L., Heitz, A., Gelly, J.C., Gracy, J., Chau, P.T., Ha, P.T., 
Hernandez, J.F. \& Le-Nguyen, D., Squash inhibitors: from structural motifs to macrocyclic knottins. Curr Protein Pept Sci, 2004. 5(5): p. 341-349.

30. Chiche, L., Heitz, A., Padilla, A., Le-Nguyen, D. \& Castro, B., Solution conformation of a synthetic bis-headed inhibitor of trypsin and carboxypeptidase A: new structural alignment between the squash inhibitors and the potato carboxypeptidase inhibitor. Protein Eng, 1993. 6(7): p. 675-82.

31. Christmann, A., Walter, K., Wentzel, A., Krätzner, R. \& Kolmar, H., The cystine knot of a squash-type protease inhibitor as a structural scaffold for Escherichia coli cell surface display of conformationally constrained peptides. Protein Eng, 1999. 12(9): p. 797-806.

32. Clark, J.M., Abraham, W.M., Fishman, C.E., Forteza, R., Ahmed, A., Cortes, A., Warne, R.L., Moore, W.R. \& Tanaka, R.D., Tryptase inhibitors block allergen-induced airway and inflammatory responses in allergic sheep. Am J Respir Crit Care Med, 1995. $152(6 \mathrm{Pt} \mathrm{1):} \mathrm{p.} \mathrm{2076-83.}$

33. Colgrave, M.L. \& Craik, D.J., Thermal, chemical, and enzymatic stability of the cyclotide kalata B1: the importance of the cyclic cystine knot. Biochemistry, 2004. 43(20): p. 5965-75.

34. Corrales, F.J. \& Fersht, A.R., The folding of GroEL-bound barnase as a model for chaperoninmediated protein folding. Proc Natl Acad Sci U S A, 1995. 92(12): p. 5326-30.

35. Costanzo, M.J., Yabut, S.C., Almond, H.R., Jr., AndradeGordon, P., Corcoran, T.W., De Garavilla, L., Kauffman, J.A., Abraham, W.M., Recacha, R., Chattopadhyay, D. \& Maryanoff, B.E., Potent, small-molecule in- hibitors of human mast cell tryptase. Antiasthmatic action of a dipeptide-based transition-state analogue containing a benzothiazole ketone. J Med Chem, 2003. 46(18): p. 3865-76.

36. Craik, D.J., Plant cyclotides: circular, knotted peptide toxins. Toxicon, 2001. 39(12): p. 1809-13.

37. Craik, D.J., Daly, N.L., Bond, T. \& Waine, C., Plant cyclotides: A unique family of cyclic and knotted proteins that defines the cyclic cystine knot structural motif. $J \mathrm{Mol}$ Biol, 1999. 294(5): p. 1327-36.

38. Craik, D.J., Daly, N.L., Mulvenna, J., Plan, M.R. \& Trabi, M., Discovery, structure and biological activities of the cyclotides. Curr Protein Pept Sci, 2004. 5(5): p. 297-315.

39. Craik, D.J., Daly, N.L., Saska, I., Trabi, M. \& Rosengren, K.J., Structures of naturally occurring circular proteins from bacteria. $J$ Bacteriol, 2003. 185(14): p. 401121.

40. Craik, D.J., Daly, N.L. \& Waine, C., The cystine knot motif in toxins and implications for drug design. Toxicon, 2001. 39(1): p. 43-60.

41. Craik, D.J., Simonsen, S. \& Daly, N.L., The cyclotides: novel macrocyclic peptides as scaffolds in drug design. Curr Opin Drug Discov Devel, 2002. 5(2): p. 251-60.

42. Cregg, J.M., Cereghino, J.L., Shi, J. \& Higgins, D.R., Recombinant protein expression in Pichia pastoris. Mol Biotechnol, 2000. 16(1): p. 23-52.

43. Cwirla, S.E., Balasubramanian, P., Duffin, D.J., Wagstrom, C.R., Gates, C.M., Singer, S.C., Davis, A.M., Tansik, R.L., Mattheakis, L.C., Boytos, C.M., Schatz, P.J., Baccanari, D.P., Wrighton, N.C., Barrett, R.W. \& Dower, W.J., Peptide agonist of the thrombopoietin receptor as potent as the 
natural cytokine. Science, 1997. 276(5319): p. 1696-9.

44. Czapinska, H. \& Otlewski, J., Structural and energetic determinants of the S1-site specificity in serine proteases. Eur J Biochem, 1999. 260(3): p. 571-95.

45. Daly, N.L. \& Craik, D.J., Acyclic permutants of naturally occurring cyclic proteins. Characterization of cystine knot and beta-sheet formation in the macrocyclic polypeptide kalata B1. $J$ Biol Chem, 2000. 275(25): p. 19068-75.

46. Daly, N.L., Love, S., Alewood, P.F. \& Craik, D.J., Chemical synthesis and folding pathways of large cyclic polypeptides: studies of the cystine knot polypeptide kalata B1. Biochemistry, 1999. 38(32): p. 10606-14.

47. Davies, J.S., The cyclization of peptides and depsipeptides. $J$ Pept Sci, 2003. 9(8): p. 471-501.

48. de Sauvage, F.J., Hass, P.E., Spencer, S.D., Malloy, B.E., Gurney, A.L., Spencer, S.A., Darbonne, W.C., Henzel, W.J., Wong, S.C., Kuang, W.J. \& et al., Stimulation of megakaryocytopoiesis and thrombopoiesis by the c-Mpl ligand. Nature, 1994. 369(6481): p. 533-8.

49. Deyev, S.M., Waibel, R., Lebedenko, E.N., Schubiger, A.P. \& Plückthun, A., Design of multivalent complexes using the barnase*barstar module. Nat. Biotechnol., 2003. 21(12): p. 148692.

50. Döbeli, H., Andres, H., Breyer, N., Draeger, N., Sizmann, D., Zuber, M.T., Weinert, B. \& Wipf, B., Recombinant fusion proteins for the industrial production of disulfide bridge containing peptides: purification, oxidation without concatamer formation, and selective cleavage. Protein Expr. Purif., 1998. 12(3): p. 404-14.
51. Dower, W.J., Cwirla, S.E., Balasubramanian, P., Schatz, P.J., Baccanari, D.P. \& Barrett, R.W., Peptide agonists of the thrombopoietin receptor. Stem Cells, 1998. 16 Suppl 2: p. 21-9.

52. Dower, W.J., Miller, J.F. \& Ragsdale, C.W., High efficiency transformation of E. coli by high voltage electroporation. Nucleic Acids Res, 1988. 16(13): p. 612745.

53. Drachman, J.G., Millett, K.M. \& Kaushansky, K., Thrombopoietin signal transduction requires functional JAK2, not TYK2. J Biol Chem, 1999. 274(19): p. 13480-4.

54. Dvorak, A.M., Ultrastructure of human mast cells. Int Arch Allergy Immunol, 2002. 127(2): p. 100-5.

55. Elrod, K.C., Moore, W.R., Abraham, W.M. \& Tanaka, R.D., Lactoferrin, a potent tryptase inhibitor, abolishes late-phase airway responses in allergic sheep. Am J Respir Crit Care Med, 1997. 156(2 Pt 1): p. 375-81.

56. Erickson-Miller, C.L., Delorme, E., Tian, S.S., Hopson, C.B., Stark, K., Giampa, L., Valoret, E.I., Duffy, K.J., Luengo, J.L., Rosen, J., Miller, S.G., Dillon, S.B. \& Lamb, P., Discovery and characterization of a selective, nonpeptidyl thrombopoietin receptor agonist. Exp Hematol, 2005. 33(1): p. 85-93.

57. Evans, T.C., Jr., Benner, J. \& Xu, M.Q., The cyclization and polymerization of bacterially expressed proteins using modified self-splicing inteins. $J$ Biol Chem, 1999. 274(26): p. 18359-63.

58. Fairlie, W.D., Uboldi, A.D., De Souza, D.P., Hemmings, G.J., Nicola, N.A. \& Baca, M., A fusion protein system for the recombinant production of short disulfide-containing peptides. Protein Expr. Purif., 2002. 26(1): p. 171-8. 
59. Fanucchi, M., Glaspy, J., Crawford, J., Garst, J., Figlin, R., Sheridan, W., Menchaca, D., Tomita, D., Ozer, H. \& Harker, L., Effects of polyethylene glycolconjugated recombinant human megakaryocyte growth and development factor on platelet counts after chemotherapy for lung cancer. $N$ Engl $J$ Med, 1997. 336(6): p. 404-9.

60. Favel, A., Mattras, H., ColettiPreviero, M.A., Zwilling, R., Robinson, E.A. \& Castro, B., Protease inhibitors from Ecballium elaterium seeds. Int J Pept Protein Res, 1989. 33(3): p. 202-8.

61. Feese, M.D., Tamada, T., Kato, Y., Maeda, Y., Hirose, M., Matsukura, Y., Shigematsu, H., Muto, T., Matsumoto, A., Watarai, H., Ogami, K., Tahara, T., Kato, T., Miyazaki, H. \& Kuroki, R., Structure of the receptor-binding domain of human thrombopoietin determined by complexation with a neutralizing antibody fragment. Proc Natl Acad Sci U S A, 2004. 101(7): p. 181621.

62. Felizmenio-Quimio, M.E., Daly, N.L. \& Craik, D.J., Circular proteins in plants: solution structure of a novel macrocyclic trypsin inhibitor from Momordica cochinchinensis. $J$ Biol Chem, 2001. 276(25): p. 22875-82.

63. Fields, R. \& Dixon, H.B., A spectrophotometric method for the microdetermination of periodate. Biochem J, 1968. 108(5): p. 883-7.

64. Fink, E., Rehm, H., Gippner, C., Bode, W., Eulitz, M., Machleidt, W. \& Fritz, H., The primary structure of bdellin B-3 from the leech Hirudo medicinalis. Bdellin B-3 is a compact proteinase inhibitor of a "non-classical" Kazal type. It is present in the leech in a high molecular mass form. Biol
Chem Hoppe Seyler, 1986. 367(12): p. 1235-42.

65. Frank, S.J., Receptor dimerization in GH and erythropoietin action--it takes two to tango, but how? Endocrinology, 2002. 143(1): p. 210.

66. Friedrich, T., Kroger, B., Bialojan, S., Lemaire, H.G., Hoffken, H.W., Reuschenbach, P., Otte, M. \& Dodt, J., A Kazaltype inhibitor with thrombin specificity from Rhodnius prolixus. $J$ Biol Chem, 1993. 268(22): p. 16216-22.

67. Gaertner, H.F., Rose, K., Cotton, R., Timms, D., Camble, R. \& Offord, R.E., Construction of protein analogues by site-specific condensation of unprotected fragments. Bioconjug Chem, 1992. 3(3): p. 262-8.

68. Gangloff, A.R., Tryptase inhibitors in the treatment of pulmonary diseases. Curr Opin Investig Drugs, 2000. 1(1): p. 79-85.

69. Geddis, A.E., Linden, H.M. \& Kaushansky, K., Thrombopoietin: a pan-hematopoietic cytokine. Cytokine Growth Factor Rev, 2002. 13(1): p. 61-73.

70. Gelly, J.C., Gracy, J., Kaas, Q., Le-Nguyen, D., Heitz, A. \& Chiche, L., The KNOTTIN website and database: a new information system dedicated to the knottin scaffold. Nucleic Acids Res, 2004. 32(Database issue): p. D1569.

71. Geoghegan, K.F. \& Stroh, J.G., Site-directed conjugation of nonpeptide groups to peptides and proteins via periodate oxidation of a 2-amino alcohol. Application to modification at $\mathrm{N}$-terminal serine. Bioconjug Chem, 1992. 3(2): p. 138-46.

72. Goldenberg, D.P., Native and nonnative intermediates in the BPTI folding pathway. Trends Biochem Sci, 1992. 17(7): p. 257-61. 
73. Gonzalez, C., Langdon, G.M., Bruix, M., Galvez, A., Valdivia, E., Maqueda, M. \& Rico, M., Bacteriocin AS-48, a microbial cyclic polypeptide structurally and functionally related to mammalian NK-lysin. Proc Natl Acad Sci U S A, 2000. 97(21): p. 11221-6.

74. Gran, L., On the effect of a polypeptide isolated from "KalataKalata" (Oldenlandia affinis DC) on the oestrogen dominated uterus. Acta Pharmacol Toxicol (Copenh), 1973. 33(5): p. 400-8.

75. Grinsted, J. \& Bennett, P.M., Methods in microbiology: plasmid technology, 21. 1988, Academic Press, San Diego.

76. Grötzinger, J., Molecular mechanisms of cytokine receptor activation. Biochim Biophys Acta, 2002. 1592(3): p. 215-23.

77. Gustafson, K.R., McKee, T.C. \& Bokesch, H.R., Anti-HIV cyclotides. Curr Protein Pept Sci, 2004. 5(5): p. 331-40.

78. Hallgren, J., Estrada, S., Karlson, U., Alving, K. \& Pejler, G., Heparin antagonists are potent inhibitors of mast cell tryptase. Biochemistry, 2001. 40(24): p. 7342-9.

79. Hamato, N., Koshiba, T., Pham, T.N., Tatsumi, Y., Nakamura, D., Takano, R., Hayashi, K., Hong, Y.M. \& Hara, S., Trypsin and elastase inhibitors from bitter gourd (Momordica charantia LINN.) seeds: purification, amino acid sequences, and inhibitory activities of four new inhibitors. $J$ Biochem (Tokyo), 1995. 117(2): p. 432-7.

80. Hartley, R.W., Barnase and barstar. Expression of its cloned inhibitor permits expression of a cloned ribonuclease. J. Mol. Biol., 1988. 202(4): p. 913-5.

81. Hartley, R.W., Barnase-barstar interaction. Methods Enzymol, 2001. 341: p. 599-611.
82. Heitz, A., Chiche, L., Le-Nguyen, D. \& Castro, B., 1H 2D NMR and distance geometry study of the folding of Ecballium elaterium trypsin inhibitor, a member of the squash inhibitors family. Biochemistry, 1989. 28(6): p. 2392-8.

83. Heitz, A., Hernandez, J.F., Gagnon, J., Hong, T.T., Pham, T.T., Nguyen, T.M., Le-Nguyen, D. \& Chiche, L., Solution structure of the squash trypsin inhibitor MCoTI-II. A new family for cyclic knottins. Biochemistry, 2001. 40(27): p. 7973-83.

84. Helland, R., Berglund, G.I., Otlewski, J., Apostoluk, W., Andersen, O.A., Willassen, N.P. \& Smalas, A.O., High-resolution structures of three new trypsinsquash-inhibitor complexes: a detailed comparison with other trypsins and their complexes. Acta Crystallogr D Biol Crystallogr, 1999. 55 ( Pt 1): p. 139-48.

85. Henz, B.M., Maurer, M., Lippert, U., Worm, M. \& Babina, M., Mast cells as initiators of immunity and host defense. Exp Dermatol, 2001. 10(1): p. 1-10.

86. Hernandez, J.F., Gagnon, J., Chiche, L., Nguyen, T.M., Andrieu, J.P., Heitz, A., Trinh Hong, T., Pham, T.T. \& Le Nguyen, D., Squash trypsin inhibitors from Momordica cochinchinensis exhibit an atypical macrocyclic structure. Biochemistry, 2000. 39(19): p. 572230.

87. Higgins, D.R. \& Cregg, J.M., Introduction to Pichia pastoris. Methods Mol Biol, 1998. 103: p. 115.

88. Hill, R.B., Raleigh, D.P., Lombardi, A. \& DeGrado, W.F., De novo design of helical bundles as models for understanding protein folding and function. Acc Chem Res, 2000. 33(11): p. 745-54. 
89. Hilpert, K., Wessner, H., Schneider-Mergener, J., Welfle, K., Misselwitz, R., Welfle, H., Hocke, A.C., Hippenstiel, S. \& Höhne, W., Design and characterization of a hybrid miniprotein that specifically inhibits porcine pancreatic elastase. $J$ Biol Chem, 2003. 278(27): p. 24986-93.

90. Hofmann, M.A. \& Brian, D.A., Sequencing PCR DNA amplified directly from a bacterial colony. Biotechniques, 1991. 11(1): p. 301.

91. Holland, D.R., Cousens, L.S., Meng, W. \& Matthews, B.W., Nerve growth factor in different crystal forms displays structural flexibility and reveals zinc binding sites. J Mol Biol, 1994. 239(3): p. 385-400.

92. Hollenberg, C.P. \& Gellissen, G., Production of recombinant proteins by methylotrophic yeasts. Curr Opin Biotechnol, 1997. 8(5): p. 554-60.

93. Inagaki, K., Oda, T., Naka, Y., Shinkai, H., Komatsu, N. \& Iwamura, H., Induction of megakaryocytopoiesis and thrombocytopoiesis by JTZ-132, a novel small molecule with thrombopoietin mimetic activities. Blood, 2004. 104(1): p. 58-64.

94. Irani, A.A., Schechter, N.M., Craig, S.S., DeBlois, G. \& Schwartz, L.B., Two types of human mast cells that have distinct neutral protease compositions. Proc Natl Acad Sci U S A, 1986. 83(12): p. 4464-8.

95. Jackson, P.J., McNulty, J.C., Yang, Y.K., Thompson, D.A., Chai, B., Gantz, I., Barsh, G.S. \& Millhauser, G.L., Design, pharmacology, and NMR structure of a minimized cystine knot with agouti-related protein activity. Biochemistry, 2002. 41(24): p. 7565-72.
96. Jogie-Brahim, S., Min, H.K., Fukuoka, Y., Xia, H.Z. \& Schwartz, L.B., Expression of alpha-tryptase and beta-tryptase by human basophils. $J$ Allergy Clin Immunol, 2004. 113(6): p. 1086-92.

97. Johnson, P.R., Ammit, A.J., Carlin, S.M., Armour, C.L., Caughey, G.H. \& Black, J.L., Mast cell tryptase potentiates histamine-induced contraction in human sensitized bronchus. Eur Respir J, 1997. 10(1): p. 38-43.

98. Jones, D.V., Jr., Ashby, M., Vadhan-Raj, S., Somlo, G., Champlin, R., Gajewski, J., Hellmann, S. \& Fyfe, G., Recombinant human thrombopoietin clinical development. Stem Cells, 1998. 16 Suppl 2: p. 199206.

99. Joseph, C.G., Bauzo, R.M., Xiang, Z., Shaw, A.M., Millard, W.J. \& Haskell-Luevano, C., Elongation studies of the human agouti-related protein (AGRP) core decapeptide (Yc[CRFFNAFC]Y) results in antagonism at the mouse melanocortin-3 receptor. Peptides, 2003. 24(2): p. 263-70.

100. Jucovic, M. \& Hartley, R.W., In vivo system for the detection of low level activity barnase mutants. Protein Eng., 1995. 8(5): p. 497-9.

101. Kaiser, R. \& Metzka, L., Enhancement of cyanogen bromide cleavage yields for methionylserine and methionyl-threonine peptide bonds. Anal Biochem, 1999. 266(1): p. 1-8.

102. Katz, B.A., Clark, J.M., FinerMoore, J.S., Jenkins, T.E., Johnson, C.R., Ross, M.J., Luong, C., Moore, W.R. \& Stroud, R.M., Design of potent selective zinc-mediated serine protease inhibitors. Nature, 1998. 391(6667): p. 608-12.

103. Kaushansky, K., Thrombopoietin: the primary regulator of platelet 
production. Blood, 1995. 86(2): p. 419-31.

104. Kaushansky, K., Broudy, V.C., Lin, N., Jorgensen, M.J., McCarty, J., Fox, N., ZuckerFranklin, D. \& Lofton-Day, C., Thrombopoietin, the Mp1 ligand, is essential for full megakaryocyte development. Proc Natl Acad Sci U $S A$, 1995. 92(8): p. 3234-8.

105. Kaushansky, K. \& Drachman, J.G., The molecular and cellular biology of thrombopoietin: the primary regulator of platelet production. Oncogene, 2002. 21(21): p. 3359-67.

106. Kaushansky, K., Lok, S., Holly, R.D., Broudy, V.C., Lin, N., Bailey, M.C., Forstrom, J.W., Buddle, M.M., Oort, P.J., Hagen, F.S. et al., Promotion of megakaryocyte progenitor expansion and differentiation by the c-Mpl ligand thrombopoietin. Nature, 1994. 369(6481): p. 568-71.

107. Kelemen, E., Cserhati, I. \& Tanos, B., Demonstration and some properties of human thrombopoietin in thrombocythaemic sera. Acta Haematol, 1958. 20(6): p. 350-5.

108. King, T.P., Zhao, S.W. \& Lam, T., Preparation of protein conjugates via intermolecular hydrazone linkage. Biochemistry, 1986. 25(19): p. 5774-9.

109. Kojima, S., Miyoshi, K. \& Miura, K., Synthesis of a squash-type protease inhibitor by gene engineering and effects of replacements of conserved hydrophobic amino acid residues on its inhibitory activity. Protein Eng, 1996. 9(12): p. 1241-6.

110. Krause, S., Würdemann, D., Wentzel, A., Christmann, A., Fehr, H., Kolmar, H. \& Friedrich, K., Bacteria displaying interleukin-4 mutants stimulate mammalian cells and reflect the biological activities of variant soluble cytokines. Chembiochem, 2004. 5(6): p. 804-10.

111. Krishna, M.T., Chauhan, A., Little, L., Sampson, K., Hawksworth, R., Mant, T., Djukanovic, R., Lee, T. \& Holgate, S., Inhibition of mast cell tryptase by inhaled APC 366 attenuates allergen-induced latephase airway obstruction in asthma. $J$ Allergy Clin Immunol, 2001. 107(6): p. 1039-45.

112. Kuter, D.J. \& Rosenberg, R.D., Appearance of a megakaryocyte growth-promoting activity, megapoietin, during acute thrombocytopenia in the rabbit. Blood, 1994. 84(5): p. 1464-72.

113. Laemmli, U.K., Cleavage of structural proteins during the assembly of the head of bacteriophage T4. Nature, 1970. 227(5259): p. 680-5.

114. Lautz, J., Kessler, H., Blaney, J.M., Scheek, R.M. \& Van Gunsteren, W.F., Calculating three-dimensional molecular structure from atom-atom distance information: cyclosporin A. Int $J$ Pept Protein Res, 1989. 33(4): p. 281-8.

115. Le Nguyen, D., Heitz, A., Chiche, L., Castro, B., Boigegrain, R.A., Favel, A. \& Coletti-Previero, M.A., Molecular recognition between serine proteases and new bioactive microproteins with a knotted structure. Biochimie, 1990. 72(6-7): p. 431-5.

116. Le-Nguyen, D., Mattras, H., Coletti-Previero, M.A. \& Castro, B., Design and chemical synthesis of a 32 residues chimeric microprotein inhibiting both trypsin and carboxypeptidase A. Biochem Biophys Res Commun, 1989. 162(3): p. 1425-30.

117. Le-Nguyen, D., Nalis, D. \& Castro, B., Solid phase synthesis of a trypsin inhibitor isolated from the Cucurbitaceae Ecballium 
elaterium. Int J Pept Protein Res, 1989. 34(6): p. 492-7.

118. Levi-Schaffer, F. \& Piliponsky, A.M., Tryptase, a novel link between allergic inflammation and fibrosis. Trends Immunol, 2003. 24(4): p. 158-61.

119. Li, J., Yang, C., Xia, Y., Bertino, A., Glaspy, J., Roberts, M. \& Kuter, D.J., Thrombocytopenia caused by the development of antibodies to thrombopoietin. Blood, 2001. 98(12): p. 3241-8.

120. Liébecq, C., Biochemical nomenclature and related documents. International Union for Biochemistry. London: The Biochemical Society, 1978.

121. Lohi, J., Harvima, I. \& KeskiOja, J., Pericellular substrates of human mast cell tryptase: 72,000 dalton gelatinase and fibronectin. $J$ Cell Biochem, 1992. 50(4): p. 33749.

122. Lok, S. \& Foster, D.C., The structure, biology and potential therapeutic applications of recombinant thrombopoietin. Stem Cells, 1994. 12(6): p. 586-98.

123. Ludolph-Hauser, D., Rueff, F., Sommerhoff, C.P. \& Przybilla, B., [Tryptase, a marker for the activation and localization of mast cells]. Hautarzt, 1999. 50(8): p. 556-61.

124. Marshall, J.S. \& Jawdat, D.M., Mast cells in innate immunity. $J$ Allergy Clin Immunol, 2004. 114(1): p. 21-7.

125. Martinez-Bueno, M., Maqueda, M., Galvez, A., Samyn, B., Van Beeumen, J., Coyette, J. \& Valdivia, E., Determination of the gene sequence and the molecular structure of the enterococcal peptide antibiotic AS-48. $J$ Bacteriol, 1994. 176(20): p. 63349.

126. Mauguen, Y., Hartley, R.W., Dodson, E.J., Dodson, G.G., Bricogne, G., Chothia, C. \& Jack,
A., Molecular structure of a new family of ribonucleases. Nature, 1982. 297(5862): p. 162-4.

127. McDonald, N.Q. \& Blundell, T.L., Crystallization and characterization of the high molecular weight form of nerve growth factor (7 S NGF). J Mol Biol, 1991. 219(4): p. 595-601.

128. McDonald, N.Q. \& Hendrickson, W.A., A structural superfamily of growth factors containing a cystine knot motif. Cell, 1993. 73(3): p. 421-4.

129. McNulty, J.C., Jackson, P.J., Thompson, D.A., Chai, B., Gantz, I., Barsh, G.S., Dawson, P.E. \& Millhauser, G.L., Structures of the agouti signaling protein. $J \mathrm{Mol}$ Biol, 2005. 346(4): p. 1059-70.

130. McNulty, J.C., Thompson, D.A., Bolin, K.A., Wilken, J., Barsh, G.S. \& Millhauser, G.L., Highresolution NMR structure of the chemically-synthesized melanocortin receptor binding domain $\operatorname{AGRP}(87-132)$ of the agoutirelated protein. Biochemistry, 2001. 40(51): p. 15520-7.

131. Mellado, M., Vila-Coro, A.J., Martinez, C. \& Rodriguez-Frade, J.M., Receptor dimerization: a key step in chemokine signaling. Cell Mol Biol (Noisy-le-grand), 2001. 47(4): p. 575-82.

132. Miura, S. \& Funatsu, G., Isolation and amino acid sequences of two trypsin inhibitors from the seeds of bitter gourd (Momordica charantia). Biosci Biotechnol Biochem, 1995. 59(3): p. 469-73.

133. Molina, M.A., Aviles, F.X. \& Querol, E., Expression of a synthetic gene encoding potato carboxypeptidase inhibitor using a bacterial secretion vector. Gene, 1992. 116(2): p. 129-38.

134. Molino, M., Barnathan, E.S., Numerof, R., Clark, J., Dreyer, M., Cumashi, A., Hoxie, J.A., Schechter, N., Woolkalis, M. \& 
Brass, L.F., Interactions of mast cell tryptase with thrombin receptors and PAR-2. J Biol Chem, 1997. 272(7): p. 4043-9.

135. Morrison, J.F., Kinetics of the reversible inhibition of enzymecatalysed reactions by tight-binding inhibitors. Biochim Biophys Acta, 1969. 185(2): p. 269-86.

136. Mühlhahn, P., Czisch, M., Morenweiser, R., Habermann, B., Engh, R.A., Sommerhoff, C.P., Auerswald, E.A. \& Holak, T.A., Structure of leech derived tryptase inhibitor (LDTI-C) in solution. FEBS Lett, 1994. 355(3): p. 290-6.

137. Muir, T.W., Semisynthesis of proteins by expressed protein ligation. Annu Rev Biochem, 2003. 72: p. 249-89.

138. Mullis, K.B. \& Faloona, F.A., Specific synthesis of DNA in vitro via a polymerase-catalyzed chain reaction. Methods Enzymol, 1987. 155: p. 335-50.

139. Murray-Rust, J., McDonald, N.Q., Blundell, T.L., Hosang, M., Oefner, C., Winkler, F. \& Bradshaw, R.A., Topological similarities in TGF-beta 2, PDGF$\mathrm{BB}$ and NGF define a superfamily of polypeptide growth factors. Structure, 1993. 1(2): p. 153-9.

140. Nash, R.A., Kurzrock, R., DiPersio, J., Vose, J., Linker, C., Maharaj, D., Nademanee, A.P., Negrin, R., Nimer, S., Shulman, H., Ashby, M., Jones, D., Appelbaum, F.R. \& Champlin, R., A phase I trial of recombinant human thrombopoietin in patients with delayed platelet recovery after hematopoietic stem cell transplantation. Biol Blood Marrow Transplant, 2000. 6(1): p. 25-34.

141. Neira, J.L., Vazquez, E. \& Fersht, A.R., Stability and folding of the protein complexes of barnase. Eur $J$ Biochem, 2000. 267(10): p. 2859-70.
142. Newhouse, B.J., Tryptase inhibitors - review of the recent patent literature. IDrugs, 2002. 5(7): p. 682-8.

143. Nygren, P.A. \& Skerra, A., Binding proteins from alternative scaffolds. $J$ Immunol Methods, 2004. 290(1-2): p. 3-28.

144. Oefner, C., D'Arcy, A., Winkler, F.K., Eggimann, B. \& Hosang, M., Crystal structure of human platelet-derived growth factor BB. Embo J, 1992. 11(11): p. 3921-6.

145. Oh, S.W., Pae, C.I., Lee, D.K., Jones, F., Chiang, G.K., Kim, H.O., Moon, S.H., Cao, B., Ogbu, C., Jeong, K.W., Kozu, G., Nakanishi, H., Kahn, M., Chi, E.Y. \& Henderson, W.R., Jr., Tryptase inhibition blocks airway inflammation in a mouse asthma model. J Immunol, 2002. 168(4): p. 1992-2000.

146. Olsen, M., Iverson, B. \& Georgiou, G., High-throughput screening of enzyme libraries. Curr Opin Biotechnol, 2000. 11(4): p. 331-7.

147. Orita, T., Tsunoda, H., Yabuta, N., Nakano, K., Yoshino, T., Hirata, Y., Ohtomo, T., Nezu, J., Sakumoto, H., Ono, K., Saito, M., Kumagai, E., Nanami, M., Kaneko, A., Yoshikubo, T. \& Tsuchiya, M., A novel therapeutic approach for thrombocytopenia by minibody agonist of the thrombopoietin receptor. Blood, 2005. 105(2): p. 562-6.

148. Otlewski, J., Polanowski, A., Leluk, J. \& Wilusz, T., Trypsin inhibitors in summer squash (Cucurbita pepo) seeds. Isolation, purification and partial characterization of three inhibitors. Acta Biochim Pol, 1984. 31(3): p. 267-78.

149. Pace, C.N., Vajdos, F., Fee, L., Grimsley, G. \& Gray, T., How to measure and predict the molar absorption coefficient of a protein. 
Protein Sci, 1995. 4(11): p. 241123.

150. Pallaghy, P.K., Nielsen, K.J., Craik, D.J. \& Norton, R.S., A common structural motif incorporating a cystine knot and a triple-stranded beta-sheet in toxic and inhibitory polypeptides. Protein Sci., 1994. 3(10): p. 1833-9.

151. Payne, V. \& Kam, P.C., Mast cell tryptase: a review of its physiology and clinical significance. Anaesthesia, 2004. 59(7): p. 695703.

152. Peng, Q., McEuen, A.R., Benyon, R.C. \& Walls, A.F., The heterogeneity of mast cell tryptase from human lung and skin. Eur $J$ Biochem, 2003. 270(2): p. 270-83.

153. Pereira, P.J., Bergner, A., Macedo-Ribeiro, S., Huber, R., Matschiner, G., Fritz, H., Sommerhoff, C.P. \& Bode, W., Human beta-tryptase is a ring-like tetramer with active sites facing a central pore. Nature, 1998. 392(6673): p. 306-11.

154. Perelson, A. \& DeLisi, C., Receptor clustering on a cell surface. I. Theory of receptor crosslinking by ligands bearing two chemically identical functional groups. Math Biosciences, 1980. 48: p. 71-110.

155. Pohlig, G., Fendrich, G., Knecht, R., Eder, B., Piechottka, G., Sommerhoff, C.P. \& Heim, J., Purification, characterization and biological evaluation of recombinant leech-derived tryptase inhibitor (rLDTI) expressed at high level in the yeast Saccharomyces cerevisiae. Eur J Biochem, 1996. 241(2): p. 619-26.

156. Polanowski, A., Wilusz, T., Nienartowicz, B., Cieslar, E., Slominska, A. \& Nowak, K., Isolation and partial amino acid sequence of the trypsin inhibitor from the seeds of Cucurbita maxima. Acta Biochim. Pol., 1980. 27(3-4): p. 371-82.

157. Rice, K.D., Tanaka, R.D., Katz, B.A., Numerof, R.P. \& Moore, W.R., Inhibitors of tryptase for the treatment of mast cell-mediated diseases. Curr Pharm Des, 1998. 4(5): p. 381-96.

158. Rice, K.D., Wang, V.R., Gangloff, A.R., Kuo, E.Y., Dener, J.M., Newcomb, W.S., Young, W.B., Putnam, D., Cregar, L., Wong, M. \& Simpson, P.J., Dibasic inhibitors of human mast cell tryptase. Part 2: structure-activity relationships and requirements for potent activity. Bioorg Med Chem Lett, 2000. 10(20): p. 2361-6.

159. Rosengren, K.J., Daly, N.L., Plan, M.R., Waine, C. \& Craik, D.J., Twists, knots, and rings in proteins. Structural definition of the cyclotide framework. $J$ Biol Chem, 2003. 278(10): p. 8606-16.

160. Ruoss, S.J., Hartmann, T. \& Caughey, G.H., Mast cell tryptase is a mitogen for cultured fibroblasts. J Clin Invest, 1991. 88(2): p. 493-9.

161. Saether, O., Craik, D.J., Campbell, I.D., Sletten, K., Juul, J. \& Norman, D.G., Elucidation of the primary and three-dimensional structure of the uterotonic polypeptide kalata B1. Biochemistry, 1995. 34(13): p. 4147-58.

162. Saiki, R.K., Gelfand, D.H., Stoffel, S., Scharf, S.J., Higuchi, R., Horn, G.T., Mullis, K.B. \& Erlich, H.A., Primer-directed enzymatic amplification of DNA with a thermostable DNA polymerase. Science, 1988. 239(4839): p. 487-91.

163. Sakai, K., Ren, S. \& Schwartz, L.B., A novel heparin-dependent processing pathway for human tryptase. Autocatalysis followed by activation with dipeptidyl peptidase I. J Clin Invest, 1996. 97(4): p. 98895. 
164. Schägger, H. \& von Jagow, G., Tricine-sodium dodecyl sulfatepolyacrylamide gel electrophoresis for the separation of proteins in the range from 1 to $100 \mathrm{kDa}$. Anal Biochem, 1987. 166(2): p. 368-79.

165. Schaschke, N., Dominik, A., Matschiner, G. \& Sommerhoff, C.P., Bivalent inhibition of betatryptase: distance scan of neighboring subunits by dibasic inhibitors. Bioorg Med Chem Lett, 2002. 12(6): p. 985-8.

166. Schaschke, N., Matschiner, G., Zettl, F., Marquardt, U., Bergner, A., Bode, W., Sommerhoff, C.P. \& Moroder, L., Bivalent inhibition of human betatryptase. Chem Biol, 2001. 8(4): p. 313-27.

167. Schindler, C.W., Series introduction. JAK-STAT signaling in human disease. $J$ Clin Invest, 2002. 109(9): p. 1133-7.

168. Schlunegger, M.P. \& Grutter, M.G., An unusual feature revealed by the crystal structure at $2.2 \mathrm{~A}$ resolution of human transforming growth factor-beta 2. Nature, 1992. 358(6385): p. 430-4.

169. Schmoldt, H.U., Wentzel, A., Becker, S. \& Kolmar, H., A fusion protein system for the recombinant production of short disulfide bond rich cystine knot peptides using barnase as a purification handle. Protein Expr Purif, 2005. 39(1): p. 82-89.

170. Schreiber, G. \& Fersht, A.R., Rapid, electrostatically assisted association of proteins. Nat Struct Biol, 1996. 3(5): p. 427-31.

171. Schulze, H., Ballmaier, M., Welte, K. \& Germeshausen, M., Thrombopoietin induces the generation of distinct Stat1, Stat3, Stat5a and Stat5b homo- and heterodimeric complexes with different kinetics in human platelets. Exp Hematol, 2000. 28(3): p. 294-304.
172. Schwartz, L.B., Clinical utility of tryptase levels in systemic mastocytosis and associated hematologic disorders. Leuk Res, 2001. 25(7): p. 553-62.

173. Schwartz, L.B., Irani, A.M., Roller, K., Castells, M.C. \& Schechter, N.M., Quantitation of histamine, tryptase, and chymase in dispersed human $\mathrm{T}$ and $\mathrm{TC}$ mast cells. J Immunol, 1987. 138(8): p. 2611-5.

174. Schwartz, L.B., Sakai, K., Bradford, T.R., Ren, S., Zweiman, B., Worobec, A.S. \& Metcalfe, D.D., The alpha form of human tryptase is the predominant type present in blood at baseline in normal subjects and is elevated in those with systemic mastocytosis. $J$ Clin Invest, 1995. 96(6): p. 2702-10.

175. Scorer, C.A., Clare, J.J., McCombie, W.R., Romanos, M.A. \& Sreekrishna, K., Rapid selection using G418 of high copy number transformants of Pichia pastoris for high-level foreign gene expression. Biotechnology (N Y), 1994. 12(2): p. 181-4.

176. Scott, C.P., Abel-Santos, E., Wall, M., Wahnon, D.C. \& Benkovic, S.J., Production of cyclic peptides and proteins in vivo. Proc Natl Acad Sci U S A, 1999. 96(24): p. 13638-43.

177. Selwood, T., Elrod, K.C. \& Schechter, N.M., Potent bivalent inhibition of human tryptase-beta by a synthetic inhibitor. Biol Chem, 2003. 384(12): p. 1605-11.

178. Sinha, U., Wolz, S.A. \& Lad, P.J., Two new extracellular serine proteases from Streptomyces fradiae. Int. J. Biochem., 1991. 23(10): p. 979-84.

179. Skerra, A., Engineered protein scaffolds for molecular recognition. J Mol Recognit, 2000. 13(4): p. 167-87.

180. Sohma, Y., Akahori, H., Seki, N., Hori, T., Ogami, K., Kato, T., 
Shimada, Y., Kawamura, K. \& Miyazaki, H., Molecular cloning and chromosomal localization of the human thrombopoietin gene. FEBS Lett, 1994. 353(1): p. 57-61.

181. Sommerhoff, C.P., Bode, W., Pereira, P.J., Stubbs, M.T., Stürzebecher, J., Piechottka, G.P., Matschiner, G. \& Bergner, A., The structure of the human betaII-tryptase tetramer: fo(u)r better or worse. Proc Natl Acad Sci US A, 1999. 96(20): p. 10984-91.

182. Sommerhoff, C.P., Sollner, C., Mentele, R., Piechottka, G.P., Auerswald, E.A. \& Fritz, H., A Kazal-type inhibitor of human mast cell tryptase: isolation from the medical leech Hirudo medicinalis, characterization, and sequence analysis. Biol Chem Hoppe Seyler, 1994. 375(10): p. 685-94.

183. Soto, D., Malmsten, C., Blount, J.L., Muilenburg, D.J. \& Caughey, G.H., Genetic deficiency of human mast cell alpha-tryptase. Clin Exp Allergy, 2002. 32(7): p. 1000-6.

184. Sreekrishna, K., Potenz, R.H., Cruze, J.A., McCombie, W.R., Parker, K.A., Nelles, L., Mazzaferro, P.K., Holden, K.A., Harrison, R.G., Wood, P.J. \& et al., High level expression of heterologous proteins in methylotrophic yeast Pichia pastoris. $J$. Basic Microbiol., 1988. 28(4): p. 265-78.

185. Steinhoff, M., Vergnolle, N., Young, S.H., Tognetto, M., Amadesi, S., Ennes, H.S., Trevisani, M., Hollenberg, M.D., Wallace, J.L., Caughey, G.H., Mitchell, S.E., Williams, L.M., Geppetti, P., Mayer, E.A. \& Bunnett, N.W., Agonists of proteinase-activated receptor 2 induce inflammation by a neurogenic mechanism. Nat Med, 2000. 6(2): p. 151-8.
186. Stevens, R.L. \& Huang, C., Mast cell protease peptide inhibitors. 1999, Brigham and Women's Hospital, Inc., Boston, Mass.: USA. p. 1-43.

187. Tam, J.P. \& Lu, Y.A., A biomimetic strategy in the synthesis and fragmentation of cyclic protein. Protein Sci, 1998. 7(7): p. 1583-92.

188. Tam, J.P., Lu, Y.A., Yang, J.L. \& Chiu, K.W., An unusual structural motif of antimicrobial peptides containing end-to-end macrocycle and cystine-knot disulfides. Proc. Natl. Acad. Sci. U S A, 1999. 96(16): p. 8913-8.

189. Tanaka, R.D., Clark, J.M., Warne, R.L., Abraham, W.M. \& Moore, W.R., Mast cell tryptase: a new target for therapeutic intervention in asthma. Int Arch Allergy Immunol, 1995. 107(1-3): p. 408-9.

190. Temann, U.A., Geba, G.P., Rankin, J.A. \& Flavell, R.A., Expression of interleukin 9 in the lungs of transgenic mice causes airway inflammation, mast cell hyperplasia, and bronchial hyperresponsiveness. J Exp Med, 1998. 188(7): p. 1307-20.

191. Temple, M.D., Hinds, M.G., Sheumack, D.D., Howden, M.E. \& Norton, R.S., 1H NMR study of robustoxin, the lethal neurotoxin from the funnel web spider Atrax robustus. Toxicon, 1999. 37(3): p. 485-506.

192. Terlau, H. \& Olivera, B.M., Conus venoms: a rich source of novel ion channel-targeted peptides. Physiol Rev, 2004. 84(1): p. 41-68.

193. Thompson, D. \& Larson, G., Western blots using stained protein gels. Biotechniques, 1992. 12(5): p. 656-8.

194. Trabi, M. \& Craik, D.J., Circular proteins--no end in sight. Trends Biochem Sci, 2002. 27(3): p. 132-8.

195. Trabi, M., Schirra, H.J. \& Craik, D.J., Three-dimensional structure 
of RTD-1, a cyclic antimicrobial defensin from Rhesus macaque leukocytes. Biochemistry, 2001. 40(14): p. 4211-21.

196. Tremaine, W.J., Brzezinski, A., Katz, J.A., Wolf, D.C., Fleming, T.J., Mordenti, J., StrenkoskiNix, L.C. \& Kurth, M.C., Treatment of mildly to moderately active ulcerative colitis with a tryptase inhibitor (APC 2059): an open-label pilot study. Aliment Pharmacol Ther, 2002. 16(3): p. 407-13.

197. Tremblay, G.M., Janelle, M.F. \& Bourbonnais, Y., Anti-inflammatory activity of neutrophil elastase inhibitors. Curr Opin Investig Drugs, 2003. 4(5): p. 556-65.

198. Van Nostrand, W.E., Wagner, S.L., Farrow, J.S. \& Cunningham, D.D., Immunopurification and protease inhibitory properties of protease nexin2/amyloid beta-protein precursor. $J$. Biol. Chem., 1990. 265(17): p. 9591-4.

199. Vigon, I., Mornon, J.P., Cocault, L., Mitjavila, M.T., Tambourin, P., Gisselbrecht, S. \& Souyri, M., Molecular cloning and characterization of MPL, the human homolog of the $\mathrm{v}$-mpl oncogene: identification of a member of the hematopoietic growth factor receptor superfamily. Proc Natl Acad Sci U S A, 1992. 89(12): p. 5640-4.

200. Villa, S., De Fazio, G. \& Canosi, U., Cyanogen bromide cleavage at methionine residues of polypeptides containing disulfide bonds. Anal Biochem, 1989. 177(1): p. 161-4.

201. Walls, A.F., Bennett, A.R., Sueiras-Diaz, J. \& Olsson, H., The kininogenase activity of human mast cell tryptase. Biochem Soc Trans, 1992. 20(3): p. 260S.

202. Wendling, F., Thrombopoietin: its role from early hematopoiesis to platelet production. Haematologica, 1999. 84(2): p. 158-66.

203. Wentzel, A., Christmann, A., Adams, T. \& Kolmar, H., Display of passenger proteins on the surface of Escherichia coli K-12 by the enterohemorrhagic E. coli intimin EaeA. J. Bacteriol., 2001. 183(24): p. 7273-84.

204. Wentzel, A., Christmann, A., Krätzner, R. \& Kolmar, H., Sequence requirements of the GPNG beta-turn of the Ecballium elaterium trypsin inhibitor II explored by combinatorial library screening. $J$ Biol Chem, 1999. 274(30): p. 21037-43.

205. White, C.E., Kempi, N.M. \& Komives, E.A., Expression of highly disulfide-bonded proteins in Pichia pastoris. Structure, 1994. 2(11): p. 1003-5.

206. Wieczorek, M., Otlewski, J., Cook, J., Parks, K., Leluk, J., Wilimowska-Pelc, A., Polanowski, A., Wilusz, T. \& Laskowski, M., Jr., The squash family of serine proteinase inhibitors. Amino acid sequences and association equilibrium constants of inhibitors from squash, summer squash, zucchini, and cucumber seeds. Biochem Biophys Res Commun, 1985. 126(2): p. 64652.

207. Williams, N.K., Prosselkov, P., Liepinsh, E., Line, I., Sharipo, A., Littler, D.R., Curmi, P.M., Otting, G. \& Dixon, N.E., In vivo protein cyclization promoted by a circularly permuted Synechocystis sp. PCC6803 DnaB mini-intein. $J$ Biol Chem, 2002. 277(10): p. 77908.

208. Xia, H.Z., Kepley, C.L., Sakai, K., Chelliah, J., Irani, A.M. \& Schwartz, L.B., Quantitation of tryptase, chymase, Fc epsilon RI alpha, and Fc epsilon RI gamma mRNAs in human mast cells and basophils by competitive reverse 
transcription-polymerase chain reaction. J Immunol, 1995. 154(10): p. 5472-80.

209. Zhao, G., Bolton, S.A., Kwon, C., Hartl, K.S., Seiler, S.M., Slusarchyk, W.A., Sutton, J.C. \& Bisacchi, G.S., Synthesis of potent and selective 2-azepanone inhibitors of human tryptase. Bioorg Med Chem Lett, 2004. 14(2): p. 309-12. 


\section{Anhang}

\subsection{Abkürzungsverzeichnis}

Die verwendeten ein- und dreibuchstabigen Abkürzungen für Aminosäuren, sowie alle verwendeten physikalischen Größen entsprechen der Konvention der International Union for Biochemistry [Liébecq, 1978].

A

Abb.

APS

AS

bp

$\mathrm{BrCN}$

BSA

$\mathrm{C}$

C-Terminus

cat

$\mathrm{Cm}^{\mathrm{x}}$

DMF

DMSO

DNA

dNTP

DSS

DTT

dYT

E. coli

EDTA

ESI

G

IPTG

$\mathrm{kb}$

$\mathrm{kDa}$

$\mathrm{K}_{\mathrm{i}}$
Adenin

Abbildung

Amoniumperoxydisulfat

Aminosäure(n)

Basenpaare

Bromcyan

Rinderserum-Albumin

Cytosin

Carboxyterminus

Gen für die Chloramphenicol-Acetyltransferase

Chloramphenicol, $\mathrm{x} \mu \mathrm{g} / \mathrm{ml}$

Dimethylformamid

Dimethylsulfoxid

Desoxyribonucleic Acid, Desoxyribonukleinsäure

Desoxynukleosidtriphosphat

Disuccinimidylsuberat

Dithiothreitol

double Yeast Tryptone

Escherichia coli

Ethylendiamintetraacetat

Electrospray Ionization (Ionisierungsverfahren in der Massenspektrometrie)

Guanin

Isopropyl- $\beta$-D-thiogalactopyranosid

Kilobasen

Kilo-Dalton

Dissoziationskonstante des Enzym/Inhibitor Komplex 
$\mathrm{M}_{\mathrm{r}} \quad$ relatives Molekulargewicht

MS Massenspektrometrie

NHS N-Hydroxysuccinimid

N-Terminus Aminoterminus

$\mathrm{OD}_{\mathrm{x}} \quad$ Optische Dichte bei einer Wellenlänge von $\mathrm{x} \mathrm{nm}$

ori Replikationsursprung

PAGE Polyacrylamid-Gelelektrophorese

PAG Polyacrylamid-Gel

PBS Phosphate Buffered Saline(-Puffer)

PBS Phosphate Buffered Saline Tween20(-Puffer)

PCR Polymerase Chain Reaction, Polymerase-Kettenreaktion

PEG Polyethylenglycol

PNA Paranitroanilid

$\mathrm{P} / \mathrm{O} \quad$ Promotor/Operator

RNA Ribonucleic Acid, Ribonukleinsäure

RP-HPLC Reversed phase high pressure/performance liquid chromatography

RT Raumtemperatur $\left(\sim 20^{\circ} \mathrm{C}\right)$

SDS Sodiumdodecylsulfate, Natriumdodecylsulfat

T Thymin

TBE Tris-Borate-EDTA(-Puffer)

TCA Trichloressigsäure

TE Tris-EDTA(-Puffer)

TEMED N,N,N`,N`-Tetramethylethylendiamin

TFA Trifluoressigsäure

U Uracil

u, U Einheiten (units)

ü.N. $\quad$ über Nacht

$\mathrm{u} / \mathrm{min} \quad$ Umdrehungen pro Minute

UV Ultraviolett

$\mathrm{v} / \mathrm{V} \quad$ Volumen pro Volumen

Vol Volumen

w/v Masse pro Volumen 


\subsection{Aus dieser Arbeit hervorgegangene Veröffentlichungen}

- Originalarbeiten

Avrutina, O., Schmoldt, H.U., Kolmar, H. \& Diederichsen, U., Fmoc-Assisted Synthesis of a 29Residue Cystine-Knot Trypsin Inhibitor Containing a Guaninyl Amino Acid at the P1Position. Eur J Org Chem, 2004(23): p. 4931-4935.

Schmoldt, H.U., Wentzel, A., Becker, S. \& Kolmar, H., A fusion protein system for the recombinant production of short disulfide bond rich cystine knot peptides using barnase as a purification handle. Protein Expr Purif, 2005. 39(1): p. 82-89.

Avrutina, O., Schmoldt, H.U., Gabrijelcic-Geiger, D. Le Nguyen, D., Sommerhoff, C.P. Diederichsen, U. \& Kolmar, H., Trypsin inhibition by macrocyclic and open chain variants of the squash inhibitor MCoTI-II. Zur Publikation eingereicht bei Biological Chemistry.

Zudem sind Artikel über ein Verfahren zur Kristallisation von Cystin-Knoten Mikroproteinen durch Fusionierung an Barnase', die Entwicklung potenter Tryptase Inhibitoren auf der Basis von Cystin-Knoten Mikroproteinen und der Generierung von Thrombopoietin mimetischen Mikroproteinen in Vorbereitung.

\section{- Buchkapitel}

Adams, T.M., Schmoldt, H.U. \& Kolmar, H., FACS Screening of Combinatorial Peptide and Protein Libraries Displayed on the Surface of Escherichia coli cells, in Evolutionary Methods in Biotechnology, S. Brakmann and A. Schwienhorst, Editors. 2004, Wiley-VCH: Weinheim. p. 31-44.

\section{- Reviews}

Becker, S., Schmoldt, H.U., Adams, T.M., Wilhelm, S. \& Kolmar, H., Ultra-high-throughput screening based on cell-surface display and fluorescence-activated cell sorting for the identification of novel biocatalysts. Curr Opin Biotechnol, 2004. 15(4): p. 323-9.

\section{- Poster}

Schmoldt, H.U., Wentzel, A., Avrutina, O., Gabrijelcic-Geiger, D., Diederichsen, U. Kolmar, H., \& Sommerhoff, C.P., Cystine Knot Microproteins as a Source of Novel Pharmaceutical Compounds. Bioperspectives, 10.-12. Mai 2005.

Avrutina, O., Schmoldt, H.U., Kolmar, H., Diederichsen, U., Synthetic Microproteins as Pharmaceutically Valuable Inhibitors. Siebtes Deutsches Peptid-Symposium, 27. Februar bis 2. März 2005.

Avrutina, O., Schmoldt, H.U., Wentzel, A., Diederichsen, U. \& Kolmar, H., Cyclic Microproteins via Combined Recombinant and Chemical Synthesis. 1st German-French Congress in Organic and Biomolecular Chemistry, 7. - 11. September 2005.

\section{Von der Selecore GmbH eingereichte Patente}

EP 0402 2455.2: „Cyclic and dimeric microproteins”.

EP 0402 2455.2: "Novel inhibitors of mast cell tryptase". 


\subsection{Danksagungen}

Die vorliegende Arbeit wurde in der Abteilung Molekulare Genetik und Präparative Molekularbiologie am Institut für Genetik und Mikrobiologie der Georg-August Universität Göttingen angefertigt. Dem Leiter der Abteilung Herrn Prof. Dr. H.-J. Fritz danke ich für die Bereitstellung des Arbeitsplatzes und seiner Unterstützung dieser Arbeit.

Besonders danken möchte ich meinem Betreuer PD Dr. Harald Kolmar für seine hervorragende Betreuung und seine Unterstützung durch zahlreiche Anregungen und interessante Diskussionen, die eine erfolgreiche Arbeit ermöglicht haben. Auch für die Geduld bei der Korrektur der schriftlichen Arbeit möchte ich ihm herzlich danken. PD Dr. Andreas Schwienhorst danke ich für die Übernahme des Korreferats.

Diese Arbeit wurde durch die hervorragende Zusammenarbeit in zahlreichen Kooperationen ermöglicht: Mein Dank gilt besonders der Selecore $\mathrm{GmbH}$ in Göttingen nicht nur für die finanzielle Unterstützung, sondern insbesondere Dr. Alexander Wentzel, Dr. Andreas Christmann und allen technischen Angestellten, für die tolle Zusammenarbeit bei allen Projekten. Des weiteren möchte ich Olga Avrutina und Prof. Dr. Diederichsen (Organische Chemie, Göttingen) für die Zusammenarbeit im Rahmen des Tryptase und des ZyklisierungsProjekts, Sebastian Krause, PD Dr. K.-H. Friedrich (Biochemie, Jena) und Dr. Matthias Ballmaier (MH-Hannover) für die Zusammenarbeit im TPO-Projekt und Prof. Dr. Christian Sommerhoff (LMU, München) für die Kooperation im Tryptase Projekt danken. Zudem danke ich Dr. Hartmut Niemann und Prof. Dr. Heinz (GBF, Braunschweig) für die Kristallisation und Röntgenstrukturanalyse der Mikroproteine. Meinem Kollegen Dr. Dennis Wegener danke ich für die initiale Hilfe beim Umgang mit Pichia pastoris und dem Laboratorium für Genomanalyse (LGA) in Göttingen für die DNA-Sequnzierungen.

Allen Mitgliedern der Abteilung möchte ich für die insgesamt sehr gute Arbeitsatmosphäre danken. Insbesondere den Mitgliedern der Arbeitsgruppe Kolmar Thorsten Adams, Stefan Becker und Matin Daneschdar möchte dafür danken, daß es uns immer gelungen ist, Spaß und Produktivität bei der Arbeit zu verbinden. Speziell möchte ich Matin Daneschdar für das Korrekturlesen der Arbeit, Stefan Becker für das abendliche Feierabend Bier und die gute Musik und Thorsten Adams dafür danken, daß er mich in einer schlechten Phase vom Abbrechen der Promotion abgehalten hat.

Nicht zuletzt gilt mein Dank meiner Familie und meiner Freundin Kathrin für ihre Unterstützung und Begleitung bei dieser Arbeit. 


\subsection{Lebenslauf}

Name: Hans-Ulrich Schmoldt

Geburtsdatum: $\quad$ 2. März 1977

Geburtsort: Stade

Staatsangehörigkeit: deutsch

Familienstand: ledig

Eltern: Hans-Wilhelm Schmoldt und Christa Schmoldt, geb. Baumgarte (1991 verstorben)

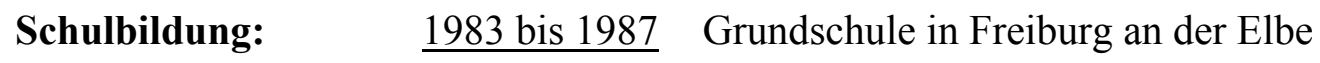

1987 bis 1989 Orientierungsstufe in Freiburg an der Elbe

1989 bis 1996 Gymnasium Warstade in Hemmoor

1996 Abitur am Gymnasium Warstade in Hemmoor

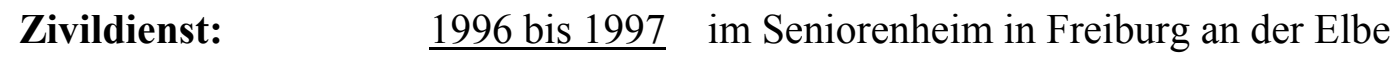

Studium der Biologie: 1997 bis 2001 an der Georg-August-Universität zu Göttingen

Diplomarbeit: $\quad \underline{2000 \text { bis } 2001}$ in der Abteilung für Molekulare Genetik und Präparative Molekularbiologie des Instituts für Mikrobiologie und Genetik der Georg-August-Universität zu Göttingen.

Titel: „Escherichia coli Zelloberflächenpräsentation Genom-basierter Peptidbibliotheken aus Pseudomonas aeruginosa", Gesamtnote: ,gut".

Dissertation: $\quad$ seit März 2002 in der Abteilung für Molekulare Genetik und Präparative Molekularbiologie des Instituts für Mikrobiologie und Genetik der Georg-August-Universität zu Göttingen. Unterstützt durch die Selecore GmbH in Göttingen und der Deutschen Forschungsgemeinschaft (DFG) im Rahmen des Sonderforschungsbereichs 416: „Chemische und biologische Synthese und Transformation von Naturstoffen und Naturstoff-Analoga“. 